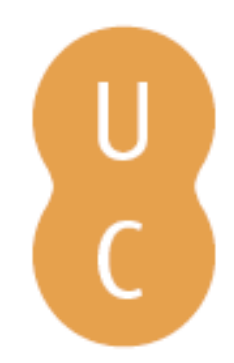

\title{
nombalina
}

\section{Teatro neolatino em Portugal no contexto da Europa: 450 anos de Diogo de Teive}

Autor(es): $\quad$ Pinho, Sebastião Tavares de, ed. lit.

Publicado por: Imprensa da Universidade de Coimbra

URL

persistente: URI:http://hdl.handle.net/10316.2/2771

DOI: $\quad$ DOI:http://dx.doi.org/10.14195/978-989-26-0482-4

Accessed : $\quad$ 26-Apr-2023 14:42:29

A navegação consulta e descarregamento dos títulos inseridos nas Bibliotecas Digitais UC Digitalis, UC Pombalina e UC Impactum, pressupõem a aceitação plena e sem reservas dos Termos e Condições de Uso destas Bibliotecas Digitais, disponíveis em https://digitalis.uc.pt/pt-pt/termos.

Conforme exposto nos referidos Termos e Condições de Uso, o descarregamento de títulos de acesso restrito requer uma licença válida de autorização devendo o utilizador aceder ao(s) documento(s) a partir de um endereço de IP da instituição detentora da supramencionada licença.

Ao utilizador é apenas permitido o descarregamento para uso pessoal, pelo que o emprego do(s) título(s) descarregado(s) para outro fim, designadamente comercial, carece de autorização do respetivo autor ou editor da obra.

Na medida em que todas as obras da UC Digitalis se encontram protegidas pelo Código do Direito de Autor e Direitos Conexos e demais legislação aplicável, toda a cópia, parcial ou total, deste documento, nos casos em que é legalmente admitida, deverá conter ou fazer-se acompanhar por este aviso. 
Sebastiāo Tavares de Pinho

Coordenação

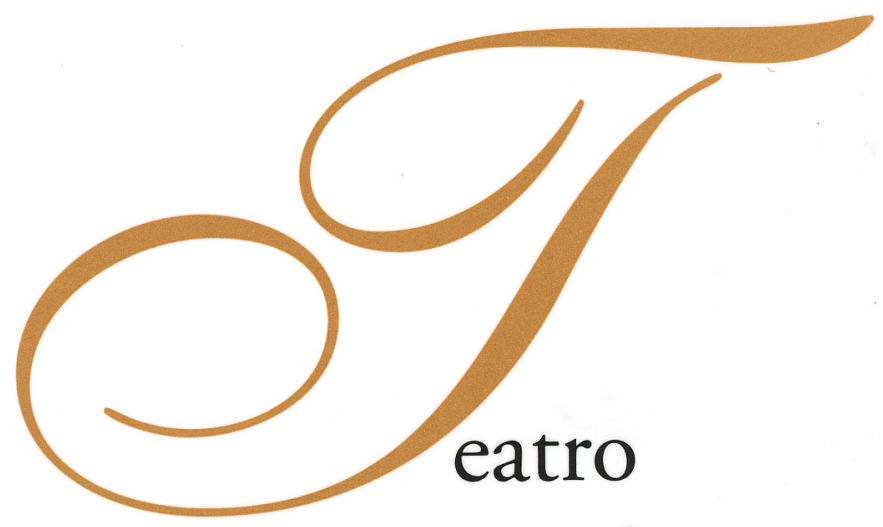

Neolatino em Portugal

no Contexto da Europa

450 Anos

de Diogo de Teive

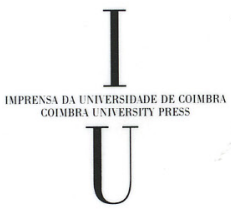

- COIMBRA 2006 
(Página deixada propositadamente em branco) 
C

U

M

E

$\mathrm{N}$

T

0

S

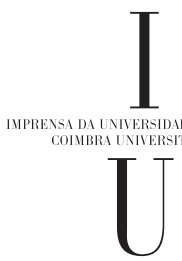




\section{COORDENAÇÃO EDITORIAL}

Imprensa da Universidade de Coimbra

Email: imprensa@uc.pt

URL: http://www.uc.pt/imprensa_uc

CONCEÇÃO GRÁFICA

António Barros

PRÉ-IMPRESSÃO

António Resende

Imprensa da Universidade de Coimbra

EXECUÇÃO GRÁFICA

SerSilito - Maia

ISBN

972-8704-75-5

ISBN DigITAL

978-989-26-0482-4

DOI

http://dx.doi.org/10.14195/978-989-26-0482-4

DEPÓSITO LEGAL

$245477 / 06$

(C) Junho 2006, Imprensa da Universidade de Coimbra

OBRA PUBLICADA COM O APOIO DE:

Centro de Estudos Clássicos e Humanísticos

FCT Fundação para a Ciência e a Tecnologia

MINISTÉRIO DA CIÊNCIA, TECNOLOGIA E ENSINO SUPERIOR Portugal 
O TEATRO NeOlatino EM PORTUGal NO CONTEXTO DA EUROPA

450 AnOs DE DIOGO DE TEIVE 
(Página deixada propositadamente em branco) 


\section{S UMÁRIO}

\section{Maria do Céu Fialho}

NOTA PRÉVIA

\section{Américo da Costa Ramalho}

AINDA, OS QUATRO DÁIMIOS JAPONESES EM COIMBRA (1585): OS ESPECTÁCULOS .9

\section{Nigel Griffin}

'I SPY STANGERS': JESUIT PLAYS AND THEIR TRAVELS 21

\section{Vicente Picón García}

EL TEATRO NEO-LATINO HUMANístico Y ESCOlaR EN ESPAÑA EN EL SIGLO XVI

\section{Jesús Menéndez Peláez}

PROPAGANDA IDEOLÓGICA EN EL TEATRO NEOLATINO Y ROMANCE DE LOS COLEgios DE JESUitas EN EL SigLO DE ORO ESPAÑol

\section{Dietrich Briesemeister}

O TEATRO ESCOLAR JESUÍTICO E OS DESCOBRIMENTOS PORTUGUESES: ANTÓNIO DE SOUSA E LA REAL TRAGICOMEDIA DEL REY DOM MANOELL.

\section{Manuel José de Sousa Barbosa}

TEATRO JESUítico E ESTÉTICA BARROCA: O TESTEMUNHO DUM DRAMA TRUNCADO, ANÓNIMO E SEM TÍTULO (BPE, COD. CVIII/2-7, 61R-85V)

\section{Jean-Marie Valentin}

LES HUMANISTES ALLEMANDS ET LE THÉÂTRE NÉO-LATIN. ENTRE L'HÉRITAGE, LA MORALE ET L'ÉLOGE PRINCIER

\section{Nair de Nazaré Castro Soares}

A tragédia do PRÍNCIPE Jỗo (1554) DE DIOGO DE TEIVE, PRIMEIRO DRAMATURGo NEOLATINO PORTUGUÊS 


\section{Santiago López Moreda}

TEATRO, POÉTICA Y RETÓRICA: LA FABELLA AENARIA DE J. L. PALMIRENO

\section{Sebastião Tavares de Pinho}

BUCOLISMO NO TEATRO NOVILATINO PORTUGUÊS

António Maria Martins Melo

O ELEMENTO FEMININO NO TEATRO JESUÍTICO EM PORTUGAL NO SÉCULO XVI.

261

Maria Margarida Lopes de Miranda

Miguel VENEGAS S.I. E O PRINCÍPIO DE UM CICLO TRÁGICO NA EUROPA 


\section{NOTA PRÉVIA}

O Centro de Estudos Clássicos e Humanísticos da Faculdade de Letras da Universidade de Coimbra tem como tema do seu Projecto de Investigação a Génese e Desenvolvimento da Ideia de Europa. Raízes de Identidade. Impunha-se, naturalmente, a investigação de equipa, numa dimensão interdisciplinar, que levaria ao estudo e articulação interpretativa dos textos (entendido o termo no seu sentido mais amplo) de natureza vária que documentam, desde os Poemas Américas até ao fim da Antiguidade Clássica, a presença de uma consciência de identidade-alteridade, o seu alargamento, clarificação, questionamento, desde a sua primeira identificação com o meio de comunicação - a língua grega, por oposição à incompreensibilidade de códigos comunicativos e, de seguida, de códigos comportamentais não-gregos - até à formação de uma cultura de síntese, preparada pela dinâmica intercultural da oikoumene helenística e conscientemente valorizada e sedimentada durante o império de Roma, por Gregos e Romanos.

Nessa mesma linha se situa a investigação de alguns momentos-chave da Idade Média ou do Renascimento, documentada em textos latinos, dos volumes em preparação.

Todavia, esta investigação em curso exige uma outra linha de investigação. A medida da importância da ideia ou ideias de Europa ganha sentido pela força determinante da consciência de identidade e pelos nexos que a tecem e consolidam, que tornam possível entender o que se pretende dizer com cultura ou culturas europeias, ainda que na riqueza da sua diversidade. Assim, acompanhar esses nexos referenciais que tecem a linguagem cultural, que determinam ou determinaram, por exemplo, a percepção estética e a criação poética, a dinâmica comunicativa de persuasão, a vivência da cidadania indissociável de uma paideia e de uma ética, é vocação de uma linha de volumes temáticos, igualmente vocacionados para um labor interdisciplinar e interuniversitário. Representa este volume, editado após os 490 anos do nascimento de um dos nossos maiores humanistas, Diogo de Teive, o resultado da investigação da 
equipa da UI\&D-Centro de Estudos Clássicos e Humanísticos, na área de Estudos Medievais e do Renascimento, centrada num dos aspectos culturais de mais relevante significado na construção de uma nova Europa, aberta a outros mundos, sob o signo da mobilidade cultural: o do Teatro Novilatino do Renascimento. A inspiração nos modelos teatrais da Antiguidade serviu para equacionar criticamente, sob a forma de mimese dramática, questões ético-morais e perplexidades e limitações do homem, de um outro tempo, de raízes todavia comuns, na vivência de possíveis situações-limite. A conversão da História em Mito dramatizado, à boa maneira esquiliana, constituiu, também no Teatro Novilatino, um eficaz meio de interrogação sobre o sentido dessa História, cromatizado por outras convicções e instrumentos de leitura. Aperceberam-se, a título de exemplo, os grandes pedagogos cristãos, envolvidos no projecto educativo, evangelizador e missionário da Companhia de Jesus, de que o Colégio das Artes é modelo ilustrativo, da força pedagógica das emoções e da eficácia comunicativa e de construção de comunidade espiritual da obra de arte - no caso em apreço, da obra de arte dramática, onde, sob a forma de narração-representação se cristalizam experiências humanas fundamentais para se lhes buscar a compreensão e um sentido.

O Teatro ao serviço de uma nova pedagogia e dos novos horizontes que a Europa vem rasgando, o pressuposto de mobilidade no contexto de uma Europa onde, mais do que nunca, em nome da cultura se abrem as fronteiras ao trânsito do saber e dos sábios, constitui o fulcro deste volume. Necessariamente, ele havia de ser espelho, na sua elaboração, dessa mesma mobilidade de saberes e de colaboração entre especialistas nacionais e internacionais de renome nesta área.

Deixamos aqui expresso o nosso agradecimento à Fundação para a Ciência e a Tecnologia, que suportou, através do financiamento ao Centro, a investigação e os custos a ela associados, assim como uma parcela dos custos de publicação, bem como à Imprensa da Universidade e ao bom acolhimento, desde o primeiro momento, deste projecto de publicação, por parte do seu Director, Prof. Doutor José Francisco de Faria Costa, pautado pelos critérios de rigor universitário e amor à sabedoria. A execução gráfica muito fica a dever à supervisão da Senhora Dr ${ }^{\mathrm{a}}$ Maria João Castro, a quem deixamos expresso o nosso reconhecimento. 
Américo da Costa Ramalho

Universidade de Coimbra

\section{AINDA, OS QUATRO DÁIMIOS JAPONESES EM COIMBRA (1585): OS ESPECTÁCULOS}

Quando a Universidade regressa definitivamente a Coimbra em 1537, depois de uma ausência de 160 anos, não é a semente que cai em terreno sáfaro e hostil, para usar uma imagem não de todo gasta.

Com efeito, em 1537, em Santa Cruz de Coimbra floresciam as Humanidades com um vigor que não tinham certamente na Universidade de Lisboa, a avaliar pelo discurso pronunciado em 1534 no Estudo Geral olisiponense por André de Resende, francamente pessimista sobre o nível de toda a instituição universitária lisboeta. Para dar um só exemplo, enquanto o Grego parece não existir, por essa altura, em Lisboa, o humanista flamengo Nicolau Clenardo fica deslumbrado com uma aula do helenista alemão Vicente Fabrício no mosteiro de Santa Cruz de Coimbra.

Vicente Fabrício ensaiou possivelmente os alunos para a visita do flamengo, mas, seja como for, estudava-se Grego na escola dos frades crúzios.

Todavia, com a introdução no esquema universitário de uma escola de Humanidades, em 1548, vitalidade nova foi injectada no ambiente cultural conimbricense dos meados do século XVI.

Antes de 1548, terá havido certamente orações universitárias, como a de 1539, pronunciada em Santa Cruz por Mestre João Fernandes, um sevilhano que aí ensinava retórica e Latim. Todavia, não chegaram até nós, e esta de 1539 ficou manuscrita. 
Entretanto, a 21 de Fevereiro de 1548, era inaugurado o Colégio das Artes, com a oratio de Arnold Fabrice, um dos franceses que com vários portugueses, comandados por André de Gouveia, vieram ensinar em Coimbra.

Não vou falar aqui do elenco desse team internacional que se transferiu com um treinador português afamado, o principal do Collège de Guyenne em Bordéus, para o novo Colégio das Artes em Coimbra. É assunto que todos os presentes certamente conhecem.

A estrela de maior brilho internacional do grupo de André de Gouveia era provavelmente o escocês George Buchanan, já então famoso como poeta latino e dramaturgo.

A acção estimulante dos bordaleses no meio universitário de Coimbra principia com essa oração inaugural de Arnaldo Fabrício de que há pouco eu falava. Na verdade, logo nesse ano de 1548, ao discurso público do francês, sucedeu em Julho a oratio de João Fernandes De Celebritate Academiae Conimbricensis, pronunciada na visita do Infante D. Luís a Coimbra. E em 1 de Outubro, na abertura solene da Universidade, o português Belchior Beliago declama a oração inaugural do ano lectivo de 1548-1549. Esta, assim como a de João Fernandes, teve lugar na Universidade, ao passo que a de Arnaldo Fabrício foi proferida no Colégio das Artes.

O bordalês apresenta-se a si e aos seus companheiros como uma turma de beneméritos que vinham expulsar a barbárie gótica, entenda-se medieval, das plagas lusitanas, graças à iniciativa inteligente de D. João III. Ficaria decerto muito surpreendido se lhe mostrassem a oração do jovem conde de Alcoutim na Universidade de Lisboa, em 18 de Outubro de 1504, na presença do rei D. Manuel a quem são atribuídos generosamente os elogios agora dados ao rei seu filho, mas quarenta e quatro anos antes. Também o núcleo expositivo das duas orações inaugurais não difere muito.

D. Pedro de Meneses, $2^{\circ}$ conde de Alcoutim, tinha 17 anos de idade, quando discursou no Estudo Geral de Lisboa. Fora para isso treinado pelo seu mestre italiano Cataldo Parísio Sículo que persuadiu o rei D. Manuel, a introduzir em Portugal, esta prática das cortes italianas - o espectáculo 
de confiar a um jovem aristocrata a solenidade da abertura do ano lectivo universitário, que no começo do século se realizava em 18 de Outubro, dia de S. Lucas. Mais tarde, passou a efectuar-se em dia de São Remígio, a 1 de Outubro, "la Saint-Rémy» da Sorbonne.

Também Cataldo, entre nós desde 1485, se propôs expulsar a barbárie cultural dos portugueses, mas fê-lo sessenta anos antes dos companheiros de André de Gouveia.

Mais espectacular do que a abertura do ano lectivo, era a cerimónia do doutoramento solene ou a imposição das insígnias doutorais.

Hoje o cortejo universitário sai da Biblioteca Joanina construída no século XVIII e toda a cerimónia se passa dentro do âmbito do antigo palácio real e seus anexos. Então, em vez de se limitar a percorrer o pátio da Universidade, o cortejo atravessava uma grande parte da cidade de Coimbra, pois, com o Reitor à frente, a comitiva ia buscar o doutorando a casa e com ele percorria a parte do burgo que ficava entre a sua residência e o Paço das Escolas.

A descrição que nos dá Inácio de Morais do acontecimento, em dísticos elegíacos do seu Conimbricae Encomium compara este triunfo académico com o triunfo do general romano de outrora, até nas chufas que os soldados dirigiam ao general vencedor.

Dessa intenção de temperar o momento de glória com alguma observação graciosa, resta nos actuais estatutos a recomendação de moderar os elogios ao doutorando com alguns ditos jocosos a seu respeito, que não ofendam.

Eis o texto de Inácio de Morais, em tradução que publiquei em 1985 no meu livro Latim Renascentista em Portugal, p. 188-191:

Acrescente-se que também Coimbra distrai o seu povo com alegres festejos que celebra com frequência. Assim, todas as vezes que alguém solicita o prémio dos seus estudos e que lhe cinjam gloriosamente a cabeça com o ramo de louro, canta-se, à maneira antiga, o alegre triunfo e um cortejo se encaminha ordenadamente às doutas Escolas. 
Vai à frente o Reitor, acompanhado de áureos feixes, e segue-o multidão espessa de varões. Vai a comitiva dos doutores, com as têmporas coroadas e os trajos tingidos cada um da cor que lhe pertence.

A multidão cheia de espanto corre de todos os lados na ânsia de ver, e reboam os tambores tocados em festivo modo. E a rouca trombeta mistura, com alternado estrépito, o som e juntam as flautas ocas seus finos ritmos.

Então gostam de andar, por um lado e por outro, jovens de rosto mascarado, e de soltar graciosas troças.

Como outrora, quando o general romano, dominado o inimigo, celebrava o triunfo e conduzia vencedor os cavalos brancos, e coroado de louros era recebido com grande honra pelo Senado, e o povo em alta voz dava-lhe o seu aplauso, de igual modo toda a Academia se alegra em festivo clamor, quando alguém recebe o apolíneo louro.

Esplêndidas tapeçarias ornamentam o teatro espaçoso: senta-se a ordem dos senadores e o coro de Palas.

Então deleitar-te-á a abundância eloquente da prosa e uma graça que flui de Cícero. E há-de seduzir-te a tragédia pomposa que caminha em graves versos, ou a musa cómica, em seu leve soco.

Adde, quod et populum laetis Conimbrica ludis

Exhilarat, crebro quos celebrare solet.

Nam quoties quisquam studis sua praemia poscit,

Et lauri emeritum cingere fronde caput:

Antiquo canitur laetus de more triumphus,

Pergit et ad doctas ordine pompa Scholas.

Incedit rector, comitatus fascibus aureis.

Atque comes sequitur densa caterua uirum.

Turba it doctorum, redimitaque tempora sertis,

Textaque quisque suo tincta colore gerunt.

Plebs stupefacta ruit studio diffusa uidendi,

Et reboant festo tympana pulsa sono.

Miscet et alterno strepitu tuba rauca sonorem,

Argutos fundunt et caua buxa modos.

Tum personatis iuuenes discurrere gaudent

Vultibus, et lepidos ore referre iocos.

Sic cum Romanus domito dux hoste triumphum,

Atque olim niueos uictor agebat equos:

Laurigerum magno excipiebat honore senatus, 
Et populus plausum uoce sonante dabat.

Tota igitur gaudet clamore Academia festo,

Donatur lauru dum quis Apollinea.

Attalica exornant spatiosum aulaea theatrum:

Ordo sedet patrum, Palladiusque chorus.

Copia mulcebit tunc te facunda soluti

Eloquii, atque fluens de Cicerone lepos.

Teque graui incedens tumefacta tragoedia uersu,

Ait socco alliciet comica Musa leui.

Notar-se-á que o dístico final se refere a representações teatrais, a tragédia e a comédia, que tinham lugar em festas académicas de certas formaturas.

Mais do que os estatutos universitários são significativas a esse respeito certas recomendações expressas do rei D. João III.

Assim, um alvará de D. João III, datado de 30 de Janeiro de 1538, isto é, anterior dez anos à fundação do Colégio das Artes, autorizava os estudantes dos Colégios de Santa Cruz, a usarem trajos de seda e jóias de ouro, contra a lei vigente, nas comédias e tragédias que representavam. E só punha uma condição: a de tais trajos de seda e objectos de ouro terem sido confeccionados antes da publicação da lei em vigor.

Isto prova que o teatro escolar era então uma realidade. E anos mais tarde, por alvarás de 25 de Setembro e de 16 de Outubro de 1546, o mesmo soberano mandava que na mais alta regra de Latinidade do Colégio de São Jerónimo e nas terceira e quarta regras da mesma disciplina da Universidade, os respectivos professores fizessem representar anualmente uma comédia(1).

Com a sua preocupação de juntar ao ensino do Latim a formação cristã, os jesuítas devem ter substituído Plauto e Terêncio por comédias da sua própria autoria. E como inventar uma comédia em cada ano não era tarefa fácil, creio que muitos dos diálogos que encontramos nos manuscritos dos

(1) Vide Mário Brandão, Coimbra e D. António Rei de Portugal. I A Educação de D. António, Coimbra, 1939, p. 31 e 96 ss. 
jesuítas se destinaram a substituir as comédias de representação obrigatória. Aliás a feição jocosa e satírica de muitos deles acentua a sua proximidade com a atmosfera da comédia.

Por outro lado, desde o Renascimento italiano que as éclogas pastoris, piscatórias e mitológicas eram representadas nas cortes de Itália. Tal aconteceu, por exemplo, com as produções bucólicas de Henrique Caiado, cuja obra literária foi realizada em cortes italianas.

A bucólica, além de dramatizar situações da vida corrente, podia servir também de veículo da crítica literária, por vezes dissimuladamente.

Assim no poema De Agnetis Caede que o Prof. John Martyn atribui a André de Resende ${ }^{(2)}$, mas decerto não é obra do humanista eborense, Inês goza os aprazíveis frutos do Mondego.

Nos Lusíadas, III, 120, 2, estava Inês «de seus anos colhendo o doce fruito".

O Autor do De Agnetis Caede, provavelmente um discípulo dos jesuítas, sabia perfeitamente o que quer dizer "de teus anos colhendo o doce fruito", mas fugindo à implícita sugestão sexual, substitui «anos» por «aprazíveis frutos do Mondego». Só não explica o que eram os frutos do Mondego. Seriam os peixes do rio ou as laranjas dos campos vizinhos?

Um outro poema da mesma colectânea a Ecloga Conimbrica explica no final quais eram os frutos do Mondego, isto é, as lampreias. E zombeteiramente acrescenta que elas surgem nas águas do Mondego nascidas das lágrimas de Inês.

Voltemos porém, ao Conimbricae Encomium de Inácio de Morais, publicado em Coimbra, um ano antes da entrega do Colégio das Artes aos padres da Companhia de Jesus. Aí se pode verificar que a vida do pequeno burgo era dominada pela sua universidade. Fora das festas académicas, há pouco mais do que procissões religiosas, marchas militares, largadas de touros e exibições de acrobatas ao ar livre.

(2) Cf. A. Costa Ramalho, "O poema De Agnetis Caede será uma fonte de Os Lusíadas?", Península 1, Porto, Faculdade de Letras, 2004, 113-121. 
No poema sobressaem, por contraste, a tranquilidade bucólica da cidade e o bulício estudantil.

Do mesmo ano do Conimbricae Encomium é a Descriptio Vrbis Olisiponensis de Damião de Góis onde a escola lisboeta, então inexistente merece pouco mais que uma alusão passageira «à Universidade que apenas se tornara famosa, depois que o rei D. João III a transferiu para Coimbra»(3).

Em Janeiro desse mesmo ano de 1554, falecia o príncipe herdeiro D. João, filho de D. João III, e dezoito dias mais tarde, a 20 de Janeiro, nascia seu filho póstumo, o futuro rei D. Sebastião, de triste memória para os portugueses.

À morte do príncipe dedicou Diogo de Teive a Tragoedia Ioannes Princeps publicada em 1558. A Tragédia do Príncipe João foi traduzida, comentada e criteriosamente estudada na tese de licenciatura da Doutora Nair de Castro Soares, actualmente já em segunda edição(4).

Em 1550 fizera Teive representar a tragédia Dauid nas festas do bacharelato de D. António, filho bastardo do infante D. Luís, mais tarde prior do Crato e efémero rei de Portugal.

Mas a passagem de Teive pelos calabouços da Inquisição, onde entrou em Julho desse mesmo ano de 1550, levou ao desaparecimento desta e de outra tragédia intitulada Judith.

Seria tratado pela Inquisição melhor do que Damião de Góis, anos mais tarde.

Depois da sua libertação, Teive ainda foi, por pouco tempo, o principal do Colégio das Artes, mas em Outubro de 1555, entregou-o à Companhia de Jesus, por ordem de D. João III.

Quando os quatro fidalgos (dáimios) japoneses visitaram expressamente Coimbra, a pedido dos seus professores no Japão, todos eles jesuítas portu-

(3) Gymnasio non ita pridem celebri, antequam Rex Ioannes Tertius illud Conimbricam transtulisset. "A Universidade não lá muito célebre, antes que o rei D. João III a tivesse transferido para Coimbra». Cf. Aires A. Nascimento, Damião de Góis. Elogio da Cidade de Lisboa, Lisboa, Guimarães Editores, 2002, p. 144.

(4) Lisboa, FCG / FCT, 21999. 
gueses, o Colégio das Artes estava, há trinta anos, nas mãos da Companhia de Jesus.

O relato dessa visita constitui o capítulo XXXI do De Missione Legatorum Iaponiensium ad Romanam Curiam ... Dialogus do P. e Duarte de Sande, S.I., publicado em Macau, em 1590. Foi editado em português, em 1997, quatrocentos e sete anos depois de ter sido impresso na mesma cidade de Macau(5). Uma edição em português, de que fala Barbosa Machado, nunca existiu $^{(6)}$.

Os japoneses foram recebidos nas classes mais adiantadas de Latinidade, com diálogos representados pelos alunos, de que a seguir dou o resumo de um deles, traduzido do latim do Padre Duarte de Sande(7).

"No dia em que visitámos a classe primeira e a mais alta, foi-nos apresentado um drama muito interessante, que representava de modo notável os 'Anjos' a que chamam 'da Guarda'. Dialogaram entre si os que têm sob a sua protecção o Japão e a Europa. Este último perguntou ao outro qual a situação das coisas no Japão, e na resposta foram desenvolvidas muitas vitórias admiráveis e os feitos praticados no Japão, que redundaram em louvor da religião cristã. Para os confirmar todos, apareceu em público a Fé, acompanhada de grande cortejo de santos (caelitum) e apregoou à boca cheia os louvores da Igreja japonesa, e finalmente, atribuindo todos estes bens ao símbolo da cruz, venerou-o com espírito religioso e grande respeito.

Retomando a palavra, o Anjo da Guarda da Europa, contou em longa fala, quanto se esforçou por que fôssemos recebidos com grande aplauso pelas várias regiões da Europa e por que os Sumos Pontífices nos cumulassem das provas do seu amor, como era justo que os pais mostrassem por filhos de novo nascidos. Depois entregou-nos ao Anjo, patrono do Japão, para que nos reconduzisse à pátria, sãos e salvos. Tudo isto foi representado com suma graciosidade das personagens e elegância das falas.

(5) Duarte de Sande, S.J., Diálogo sobre a Missão dos Embaixadores Japoneses à Cúria Romana. Prefácio, tradução do latim e comentário de Américo da Costa Ramalho. Macau, Comissão Territorial de Macau para as Comemorações dos Descobrimentos Portugueses e Fundação Oriente, 1997, 353 páginas.

(6) Innocencio Francisco da Silva, Diccionario Bibliographico Portuguez, T. II, Lisboa, Imprensa Nacional, 1859, p. 216-217; 473-474; T. IX, p. 155.

(7) Para o latim, aqui traduzido, veja A. Costa Ramalho, Para a História do Humanismo em Portugal, Lisboa, INCM, III, 1998, pág. 268, nn. 10 e 11. 
Também o Mestre, durante o diálogo, dirigindo-se a nós, comparou a nossa entrada na cidade com o regresso, cheio de alegria do rei D. Afonso Henriques à mesma cidade, depois de ganhar sobre os inimigos famosa vitória, e mostrou, em termos eloquentes, quanto mais gloriosos eram os nossos despojos da derrota da Idolatria que no Japão dominava ao longe e ao largo.»

Segue-se o resumo de mais dois diálogos dramáticos que me dispenso de citar.

Tinha, há pouco, chegado a Coimbra o novo bispo D. Afonso de Castelo Branco. E os professores do Colégio das Artes resolveram homenagear o prelado e os visitantes japoneses, pondo em cena a tragédia Ioannes Baptista da autoria do jesuíta padre António de Abreu.

Dou seguidamente o resumo feito por Duarte de Sande:

"No primeiro acto, foi apresentado João, menino de 5 anos de idade, que abandona os pais e as delícias da vida, fugindo para o ermo e para um modo de viver severíssimo, em que passou, no rigor, toda a sua existência até aos 30 anos.

No segundo acto, os povos da Judeia, impressionados pela fama da sua santidade, vieram ter com ele em grande número e, arrependidos dos pecados, foram por ele purificados nas águas do rio Jordão.

O terceiro era preenchido pela viagem progressiva deste santo até à cidade de Jerusalém e pelos frequentes avisos ao rei Herodes, pelos quais, ameaçando-o com a justiça divina, procurava desviá-lo, pelo medo, do seu criminoso incesto. No decurso deste acto pintava-se notavelmente, quer o fogo do divino amor que incendiava a mente de S. João, quer a irritação do tirano que se tornava cada vez mais duro contra os salutares avisos.

No quarto acto, tratava-se das cadeias que injustamente foram postas ao santíssimo varão e brilhava sobremaneira a sua paciência em tolerar todas as adversidades.

Concluía toda a acção a decapitação crudelíssima do santo, exposta por tal forma que não se passava em cena, mas parecia ter realmente acontecido.

A cada acto desta tragédia juntava-se um canto suavíssimo de muitas vozes. Principalmente o terceiro acto foi digno de nota por aquela virtude, que com um vocabulário comum se designa por penitência, a qual exortava os Anjos a proclamar os louvores de São João, que eles celebravam com notável canto. 
A esta peça conferiu não pequeno ornamento a descrição de alguns lugares, por exemplo, o da solidão em que São João se mortificava com a fome e outros sofrimentos e o da mansão infernal, de onde irrompiam as fúrias que impeliam a alma do ímpio Herodes às fraudes e aos crimes».

O latim correspondente à parte acabada de traduzir, pode ler-se no meu livro Para a História do Humanismo em Portugal, vol. III, p. 271.

A procura de lugares para assistir ao espectáculo foi renhida em toda a cidade de Coimbra. Houve quem levasse cadeiras e cobertores e se sentasse à porta do Colégio desde a véspera, passando a noite fria de Dezembro ao relento, para no dia seguinte ter direito a um lugar.

Um estudante de cânones que quis entrar no Colégio durante a noite caiu numa cisterna donde a custo foi salvo. Pergunto a mim mesmo se a cisterna não será a que, há pouco, foi descoberta sob o edifício do "Laboratório Chimico» construído no século XVIII, ao lado do Colégio das Artes, e em frente do Colégio de Jesus.

A representação da tragédia Ioannes Baptista durou sete horas, e foi entusiasticamente aplaudida ${ }^{(8)}$. Impressionaram particularmente a assistência alguns cenários e a harmonia musical dos coros. Mas deixemos os japoneses.

Tenho algumas recordações do meu contacto com os manuscritos do Colégio das Artes.

Entre 1959 e 1962, fui professor visitante da New York University. Uma tarde, em que trabalhava na biblioteca da Hispanic Society of America fui procurado pela bibliotecária-chefe, Miss Clara Penny, já então aposentada, mas sempre presente, que me informou de que tinha uma novidade para mim. Entregou-me um livro manuscrito, adquirido há pouco e proveniente do Colégio das Artes de Coimbra, onde reconheci imediatamente a Achabus

(8) Sobre a embaixada dos japoneses ver no livro citado na nota anterior os capítulos XXIV a XXIX, p. 209-276. 
que eu conhecia dos manuscritos de Coimbra. Com efeito, no final do meu curso de Filologia Clássica, e antes da licenciatura, publiquei um Catálogo dos Manuscritos da Biblioteca Geral da Universidade de Coimbra, relativos à Antiguidade Clássica, em 1945. Quando fiz o catálogo, não sabia que o autor da tragédia era Miguel Venegas, pois os manuscritos de Coimbra omitem o nome do autor, assim como o de Nova Iorque.

Vim a encontrar o autor em manuscritos da biblioteca de Évora. Tanto o meu Catálogo como o artigo que publiquei sobre o manuscrito de Nova Iorque são devidamente citados no Iter Italicum de Paul Oskar Kristeller ${ }^{(9)}$.

Outro encontro com um manuscrito conimbricense do Colégio das Artes deu-se no Rio de Janeiro. Em 1976, dava eu um curso sobre o humanista José de Anchieta, S.I., a doutorandos na Faculdade de Letras da Universidade Federal, quando fui surpreendido com a informação de que o Rev.

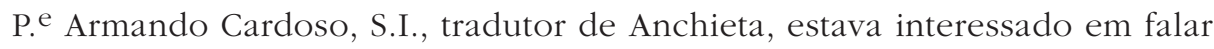
comigo.

Informado de que o Senhor Padre Cardoso era pessoa de idade avançada, tomei a iniciativa de ir visitá-lo ao Colégio de Santo Inácio que, por acaso, ficava perto do lugar em que eu vivia. O P. e Armando Cardoso queria a minha opinião sobre um manuscrito que existia no Colégio, trazido de Itália, com poemas do século XVI que o seu colega Padre José R. Zabala considerava serem possivelmente de Anchieta.

Ao folhear o códice, ali mesmo, encontrei os coros de Achabus e completo o Saul Gelboaeus, muito meu conhecido, pois já orientara em Coimbra uma tese de licenciatura sobre essa tragédia. Mais uma vez, Miguel Venegas no meu caminho.

(9) Paul Oskar Kristeller, Iter Italicum, IV (Alia Itinera, II), London, Warburg Institute; Leiden, J. Brill, 1989, p. 446-449.

Para o manuscrito de Nova Iorque, ver A. Costa Ramalho, Estudos sobre a Época do Renascimento, Lisboa, FCG / JNICT, ${ }^{2} 1997$, p. 333-345.

Sebastião Tavares de Pinho "Literatura Humanística inédita do Colégio das Artes da Universidade de Coimbra no século XVI». Actas do Congresso de História da Universidade no VII Centenário, Coimbra, 1991, p. 1-20 da separata. 
O Padre Armando Cardoso era uma pessoa encantadora (ignoro se é ainda vivo) e agradeceu-me satisfeito o esclarecimento da autoria, facultando-me uma cópia dactilografada do manuscrito. O códice do Rio de Janeiro já o tenho citado em trabalhos meus.

Com estas notas soltas do meu percurso na Literatura Novilatina em Portugal, iniciado por um Catálogo de Manuscritos em 1945 e continuado até hoje, espero sinceramente não vos ter fatigado nem desiludido em demasia. 


\author{
Nigel Griffin \\ Christ Church Oxford
}

'I SPY STRANGERS': JESUIT PLAYS AND THEIR TRAVELS

In the summer of 1566, the Jesuit college in the Southern German town of Dillingen was busily occupied with preparations for the arrival of a distinguished guest.

This Bavarian town, close to Augsburg and Munich and strategically located on the north bank of the Danube astride one of the much travelled routes between Vienna and Trent, had seen a steady stream of important political and ecclesiastical emissaries pass through its gates over the course of the 1550s and 1560s. Dillingen University, founded by the bishop of Augsburg and accorded official recognition in 1551 by Julius III, one of the two co-presidents of the opening sessions of the Council of Trent six years earlier, was the only new university created at this period in Southern Germany and it boasted a large, international, and swelling student population. (1)

(1) See the figures for 1550-60 in Franz EULENBERG, "Die Frequenz der deutschen Universitäten von ihrer Gründung bis zur Gegenwart", Abhandlung der Philosophisch-historische Klasse der Königliche Sächsichen Gesellschaft der Wissenschaften (Leipzig), XXIV (1904), 102-3. On the importance of the university and the college, see also Thomas SPECHT, Geschichte der ebemaligen Universität Dillingen (1549-1804) und der mit ibr verbundenen Lebr- und Erziebungs-Anstalten (Freiburg im Breisgau \& St Louis MO: Herder, 1902), 1043 56-8; Laetitia BÖHM, "Usus Dilingae: Modell oder Ärgernis?: Ein Besinnung auf die Bedeutung der ehemaligen Universität Dillingen als Glückwunsch zum ersten Jubiläum der Universität Augsburg», in Probleme der Integration Ostschwabens in den bayerischen Staat: Bayern und Wittelsbach in Ostschwaben: Referate und Beiträge der Tagung auf der Reisenburg am 21./22. März 1980, Veröffentlichungen der Schwäbischen Forschungsgemeinschaft bei der Kommission für Bayerische Landesgeschichte, Reihe 7: Augsburger Beiträge zur Landesgeschichte Bayerisch-Schwabens 2, ed. Pankraz FRIED (Sigmarigen: J. Thorbecke, 1982), 245-68; and Karl HENGST, Jesuiten an Universitäten und Jesuitenuniversitäten: Zur Geschichte der Universitäten in der Oberdeutschen und Rheinischen 
The Jesuit college had been licenced by Pius IV in 1561 to issue its own independent degrees but did not begin a full teaching programme until 1564; even then it had to wait until 1566 before it could hold its official opening ceremony. The college authorities were throughout the 1560 s heavily involved in the protracted piecemeal negotiations between the papacy, the German bishops, and various local independent princes, that did so much to decide the eventual religious affiliations of the towns and estates of the region. One weapon the Jesuit community had in its armoury when it wished to make common cause with those working on Rome's behalf was to mark the presence of important Catholic visitors to the town by staging public festivities in their honour. The four-monthly letters for 1564 , for example, are full of references to events held to mark the presence of distinguished guests, and a lengthy account dated 1 July 1565 describes some of these in detail. Such depatches reveal a community revelling in its new-found importance and increasingly adept at staging literary festivals; there would even seem to have been some kind of standing arrangement with local citizens who were prepared to loan ornaments and costumes for occasions such as these. (2)

The guest the college was expecting in the summer of 1566 was none other than Cardinal Giovanni Francesco Commendone, one of those most closely involved in the whole question of the Imperial succession as it affected Poland and Bohemia. Two years previously, he and his fellow cardinal

Provinz der Gesellschaft Jesu im Zeitalter der konfessionellen Auseinandersetzung, Quellen und Forschungen aus dem Gebiet der Geschichte ns 2 (Paderborn, etc.: Schöningh, 1981). See also the comments of Jerome Nadal SI on the University student population in a letter sent from Vienna on 8 May 1555: «Son los schólares 200 más o menos y lo que paresce mucho quasi todos son estrangeros" (Archivum Romanum Societatis Iesu (= ARSI), Epp. NN. 59, 138 [259]r-141[262] ${ }^{\mathrm{v}}$ $\left[\mathrm{n}^{\circ}\right.$ 73(31)] at $139[260]^{\mathrm{v}}$, repr. in Epistulae P. Hieronymi Nadal Societatis Iesu ab anno 1546 ad $1577(=E N)$, ed. Fridericus CERVÓs SI, 5 vols (Madrid: A. Avrial, 1898-1962), I: 1546-1562 (1898), Monumenta Historica Societatis Iesu (MHSI) 13, 299-306, letter 77, at 303).

(2) Unsigned letter from the Upper German Province to Rome, Dillingen, 1 July 1565 (AHSI, Germ. 139, 293a[158]r-293h $\mathrm{h}^{\mathrm{V}}$ at $\left.293 \mathrm{a}^{\mathrm{v}}-293 \mathrm{~b}[159]^{\mathrm{v}}\right)$; four-monthly letter signed simply "Erasmus", Dillingen, 22 January 1565 (ARSI Germ. 139, 286[113(4)]r-288[121(sic)] $]^{\mathrm{V}}$ at 187v). The first of these has a very full description of the use of Greek, Latin, and Hebrew poetry as part of the décor at a literary festival. 
Stanisław Hozyusz (Hosius) had been instrumental in bolstering the Catholic cause in the East by helping to establish a Jesuit mission to Poland, and he had continued ever since then to warn Rome of the urgent need to support Jesuit efforts in southern Germany, describing these to Pius IV in 1562 as "gran seruitio di questa santa sede». (3)

Commendone had spent the winter of 1565-6 travelling the roads between Trent, Augsburg, and Dillingen. (4) The purpose of this shuttle diplomacy was quite clear: he had been instructed to proceed to Augsburg, there to oppose by every means at his disposal any attempt on the part of the second so-called Diet of Augsburg to obtain a further measure of tolerance for Lutherans. The Diet had been convened by Emperor Maximilian, known to be secretly sympathetic to Protestant Reform. Commendone was also directed to ensure that the Elector of Cologne, Count Friedrich von Wied, who still persisted in the hope that some sort of accommodation might be possible with the heretics, was persuaded to take the oath and make the profession of faith prescribed by Trent. Commendone was also given overall responsibility for seeing that any episcopal sees that fell vacant in the meantime were filled by those loyal to Rome. (5)

(3) Rome, Bibliotheca Apostolica Vaticana (BAV), MS Barb. Lat. 5798, repr. in Nuntius Commendone, 1560 (Dezember)-1562 (März), ed. Adam WANDRUSKA, Nuntiaturberichte aus Deutschland nebst ergänzenden Aktenstücken II/ii (Graz \& Cologne: H. Böhlaus, 1953), 50-66, doc. 66 , at 52 .

(4) Stanisław ROSTOWSKI SI, Lituanicarum Societatis Iesu historiarum libri decem, ed. Ivan MARTYNOV SI (Paris \& Brussels: Victor Palmé, 1877), 1112 409; Stanisław ZAŁESKI SI, Jezuicki $w$ Polsce, 5 vols (11 parts) (Lwów: Drukarnia Ludowa [I-III] and Krakow: W. L. Anczyc [IV-V], 1900-6), I/i-ii, passim; Mario SCADUTO SI, L'epoca di Giacomo Lainez 1556-1565, 2 vols, Storia della Compagnia di Gesù in Italia III-IV (Rome: La Civiltà Cattolica, 1964-74), II. 310-11; Paulus RABIKAUSKAS SI, "Die Gründungsbulle der Universität Vilnius (30. Oktober 1579): Vorgeschichte, Ausstellung und Bedeutung", Archivum Historiae Pontificiae (Rome), XVI (1978), 113-70 at 121 ff.; Jan KOREWA SI, "Les débuts de la Compagnie de Jésus en Pologne 1549-1564", Archivum Historicum Societatis Iesu (Rome), XXXIV (1965), 3-35.

(5) See the instruction sent to Commendone from Rome, 27 February 1566 (Città di Castello, Archivo Graziana-Margherini, MS 15, 162r-v, repr. in Nuntius Biglia, 1565-1566 (Juni): Commendone als Legat auf dem Reichstag zu Augsburg 1566, ed. Ignaz P. DENGEL, Nuntiaturberichte aus Deutschland nebst ergänzenden Aktenstücken II/v (Vienna \& Leipzig: Hölder-Picher-Tempsky, 1926), 56-71, doc. 18. 
In the event, not all of these enterprises ended happily. Although the Diet broke up at the end of May 1566 without issuing any firm recommendations, Von Wied, for one, resigned his see, unrepentant, in 1567, and the following year, the Protestants persuaded Maximilian to allow the free practice of the Lutheran faith. But in the high summer of 1566, these reverses were still in the future and Commendone's course of action was clear. The detailed briefing he received from the new Pope, Pius V, reminded him that his natural allies in this struggle for hearts and minds were Duke Albrecht of Bavaria, the Spanish ambassador, and the fledgling Jesuit communities in the region. Indeed, Jesuit luminaries of the stature of Nadal, Ledesma, and Peter Canisius were on hand to lend their weight to Nuncio Biglia's campaign at the Imperial Court, as was the founder of the Dillingen College, Otto Truchsess von Waldburg, who had left Rome in late February in order to attend the Diet and whose activities in the region were directly subvented by Rome. ${ }^{(6)}$

As soon as he arrived in Dillingen for consultations at the beginning of June, Commendone, ever keen to ensure a high level of Latin learning in the colleges, dioceses, and monasteries he visited, ${ }^{(7)}$ hastened to make common cause with the Catholic faithful in the most public way possible by attending, along with Archduke Albrecht, Nuncio Biglia, and the founder himself, a performance of a play at the college Nadal had characterized some ten years earlier as «un propugnáculo de la fe». ${ }^{(8)}$ In two letters, written

(6) BAV, MS Cod. Urb. Lat. 1040, 188r-v [1040/11, 3r-v].

(7) See Michael MAYR, "Cardinal Commendones Kloster- und Kirchen-Visitationen von 1569 in den Diöcesen Passau und Salzburg», Studien und Mitteilungen aus dem Benediktiner-und Cisterzienser-Orden (Würzburg), XIV (1893), 385-98, 567-89.

(8) ARSI, EPp. NN. 59, at 139v. The Archduke was to prove one of the most assiduous enthusiasts for Jesuit plays: see Friedrich SCHMIDT, "Ein Festspiel der Münchener Jesuitenschule im XVI. Jahrhundert", Forschungen zur Kultur-und Literaturgeschichte Bayerns (Ansbach \& Leipzig), III (1895), 12-32. The 1566-67 Annual Letter of the Dillingen College, signed "Antonius Flander" and dated 1 October 1567, singles out Cardinal Truchsess's pride in his college's plays and dialogues, saying that he always made every effort to be present at them (ARSI, Germ. 140, $85[8(245)] \mathrm{r}-88[11(248)]^{\mathrm{V}}$ at $85^{\mathrm{V}}$ ). Otto Truchsess and his family had a tradition of service to the houses of Württenburg and Habsburg, as well as close connexions with the episcopal court at Dillingen: see Georg GRUPP, Oettingische Geschichte der Reformationszeit (Nördlingen: Reichle, 1894), and Virginia M. E. DEMARCE, "The official career of Georg III Truchsess von Waldburg: A 
from Augsburg over a space of just ten days by Nadal to the Jesuit General Francisco Borja in Rome, we can glimpse a sense of the importance this occasion had for these leaders of the Bavarian Catholic community, with their references to «la representatione ... che si fara là [i. e. in Dillingen] dinanzi all Reverendissimj legato, Augustano, et Nuncio» and to the Legate's journey to Dillingen, where he and Father Ledesma «uerrano a far' la pentecoste [5-8 June] in Dilinga doue si recitarà la tragedia ... et parechi epigrami à questi Reverendissimi Cardinali, et al Nuncio, et a monsignor lancilloto etc et forse anchora uerra il Reverendissimo Cameracense». (9) The Annual Letter written that autumn and signed by Christoph Ziegler SI on behalf of the Rector confirms that the Bishop of Cambrai was indeed present at the performance and furnishes yet more detail of the founder's attachment to his college and the steady stream of dignitaries whom he persuaded to grace the college with their presence.

Cum Dilingae est [Otto Truchsess], nullus ad eum Princeps accedit (accedunt autem plurimi) quem ad Collegium nostrum non adducat, ut hac ratione nostra rectius studia exteri intelligant ... Vno e[t] eodem tempore Cardinalem Commendonum Sedis Apostolicae à latere Legatum, Archiepiscopos Moguntinum et Treuerensem, qui Romani Imperij sunt electores praecipuj, unà cum Archiepiscopo Cameracensi, alijsque uiris primarijs ad templum nostrum adduxit, quos diuinis peractis officijs, quae integrè illi audierunt, generatim primum omnes, et Praesules deinde singulos Hebraicis, Graecis et latinis carminimus [ sic] à quodam ex societate compositis et per selectos pueros recitatis, excipiendos curauit, quibus etiam Tragedia non minus pia quam docta eiudem Reverendjssimi nostri sumptibus instructa, per discipulos scholae nostrae exhibita fuit. ${ }^{(10)}$

study in the administration of religious policy by a Catholic government during the first years of the Reformation", unpublished doctoral dissertation, Stanford University, 1966, 13.

(9) Letters of 11 and 21 May 1566 (ARSI, EPp. NN. 62, 156[90]r-157v at 156r and 165[96]r$166[97]^{\mathrm{V}}$ at 165 r, both repr. in $E N$ III $(1902), 122-4$, letter 391, at 123, and 140-44, letter 398, at 140-1. Scipione Lancilotti, canonist to Commendone and later created Cardinal by Gregory XIII, had been sent by Pius V to Archduke Albrecht and to the Emperor. The Bishop of Cambrai in 1566 was Maximilian de Walhain.

(10) Although the Jesuits were later to become disenchanted with Von der Leyen, archbishop of Trier from 9 March 1566 until his death in February of the following year, both he and his Mainz colleague Daniel von Brendel (elected 23 August 1555, died 22 March 1582) were at 
Details of the background to this play, as well as the documents cited here, are already in the public domain. ${ }^{(11)}$ But I have cited them here in extenso for a reason : these accounts focus on the local concerns of this particular Jesuit college and of those who publicly identified with it and them by being in the audience for the occasion. Let us now turn, more briefly, to two other Jesuit plays of which details have already been published.

Towards the end of that same century and some three hundred kilometers to the north-west, the college founded in 1561 in the strategically important city of Mainz at the confluence of the Main and the Rhine, twice staged plays on the biblical story of Ahab and Jezabel, taken from the third and fourth books of Kings. We do not know who wrote the piece that the Jesuits put on there in 1592 even though the text survives in at least three manuscripts, in Paderborn, Koblenz, and Cologne, a fact which may indicate that it was also performed in other German colleges. ${ }^{(12)}$ A fourth copy, recorded by Müller as being in the Münster Paulinum was probably destroyed by Allied bombing in World War II. (13) But the other play on this story, which was probably performed at Mainz in 1595 and again in Würzburg in 1611, survives in at least eight manuscripts. The one copy that is to be found today in Germany

this juncture seen by Commendone as the staunchest of allies. Both had been urged by Pius $\mathrm{V}$ to give the nuncio's mission their full support, just as they had his predecessor Canisius in November 1565. Given the international nature of the Jesuit studium, most of the cast were probably from Bohemia.

(11) Nigel GRIFFIN, "Lewin Brecht, Miguel Venegas, and the school drama: Some further observations", Humanitas (Coimbra), XXXV/XXXVI (1983-84 [1985]), 19-86 at 64-71.

(12) Details of these were originally provided by: Fritz REDIGER, Zur dramatischen Literatur der Paderborner Jesuiten, dissertation, University of Münster, 1935 (Emsdetten: H. \& J. Lechte, 1935), 7; Paul BAHLMAnN, Jesuitendramen der niederrbeinischen Ordensprovinz, Beiheft zum Centralblatt für Bibliothekswesen 15 (Leipzig: Otto Harrassowitz, 1896; repr. Nendeln, Liechtenstein: Kraus Reprint Limited, 1968), 119; Johannes MÜLLER SI, Das Jesuitendrama in den Ländern deutscher Zunge vom Anfang (1555) bis zum Hochbarock (1665), 2 vols, Schriften zur Deutschen Literatur 7-8 (Augsburg: Benno Filser, 1930), II. 52; and Wilhelm RICHTER, "Paderborner Jesuitendramen von 1592-1770", Mitteilungen der Gesellschaft für Deutsche Erziehungs- und Schulgeschichte (Berlin), IV (1894), 5-16.

(13) See Nigel GRIFFIN, Two Jesuit Ahab dramas, Exeter Hispanic Texts 13 (Exeter: University of Exeter, 1976), xiv, and, for further details and discussion of other possible performances, Jean-Marie VALENTIN, Le théâtre des jésuites dans les pays de langue allemande: Répertoire chronologique des pièces représentées et des documents conservés (1555-1773), 2 vols, Hiersemanns Bibliographische Handbücher 3/i-ii (Stuttgart: Anton Hiersemann, 1983-4), I. 
is in the same Cologne collection that includes the 1592 piece as well as dramatic treatments of the stories of two of kings of Judah, Manasseh and Zedekiah; it bears the legend, written in a seventeenth-century hand (fol. $\mathrm{B}^{\mathrm{v}}$ ): "Probabile existimo sequens Drama exhibitum Moguntiae aut Herbipoli eo tempore quo Philippus \& ferdinandus (postea Elector Coloniae) fratres Bauariae Ducis Moguntiam \& Herbipolim visitarunt cum ambos iuuenes essent, (? puto) inter annum 161590 \& 1600».

The date of the performance of the third play to which I should like to draw attention is unknown, but it almost certainly dates from the early years of the seventeenth century. Preserved in a manuscript in the Historisches Archiv der Stadt in Cologne (MS Univ. Akten 1058, formerly Univ. IX. 661) alongside twenty-two others, written in a variety of hands, and most of them treating themes we know, from Valentin and others, to have been popular in Jesuit studia in the sixteenth and early seventeenth centuries, it is entitled Tragoedia sacra Hierosolyma eversa per Nabvchodonosorem. A note on the first folio of the manuscript, written in a seventeenth-century hand (fol. Ar), describes the collection as being of "Tragoediae, Comoediae et Dramata pro Gymnasium trium Coronarum Societatis Jesu Coloniae ex variis theologiae studiosorum scriptis sub annum 1640 collecta». The play, then, was performed at the Cologne college, yet another 150 kilometers or so further to the north and west of Mainz. Occupying thirty-nine folios (150r-188v) and running to some sixteen hundred lines, the text and its stage-directions make it clear that this was a highly dynamic production, with great emphasis on stage business. It was also a play with a clear, local political message.

During the later sixteenth century, Cologne had acquired a reputation as a crucible of heterodox thought and political dissent. We have already noted that one Elector, Count Friedrich von Wied, was forced out of office; two others, Hermann V von Wied (Elector 1515-47) and Gebhard Truchsess von Waldburg (Elector 1577-83 and the nephew of the Otto Truchsess we just encountered as founder of the Dillingen college) were also charged with 
Lutheranism and removed, Gebhard having attempted to secularize Cologne and make it a free religious city only to be excommunicated by Gregory XIII in 1583 when he married, according to the Lutheran rite, his mistress Countess Agnes von Mansfeld. (14) The events that followed, as Gebhart, with the support of the Calvinistic Count Palatine, Johann Casimir, and of William of Orange, took up arms against his Wittelsbach successor Ernst of Austria, led to the co-called War of Cologne, a particular bloody affair which saw disaffected and unpaid Spanish troops from the Netherlands drafted in to sack and loot the towns and villages that supported Gebhard. (15)

Many of those who watched Hierosolyma eversa would have recalled the events of the 1580 s only too vividly. The play, with its emphasis on the twin themes of rebellion and punishment, clearly delivered a reminder that was as much political as it was theological. Although widespread devastation of town and countryside had eventually secured tenure of the Electorate by cadets of the Bavarian house and hence both the continuity of Catholicism in the region and a Catholic majority in the College of Electors, the events of 1609 to 1616 show beyond doubt that many independently-minded citizens of Cologne still felt a deep attraction for a possible anti-Habsburg alliance centering on the ill-fated Frederick V Elector Palatine and his young English bride, the Princess Elizabeth. ${ }^{(16)}$ The Jesuits were naturally in the forefront

(14) F. SEIBERT, "Zwischen Kaiser und Papst: Kardinal Truchsess von Waldburg und die Anfänge der Gegenreformation in Deutschland", unpublished doctoral dissertation, University of Berlin, 1943.

(15) Max LOSSEN, Der Kölnische Krieg: Vorgeschichte 1565-1581 (Gotha: F. A. Perthes, 1882); August FRANZEN, "Die Durchführung des Konzils von Trient in der Diözese Köln", in Das Weltkonzil von Trient: Sein Werden und Wirken, ed. Georg SCHREIBER, 2 vols (Frieburg im Breisgau: Herder, 1951), II. 267-94 at 271-2; Leonhard ENNEN, Geschichte der Stadt Köln: Meist aus dem Quellen des Kölner Stadt-Archivs, 5 vols (Cologne, etc.: L. Schwann, 1863-80), V: Zeit der Gegenreformation, 80-95 120-9 366-80; Friedrich REIFFENBERG SI, Historia Societatis Iesu ad Rhenum Inferiorem e MSS codicibus, principum, urbiumque diplomatis, et authoribus synchronis nunc primum eruta, atque ad historiam patriae ex occasione illustrandam accommodata, I (Cologne: Franz Wilhelm Joseph Metternich, 1764), Book VIII, Chapters 8-9 (209-20); ClausPeter Clasen, The Palatinate in European History 1555-1618 (Oxford: Basil Blackwell, 1963; revised edn 1966).

(16) REIFFEnBERG, Historia, Book XV, Chapter 1 (498); Cicely V. WEDGWOOD, The Thirty Years War (London: Jonathan Cape, 1938); Frances YATES, The Rosicrucian Enlightenment (London: Routledge \& Kegan Paul, 1972). 
of the opposition to any such development, and the message of Hierosolyma eversa, with its mayhem and its on-stage executions of the rebels, is clear and uncompromising. Those who flirt with rebellion against an absent «lawful» (Habsburg) monarch and conspire with the pro-Palatinate cabal against the true religion represented by the Bavarian Elector chosen to replace Gebhard will suffer the full Aeschylean horror of the fate that befalls the central character of the play, Sedecias, and his entourage. Their palaces and cities will be sacked and razed to the ground, as much of Cologne had been in the 1580s, and as Jerusalem was in the sixth century BC when the Babylonian hordes descended upon it; they themselves will be summarily executed as were the anti-Yahwist counsellors who ignored the warnings of Hieremias; and all that they hold dear will be destroyed before their very eyes. They will be left amid the ruins of their cause and their city, as is Sedecias in the play, ranting and raving in a blind fury while the victorious monarch and his loyal henchmen jeer at their fall and their impotence.

We have here, then, three performances, separated by some fifty years and by nearly five hundred kilometers. At first sight, they seem to have little in common with each other beyond their being staged in Jesuit colleges by Jesuit pupils, their obeying standing orders to the effect that such pieces should be written and staged exclusively in Latin (an order generally more honoured in the breach than in the observance), and their being tailored to the particular local religious and political concerns of the college where they were staged. The scholars who first drew attention to the existence of these three plays were, it would seem, quite unaware of any other possible connexion between them. ${ }^{(17)}$

Yet it happens that these three performances have a great deal in common. Two of them were written by Jesuit Fathers teaching in Portugal and had

(17) See, for example, Josef KUCKHOFF, "Das erste Jahrhundert des Jesuitenschauspiels am Tricoronatum in Köln», Jabrbuch des Kölner Geschichts-Vereins (Cologne), X (1928), 25-49; MÜLLER, Das Jesuitendrama. 
already been staged there before they arrived in Germany, and the third was supervised by an exiled dramatist from that same Portuguese Province.

The Mainz Ahab drama of 1595 is an adaptation of the Tragoedia cui nomen inditum Achabus of the best-known early dramatist of the Portuguese Province, Miguel Venegas. In addition to the Cologne manuscript mentioned above, there are manuscript copies in Portugal (two in Lisbon, and one each in Coimbra and Évora), France (in the Jesuit archives at Chantilly, outside Paris, where Venegas was active from November 1563 to February 1566, the copy of his Saul Gelboaeus contained in that same manuscript indicating that it, if not Achabus, had also been staged in Rome, in the Collegio Germanico), at Messina in Sicily (where manuscript play exchanges with Portugal are emerging as an intriguing possibility)(18) and at Perugia, and even, as Américo da Costa Ramalho discovered over forty years ago, in New York. (19) The play, which was transcribed and edited in 1976 by the present author alongside a second, anonymous Jesuit piece on the same subject from the Castile Province, is about to appear in a proper scholarly edition prepared by another contributor to this volume, Maria Margarida Lopes Miranda, who has already published widely on the play and on Portuguese Jesuit drama more generally. ${ }^{(20)}$

(18) See the characteristically cautious but intriguing remarks of Manuel José de Sousa BARBOSA, "Luzes e mistérios no teatro jesuítico: BPE, Cod. CVIII/2-7, fols 61r-85v: O Nabuchodonosor de Stephanus Tuccius? Interpelações de um texto truncado", Euphrosyne (Lisbon), XXXI (2003), 415-26.

(19) "Um manuscrito de teatro humanístico conimbricense», Humanitas (Coimbra), XIII/XIV (1960-61), I-VII b, repr. in his Estudos sobre a época do Renascimento (Coimbra: Instituto de Alta Cultura, Centro de Estudos Clássicos e Humanísticos anexo à Faculdade de Letras da Universidade de Coimbra, 1969), 333-45; also COSTA RAMALHO, "Eborae et Novi Eboraci», Humanitas (Coimbra), XV/XVI (1963-64), 434-35.

(20) See also her pilot studies : "Teatro jesuítico: Miguel Venegas, dramaturgo e mestre de retórica", in A retórica greco-latina e a sua perenidade (Coimbra, 11-14 de Março 1997), ed. José Ribeiro FERreira, 2 vols (Porto: Fundação Eng. António de Almeida, 2000), II. 655-69, and "Teatro bíblico novilatino: A Tragédia de Acab de Miguel Venegas", Humanitas (Coimbra), XLVI (1994), 351-71. Margarida Miranda's forthcoming edition is based on her 2002 Coimbra doctoral dissertation, "Miguel Venegas e o nascimento da tragédia jesuítica», which also incorporates significant discoveries made by Julio ALONSO ASENJO, of the University of Valencia, concerning Venegas's later years after he left the Society of Jesus: "Reencuentro con el $M^{\circ}$ Miguel Venegas: Su Comedia en la fiesta del santísimo sacramento", Cuadernos de Filología (Valencia), Anejo L (2002), 1-23 (see also http://parnaseo.uv.es/Ars/teatresco/textos/ComediaMVenegas.htm). 
Tragoedia sacra Hierosolyma eversa per Nabvchodonosorem, meanwhile, was also originally written in Portugal, and by Venegas's star pupil, the Lisbon-born Luís da Cruz (1542-1604). Entitled in the 1605 edition of da Cruz's plays Sedecias, Tragoedia de excidio Hierosolymae per Nabucdonosorem, it had been played in October 1570 at the Coimbra college in the presence of the sixteen-year-old King Sebastião, who eight years later was to perish along with the flower of the Portuguese nobility at the battle of Ksar el-Kébir. The considerable degree to which the play was adapted for performance in Cologne to emphasize local issues has been studied at length elsewhere. ${ }^{(21)}$

The final performance, that at Dillingen in 1566, attended by so many of the big hitters prominent in the protracted local struggle against Lutheranism (and I have included so much detail of that campaign in order to emphasize those particular local concerns), was of a play that was not of Jesuit authorship, the Euripus sive de inanitate omnium rerum, written by an Antwerp-born Franciscan, Livinus Brechtus, or Brechtanus, and first published in the author's adopted city of Leuven by Bathenius in 1549.(22) Yet here, too, there is a Portuguese connection, for the man drafted in from Augsburg - that same "quidam ex societate» singled out in the Annual Letter from Dillingen cited above - so that he might write some of the incidental material to be recited on this occasion and help to orchestrate the performance was none other than Venegas himself. As Nadal informed Borja on 11 May 1566 from Augsburg: «Il P. Vanegas è arrivato qua sono quatro o cinco

(21) GRIFFIN, "A Portuguese Jesuit play in seventeenth-century Cologne», in Studies in the sixteenth-and seventeenth-century theatre of the Iberian Peninsula, ed. Michael J. RUGGERIO, Folio: Essays on Foreign Languages and Literatures 12 (New York: Folio, 1980 [1981]), 46-69 at 56-61.

(22) On the importance of this play see Fidel RÄDLE, "Die Bühne des Euripus», Maske und Kothurn (Vienna), XVIII (1972), 197-206; Jean-Marie VALENTIN, "Aux origines du théâtre néolatin de la Réforme catholique: L'Euripus (1549) de Livinus Brechtus", Humanistica Lovaniensia (Louvain), XXI (1972), 81-188, repr. in VALENTIN, Theatrum catholicum, XVI ${ }^{-}$XVII ${ }^{e}$ siècles, Études Allemandes (Nancy: Presses Universitaires de Nancy, 1990), 131-206; RÄDLE, "Aus der Frühzeit des Jesuitentheaters: Zur Begleitung einer Edition lateinischer Ordensdramen», Daphnis: Zeitschrift für Mittlere Deutsche Literatur (Amsterdam), VII (1978), 403-62; and, for information on Jesuit performances of it, GRIFFIN, «Lewin Brecht», 47-76. 
giorni, et l'hier' l'altro l'habbiamo mandato in Dilinga... In questo mezzo puotra aiutar' a far' alchuni uersi per la representatione dell'Euripo che si fara là... Il giorno stesso che arriuò là, fece alchunj Epigrami all'Imperatore, al Reverendissimo de Augusta, all Illustrissimo legato et al ducca de Bauiera, et hoggi li hauemo mostrato al Augustano, et li contentano molto.»(23) It may be of some interest that one of several surviving manuscript copies of Venegas's own Tragoedia cui nomen inditum Saul Gelboaeus, first performed by the pupils of the Coimbra Colégio das Artes on Sunday 9 July 1559, is to be found today in Dillingen, in the Studienbibliothek, in a miscellany (Hs 219) which once belonged to the most prolific of all Jesuit dramatists, Jakob Gretser (1562-1625) and which also contains a copy of Euripus, and that the play was also staged at the Avignon college in 1570, perhaps as a way of celebrating the apparent end of the local difficulties the Jesuits had encountered the previous year. The Rector at the southern French studium was the distinguished diplomat Antonio Possevino, who had been a good friend of Venegas and invited him to stay for some time at the college. (24)

Nowhere, either in the surviving manuscripts of the texts or in the contemporary accounts we have cited, is there even the merest hint of a Portuguese connection. Someone reading these plays without recourse to the secondary literature would never suspect that they were the work of writers from outside the cultural miniclimats in which they were performed.

One reason we know of these links is that the relatively small dramatic output of the Portuguese Province has been studied closely by Professor

(23) ARSI, Epp. NN. 62, 156r-157v at 156r, repr. in EN III (1902), 122-4, letter 391, at 123.

(24) Anton DÜRRWÄCHTER, "Aus der Frühzeit des Jesuitendramas nach Dillingen Manuskripten", Jahrbuch des Historischen Vereins Dillingen (Dillingen), IX (1897), 1-54 at 4; Nigel GRIFFIN, "Miguel Venegas and the sixteenth-century Jesuit school drama", Modern Language Review (London), LXVIII (1973), 796-806 at 801; GRIFFIN, "Some Jesuit theatre manuscripts", Humanitas (Coimbra), XXIII/XXIV (1971-2), 427-34 at 433; VALENTIN, Répertoire, I. 2, $\mathrm{n}^{\circ} 11$; Marcel Chossat SI, Les Jésuites et leurs oeuvres à Avignon (Avignon: F. Seguin, 1896), 1-25; Henri FOUQUERAY, Histoire de la Compagnie de Jésus en France des origines à la suppression (1528-1762), 5 vols (Paris: A. Picard, 1910-25), I. 434-40; GRIFFIN, "Lewin Brecht», 74-6. 
Américo da Costa Ramalho, his Coimbra pupils, and the pupils of those pupils. There are many other regions of Europe, some of them much more productive in terms of plays, where a good deal of the necessary spadework still remains to be done. The German-speaking lands of Europe have been minutely trawled and magnificently chronicled by Professor Jean-Marie Valentin of the Sorbonne, happily a contributor to this present volume, and we also have, for those same lands, the 7500-page edition of printed play summaries, or periochae, compiled by Elida-Maria Szarota. Elsewhere, however, the picture is still very patchy and for some countries, most notably France, there is no overview of Jesuit production for the whole period up to the dissolution of the Society in the second half of the eighteenth century. ${ }^{(25)}$

Valentin has shown, by using contemporary correspondence, manuscript college histories, secondary literature, manuscript catalogues past and present, and the surviving texts of plays, that it is possible, even if exhausting and painstakingly slow, to trace a play staged at a particular college back to its author and college of origin. The evidence he furnishes in his Répertoire not only demonstrates beyond doubt that plays written and performed in one college or in one Province of the Society frequently found their way to other colleges and other Provinces, but it also suggests many avenues of possible research. An entry such as «1566. Munich (octave de Pâques). David et Goliath. Texte latin manuscript peut-être cod. Dil. 219, ff. 194-246 : Goliat sive David vincens, Cf. également infra, Mayence, 1587», sets more than one hare going. ${ }^{(26)}$

(25) See the account of the secondary literature by GRIFFIN, "Jesuit Drama: A guide to the literature", in I gesuiti e i primordi del teatro barocco in Europa: Roma, 26-29 ottobre 1994, Anagni 30 ottobre 1994, XVIII Convegno Internazionale del Centro Studi Medioevale e Rinascimentale, ed. Miriam CHIABÒ \& Federico Doglio (Rome: Centro Studi Medioevale e Rinascimentale, 1995), 465-96. Some advances have been made since then, but not many.

(26) VAlEnTIN, Répertoire, I. 7, n 49. One such hare concerns the whole family of plays on the story of David and Goliath. See, in addition to the two alluded to here: Vienna 1645 and Dillingen 1648 (VALENTIN, Répertoire, I. 172 182, n ${ }^{\text {os }} 1420$ 1491); Pułtusk 1609-22? and Lublin 1637 (Jan Okoń, Dramat i teatr szkolny: Sceny jezuickie XVII wieku, Studia Staropolskie 26 (Wrocław, Warsaw \& Krakow: Zakład Narodowy imienia Ossolińskich, 1970), 358, 365); Cahors 1622 (Louis Desgraves, Répertoire des programmes des pièces de théâtre jouées dans les collèges en France (1601-1700), École Pratique des Hautes Études, $2^{\text {nd }}$ s, IV ${ }^{\mathrm{e}}$ section: Sciences 
We are also beginning to identify some of the ways in which literary texts travelled from one college to another. In a recent essay, Valentin talks of Stefano Tuccio's Christus Iudex, as having been staged at the Collegio Romano in 1569 «avant de faire le tour des grands collèges jésuites européennes». (27) The question of just how such a tour might happen and of how far, when it does, the play may be adapted to embody local concerns and capture the attention of those present, is not without interest. I have yet to find archival evidence (though, of course, it may exist) of copies of plays being sent with a covering letter from one college to another. But there are plenty of examples of dramatists who, as in the case of Venegas, carried manuscript copies of his works with them on their travels and, in his case, it seems that he may even have kept some of his manuscripts when he left the Society and returned to Spain to teach (and, incidentally, write plays), first at the University of Salamanca and then at his alma mater at Alcalá de Henares. Another channel of dissemination came in the form of fair copies of literary compositions, sometimes expensively bound for the occasion (and accordingly more likely to survive), presented to a distinguished college guest as a memento of the festival he had witnessed. Such presentation copies were often gifted or bequeathed to the dedicatee's local Jesuit college, once he had returned home. This, we know, happened in the

\footnotetext{
Historiques et Philologiques 6: Histoire et Civilisation du Livre 17 (Geneva: Droz \& Paris: Champion, 1986), 40); Rome 1632 and 1647 (Bruna FILIPPI, Il teatro degli argomenti: Gli scenari secenteschi del teatro gesuitico romano: Catalogo analitico, Bibliotheca Instituti Historici SI 54 (Rome: Institum Historicum SI, 2001), 131-40 196-200); Zsolna (Sillein) 16494 (Géza STAUD, A magyarországi jezsuita iskolai szinjátékok forrásai I: 1561-1773/ Fontes ludorum scenicorum in scholis S.I. Hungariae, 4 vols, Magyar Tudományos Akadémia Irodalomtudományi Intézete 1-4 (Budapest: A Magyar Tudományos Akadémiai Könyvtárának Kiadása, 1984-94), II. 465).

(27) Jean-Marie VALENTin, Les jésuites et le théâtre (1554-1680): Contribution à l'bistoire culturelle du monde catholique dans le Saint-Empire romain germanique, La Mesure des Choses (Paris: Éditions Desjonquères, 2001), 337. The play has been the subject of two recent studies by Mirella SAULINI, in one of which there is a discussion of adaptations for performance in different venues: «La città nel teatro, il teatro per la città: Le tragedie del P. Stefano Tuccio SJ", in Vita cittadina nel teatro fra Cinque e Seicento, Anagni 4-5-6 settembre 1998, XXII Convegno internazionale del Centro Studi Medioevale e Rinascimentale, ed. Miriam CHIABÒ \& Federico DOGLIO (Rome: Edizioni Torre d'Orfeo, 1999), 281-96, and "Un nuovo manoscritto del Christus iudex del P. Stefano Tuccio SI: La 'versione' messinese e la 'versione' romana”, Giornale Storico della Letteratura Italiana (Turin), CLXXVI (1999), 196-221.
} 
case of the plays of Venegas that were presented in the summer of 1561 to Próspero Publícola de Santa Cruz, Bishop of the Cretan see of Quissamo in partibus infidelium and Pius IV's legate to the Portuguese Court, even though the manuscript which eventually found its way into the Hispanic Society of New York, where it was discovered by Costa Ramalho, may not, in his judgement, be the actual volume presented to the visitor, but rather a copy of it. ${ }^{(28)}$ Then there are the cases of the volumes which, removed from Jesuit colleges by occupying forces or rapacious individuals, eventually found their way into libraries and archives. An example would be the manuscripts, including one with plays by Grzegorz Knapski (1564-1638), that were taken from the Poznan college by the Swedish diplomat and bibliophile Claes Rålamb during the hostilities sparked by Charles X's 1655 invasion of the Polish-Lithuanian republic and which were later deposited in the library at Uppsala. ${ }^{(29)}$ The printing of plays, most famously in the case of Luís da Cruz's Tragicae comicaeque actiones from the Lyon presses of Horace Cardon in 1605, also made individual texts available for performance as well as schoolroom use. (30) Decisions in principle to authorize the

(28) COSTA RAmalho, Estudos, 338-40. King João III of Portugal was similarly presented with a copy of the pieces he had heard at Lisbon in 1556: Diogo de Bairros from Lisbon, ?January 1557, Litterae quadrimestres (=LQ), ed. Mariano LECINA SI, 7 vols (Madrid: A. Avrial, 1894-1932), $\mathrm{V}$ (MHSI 59), 18. There are recorded cases of requests for copies from other members of an audience: "Multi legendi, aliqui exscribendi eius, copiam petierunt»: Cabrera from Murcia, 29 June $1557, L Q$ V. 260, letter 70. The manuscript history of the Granada college in southern Spain refers (entry for 8 May 1583) to the making of copies as standard practice (Madrid, Archivo Histórico Nacional, MS Jesuitas Libro 773, p. 9), and one of the volumes in the Real Academia de la Historia, also in Madrid (MS 349), may well be just such a presentation volume.

(29) See Lidia WINNICZUK, "Humour in Jesuit school drama and the Roman comedy", in $A n$ tiquitas graeco-romana ac tempora nostra: Acta congressus internationalis habiti Brunae diebus 12-16 mensis Aprilis MCMLXVI, ed. Jan BURIAN \& Ladislav VIDMAN, Československá Akademie věd Kabinet pro Studia Řecká, Římská a Latinská Historický Ustav (Prague: Academia, 1968), 301-11. An excellent example of a traveller and emissary acting as an agent of international artistic diffusion is furnished by the recent study of the important library collected by Płotr Dunin-Wolski, bishop of Płock, during his embassy to the Spanish Court (1561-1573), now in the Jagellion Library in Krakow: see Volsciana: Katalog renesansowego księgozbioru Piotra Dunin-Wolskiego, biskupa płockiego, ed. Andrzej OBREBSKI, Biblioteca Iagellonica: Fontes et Studia 9 (Krakow: Księgarnia Akademicka, 1999).

(30) It might prove useful to trace the many copies of this volume in Jesuit libraries and library inventaries, and then to examine the post-1605 playlists for the colleges concerned, 
printing of material displayed, recited, or performed at ludi litterarii date from the very earliest teaching years of the Society. (31)

Yet our detailed knowledge of some of these channels of dissemination and of possible links between one play and the next is still largely serendipitous. If we are to be confident that we understand the many ways in which plays travelled and one came to influence another, we need, I suggest, a properly international database that can make the raw data available to future scholars and obviate some at least of the time-consuming labour that has characterized so much of what those gathered in Coimbra have been trying to do over the course of the past thirty years or so. Such a database would enable us to recognize and then examine potential links. What, for example, is the relationship between the Saul com filiis Abachi superatus tragoedia given at Caen in Normandy in 1628, and first recorded over a century ago by Paul de Longuemare, of which a printed play summary (or perioche) survives in the Bibliothèque Nationale de France, and the many other Saul, Ahab, and Jezabel plays that we know were staged throughout Jesuit Europe?(32) Or, again, is Fr László Lukács laconic footnote to the account of the November 1583 performance of a Comaedia Philautii contained in the notes amassed by the Rector of the college at Kolozsvár (Claudiopolis, Cluj), Jacob Wujek, "Fortasse ab aliquo magistro collegii claudiopolitani composita», accurate? Or may that play be related, directly or indirectly, to

with a view to establishing how many of da Cruz's plays were performed after the volume was printed, and where.

(31) E.g. Ignatius Loyola to Nadal, Rome, 8 February 1554, Monumenta Ignatiana, s. I, Epistolae et instructiones, ed. Mariano LECINA SI \& Vicente AGUSTİ SI, 12 vols (Madrid: G. López del Horno, 1903-11), VI (MHSI 33), 306, letter 4149; Laínez to Adriano Adriani in Louvain, Rome, 25 November 1556, Lainii Monumenta, ed. Ephrem ASTUDILLO SI, 8 vols (Madrid: G. López del Horno, 1912-17), I (MHSI 44), 167-8, letter 278. There was some discussion, however, of the need to correct student compositions, possibly at headquarters, prior to publication (see, for example, the queries sent from the Castile Province to Rome (? 1569), Madrid, Biblioteca Nacional, MS 2307, fol. 181v).

(32) "Le théâtre scolaire à Caen aux XVII et XVIII siècles", Réunion des Sociétés des Beaux-Arts des Départements (Paris) XVIII (1894), 1052-87 at 1057. See also Abbé Marie-Joseph-AugusteIsidore MASSELIN, "Le collège des jésuites de Caen", Revue Catholique de Normandie (Évreux), VII (1897), 303-11 377-88 463-79; VIII (1898), 171-86 207-14, at VII. 476; also, more recently, Desgraves, Répertoire, 38. 
the piece of the same name written by Father Pedro Pablo de Acevedo and staged in the Seville college in southern Spain in 1565?(33)

We know from the experience provided by using Valentin's Répertoire just how many avenues are opened up by having a vast mass of detailed information brought together in a single place. My suggestion is that we now use this gathering, so generously arranged by Prof. Sebastião Tavares de Pinho and his Coimbra colleagues, to embark upon the creation of a similar database, but this time one that covers the whole of the Society of Jesus.

Clearly, such an undertaking could not be contemplated by a single individual working alone. Nor would it be practicable to collect and collate the information on record-cards in the way we all had to in the pre-computer age. Nor would it be sensible to envisage the final dissemination in print of such a database. We shall need to take advantage of modern technology to establish a free exchange of data and to ensure that we are in a position to update the database at regular intervals in the light of fresh discoveries. Making the latest version of the database available on the Internet free of charge would also have the advantage that we might be able to count on the collaboration of colleagues (from Latin America, India, Eastern Europe, and so on) who have at present few if any additional financial resources for research. A good example of the practicability of Internet publication in this field is the work done over the past few years by Julio Alonso Asenjo and his colleagues at the University of Valencia in Spain.

The first task will be to establish just how much detail we wish to include about a play text, an author, a manuscript, a printed play programme, and

(33) Monumenta Antiquae Hungariae, ed. Ladislaus LUKÁCS SI, II: 1580-1586, MHSI 112 (Rome: Institutum Historicum SI, 1976), 611-12, n 240; STAUD, A magyarországi jezsuita iskolai szinjátékok forrásai, III. 240-1. There is quite possibly a cat's cradle of influences here. See, for example, Vicente PICón GARCíA, "La comedia Philautus de Acevedo: Sus deudas al Terencio cristiano (Acolastus de Gnaphaeus y Samarites de Papeus)", in Congreso internacional sobre humanismo y Renacimiento: Actas (León: Universidad de León, 1998), 599-609. The most recent edition of the Acevedo play is by Antonio CASCÓN DORADO and Vicente PICÓN GARCÍA in Teatro escolar latino del siglo XVI: La obra de Pedro Pablo de Acevedo SI, I: Lucifer furens, Occasio, Philautus, Charopus, ed. PICón GARCía et al., Bibliotheca Latina (Madrid: Ediciones Clásicas, 1997), 295-423. 
an account of a performance. To that end, I shall in the spring of 2005 be circulating those present as well as other scholars in the field who could not be with us in Coimbra, asking them to complete a questionnaire giving their views. Then we shall have to identify on-line cross-referencing systems that will perform the functions classically discharged in printed volumes by multiple indexes. Next, we shall need to design the database. Once those fundamental building blocks are in place, we should be able to proceed to identifying collaborators and sharing out the donkey work in such a way as to make the project compassible. After that, we can move to identifying possible sources of funding, since an injection of funds might allow us to engage graduate students part-time in the project, thus helping them to finance their own studies while maintaining the necessary momentum to complete the initial database by a particular dealine, say in 2010.

A small first step towards this dissemination of reference material on the Internet will be a second edition, updated and revised of my own little bibliography of secondary literature. This will become available on line during the course of 2006.(34)

(34) Jesuit school drama: A checklist of critical literature. The second edition, running to well over 3000 entries, will incorporate material published since 1985 as well as revising all the entries from the first edition of 1976 and its 1986 supplement. I am grateful to the publisher of those two volumes, Grant \& Cutler Ltd of London, now part of the Tamesis imprint owned by Boydell \& Brewer of Woodbridge, Suffolk, for permission to publish the second edition under my own imprint on the Internet. 


\section{Vicente Picón García}

Universidade Autónoma de Madrid

\section{EL TEATRO NEO-LATINO HUMANÍSTICO Y ESCOLAR EN ESPAÑA}

EN EL SIGLO XVI ${ }^{(*)}$

\section{I - De Musato al siglo XX}

Entiendo el término Neo-latín como lo entendió Ijsewijn en su Companion to Neo-latin studies, es decir, como el tercer y último periodo de literatura latina originado en los ideales y principios lingüísticos de los humanistas italianos como Petrarca (1304-1374) y Lorenzo Valla (1407-1457), que abarca por tanto desde el siglo XIV hasta la actualidad, incluido naturalmente el periodo propiamente humanístico(1).

Según él, el principal argumento en contra del uso del término neo-latín es el diferente sentido que se le da en italiano especialmente, donde 'neolatín' generalmente significa Romance, como lo entiende también entre

${ }^{*}$ Este trabajo se enmarca en el conjunto de los realizados con la ayuda del proyecto de investigación BFF2003-03795 financiado por la DGICYT, titulado: «Teatro escolar latino en España (1550-1650) II».

(1) Un término (Neo-latín) que considera mejor que el de humanístico, aunque éste se continúa empleando también hasta el presente, "Therefore, it seems better to speak of 'NeoLatin' rather than 'Humanistic' Latin when the whole period is concerned", es decir, no aplicado solamente a los siglos propiamente humanísticos. Cf. Ijsewijn, J., Companion... Part. I (nota 18) p. 27; y "Neo-Latin: an historical Survey», Humanisme i literatura neollatina, (ed. J. Lluís. Barona) Universitàt de València, 1996, pp. 43-62, donde señala que se utiliza usualmente el nombre de periodo Neolatino para denominar la tercera mayor parte de la historia de la lengua y literatura latina. 
otros autores Claude-Henri Frèches en su conocido estudio sobre el Teatro Neolatino en Portugal ${ }^{(2)}$.

Para Ijsewijn, se puede fijar una fecha precisa para el renacimiento del teatro clásico en el año 1315(3) en que Albertino Musato, el hermano de Dante por primera vez desde el periodo romano intentó componer una tragedia clásica a la que tituló Eccerinis: su personaje principal era Ezzelino, un tirano contemporáneo de Verona, y su modelo Séneca, cuyos dramas pudo encontrar en un famoso manuscrito en la Abadía Pomposa, situada no lejos de Padua.

En cambio, otros estudiosos consideran que el verdadero fundador y difusor de la comedia latina es Francisco Petrarca, quien pocos años después, en 1335, puso mano a su comedia Philologia inspirada en Terencio ${ }^{(4)}$.

A estas dos comedias, siguieron otras en el mismo siglo XIV, como la comedia Paulus, escrita posiblemente en 1390 por Pietro Paolo Vergerio, uno de los más conspicuos humanistas quizá de la primera época (1370-1444)(5) Poliscene y otras muchas como Chrysis, Philodoxus, Philogenia en el siglo XV y a comienzos del XVI(6).

En cambio, en España y Portugal el siglo XV es casi baldío respecto a la actividad dramática, situándose la producción teatral más importante en latín en el siglo XVI y parte del XVII por influencia de Italia y el teatro nórdico de Europa(7).

(2) Frèches, C.-H., Le théâtre néo-latin au Portugal (1550-1745), Paris, 1964. El inicio lo sitúa en Italia en el s. XIV apoyándose en la obra clásica de I. Lanesi, La commedia, en Storia dei generi letterari italiani, Milán (s./d.).

(3) Frèches la fija en la obra citada (p. 4) en torno al 1329.

(4) Para los datos sobre ella y los múltiples problemas que suscita esta obra, cf. Casas Homs, J. $\mathrm{M}^{\mathrm{a}}$, J. de Vallata, "Poliodorus". Comedia humanística desconocida, Madrid, 1953, pp. 37-40.

(5) Idem, pp. 40-43, para su argumento y desarrollo.

(6) Idem, pp. 43-54, para las cuatro últimas obras citadas, y el apéndice I de pp. 249-252 para 16 más.

(7) Véase el resumen de Frèches, op. cit., pp. 43-54, para las cuatro últimas obras citadas, y el apéndice I de pp. 249-252 para 16 más.

Véase el resumen de Frèches, op. cit. (nota 2), en pp. 5-8. 


\section{II - Inexactitud y visión parcial de Frèches sobre el teatro Neo-latino.}

Frèches en el estudio citado trata «El nacimiento del teatro neolatino en la península ibérica» y "El teatro de colegio en España» (sic) en los apartados de los capítulos 1 y 6 de la primera parte de su trabajo dedicada al estudio del teatro desde sus orígenes a 1550.

En ellos ofrece solamente una breve aproximación al tema que no refleja la realidad de lo acaecido, pues en el primer apartado señalado no entiende el término neolatino en el correcto sentido que hemos dado, ya que la información que ofrece en él se refiere sólo al teatro vernáculo, no al latino ${ }^{(8)}$; y, tras aludir a dos cortas representaciones del Nacimiento de Nuestro Señor y de la pasión de Gómez Manrique (1412-1490?), niega además la existencia de un teatro escolar en España (hasta 1538) con estas palabras:

«De un teatro escolar no hay traza alguna, con la excepción de que los estatutos de la Universidad de Salamanca, aprobados el 14 de octubre de 1538, ordenaron representaciones dramáticas para ciertas ocasiones. De otra parte, el teatro erudito religioso no reviste apenas importancia» (Frèches, p. 8).

Nada más lejos de la realidad. Codina Mir, en su trabajo sobre el modus parisinus en las fuentes de la pedagogía de los jesuitas ${ }^{(9)}$ sale al paso de esta opinión negativa de Freches señalando que en la Universidad de Alcalá, desde el año 1508 de su fundación ya se daba una actividad teatral importante, se componían y representaban obras en español ${ }^{(10)}$, y se conoce, si es que no se representó, la Hispaniola (1519) de Juan de Maldonado en latín, y más tarde la Samarites de Papeo(11).

(8) Así menciona representaciones del siglo XV en Gerona en 1360 de escenas del antiguo testamento y en Valencia, para el día del Corpus, del Paraíso terrenal, de San Cristóbal y de la Degollación de los Inocentes.

(9) Codina Mir, G., Aux sources de la pédagogie des jesuites le 'modus parisiensis', Roma, 1968, pp. 45 y 46.

(10) Como la Egloga de unos pastores de Martín de Herrera compuesta con ocasión de la conquista de Orán por Cisneros (1509) y publicada en 1510 o 1512, y otras.

(11) Cf. Picón García, V., "La Comedia Philautus de Acevedo: sus deudas al 'Terencio cristiano' (Acolastus de Gnaphaeus y Samarites de Papeus)", Congreso Internacional de Humanismo y Renacimiento, Universidad de León, 1996, pp. 599-609. 


\section{III - El nacimiento del teatro en España.}

Como hemos apuntado ya, efectivamente, el siglo XV en España es un erial del teatro neo-latino, pero en él se produce el germen de lo que será la Edad de Oro de la literatura neo-latina.

En la Universidad de Salamanca explican los autores latinos españoles formados en Italia como Nebrija, o italianos venidos a España por distintas circunstancias, como Lucio Marineo Sículo (1484) y Pedro Mártir de Anglería (1474).

Además, por influencia de ellos y por el renacimiento italiano se estudian distintas obras de escritores italianos del cuatrocento, como el Filodoxus (1426) del genovés León Bautista Alberti, impresa en 1501 y otras(12); la Historia Baetica de Carlos Verardi (1440-1500), impresa también pocos años antes en Salamanca, en el 1494, y representada en Italia en 1492, año de la toma de Granada, en el palacio del Cardenal Rafael Riario. Su tragicomedia Fernandus Seruatus, representada ante el Pontífice en 1493, se imprimió en Roma y se estudió también en España por esta época(13).

Pero hay otros factores que provocan la influencia italiana, como los siguientes $^{(14)}$ :

(12) Véase la lista del Polidorus de Casas Homs citada en la nota 6.

(13) Para la importancia de las dos obras, cf. Briesemeister, "Das Mittel-» (cf. nota 18), p. 7; pero para la de la primera, véase especialmente Bravo Villarroel, R., La "Historia Baetica" de Carlo Verardi, drama bistórico renacentista en Latín sobre la conquista de Granada, Instituto tecnológico Monterrey, 1971; Briesemeister, D., "Literatura épico-dramática del siglo de Oro sobre la conquista de Granada: ¿un compromiso político?», Congreso sobre Andalucía en el Siglo de Oro, Córdoba, 1987; la excelente edición de Rincón González, M ${ }^{\text {a }}$. Dolores, Historia Baetica de Carlo Verardi. Drama humanístico sobre la bistoria de Granada, Granada, 1992; y su estudio sobre el género de la obra, "El aspecto multiforme del panegírico latino: algunos ejemplos renacentistas", en J. M ${ }^{a}$ Maestre Maestre, J. Pascual Barea y L. Charlo Brea (eds.), Humanismo y pervivencia del mundo clásico. Homenaje al Profesor Antonio Fontán, AlcañizMadrid, 2002, III,2, pp. 723-729.

(14) Para más detalle véase Arróniz, A., La influencia italiana en el nacimiento de la comedia española, Madrid, Gredos, 1969, especialmente los capítulos I. 1: La deuda con Italia, pp. 9-11; 2: España e Italia, pp. 11-12; y 3: Los vehículos de relación, pp. 13-21, que sigo en esta líneas. 
El dominio sobre gran parte de Italia por el imperio (especialmente Sicilia, Nápoles, Milán y Siena) se tradujo en una influencia y dominio decisivo sobre España en distintos campos de las artes y las letras, y en especial de la Comedia.

La llegada a España de españoles residentes durante algún tiempo en Italia (Nápoles, Roma, Milán, Génova, Venecia, Siena), como Juan de Lucena, Alonso de Palencia, Juan de Mena, etc.

Los italianos que se afincan y residen en España, como los referidos Lucio Marineo Sículo, Pedro Mártir de Anglería, Alejandro Giraldino y otros.

Los impresores, libreros y comerciantes italianos que vinieron a vivir a la Península y crearon importantes focos de impresión, sobre todo em Barcelona y Valencia (pp. 13).

Esta invasión del humanismo renacentista en España tuvo como resultado, según Arróniz tres manifestaciones importantes en cuanto al teatro se refiere: 1) la comedia humanística en latín; 2) el teatro de colegio, y 3) las versiones y refundiciones de textos dramáticos de la antigüedad griega y latina.

Pero el factor más importante que contribuyó al desarrollo del teatro neolatino se debió a la influencia de la formación humanística de las universidades - y su imitación por los jesuitas, como veremos luego(15) —, para la cual desde principio del siglo XVI algunas de ellas hicieron obligatoria la representación de comedias latinas en clase de retórica.

Así, los estatutos de Alcalá lo establecen desde $1508^{(16)}$; y los de Salamanca en 1538 insisten en la necesidad de aprender a hablar y escribir latín y de hacer representaciones de comedias latinas en fechas determinadas:

(15) Decisiva será también la práctica del teatro que imponen los jesuitas en los colegios desde su fundación (Alcalá, 1543-47; Valencia, 1544; Barcelona, 1545, etc.) en las solemnidades de apertura de curso, fin de curso y principales festividades. Cf. infra el apartado $L a$ producción teatral (pp. 28-29).

(16) Véase García Soriano, El teatro, (nota 18), p. 13. 
"Tendráse especial y principal cuydado en los tales colegios de que hablen siempre latín los estudiantes en tanto grado que en ninguna manera se permita a ninguno por nuevo o ydiota que sea hablar sino en latín o griego como mejor pudiere; y en cada general y clase habrá propios acusadores, que a los que hablaren castellano los acusen y punten para que cada noche vayan a dar cuenta al regente del colegio para que él los castigue a los que ansí huvieren hablado [...] Con gran vigilancia ternán cargo los regentes lo que tocare a hablar y escribir latín sus discípulos. y imponerles cómo han de declamar y escribir, y que unos a otros entre sí mismos se carteen y envíen a menudo cartas latinas, y hacer que los de su colegio inciten a los de otro con cartas y exercicios latinos semejantes. [...] La Pascua de Navidad carnestoliendas Pascua de Resurreción y Pentecostés de cada un año saldrán estudiantes de cada uno de los tales colegios a orar y hacer declamaciones públicamente. Item de cada colegio cada año se representará una comedia de Plauto o Terencio o tragicomedia; la primera el primero Domingo de las octavas de Corpus-Christi y las otras en los Domingos siguientes; y al regente que mejor hiciere y representare las dichas comedias o tragedias se le den seis ducados del arca del estudio; y sean jueces para dar este premio el retor y el maestrescuela». (17)

\section{IV - El repertorio de piezas escolares y humanísticas Neo-latinas.}

Vamos a ver el repertorio de las obras neolatinas aparecidas en España desde las más antiguas hasta finales del s. XVI, de acuerdo con un criterio geográfico, comenzando por el antiguo reino de Aragón para acabar con Andalucía, exponiendo sólo, como es lógico, la información básica sobre ellas $^{(18)}$.

(17) Esperabé Arteaga, E., Historia de la Universidad de Salamanca, Salamanca, 1914, t. I, p. 203 .

(18) Aparte de los estudios específicos de los autores y obras concretas que se indicarán en cada caso, deben verse los siguientes de carácter más general y complexivo: García Soriano, J., El teatro universitario y humanístico en España. Estudios sobre el origen de nuestro arte dramatico; con documentos, textos inéditos y un catálogo de antiguas comedias escolares, Toledo 1945; Bradner, L., "The Rise of a Secular Drama in the Renaissance", Studies in the Renaissance, 3 (1956), pp. 7-22; Briesemeister, D., "Das Mittel- und Neulateinische Theater in Spanien", en K. Pörtl (ed.), Das Spanische Theater: Von den Anfängen bis zum Ausgang des 19. Jahrbunderts, Darmstadt, Wissenschaftliche Buchgesellschaft, 1985, pp. 1-29; Ijsewijn, J., 


\section{El carmen bucolicum de Antonio Geraldini (19).}

La primera es una colección de 12 églogas que Antonio Giraldini compuso durante su estancia en la corte literaria del arzobispo de Zaragoza, D. Alfonso de Aragón, el hijo natural del rey Católico, entre 1484 y 1485. En ellas amplía el tema de la navidad y el nacimiento de Jesús con otros relatos neotestamentarios de su vida: la primera versa sobre la natividad del Salvador (De Saluatoris nativitate) interviniendo en ella como interlocutores los pastores Mopsus y Lycidas, de resonancia virgiliana; la segunda, sobre la adoración de los Reyes Magos; la tercera, sobre el niño perdido en el templo; la cuarta sobre el bautismo y la tentación del Salvador; la quinta sobre los milagros de Cristo, la sexta sobre la institución del Sacramento de la Eucaristía; la séptima, sobre la Pasión del Salvador; la octava, sobre su resurrección, cerrando la serie las tres últimas con contenidos muy alejados del tema navideño, como el credo (Symbolum Christianae Religionis), el Juicio final y la vida bienaventurada.

Su éxito fue inmediato, como se deduce de las sucesivas ediciones que se hicieron de las églogas, de las que cabe destacar la primera de 1485 en

Companion to Neo-Latin Studies. Part I: History and diffusion of Neo-latin Literature, Lovaina, Leuven Univ. Press. 1990: para el neo-latino español, pp. 104-117; Ijsewijn, J., Companion to Neo-Latin Studies. Part II Literary, Linguistic, Philological and editorial Questions, Lovaina, Leuven Univ. Press, 1998: para el drama neo-latino en general, pp. 139-146; Alonso Asenjo, J., "Panorama del teatro estudiantil del renacimiento español", en Spettacoli Studenteschi nell" Europa Umanistica, Roma, Edizioni Torre d'Orfeo, 1998, pp.151-191, especialmente pp. 163175; Hofmann, H., "Point de vue sur les méthodes et les perspectives des études néo-latines", Les Cabiers de l'Humanisme», I (2000), pp. 11-33, esp., pp. 27-28; y Menéndez Peláez, J., "El teatro escolar latino-castellano en el siglo XVI», en J. Huerta Calvo, Historia del teatro español, Madrid, Gredos, 2003, pp. 581-608, especialmente pp. 584-591.

(19) Véase Alcina Robira, J. F., "La tragedia 'Galathea' de Hércules Florus y los inicios del teatro neolatino en la Corona de Aragón”, en Calamus renascens, Alcañiz-Cadiz, 2000, pp. 13-30; Mustard, W. P., The Eclogues of Antonio Geraldini, Baltimore, 1924; Lucero, Ll., "Sobre un poema d'Antoni Geraldini dedicat a Bernat Margarit", Annals de l'Institut d'Studis Gironins, 31 (1990-1991), pp. 89-98; y Alonso Asenjo, J., "Optimates laetificare. La Egloga in Nativitate Christi de Joan Baptista Anyés o Agnesio", Criticón 66-67 (1996), pp. 314-316 y notas 35 a 39 en los que ofrece, entre otros aspectos, los rasgos básicos de la vida del autor, la función didáctica del carmen por los textos que ofrecía en él a los escolares para el aprendizaje del latín, sus ediciones, fuentes, títulos de cada égloga y su influencia. Respecto a su carácter dramático, Alonso Asenjo afirma categóricamente en la nota 35 que, "por ningún lado aparece la posibilidad de una representación escénica del carmen». 
Roma y la de $1505^{(20)}$ en Salamanca; y su infuencia en España fue notable, haciéndose presente en la obra de Agnes que veremos luego, al que «inspiró no sólo el cultivo de la égloga y del hexámetro, sino sobre todo - aunque seguramente con la colaboración de otros autores —, la idea de reunir las verdades cristianas en un extenso poema en el que cupiera su Égloga»(21). La obra constituye un claro ejemplo de la influencia de los italianos del XV en los del XVI.

\section{Hércules Floro: la tragedia Galathea y la comedia Zaphyra(22).}

El primer dramaturgo importante en Cataluña es Hércules Floro, un chipriota que, fugitivo de las guerras de su país se exilia y, al amparo de las estrechas relaciones comerciales y políticas de Chipre con la Corona de Aragón, llegó a España hacia 1499, dando clases en Barcelona y Perpiñán y en 1503 en Zaragoza, en el Estudio de las Artes ${ }^{(23)}$

(20) Dedicadas respectivamente al Arzobispo de Zaragoza, en torno al cual se formó el principal círculo literario de la ciudad, y al arzobispo de Santiago, D. Alfonso de Fonseca.

(21) Alonso Asenjo, "Optimates laetificare", (cf. nota 19), p. 316 y nota 38.

(22) Alonso Asenjo, "Panorama», pp. 170-171; Briesemeister, "Das Mittell», p. 6, donde señala la importancia que tiene la edición de estas dos obras y la Ephigenia perdida en relación con la Celestina que se asemeja a ellas; Alonso Asenjo, J., "El teatro del humanista Hércules Floro", en F. Carbó et alii, eds., Quaderns di Filologia (Studis Literaris, 1), Homenatge a Amelia GarcíaValdecasas, València, Fac. de Filología, Univ. De València, 1991, vol. 1, pp. 31-50; donde ofrece con detalle los rasgos de su vida azarosa, su dedicación a la docencia del latín, recurriendo incluso a la mezcla de géneros de acuerdo con la pedagogía de su tiempo, la estructura del texto y de sus elementos complementarios, la exposición detallada de la acción en los distintos actos y escenas de ambas y el análisis conjunto y constractivo de los principales rasgos de su técnica teatral (número de personajes, características del diálogo, movimiento y gestos, lugar conocido de representación (sala, casas), espacio dramático (urbano), tiempo, verbalidad, movimiento en los actos, vestido, attrezzo y efectos sonoros; Alcina Rovira, J. F., "La tragedia»; y "La tragèdia Galathea d'Hercules Florus i els inicis del teatre neollatí a Barcelona i a València (1485-1527)», en Albert Rossich (Coord.) El teatre català dels orígens al segle XVIII, Universitat de Girona, Edition Reichenberger, Kassel, 2001, pp. 145-259, donde hace un breve resumen de la Zaphyra y la Galathea y estudia luego distintos pasajes de ésta destacando en ellos las referencias y reminiscencias clásicas, como el epigrama de Ausonio para las figuras de Occasio y Paenitentia (19-21), la escena del Asno de Oro (2,10) de Apuleyo y los comentarios de Terencio y Horacio para las metas del amor, y otros ecos de Horacio y Ovidio.

(23) Para más detalles sobre su nombre, su vida, las relaciones de Chipre con el reino de Aragón y las razones que le motivaron a venir a Cataluña, cf. Mesa Sanz, J. F., "Hércules Florus grammaticus: apuntes para una biografía», en E. Sánchez Salor-L.Merino-S. López Moreda (eds.), La recepción de las artes clásicas en el siglo XVI, Universidad de Extremadura, 1996, pp. 147-154. 
Su estancia en Barcelona coincide con la época em que se están poniendo de moda las representaciones de comedias italianas, como lo prueba la publicación del Philodoxus en Salamanca en 1503, y de una Ephigenia (perdida) en Barcelona (cf. nota 22).

Escribió un pequeño compendio de gramática latina en forma de diálogo para los nuevos discípulos (ad novos tyrones) que acudían a su Academia y dos obras de teatro, la tragedia Galathea y la comedia Zaphiria(24).

El texto de las dos obras está escrito en prosa latina tarazeada de ecos e imitaciones de los clásicos. Los elementos contextuales que complementan la acción son similares en ambos casos: le preceden el nombre del autor y el lugar de la representación, la indicación de los modelos, el argumento y el prólogo, y le siguen tras el valete final la didascalia, dos composiciones en 3 y 2 discos respectivamente y el colofón.

\section{- La tragedia Galathea}

En el título que precede al argumento se indica que fue representada en Perpiñán (in oppido Celtiberiae Perpiniani), donde la escribió Floro a instancias de Francinus Maler, quien le pidió que compusiera algo semejante a los ludi romani para la educación de los jóvenes de la ciudad ${ }^{(25)}$, con la vista puesta en el latín de Plauto y Pacuvio.

El argumento es como sigue:

Virginem conciuem nomine Galatheam, aureo saucius spiculo Nictilius deperit. Qua plumbea percussa sagitta dura permanente, Rhamnusiae astutia Occasionis Venus appellata Mercurio, Nictilius fruitur. Inconstantia tandem rerum harum futilium humanarum, ultima Necessitate amica priuatus, neque Rationis sententia usus, Desperationemque amplexus se gladio perforat (fol. A3r).

(24) Domínguez, G.-Sotelo, A.I., "Breves notas sobre la 'Zaphira' de Hércules Floro", Archivo Hispalense, $\mathrm{n}^{\circ}$ 171-173 (1973), pp. 63-70, con otras referencias bibliográficas.

(25) Galatheam ergo socco parua lucubratione praelusimus, et celtiberia pulpita romana uidere spectacula, dextris tibiis modulantibus. 
"Nictilio, herido por una flecha de oro, arde de amor por una doncella de su misma ciudad, Galatea. Pero ella herida por una flecha de plomo se muestra fría; merced a la astucia de la Ocasión Ramnusia, Venus es invocada por Mercurio y Nictilio obtiene su goce. Finalmente, por la inestabilidad de esta lábil vida de los hombres, la Necesidad última le priva de su amiga y sin acogerse al consejo de Razón, abraza a Desesperación y se atraviesa con una espada"(26).

El texto de la acción dramática se estructura en 4 actos con 3, 6, 3 y 4 escenas respectivamente, encabezada cada una de ellas por la indicación de los actores, de acuerdo con su orden de intervención.

Los interlocutores son personajes reales, como los protagonistas Nictilio, Galactea, sus criados y otros; los dioses Mercurio, Cupido, Júpiter, Apolo y Venus; y personajes alegóricos, como Metanea, Ocasión, Fortuna y Necesidad.

La finalidad ejemplarizante y moralizante de la obra, como cuadra a un humanista, la expone claramente Floro cuando señala por boca de uno de los personajes que, ante lo que le ha ocurrido a Nictilio, lo mejor es no abandonar las ciudades, pero sí entregarse a la soledad (Verum urbem ne deseras sed solitudinem insectemur) y dedicarse al estudio y las letras (studis litterisque uacemus), como hacen sus comparsas Lámpsaco, Nicodemo y $\operatorname{Orfeo}^{(27)}$.

Y la finalidad docente que le cuadraba como gramático y preceptor, manifestada ya expresamente por Francisco Maler cuando le pidió que la compusiera, como hemos visto se deduce también con claridad(28).

(26) Un argumento muy sencillo, como se ve: 1) A (Nictilo) ama a B (Galatea), pero B no a A; 2) Ocasión hace que A goce de B; Necesidad priva a A de B; A se suicida.

(27) Alonso Asenjo lo dice así («El teatro», p. 41): "La sensualidad, los amores y la vida disoluta conllevan graves peligros, que incluso pueden ofrecer ocasiones para la muerte. En cualquier caso distraen del estudio. Es necesario el seccessus para luego poder tomar las decisiones justas en la vida, la Ocasión debe llevar a Metanoea de sí, no a Venus...». Alcina por su parte ve un rasgo de humor de Orfeo y Lámpsaco en esta búsqueda de un tipo de vida solitaria petrarquesca, no huyendo al campo ni a los bosques, sino a la misma ciudad.

(28) Ibidem, p. 41: "De todos modos» dice Alonso Asenjo, «la representación ha servido para aprender de memoria un texto latino, para declamarlo y para practicar el gesto y los ademanes o movimientos, para lograr el dominio del cuerpo tan necesarios a los jóvenes». 


\section{- La Comedia Zaphira}

El argumento se puede resumir así:

Un par de galanes, Anaxarte y Zapiro, compiten por Zaphyra, que se lamenta por tener que aguantar a su viejo esposo. Muerto Zopiro en duelo con Anaxarte, éste ya puede casarse con Zaphyra, tras haber sido envenenado el marido de Zaphyra por común acuerdo de aquéllos, y los criados de ambos (Anaxarte y Zaphyra), Zeta y Zaclas también ${ }^{(29)}$

Es el tema de la mujer joven que, casada con un marido mayor, recurre al asesinato para casarse con su joven amante Anaxarte. Al final, los esponsales se firmarán, tras el envenenamiento del decrépito viejo, al que estaba destinada.

En ella hay preocupación por la formación moral, pero menos clara que en la Galatea, pues presenta conductas realmente reprochables, como el asesinato, y otras que actualmente parecerían demasiado licenciosas.

Asenjo ha señalado que la principal diferencia que existe entre ambas obras reside en su final, trágico en la primera y feliz en la segunda, más que en la condición de los personajes que intervienen en ellas (p. 37), y que Floro ofrece una evolución de la obra, consiguiendo una mayor perfección en la comedia que en la tragedia al dotarla de una estructura cómica más lograda y uaproximarla a lo que será la comedia renacentista, modelada sobre la comedia erudita italiana» (49).

\section{Las «Églogas» de Partenio de Joan Parteni Tovar ${ }^{(30)}$.}

Partenio nació en Sevilla y de niño fue a Italia, donde estudió en Siena y Bolonia. A finales del siglo daba clases en Roma y en 1499, año de la

(29) 1) A y B aman a C, que no ama a D, su viejo marido. 2) A y B compiten en duelo por C, tras ser envenenado D. 3) Muerto en duelo B y envenenado D, A puede casarse con C, y 4) los criados de ambos también.

(30) Véase la descripción que hace Luis Galiana (erudito y folclorista del s. XVIII) en una carta de 1767 dirigida a J. Teixidor sobre el impreso misceláneo de 1503 que recoge las obras y la vida de Tovar (pp. 132-143), y en concreto las dos églogas con el número 20 y 25 (pp.136138), en Salvadó Recasens, J., "Joan Parteni Tovar, mestre de Vives a la Universitat de València», Studia Philologica Valentina 1 (1996), pp. 125-143, especialmente pp. 136-138 para la vida y la obra; y la información que reune Alcina en "La tragedia», pp. 14-15, sobre su contenido, las circunstancias de su composición, dedicación, etc., que sintetizo a continuación. 
fundación de la Universidad de Valencia, fue elegido catedrático. Siendo estudiante en Siena escribió dos églogas a petición de sus compañeros, para representar una acción teatral (fabulam agendam) disfrazados a la italiana (de italo more personiatos) ${ }^{(31)}$ : Los títulos respectivos eran Amoris et pudicitiae Pimenimachon y Contemplatiuae uitae Dimachon.

La primera, en 19 páginas, como indica el título (Pimenimachon de poimen + mache), es "un debate entre pastores sobre el amor y la pudicitia" y la segunda, en 21 páginas, un debate entre dos interlocutores (dimachon) «sobre la vieja disputa, reformulada en el Renacimiento, entre la vida activa y la vida contemplativa».

Las dos llevaban su correspondiente argumento en verso, como si se tratara de comedias, y se las dedicaba "a Gabriel Sanchís, encargado de finanzas de Fernado el Católico, y Alfonso Sanchís, tesorero de la ciudad de Valenciam, iniciando con ellas una tradición teatral que influiría en lo sucesivo en la Corte de Valencia.

\section{La obra dramática de Juan Bautista Anyés.}

\section{- La Egloga in nativitate Christi. ${ }^{(32)}$}

«La Egloga in Nativitate Christi es una composición dramática de 213 hexámetros latinos.

Consta de dos secciones formadas por el argumento y su explicación en un monólogo pronunciado por la diosa Palas Atenea (cuius argumentum Pallas ad excellent[issimum] Principem orditum) y el texto de la representa-

(31) Véanse sus propias palabras en la carta de Galiana, en Salvadó Recasens, «Joan Parteni.. p. 138.

(32) Véase el excelente artículo citado de Alonso Asenjo, "Optimates laetificare» (nota 19), pp. 307-368, en el que hace un estudio exhaustivo de la vida y la obra dramática de Anyés contrastándola con su contemporáneo Diego Sánchez de Badajoz, con especial atención a la égloga citada, su contenido y estructura, sus relaciones con las obras de autores como Patrizi y Geraldini, sus características dramáticas, el fondo y el carácter humanístico de sus obras que sintetiza en el lema optimates laetificare que antecede al título frente al rudes erudire que atribuye a Sánchez de Badajoz, y otros aspectos. Lo cierra con la edición y traducción de la pieza (pp. 352-365) y una amplia bibliografía. 
ción compuesto en hexámetros y de forma dialogada o, en parte, cantada a $\operatorname{coro}^{(33)}$.

El diálogo se representó ante el duque de Calabria -probablemente en la noche de Navidad de 1527- interviniendo en él, como se indica en el argumento, cuatro pastores bajo cuatro formas alegóricas y con un nombre alusivo a ellas: Erácrito (Eracrittus), el Amor divino, Teopisto (Theopistus), la Fe, y Filelpes (Philelpes), la Esperanza, a quienes enseña y dirige un pastor más viejo, Nomeno (Nomennus), que representa la Ley del Antiguo Testamento.

La acción es muy sencilla: tras despertarse unos a otros, los pastores se cuentan y comentan las cosas maravillosas que están ocurriendo, que indican que ha llegado el pastor prometido (Cristo), pero desconocen el camino para ir a agasajarle. Nomeno, el último que se ha unido a ellos, dice que él se lo indicará. De camino hacia el lugar, entre cantos y alborozos llegan a una cabaña (a la que llama "Palacio de Dios Tonante»). Les presenta a los personajes que la habitan y, sorprendidos por el espectáculo, prorrumpen de nuevo en cantos loando al niño y a la madre y agasajándolos con flores y frutos del campo. Y al levantar el sol, se vuelven a sus cabañas.

La pieza es una típica composición dialogada entre pastores, en un auténtico centón virgiliano, con multitud de elementos dramáticos. Se distribuye en dos cuadros, con dos escenas cada uno de ellos (cf. Alonso Asenjo, 333-334): el primero, que recoge el desertar de los pastores y la llegada de Nomeno, se cierra en el verso 113; el segundo, anunciado con una didascalia en prosa, recoge la explicación de Nomeno y la adoración de los pastores ${ }^{(34)}$, cerrándose con el Valete final de Erácrito, tras la invita-

(33) El argumento es como sigue: Egloga personanda Valentiae / coram Excellentissimo Inclytissimoque Principe domino / Ferdinando Calabrie ubi pastores tres Eracrittus, / idest amor supernus, Theopistus, idest dei fides, et Phy / lelpes, idest spem custodiens, edocti deductique a sene / pastore Nommennus, idest a veteri lege, pastorum prin-/ cipem christum carne indutum pruni (proni) adorant et my-/ sticis donant muneribus.

(34) Nomennus Theopistum, Phylelpem atque Eracrittum, idest lex vetus, theologicas virtutes christum deum docet et hominem ad illumque adorandum manuducit: "Nomeno, es decir, la 
ción de Filelpes a volver a sus respectivas cabañas (v. 213 sunt repedanda igitur magalia nostra).

- El 'libellus' Pro Saracenis Neophytis y el Colloquium Romani Paschini, et Valentini Gonari.

Alonso Asenjo, antes de la Égloga, estudia en las páginas 316-318 y 318323, del artículo citado estas dos obras de Anyés a las que se les ha atribuido carácter dramático; pero, respecto a la primera, afirma taxativamente que "no se trata de una obra dramática», lo que confirma entre otras razones, porque en el título completo de la obra se habla de una epeisódia "venida o recibimiento", el mismo autor la compara con una "Apología» y la califica además como un «breue libellus».

El Colloquium, dedicado al duque de Calabria, en el que se celebran las muchas excelencias de Valencia por los interlocutores Pasquino de Roma y el En Gonari de Valencia (una estatua bien conocida de la Lonja de azeyte), consta de 78 dísticos elegíacos. Alonso piensa que es representable salvo los 29 versos de la dedicatoria y la presentación; sin embargo, considera que no tiene un carácter dramático totalmente definido, pues se mezcla en él "el panegírico y la sátira, las veras y las burlas, lo narrativo y lo dramático, bien centrado en las producciones de la corriente satírica valenciana de los siglos XV y XVI» (Idem, p. 320).

\section{La Oratio litteralis de Sorio(35).}

La Oratio litteralis de Sorio es un sermón renacentista en latín, en prosa y verso, predicado por el fraile dominico valenciano Baltasar Sorió en la noche de navidad en la iglesia del convento de San Mateo, y recitado,

Ley Vieja, enseña a Cristo, Dios y hombre, a las virtudes teologales, Teopisto, Filelpes y Eracrito, y los lleva ante él para adorarle».

(35) El titulo completo es Oratio litteralis fratris B. Sorio in Christi natiuitate sanctissima in conuentu sancti Matthei per quosdam discipulis recitata, s. 1., s.i., c.. 1513. Véase Rubió i Balaguer, J., Humanisme i Reinaixement, Barcelona, Publicacions de l'Abadia de Montserrat, 1990, pp. 226-229, esp. 228-229; Alcina, "La tragedia", p. 15; Alonso Asenjo, "Optimates laetificare,, pp. 335-339. Hay un ejemplar en la Biblioteca Universitaria de Barcelona. 
como añade al final del título, por algunos discípulos suyos (per quosdam sus discipulos recitata).

Rubió lo califica como «representació religiosa» (p. 22) y Asenjo considera que, aunque estructuralmente es un sermón, "contiene una representación dramática religiosa. Comienza y acaba el acto", dice, "como un sermón predicado desde el púlpito. El predicador no sólo inicia y cierra el sermón, sino que, como un mistagogo, va presentando en su desfile a los personajes, con breves acotaciones». En realidad, añade, el espectáculo consiste en «una síntesis, conglomerado o, mejor, sucesión de profetas (Ordo prophetarum): un desfile de personajes del Antiguo y Nuevo testamento y un Santo Padre (en una especie de síntesis de la Escritura y Tradición), que se culmina con el canto de las Sibilas» (p. 336).

Constituye en buena medida, según él, una pieza de «teatro humanístico escolar», en la que los estudiantes jóvenes que la representan, no lo hacen "para aprender Latinidad, ni para ejercitarse en la Retórica, pues son ya por lo menos estudiantes de Arte y Filosofía; pero sí para aprender el arte de predicar» (subr. mío) (p. 338).

\section{El Perlepidum colloquium de Juan Ángel González ${ }^{(36)}$.}

El Perlepidum colloquium in agendam Publii Terentii latinissimam Eunuchum publice recitatum de Juan Angel González es un diálogo escolar escenificado como los que se hacían, a modo de praelectiones, precediendo a las representaciones escolares de Plauto y Terencio - en este caso el Eunuco de Terencio - , para loar al destinatario de la función y captar a los alumnos para el estudio del latín.

Se representó en la Corte del Duque de Calabria, Fernando de Aragón y en el Estudio General de Valencia (in Valentino Gymnasio) por segunda vez antes de su edición en 1527.

(36) El Perlepidum colloquium in agendam Publii Terentii latinissimam Eunuchum publice recitatum editado en Valencia en 1527 se conserva en la Biblioteca Nacional de Madrid, R-19833/3, cf. Briesemeister, "Das mittel-», p. 10; Alcina, "La tragedia», p. 16; Alonso Asenjo, "Optimates laetificare», p. 319, n. 48 y 340-345. 
Se desarrolla entre dos estudiantes de poesía valencianos, Ascanio que ha ido a estudiar a Roma y Camilo que lo ha hecho en Valencia, abordando dos temas: «una interpretación oficial de la política imperial con su correspondiente justificación del saco de Roma y una loa de la enseñanza del latín en la Universidad de Valencia, cuya excelencia se demostrará con la escenificación que sigue del Eunuco» (37).

Alonso Asenjo alude a él en el estudio de la Égloga de Anyés, en atención a las coincidencias con la dramaturgia de éste, señalando su interés por varios aspectos, además de la autopresentación de los personajes responsables del montaje: por el testimonio que supone de las representaciones latinas en el ámbito cortesano de Valencia, por la loa-panegírico del duque de Calabria que incluye, como ocurre en la Égloga de Anyés, por las referencias que ofrece sobre "la escenografía y decorados preparados para esa representación; y, sobre todo, porque aporta datos muy concretos sobre la disposición de la sala y sobre el público, que también se dieron en la representación de la Égloga de Anyés» (38).

\section{La tragedia Gastrimargus de Romanyá(39).}

La Nova tragicomedia Gastrimargus appellata, del sacerdote mallorquín Jaume Romanyà, dramatiza el tema del rico Epulón y el pobre Lázaro narrado en la parábola de Lázaro del evangelio. Aunque fue compuesta con una clara intención moralizante, el autor la salpica de escenas crudas y picantes.

(37) Véase Alcina, "La tragedia”, p. 16 y, con más detalle, en Alcina, J., Juan Ángel González y la 'Sylva de laudibus poeseos' (1525), Universidad Autónoma de Barcelona, 1978, pp. 9-10, y especialmente 16-17.

(38) Para más detalles, véase Alonso Asenjo, "Optimates laetificare», pp. 341-342.

(39) Cf. Menéndez Pelayo, M., Bibliografía Hispana-Latina Clasica, Madrid, C.S.I.C., 1951, tomo VII, 416-419; María Bover, J., Biblioteca de escritores baleares, Palma, 1968, II, 291-296, donde ofrece un prefacio alusivo a la representación de 1962; Briesemeister, "Das Mittel-», 18 y nota 51; Rubió i Balaguer, Humanisme, p. 227; Romeu i Figueras J., Teatre català antic, Curiel, Barcelona, 1995, pp. 129-130. Hay una copia manuscrita en la Biblioteca de Barcelona, Ms. 1477. 
Tras haber sido representada en distintos recintos privados, el 2 de mayo de 1562 se representó en Palma de Mallorca, en la plaza pública (in foro publico), ante una numerosa multitud de 8.000 espectadores, con la asistencia de las principales personalidades de la ciudad(40).

En el Prólogo, en senarios yámbicos, el autor llama primero a la obra comedia y luego rectifica indicando que se puede llamar tragicomedia, con la alusión al género de las fuentes en que se inspira, aparte de Plauto:

\section{gaudium}

Moerore permiscet, ut eam tragicomoediam

Dicere liceat, quo genere poematis constat

Ecolastus Josephina et Celestina apud

Hispanos celebratissima, et gratissima.

\section{"la comedia mezcla}

el gozo con la tristeza, de manera que se pueda llamar

tragicomedia, el genero de poema en que está escrito

el Ecolastus (sic), la Josefina y la Celestina,

encomiadísima y estimadísima entre los españoles».

Menéndez Pelayo no entendió a qué se refería Romanyá con el Ecolastus y se pregunta "¿Qué comedia sería esta Ecolastus, que se cita aquí juntamente con la Celestina y la Josefina?» (p. 418, nota 1).

Evidentemente, las tres obras aludidas son: el Acolastus, la comedia del hijo pródigo de Gnafeo de 1529 (el llamado Terencio cristiano); la Celestina o tragicomedia de Francisco de Rojas; y la Tragedia llamada Josefina de José de Carvajal, «impresa varias veces después del 1535, y que estaba considerada como el drama religioso más importante en lengua popular en España durante el siglo XVI» (41).

(40) Véase la descripción de María Bover de la representación realizada por un discípulo del maestro Romanyá que hizo el papel del parásito Pamphagus, transcrita por Menéndez Pelayo en la obra citada (nota 40), p. 417.

(41) Briesemeister, «Das Mittel-», p. 18 y nota 52. 


\section{Argumento:}

Dum Gastrimargus Genio Venerique indulget, amore capitur Pseudo-Partheni; quae se Neophilo tradit, amoreque tenetur mutuo. Quam ob causam Gastrimargus data repetens munera, litem agitat cum Neophilo; inde aegrotat, moritur. Moritur item mendicus Lazarus: sed ille suorum scelerum pretium fert in Tartaro. At hic mercedem habet laborum in paradiso.

«Mientras Gastrimargus complace al Genio y Venus es prendido por el amor de Pseudo-Parthenos, que se entrega a Neófilo y se poseen con un amor mutuo. Por esta causa Gastrimargus multiplicando los regalos dados, se enfrenta con Neophilus, y después enferma y muere. También muere el mendigo Lázaro: pero aquél paga el precio de sus crímenes en el Tártaro, mientras éste obtiene la recompensa a sus fatigas en el paraíso».

Intervienen 23 actores junto a los dos protagonistas Gastrimargus y Lazarus: desde los más típicos de resonancia plautina, como el comilón Pamphagus, el parásito Poliphagus, el cocinero Saperda, la alcahueta Vulpecula y el soldado Neobtonemus, a otros de la época del dramaturgo como dos médicos, un confesor, dos rabinos, o los dos diablos Starotus y Nembroto, etc. ${ }^{(42)}$.

Menéndez Pelayo cierra la información que da sobre ella (p. 419) con el duro juicio de José $\mathrm{M}^{\mathrm{a}}$ Quadrado en su estudio sobre los poetas mallorquines (La Palma 1841): «miserable parodia de las de Terencio (acaso más de las de Plauto), con sus criados locuaces, sus desvergonzadas rameras, y sus máximas morales, pero sin numen, sin agudeza y casi sin versificación».

El Prof. Briesemeister señala cómo en la Universidad de Barcelona a lo largo de varios decenios de actividad en el ámbito del drama escolar surgen distintas obras que cuentan hasta el momento con escasos testimonios impresos: 1) la tragedia Delphinus Francisco Satorres; 2) una pieza en versos latinos de Pedro Antonio Pi, profesor de la Universidad de Barcelona,

(42) Gastrimargus. Catulus, servus. Pamphagus. Poliphagus, parasitus. Saperda, cocus. Pseudo-Partenos, meretrix. Vulpecula, lena. Lazarus, mendicus. Neophilus, adulescens. Sophronius, servus. Neobtonemus, miles. Austerus, medicus. Crito, mendicus. Mitio, medicus. Pharisseus confessor. Moria, ancilla. Moises, rabbi-Aaron, rabbi-Abel, frater Gastrimargi. Starotus, diabolus. Nembrotus, diabolus. Abraham, profeta. 
sobre Don Juan y la batalla de Lepanto; 3) una Sylva Comedia de vita et moribus de Jaime Cassiá; 4) la comedia Claudius de Juan Cassador; y 5) un coloquio escolar titulado Terra de Pedro Sunyer ${ }^{(43)}$. Veámoslas con un poco más detalle.

\section{La tragedia Delphinus o Delphinia de Balaguer Francisco Satorres.}

La obra, escrita por el sacerdote Francisco Satorres e impresa en Barcelona el año 1543, trata sobre un hecho de gran trascendencia histórica, como fue la derrota de las tropas del Delfín de Francia en Perpiñán el año 1542 por el ejército que mandaba el Duque de Alba, ante cuyas tropas se representó en dicha ciudad ese año el día de las Carnestolendas.

Está escrita en versos latinos en 25 escenas, con una mezcla de elementos sagrados y profanos, de historia y mitología, de acción y estatismo, de exaltación heróica y elegía alegórica, que, a pesar de cierto confusionismo en su composición, la confieren una evidente pretensión literaria, y fue representada en la ciudad de Perpiñán en las Carnestolendas de 1543. ${ }^{(44)}$

\section{La Sylva de uita et moribus de Cassiá.}

La Sylva de uita et moribus, de un capellán de Fortia, Pere Jaume Cassia, maestro de latín, es una obra de colegio publicada en Barcelona en 1576. Escrita en latín, desarrolla un ambiente rural y costumbrista. Consta de cinco actos escritos en latín, precedido cada uno de ellos de un argumento alusivo a la acción y un soneto en catalán. El autor se declara seguidor de Cicerón y Terencio, entre los autores antiguos, y de Mantuano, Verino y Juan Vives, entre los modernos, y con la obra pretendía representar distintas formas de la vida(45).

(43) Briesemeister, "Das Mittel-», p. 16, notas 43 y 44.

(44) Cf. Rubió i Balaguer, Humanisme, pp. 227-228; Romeu i Figueras, p. 129, y nota 52. Hay un ejemplar en la Biblioteca de Cataluña.

(45) Cf. Rubió i Balaguer, Humanisme, p. 228 y Romeu i Figueres, Teatre, p. 130 y nota 58. El título que da difiere del de Menéndez Pelayo de la nota siguiente. Hay también un ejemplar en la Biblioteca de Cataluña. 


\section{La comedia Claudius de Joan Cassador y el diálogo Terra de Pere Sunyer.}

Los autores son otros dos profesores del Estudio general de Barcelona que se interesaron por la actividad dramática. Juan Cassador compuso una comedia titulada Claudius en 1573, a la que dotó de notas explicativas (o escolios) Pere Sunyer(46).

A su vez, Pere Sunyer escribió un diálogo titulado Terra, dialogus in gratiam puerorum editus, publicado en 1574 por Pere Malo(47).

De la segunda citada sobre D. Juan de Austria y la batalla de Lepanto por Briesemeister (p. 16) y Romeu i Figueres (p. 130, nota 57), no tenemos más que la referencia que da F. Torres Amat en sus Memorias para ayudar a formar un diccionario crítico de los escritores catalanes, Barcelona, 1836 (reimpr. 1973), vol I, p. 482.

\section{La obra dramática de Juan Lorenzo Palmireno.}

De los escritores que desarrollaron su actividad dramática en la Universidad de Valencia en el ámbito escolar, la figura más prestigiosa fue Juan Lorenzo Palmireno, del que no podemos ofrecer aquí nada más que unas pocas notas sobre su vida y su obra, para la que contamos ya con una abundante y rica bibliografía(48).

(46) Cf. Romeu i Figueras, Teatre, p. 130, nota 55. Menéndez Pelayo en la obra citada (nota 39), pp. 419-420, recogía la Sylva y el Claudius, junto al Gastrimargus, como imitaciones de Plauto y las ubicaba en la Biblioteca Episcopal de Barcelona y en la Biblioteca de los Dominicos de Vich respectivamente en tiempo de Torres Amat, y aunque no debía haberlas visto -a juzgar por la apostilla final con que concluía su información: "Hay que ver estas comedias»-, sin embargo daba ya estos datos sobre ellas (título, autor, genero, año de la edición y editor): Claudius. Comoedia auctore Ioanne Cassadoro publico Barcinonensi academia professore. Accesserunt Petri Sunyerii publici etiam proffesoris annotationes. Barcinone in aedibus Claudii Bornat et vidua Monpesat. MDLXXIII (1573) // Sylva, comoedia de vita et moribus authore Jacobo Cassiano presbytero virgiensi diocesis Gerundensis. Sequitur libellus de constructione cum forma perdiscendi calendas. Barcinone excudebat Petrus Malus anno MDLXXVI (1576).

(47) Cf. Romeu i Figueras, Teatre, p. 130, nota 56.

(48) Para más detalle, véase en general, Briesemeister, "Das Mittel-», p. 15; García Soriano, El teatro, p. 1 y 12; Alonso Asenjo, "Panorama», pp. 166-167; Menéndez Peláez, "El teatro escolar», pp. 586-588. Para la vida y la obra, cf. de la Vega y Luque, C. L., "Vida y obras de Juan Lorenzo Palmireno", en Teruel, $n^{\circ}$ 49-50, Instituto de Estudios Riojanos, 1973. Para el análisis de las obras, véanse Mérimée, H., [1913]: El arte dramático en Valencia, Valencia 1985, vol. I, pp. 248-270; Gallego Barnés, A., Juan Lorenzo Palmireno (1524-1579). Un humanista aragonés en el "Studi General" de Valencia, Zaragoza, 1982, esp. pp. 151-162; y Maestre Maestre, J. M"., 
Nacido en Alcañiz en 1524, fue nombrado Catedrático de Poesía del Estudi General de Valencia en 1550. Tras cinco años de docencia en su ciudad natal y Zaragoza (1556-1561) regresó a Valencia regentando las cátedras de Griego y de Retórica desde 1562 hasta su muerte en 1579, excepto dos años de docencia en Alcañiz (1570-1572).

Su actividad teatral la desarrolló durante estos 16 últimos años escribiendo muchas piezas teatrales — una por año, según su propio testimonio —, de las que nos han llegado 7: un Dialogus (1562), cinco comedias: Sigonia (1563), Thalassina (1564), Octavia (1564), Lobenia (1566) y Trebiana (1567), conservadas de forma fragmentaria en las partes $1^{\mathrm{a}}, 2^{\mathrm{a}}$ y $3^{\mathrm{a}}$ de la retórica, y la Fabella Aenaria (1574), la única conservada en su integridad, publicada en 1574, dentro de las Phrases Ciceronis(49).

Están escritas en latín y castellano, incluyendo frases o pasajes en valenciano, incluso en griego, italiano o portugués, acentuándose la presencia de la lengua vulgar en la Fabella Aenaria, en la que compagina los modelos Plauto y Terencio con los del teatro contemporáneo que gustaba más a los alumnos, como el mismo Palmiro reconoce en ella.

El humanismo alcañizano del siglo XVI. Textos y estudios del latin renacentista, Cádiz 1990, esp. pp. 125-227. Y para los principales estudios específicos, Gallego Barnés, A., "La risa en el teatro escolar de Juan Lorenzo Palmireno", en Actes du 3e Colloque du Groupe d'Étude sur le Théatre Espagnol (Toulouse, 31 janvier-2 fevrier, 1980), París, 1951, pp. 187-196; Maestre Maestre, J. Ma ., "Formación humanística y literatura latino-renacentista: a propósito de Juan Lorenzo Palmireno», en Los humanistas españoles y el humanismo europeo. IV Simposio de Filología Clásica, Universidad de Murcia, 1990, pp. 191-202; Alonso Asenjo, J., "Los elementos mágicos del teatro de J. Lorenzo Palmireno", en E. J. Blasco et alii, La Comedias de Magia y de Santos, Barcelona 1992, pp. 33-50; y Maestre Maestre, J. M., "Valencia y su Studi General en el teatro de Juan Lorenzo Palmireno", El teatre Clàssic al marc de la Cultura Graeca i la seua pervivència dins la cultura occidental, Ed. J. Vicente Bañuls, Francisco de Martino, Carmen Morenilla i Jordi Redondo, Levante Editori-Bari, 1998, pp. 335-367.

(49) Phrases Ciceronis. Hypotiposis clarissimorum uirorum. Oratio Palmyreni post reditum. Eiusdem Fabella Aenaria... Cf. Maestre Maestre, "El bumanismo", p. 147, con las 3 notas. Sobre la discusión de las hipótesis o razones de la publicación sólo fragmentaria de ellas, especialmente de las tres primeras, frente a la publicación íntegra de la Aenaria, véase Mérimée, El arte dramático, pp. 260-262: tras señalar que no se sabe si se debió al deseo de complacer a los jurados que le habían negado su apoyo o al deseo de rivalizar con las comedias y dialogos Claudius, Terra y Sylva, publicados por entonces en Barcelona, dirime la cuestión con estas palabras: "Cualquiera que fueran los motivos, su insistencia nos ha valido la Fabula Aenaria» (p. 262). 
Palmireno concibe el teatro como un instrumento pedagógico para instruir a los alumnos en el conocimiento del latín y la retórica, especialmente en la acción( ${ }^{(50)}$. En la Octavia (Barnes, p. 151) señala en concreto tres objetivos claros: el entrenamiento de los jóvenes, la profundización en el latín y la captación de su atención en los periodos caniculares; y en la Aenaria, entre otros, divertir y enseñar a los alumnos a expresarse en público, conseguir su formación moral e intelectual y la soltura en sus modales; y abrirse a la actualidad y la moda (Barnes, pp. 151-162) y conectar su teatro con el contemporáneo de Juan de Timoneda, no siguiendo como modelo a Menandro ni a Terencio, sino otro teatro más popular y actual con predominio del castellano.

\section{- La Fabella Aenaria(51)}

El argumento se puede resumir así:

En tiempos del emperador Vespasiano, después de una rebelión de muchos príncipes de la Galia, uno de ellos llamado Julio Sabino, mientras los otros huyeron o se mataron para escapar de sus enemigos, hizo correr la voz de que había muerto. Su mujer, Eponina, acudiendo a hurtadillas a la cueva donde se escondía su marido, quedó preñada y dio a luz dos hijos mellizos, Petronio y Lauredana. Las adversidades y el fin venturoso de éstos los narrarán sus criados y los de su hermano, el Príncipe Alberto.

Los rasgos básicos de la pieza los ofrece Palmireno en el Prólogo al acabar el juego del Eco con la intervención de Jeroni que le dice que lo mejor

(50) "La pasión docente de nuestro autor», dicen Leal-Sirera, "le llevará a recurrir al teatro como método auxiliar para lograr que sus estudiantes mejorasen sus conocimientos gramaticales y lingüísticos, así como la actio. En este campo, Palmireno partirá de una concepción del teatro que lo vincula claramente al llamado teatro escolar, que tanto desarrollo alcanzó en la península ibérica a lo largo del siglo XVI»: cf. Maestre, J. $\mathrm{M}^{\mathrm{a}}$, Leal, Sirera, Juan Lorenzo Palmireno (nota 51), p. 11

(51) Cf. Maestre Maestre, J. M., "El papel del teatro escolar en la enseñanza de la Retórica y del Latín durante el Renacimiento: en torno a la Fabella Aenaria de Juan Lorenzo Palmireno, en Los humanistas valencianos y sus relaciones con Europa: De Vives a Mayans, ed. Jordi Pérez i Durà y José María Estelles, Valencia, Ayuntamiento, 1998, pp. 95-114; y Maestre, J. Mª., Leal, J. y Sirera, J. L, Juan Lorenzo Palmireno ensaya la "Fabella Aenaria" con sus aumnos del Estudi General de Valencia, Dramaturgia de Juli Leal y Josep Lluís Sirera, a partir de la edición de José María Maestre, con prólogo de Josep Lluís Sirera y Juli Leal, Universitat de València, 2000. 
será «ayuntar el lenguaje latino con el castellano» en la obra. El maestro le asegura que seguirá su consejo, indicándole el fin que se propone con ella, su carácter dramático y la lengua que utilizará en su composición ${ }^{(52)}$ :

Palmireno. - «Pues esto te parece llano seguiré tu consejo, consolándome que, si es fría mi comedia, no es ese mi oficio, y que por divertir a mis discípulos del naipe en estas vacaciones, les he ejercitado la acción y voz en esto, que es ni comedia ni farsa, sino entretenimiento. Y porque me quitaron la joya de terciopelo carmesí, hará seis meses, diciendo que toda mi obra iba latina, pongo en esta mucho romance. No sé si habré acertado»

Así sintetizan su significado Leal-Sirera: "todos los investigadores que han estudiado esta obra coinciden en que significa el punto máximo de la evolución hacia el teatro en vulgar dentro de la producción de Juan Lorenzo Palmireno: presencia notable del castellano, argumento en el que el enredo juega un papel significativo y en el que el tema del honor se hace visible, personajes que corresponden a los roles que la comedia española del momento (Joan Timoneda, Alonso de la Vega, Lope de Rueda) había ya consagrado (dama, galán, bobo), presencia de personajes femeninos particularmente activos, gotas de costumbrismo, etc.» ${ }^{(53)}$.

\section{- El Dialogus.}

Para el Dialogus remitimos al estudio de Maestre de 1994(54) en el que, tras mostrar que la pieza era una hábil adaptación de una narración de una escena de fantasmas realizada por Alesssandro Alessandri en el cap. IX del Genialium dierum liber VI (p. 544-546), demuestra la estrecha rela-

(52) Cf. Maestre, J.M a Leal, Sirera, Juan Lorenzo Palmireno, (nota 51), p. 37.

(53) Idem, pp. 12-13. Para algunos de esos personajes femeninos, véase Alonso Asenjo, J., "Dos mujeres de armas tomar en la Fabella Aenaria de Palmireno", en Edad de Oro, XVI; Madrid, Universidad Autónoma de Madrid, 1997, pp. 29-52.

(54) Maestre Maestre, J. Mª, "En torno a las fuentes del Dialogus de Juan Lorenzo Palmireno, en F. Sojo Rodríguez, F. (coord.), Latinitas Biblica et Christiana. Studia Philologica varia in Honorem Olegario García de la Fuente, Madrid, 1994, pp. 543-550. 
ción de las comedias de Palmireno con las hypotyposis o descripciones que los alumnos del humanista aprendían en sus clases de retórica, así como la utilidad de las piezas dramáticas por sí mismas para la enseñanza del latín clásico y, más concretamente, del ciceroniano en el Studi General de Valencia (p. 543), la utilidad del diálogo para la enseñanza de la retórica y del latín (pp. 548-549), la influencia humanística en su reelaboración y su proximidad desde el punto de vista del género a la comedia.

En la zona de Castilla, Salamanca constituyó otro foco importante para el desarrollo del teatro escolar, aunque no sea precisamente en ella donde se han conservado más obras en latín, ni la que más obras dramáticas en latín produjo o se nos han conservado, salvo la Hispaniola, quizá la mejor de todas ellas.

Dos escritores de especial relieve provocaron el conocimiento de los clásicos y las imitaciones del teatro latino en Salamanca, Francisco López de Villa Lobos (1473-1549), quien siendo estudiante realizó ya una versión del Amphitruo de Plauto, aunque no se publicara hasta el 1515, y Fernán Pérez de Oliva (1494-1533), que refundió esta misma obra de Plauto y tradujo distintas tragedias griegas ${ }^{(55)}$. Su actividad universitaria fue capital para el desarrollo del teatro.

Oliva nació en Córdoba en torno a 1494. Su paso por la Universidad de Salamanca fue sumamente accidentado, pero muy fecundo. Estudió en ella de 1511 a 1514 y 1525 volvió a ella como profesor, con el título de Maestro. Sus deseos de saber y de promover y organizar el saber le llevó a poner sus objetivos en el gobierno de la Universidad, que consiguió en el 12 de Mayo de 1529, siendo elegido Rector por el claustro.

(55) Para su labor como traductor y autor trágico, véase Hermenegildo, A., La tragedia del Renacimiento español, Barcelona, Planeta, 1973, pp. 70-88. 
Disconforme con los estatutos que la regían, promovió la aprobación de otros nuevos que quedaron redactados el 24 de mayo de 1529, en los que se imponía, entre otras disposiciones, la obligación de representar dos comedias, una de Terencio y otra de Plauto, 15 días antes o después de San Juan (Hermenegildo, 70).

La influencia de sus tragedias, aunque algunas no tuvieran mucho éxito, la influencia de la versión de Plauto realizada por Villa Lobos, y la ampliación de la obligación impuesta en 1529 de representar dos comedias al año a un mayor número de representaciones en el título LXI siempre citado de los estatutos de 1538, hizo que éstas se multiplicaran y que otros escritores se decidieran a escribir teatro.

Los Dialogi quatuor sobre la muerte del Príncipe D. Juan, de Diego Ramírez de Villaescusa y la Consolatoria de Alfonso Ortiz.

De finales del siglo XV tenemos conocimiento de la actividad teatral o parateatral desarrollada en Castilla por el testimonio de estos cuatro diálogos y una égloga.

El primero son estos diálogos de Diego Ramírez de Villaescusa, que nació en la localidad conquense de Villaescusa de Haro en 1459 y murió en 1537. Fue discípulo de Lucio Marineo Sículo y de Nebrija y dio las Constituciones del Colegio de Cuenca en Salamanca, del que fue fundador(56).

(56) Dialogi quatuor super suspicato Joannis Hispaniarum Principis emortuali die Ja / cobi a Villascusa auctore quam celeberrimo nouissimi / me impressi foeliciter incipiuntur, Amberes, Godfridus Bach, 1498. Hay un ejemplar en la RAH; Para las traducciones, véanse la monografía de García Olmedo, F., (1944), Diego Ramírez de Villaescusa (1459-1537) fundador del Colegio de Cuenca y autor de los Cuatro Diálogos sobre la muerte del Príncipe don Juan, Madrid, Editora Nacional, 1944, pp. 239-296; y la más moderna de Almansa Tollante, R., Cuatro diálogos que tratan sobre el infausto día en que murió el Príncipe D. Juan, heredero de España de Diego Ramírez de Villaescusa, Prólogo, edición facsímil del texto latino, transcripción y traducción, Diputación provincial de Jaén, 1997; y para más datos e información de éstas y otras obras en latín y en castellano dedicadas a la muerte del Rey, el estudio de Pérez Priego, Miguel Ángel, El Príncipe Don Juan, heredero de los reyes católicos y la literatura de su época. Lección inaugural del curso 1997-1998, UNED, 1997, esp. las pp. 31-33 y pp. 105-122, con las fuentes literarias alusivas al tema y la bibliografía de referencia concreta. 
En el primero de ellos la reina Isabel conversa con un personaje que resulta ser la muerte. Al decirla ésta que viene a arrebatar al príncipe de parte de Dios se desmaya y recuperándose trata de disuadir a la muerte de su propósito con distintos argumentos, pero ésta ejecuta su sentencia y el príncipe muere.

En el segundo, Don Fernando le da la noticia a su nuera Margarita de Austria que pierde el sentido y, al volver en sí, prorrumpe en una tristísima lamentación. En ella expresa su deseo de morir e invita a llorar a toda Europa, mientras adivina el alivio de África, Asia, Turquía o Babilonia, recordando a las esposas de los Argonautas, a Artemisa reina de Caria, Hipsicratea mujer de Mitrídates y otras mujeres que siguieron en la muerte a sus maridos, dispuesta a hacer lo mismo, pero acabando por pedir a las Parcas y a las Furias que lo hagan por ella, con estas palabras:

"Si la noble Sulpicia marchó al destierro para no abandonar a Léntulo Trustelio, yo, la infeliz Margarita saldré al encuentro de Juan, único y vital aliento de mi desgraciada vida, separado ya de la convivencia de los hombres

Pero ¿qué digo, infeliz? Soy la más infeliz de todos los mortales y este calificativo es tanto más justo cuanto llegué a ser la más feliz por mi matrimonio en España, con el Príncipe Don Juan, pero ahora, en un abrir y cerrar de ojos, me veo inmersa en mi viudez, en el suplicio de Tántalo, pues no puedo gustar la fruta que ya estaba tocando con mi mano, ni llevar a mis labios sedientos el agua que descubrí por fin para apagar mi sed.

¡Ay de mi, infeliz! Venid Parcas, y cortad el hilo de mi existencia. Llegad Furias, y entregadme ya a la muerte».

En el tercero, el rey comunica la muerte a Doña Isabel y al ver que ella no halla consuelo la anima con distintas reflexiones teológicas, consideraciones filosóficas, ejemplos de los Santos Padres, etc. instándola a dar ejemplo a los príncipes y a acatar con él la voluntad de Dios.

En el cuarto, los monarcas visitan a Margarita para consolarla en su viudez y ofrecerle sus cuidados augurándola que el hijo que latía en sus entrañas aliviaría su dolor. Pero, por un triste sino, nacería muerto. 
El Canónigo toledano Alfonso Ortiz, escribió asimismo una obra titulada Tratado del fallescimiento del muy ínclito señor don Juan el tercero príncipe de las / Españas, compuesto por Alfonso Ortiz, doctor de Utroque iure, canónigo de la santa Iglesia de Toledo(57).

Es, con algunas modificaciones, la traducción del propio autor de su obra consolatoria en latín titulada Consolatoria super obitu inclyti principis Hispaniarum Johannis domini nostri, cancellario et rectori, diffinitoribus et doctoribus et magistris Alme Vniversitatis Salmanticensis directa per Alfonsum Ortiz(58).

Briesemeister sitúa los diálogos de Villaescusa en un lugar intermedio entre el drama y el discurso y, en comparación con la obra de Ortiz, considera que aquél «presenta lo ocurrido de una forma escénica más conmovedora y con más movimiento. Así», dice, "mientras que Ortiz aparece más vinculado a la conversación didáctica humanística y a la visión alegórica de los sueños, Villaescusa, como Capellán mayor de la Corte, combina en su diálogos retóricos las alabanzas al soberano con una enseñanza más edificante» (p. 9).

Para su parte, Almansa considera que los diálogos de Villaescusa contienen indudables momentos dramáticos y se inscriben dentro de la tradición de la literatura antigua, seguida por la paleo-cristiana y la medieval que seguía vigente en autores castellanos del s. XV, como el Marqués de Santilla (Diálogo de Bias contra Fortuna) y el de Don Pedro de Toledo (Diálogo e rasonamiento entre el noble e generoso señor don Fernando Alvarez de Toledo... e el Doctor Pero Díaz de Toledo y Ovale...) utilizados por Villaescusa, y el de Alfonso de Valdés (Diálogo entre Caronte y el alma) y otros (p. 34-35); y Pérez Priego, por la suya, señala el notable interés que tiene el tratado de Ortiz por su valor histórico y por su propia factura literaria, indicando

(57) Hay manuscrito en la Biblioteca Universitaria de Salamanca, Ms. 367, fols. 1-32. Los folios iniciales de la versión castellana los transcribió y editó José Camón Aznar en su estudio Sobre la muerte del Príncipe don Juan, Madrid, Real Academia de la Historia, 1963, pp. 99-112.

(58) Autógrafo de la Biblioteca Universitaria de Salamanca Ms. 368, fols. 62r-93v. Cf. Sanz Hermida, J., "Literatura consolatoria en torno a la muerte del Príncipe Dn. Juan», Studia Historica-Historia Medieval 11(1993), pp. 157-170. 
en este sentido que está construido «en una prosa retórica y altisonante, propia del género consolatorio, y que combina hábilmente la forma dialogada (en compleja polifonía de voces y tiempos), el relato retrospectivo y la visión alegórica» (p. 35).

La égloga In laudem Calagurritani Episcopi del Bachiller de la Pradilla.

Un testimonio un poco posterior que poseemos sobre la actividad del drama humanístico religioso es la égloga semidramática latino-romance del Bachiller de la Pradilla titulada In laudem Calagurritani Episcopi de suo in episcopatu adventu Aegloga (Pamplona, 1499), que ha sido muy bien estudiada últimamente por González-Ollé y Pérez Rioja(59).

\section{Mal Lara. La Comedia Locusta y la tragedia Absalón ${ }^{(60)}$.}

El sevillano Mal Lara estudió en Salamanca con Hernán Núñez y en Barcelona con el valenciano Francisco Escobar. Después de unos años de docencia en la Universidad de Salamanca, en 1548 estaba ya en Sevilla, cursando Artes, y luego abrió allí (1524-1571) una escuela célebre de Gramática y Humanidades (junto a la Alameda de Hércules), donde estudiaron prestigiosos nobles como Francisco de Medina, Diego Girón y otros, contribuyendo activamente al desarrollo de las aficiones literarias de la Ciudad.

Entre su intensa actividad literaria destacó por la dedicada a la producción teatral: según el testimonio de Francisco Pacheco en el Libro de retratos y elogios, que recoge Alberto de la Barrera, "compuso muchas comedias y tragedias divinas y humanas, adornadas de maravillosos discursos

(59) Cf. Bonilla y San Martín, A., "Fernán López de Yanguas y el Bachiller de la Pradilla", Revista Crítica Hispano-Americana 1 (1915), pp. 44-51; Briesemeister, "Das Mittel-», p. 17; González-Ollé, F., "El Bachiller de la Pradilla, humanista y dramaturgo», Romanische Jabrbuch 17 (1966), pp. 285-300 y Pérez-Rioja, J. A., "Hernán Pérez de Yangüas, humanista y autor dramático", Celtiberia 36 (1968), pp. 163-182, que defiende junto con Bonilla y otros, contra la identificación de Yanguas y el Bachiller que hizo Amador de los Ríos, la diferencia de ambos: el primero nació en Yanguas (Soria) y el segundo en Pancorbo (Burgos), caracterizándose el uno y el otro respectivamente, según Menéndez Pelayo, por un estilo pedante y clásico.

(60) García Soriano, El teatro, pp. 10, 15, 29, 50, 87, 112, 223 y 228; Alonso Asenjo, "Panorama», pp. 171-172; Menéndez Peláez, «El teatro escolar», p. 585. 
y ejemplos, llenas de epigramas, odas y versos elegíacos, así latinos como españoles»; pero a continuación añade que «no existe conocida ni una sola de estas producciones» $(61)$.

Consta por el testimonio del propio Mal Lara, en otras obras suyas, que representó la comedia Locusta en latín y romance en la Universidad de Salamanca en 1548 y una tragedia llamada Absalón ${ }^{(62)}$ por la misma fecha.

Además, sabemos también que durante su estancia en Sevilla se representaban obras de teatro en su Estudio público de Humanidades, de las que sin duda serían algunas suyas. En 1561 compuso en verso una comedia en elogio de Nuestra Señora de la Consolación, que representó con sus discípulos en Utrera(63) y allí escribió también dos églogas representables, tituladas Laurea y Narciso y, según Alonso Asenjo, una Tragedia de San Hermenegildo ${ }^{(64)}$.

\section{Francisco Sánchez de las Brozas. La Appollinis Fabula.}

La actividad teatral del Brocense la conocemos gracias a las noticias que nos dan de él los libros de Claustros de diputados y de cuentas en las que se alude a sus representaciones y otros aspectos relacionados con ella, amén de otras fuentes. En ellos se alude a dos tragedias representadas en 1566 y 1568, a la tragedia David, representada en 1569, a otras llevadas a cabo en 1570, 1572, 1573, 1574, 1576 y a otras que García Soriano silencia(65).

(61) Cf. Alberto de la Barrera y Leirado, Cayetano, Catálogo bibliográfico y biográfico del teatro antiguo español, desde sus orígenes hasta mediados del s. XVIII, Madrid, Gredos (facsímil), 1960 , p. 233.

(62) Esta tragedia la cita Mal Lara en su Primera parte de la Philosophia vulgar, Sevilla, 1569, p. 546 al aludir al nombre Bambalio: "Así llamé yo", dice, "a un bobo de una comedia mía, que hice en latín y la misma en Romance, representada en las escuelas de la insigne Universidad de Salamanca, año de 1548, llamada Locusta».

(63) Alberto de la Barrera, Catálogo, p. 233; García Soriano, El teatro, p. 234.

(64) Alonso Asenjo, en "Panorama», p. 72, aduce el testimonio de Rodrigo Caro. Pero ya García Soriano aludió en las páginas 87 y 112 de su estudio a la equivocación de Matute y Sánchez Arjona por atribuir a Mal Lara esta obra.

(65) Cf. Briesemeister, "Das Mittel-», p. 15; García Soriano, El teatro, pp. 223-227; Alonso Asenjo, "Panorama», pp. 173-174; Menéndez Peláez, "El teatro escolar», pp. 585-586; y el estupendo trabajo reciente de Framiñán de Miguel, $M^{a}$ J., "Actividad dramática en el Estudio Salmantino del Renacimiento, Plauto y Terencion, en J. Ma Maestre Maestre, J. Pascual Barea y L. Charlo Brea (eds.), Humanismo y pervivencia del mundo clásico. Homenaje al Profesor 
Por otras fuentes sabemos que escribió comedias de tema mitológico, como Calirrboe y Achilles inventus, las comedias y tragicomedias Asuero, Bethsabee/Bersabé y Trepidaria, algunas de ellas en latín traducidas al romance por él, y la Apollinis fabula en latín, la única que conservamos, muy bien estudiada por el Prof. Maestre(66).

\section{- La Apollinis fabula.}

Es una adaptación dramática en 170 versos del mito de Apolo y Dafne de Ovidio, que iba precedida también como en este autor del episodio en que el Delio da muerte a Pitón, con lo cual el autor juega en el título con el doble sentido de "drama» (fabula) y "mito" (Apolo) que, como sabemos, era tan usual en latín clásico (p. 161 y notas).

El Prof. Maestre demuestra cómo en ella se dan distintos procedimientos del llamado Latín de laboratorio para adaptar las fuentes al poema - Ovidio en este caso sobre todo pero también otras —-, recurriendo a unas técnicas de composición similares a las utilizadas para el centón, como el cambio de tercera a primera persona, como exigía la representación, la utilización de calcos léxicos, la supresión de palabras, el recurso a las palabras puente, la adaptación de cláusulas finales, etc.; y, por lo que respecta al género, Maestre demuestra que en ella el autor amalgama y mezcla distintos géneros con el dramático, como el épico, el bucólico, etc., una mezcla que constituye una característica típica de la literatura neo-latina en poesía y prosa (pp. 185 ss.).

\footnotetext{
Antonio Fontán, Alcañiz, Madrid, 2002, III, 33, pp. 1187-1200, especialmente la parte dedicada a la práctica dramática, donde alude a las piezas nuevas representadas (p. 1195) y el Apéndice documental (pp. 1196-1200) con datos sobre las representaciones de Francisco Sánchez de las Brozas, Francisco Martínez y el Maestro Pérez. Es reveladora la información que se da en el Apéndice 16, p. 1200, respecto a la actitud del Claustro o determinados claustrales cuando algún maestro compone y representa obras malas, ordenando "que no pueda hacer ni representar ya comedia alguna, si no fuera de Plauto o Terenciom.

(66) Cf. Maestre Maestre, J. Ma ., "La mezcla de géneros en la literatura latina renacentista: a propósito de la 'Apollinis fabula' del Brocense, en Simposio IV Centenario de la publicación de la "Minerva" del Brocense: 1587-1987, Cáceres, 1989, pp.145-187.
} 
Las tragedias De Illiberitanorum maurorum seditione de Barrientos y Iudith de Vanegas, y otros autores y obras.

Por el libro de Claustro de Diputados y alguna fuente más (como el propio Barrientos, cf. nota 68) poseemos diversas noticias sobre la representación de otras obras de distintos maestros de la Universidad en latín y en castellano y las circunstancias que las rodearon ${ }^{(67)}$.

De obras neo-latinas, cabe destacar, en 1568 o 1569 una tragedia titulada De Illiberitanorum maurorum seditione del catedrático de Latín Bartolomé Barrientos sobre la sublevación de los moriscos de las Alpujarras(68); y en 1569 la tragedia Iudith, del Maestro Vanegas, junto con la tragedia David mencionada del Brocense, por las que ambos fueron remunerados por el Claustro ${ }^{(69)}$.

\section{La obra dramática de Juan Petreyo.}

La máxima influencia de los dramaturgos italianos y su clasicismo la representó quizá Juan Pérez Petreyo.

Nació en Toledo en 1512 y murió en 1545, probablemente en Alcalá. Inició sus estudios quizá en el Colegio de Santa Catalina de Toledo, los continuó

(67) Cf. García Soriano, El teatro, pp. 224-227, y el estudio citado de Framiñán.

(68) La autoría la conocemos por el mismo Barrientos en su libro titulado Lima Barbri, et Synonymis Latinis. Annotationum Sylva, Salmanticae, 1570. Quizá haya tenido que ver algo con ella la titulada In adventu Regis de 1570 de Acevedo compuesta para celebrar la presencia de Felipe II al colegio en su visita a Sevilla con ocasión de la guerra de las Alpujarras, cf. Picón García, V., "La comedia Desiderius? de P. P. de Acevedo en honor de Felipe II: historia y alegoría", en Ana Ma . Aldama et alii, La Filología latina boy. Actualización y perspectivas, Sociedad de Estudios Latinos, Madrid, 1999, pp. 1217-1230.

(69) De obras que se compusieron y representaron en español o que no se sabe si se hizo también en latín, se pueden recordar éstas: en 1570 dos comedias de los mismos autores citados, siendo premiado en este caso Venegas y quedando sin remuneración su compañero; en 1574 una comedia del Maestro Francisco Pérez, que por sus cualidades («mala e de malos entremeses e sin latin nj orden e que dio que desir a los que la oyeron e se hallaron presentes e la vieron»), provocó un gran escándalo, hasta el punto que se le quiso imponer una multa, pero por mediación del Brocense la Universidad amainó el castigo prohibiéndole hacer o representar comedia alguna que no fuese de Plauto o de Terencio; y en 1574 otra de Juan de Flandes que mereció el premio de diez ducados establecido por el estatuto 16 del título 63, entre otras que se presentaron (cf. García Soriano, El teatro, pp. 224-227). 
en el de San Clemente de Bolonia y desde el año 1537, en el que obtuvo la cátedra de retórica, fue profesor del Colegio Trilingüe de Alcalá(70)

De entre las diversas obras literarias que escribió, nos interesan las seis de su producción dramática que conocemos, aunque debió escribir más, a juzgar por las noticias que nos da su hermano Antonio Pérez en la carta introductoria a la edición de cuatro de ellas que hizo en Toledo(71). Cinco se conservan completas y, de otra sólo se conserva el prólogo. Son las siguientes:

\section{- Un coloquio titulado Ate Religata et Minerva restituta(72).}

- Cuatro comedias de dramaturgos italianos entonces en boga traducidas al latín, que revelan la máxima influencia de la comedia italiana en España y representan quizá la más clara expresión del clasicismo de Petreyo ${ }^{(73)}$ : tres de Ludovico Ariosto: il Negromante, la Lena, I Suppossiti titulados en la traducción latina Necromanticus, Lena, Suppositi; y Gl'Ingannati, de autoría poco segura (cf. Cortijo, p. 23), convertida en los Decepti ${ }^{(74)}$. Las fechas en

(70) La obra ha sido estudiada, pero aún faltan otros trabajos por realizar sobre sus obras, como el de Cortijo Ocaña, que se reseña mas adelante. Para una visión básica, Briesemeister, «Das Mittel-», pp. 14-15; García Soriano, El teatro, pp. 344-359, esp. 355-359 para la vida; Menéndez Peláez, "El teatro escolar», pp. 588-589. Para la vida y la obra, Sojo Rodríguez, F., "Sobre el humanista español Juan Pérez (Petreyo)», Analecta malacitana 9,1 (1986), pp. 27-37, con noticias biográficas, revisión de las obras impresas, análisis de los tratados manuscritos y descripción del Ms. e-II-15 del Escorial.

(71) Ioannis Petreii Toletani Rhe / toris dissertiss. et Oratoris eloquentiss. / in Academia Complutensi / Rhetoricae professo / ris Comoediae / quattuor. / Nunc primum in lucem / editae. Toleti, / Apud Ioannam Ayalam. / Anno 1574. / Cum Priuilegio. Hay un ejemplar de ellas en la Biblioteca Nacional de Madrid.

(72) Se conserva en el Ms. de la Biblioteca Nacional de Paris, 8762 de la colección latina.

(73) Véase en Arróniz, La influencia, el apartado "De Petreyo a Lope de Rueda», pp. 51-62, especialmente 51-55.

(74) Cf. Alvar Ezquerra, A., "Juan Pérez (Petreius) y el teatro humanístico", en Unidad y pluralidad en el mundo antiguo. Actas, Madrid, 1983, pp. 205-212, con una buena descripción de las obras: de Ate, en pp. 297-209; de las otras 4, en pp. 209-211; y de Chrysnia, en p. 212; y Cortijo Ocaña, A., Juan Pérez 'Petreyo', Teatro latino escolar: Suppositi-Los Supuestos de Juan Pérez 'Petreyo' (ca. 1540), Edición, introducción, traducción y notas, Pamplona, 2001: en la introducción estudia en su conjunto la obra de Petreyo, y especialmente los Suppositi, ofreciendo sus rasgos característicos y señalando la originalidad del experimento del gran humanista al traducir al latín cuatro comedias vernáculas italianas adaptadas de los clásicos, para "ofrecer a los alumnos un ejercicio retórico de la declamatio y un ejemplo práctico de traducción y estilo» (p. 25), y ponerlos en contacto con el teatro culto italiano desde la lengua 
que compuso Ariosto los originales son 1509 para I Suppositi, 1528 para la Lena, 1530 para el Nigromante y quizá también para Gl'Ingannati, o antes, pues Decepti se sabe que fue estrenada en 1531; y las de las traducciones de Petreyo entre 1537 en que comenzó su actividad como catedrático y 1545 en que murió.

- Y Chrysonia, una adaptación de la novela de Apuleyo, como indica su título completo ${ }^{(75)}$.

\section{- La Ate religata et Minerva restituta(76).}

Prologo:

"Ate, diosa del castigo y del maleficio, celosa de Minerva, a la que veía consagrada en un lugar honorífico en la Universidad Complutense, se apresta a expulsarla de allí, trama con Momo, dios de la maleficencia (burla/mofa) un plan para que ambos, en estrecha colaboración, tramen la calumnia contra ella ante sus patronos (representantes) y les persuadan de que ella es mal vista por el Cardenal toledano. // Una vez descubiertas las asechanzas, Mercurio reanima a Minerva que soporta esto con dificultad, y ambos deciden vengar la injuria y castigar a los criminales. // Se presenta Apolo que de parte de Júpiter anuncia que Ate debe ser enviada lejos contra los Turcos y los Bárbaros. Desterrada ella, se presenta Vulcano a los que quieren castigar también a Momo, prohibiéndoles que lo hagan por orden de Júpiter. // Se difunde la noticia de las bodas de Minerva con Mercurio, respecto a lo cual, después que aquélla lo rechazó durante mucho tiempo, al fin es convencido con esta razón: que Mercurio la recomienda a ella diligentemente ante el Cardenal. // Como consecuencia, después de sopesado y cambiado el plan, se acercan a él, le saludan y le dan gracias, haciendo salir incluso a las Gracias para la acción de agradecimiento. Cierra toda la acción el convite de Vulcano».

latina, «en sintonía con la práctica universitaria de adaptar y refundir obras clásicas y crear dramas latinos originales» (p. 37). Se completa con una amplia bibliografía.

(75) Chrysonia comedia ex Apulei Asino aureo in dramatis forma redacta. Se conserva en el e-II-15 de la Biblioteca del Escorial. Cf. Bonilla y San Martín, A., "El teatro escolar en el Renacimiento español y un fragmento inédito del toledano Juan Pérez", Homenage a Menéndez Pidal, 3, Madrid, 1925, pp. 143-155.

(76) Traduzco el prólogo y doy una breves notas siguiendo a García Soriano en las páginas citadas supra (nota 70). Para más detalle, véase la edición de Morel-Fatio, A., Ate religata et Minerva restituta, comédie de collège représentée à Alcalá de Henares en 1539 ou 1540", Bulletin Hispanique 5 (1903), pp. 9-24; y las páginas 207-209 citadas de Alvar. 
Los interlocutores son un conjunto de divinidades de las que algunas simbolizan alegóricamente instituciones reales, como la Universidad y su patronazgo: Ate (diosa del daño y del malificio) Minerva, (alegoría de la Universidad) Momo (dios de la burla) Mercurio (alegoría del Cardenal patrón de la Universidad), Apollo, Vulcano y Júpiter.

Se trata de una pieza escolar de circunstancias, representada por los estudiantes de Alcalá en 1539 o 1540 en un certamen poético en la Universidad Complutense con ocasión de una vistita que hicieron el príncipe Don Felipe y el Cardenal Juan de Tavera, recien elegido a la archidiócesis de Toledo, o más probablemente cuando lo fue Don Juan Martínez de Silicio. Aparte del mérito literario, la pieza tiene un singular interés histórico, por aludir a las discordias que mantenía la Universidad (simbolizada por Minerva) y los arzobispados (simbolizados por su patrón Mercurio).

Petreyo trata de ofrecer un mensaje de concordia entre ellos de forma simbólica sustituyendo los personajes e instituciones reales por alegorías. Pero sus propósitos quedaron defraudados. "Los requerimientos que hicieron al Cardenal desde la escena Minerva y Mercurio sirvieron de poco. Ate no fue relegata, ni Minerva restituta, y los pleitos entre Tavera y la Universidad siguieron cada vez más enconados, hasta la muerte de aquél en 1545» (García Soriano, p. 356).

Las otras cuatro obras de Petreyo son para Alvar menos comprometidas; "se trata", dice, "de ejercicios escolares destinados al aprendizaje y dominio del latín, que eso son la gran mayoría de las comedias humanísticas. Si hemos de creer a su hermano Antonio Pérez, pretendía con ellas sustituir a las de Plauto y Terencio» (p. 209).

\section{Los Suppositi.}

Una buena muestra del carácter de estas obras se puede ver en la edición citada de Cortijo de los Suppositi, pieza una que se representó en su versión original en el teatro Ducal de Ferrara el 6 de Febrero de 1509 y en el palacio Vaticano de Roma el 6 de febrero de 1519. El argumento dice así: 
"Filógono de Catania, comerciante siciliano no carente de prosapia, envía a su único hijo, Eróstrato, a Ferrara para que estudie derecho civil y con él envía a su esclavo Dulipo, al que compró hace mucho tiempo a la edad de cinco años y lo crió en su casa. Nada más llegar Eróstrato a Ferrara se enamora de la doncella Polimnesta, hija de Damón, e intercambia nombre y vestido con su esclavo Dulipo, de modo que a Eróstrato se le llamará siempre Dulipo. Como se ofreciera al servicio doméstico, tuvo ocasión para un trato furtivo con Polimnesta. Como a ésta la quería dar su padre en matrimonio a Cleandro, un abogado que se la pedía con insistencia, el verdadero Eróstrato pide al esclavo Dulipo que se la pida a su vez, por eso de provocar una demora en las bodas. Entre los dos se entromete el parásito Pasífilo, que trabaja para uno y otro sin ser fiel a ninguno de los dos. Como hubiera necesidad de la autoridad de un padre para que el asunto se resolviera ventajosamente, Eróstrato persuade a un cierto sienés para que se finja el padre Filógono, a fin de que otorgue credibilidad a sus promesas ante Damón. Entre tanto en la casa se descubren las añagazas de Eróstrato con Polimnesta. Llega el padre de éste de improviso, que había venido de Sicilia para ver a su hijo, y se topa por casualidad con el falso Filógono. Se da cuenta de que aquél ha usurpado su propio nombre y todo lo demás; y sobre todo cuando descubre que su propio esclavo, Dulipo, no le reconoce, se queda confuso y admirado y se va a declararle el asunto al magistrado. Pide consejo al abogado Cleandro y de la conversación entre los dos descubre que Dulipo es el hijo de Cleandro. Éste lleva a Filógono a casa de Damón y, con su intervención, Polimnesta se casa con Eróstrato, el hijo de Filógono» (trad. de Cortijo, p. 111).

En él se explican los elementos principales que adoban la obra: el amor del protagonista Eróstrato por una doncella a la que su padre quería dar en matrimonio a otro; la suplantación de dos pares de personalidades que logra aquél (de su esclavo por él y de su padre por un vienés) para conseguirla; las circunstancias que ayudan a la anagnórisis final; y la celebración de la boda con la amada deseada.

A continuación sigue el texto repartido en 5 actos de 4, 3, 3, 5 y 7 escenas cada uno de ellos, cerrándose con el Valete final.

En el prólogo de 61 versos que precede al argumento Petreyo explica que el nombre de la obra se debe a las suplantaciones que se dan en ella, como solía ocurrir en las comedias latinas: 
Sic senex por sene et iunenis supponitur

Pro sui simili, unde et comoedia

Suppositorum appellata est nomine.

"Asi un viejo es suplantado por otro y un joven

por otro semejante a él, de donde también la comedia

se denomina con el nombre de los suplantados"

y a continuación intenta captarse la benevolencia del rector de la Universidad diciéndole que la ha compuesto en su honor para que, teniéndole de guía, «sirva para que goce la comunidad escolar: que se alegren los buenos, que se partan de risa las musas y de gracias la asamblea de los escolares»; y, amén de otras observaciones sobre la puesta en escena, le hace ver los dos propósitos básicos que ha procurado lograr en su composición, «la calidad del argumento y la pureza de la lengua», y los dos que intentarán conseguir también sus alumnos en el desarrollo de la acción (actio), «la pronunciación cuidada y la representación sin gestos exagerados».

Petreyo, pues, intentó dar a su traducción una finalidad marcadamente escolar, sacando así de su ambiente cortesano y palaciego habitual a la comedia erudita humanística representada por ésta y las otras tres obras aludidas, para implantarla en el ámbito universitario. De ahí que su propuesta supone «una avanzadilla teatral sin precedentes en el ámbito escolar, pues ni nadie había emprendido de manera tan sistemática la traducción de comedias cultas italianas, ni se había intentado el aupamiento del teatro vernáculo a una categoría superior mediante su traducción al latín» (Cortijo, p. 20).

El aspecto negativo sin embargo, como apunta Arróniz, es que, remontándose a la fuente original como hacían otros profesores de retórica, se alejaba del contacto con «un gran público que hubiera podido fecundar la experiencia con su aplauso» (p. 54) y privaba a sus obras de su influencia esperada en la orientación artística del teatro popular.

Respecto a la Chrysonia, lo único que nos queda es el prólogo. Está compuesto en 96 senarios yámbicos imitando a los del carmen IV, 1 de Catulo: Phasellus ille quem uidetis hospites, pero con ritmo acentuativo. Para Alvar (p. 212) es "lo mejor de toda su producción dramática». 


\section{Juan de Maldonado. Hispaniola, Eremitae y Geniale iudicium ${ }^{(77)}$.}

Juan de Maldonado nació en la aldea de Bonilla, Cuenca hacia 1465 y, tras estudiar Artes y Derecho en la Universidad de Salamanca, se afincó definitivamente en Burgos como mayordomo y capellan de la capilla de la Visitación de la Catedral. Protegido por D. Diego Osorio y relacionado con la nobleza y notables humanistas españoles y extranjeros, fue un erasmista decidido, replegándose luego a la ortodoxia de la Iglesia.

Entre sus múltiples obras escribió las dos arriba citadas que son las que aquí nos interesan.

\section{- La Hispaniola.}

Es una comedia en prosa latina que consta de 5 actos, con 4, 3, 11, 7 y 7 escenas respectivamente.

Por las amplias informaciones que nos da en las piezas preliminares, Saludo al lector, Dedicatoria a D. Diego Osorio y Prólogo, conocemos bien las circunstancias en que fue compuesta, el modelo y la finalidad de la obra y la representación.

El autor la calificaba de lusus o juego y, en efecto, se trata de una farsa inspirada en Plauto, que por su asunto se asemeja bastante a las comedias italianas del siglo XV que satirizaban la incontinencia del clero. Los toques de color local y la caracterización regional de los personajes traen a la memoria la Serafina y la Tinelaria de Torres Naharro.

La compuso en el castillo de Vallegera, durante el ocio que se vio forzado a guardar mientras la peste se ensañaba en Burgos, en el invierno de 1519-1520. Copiada por escolares, reimpresa y difundida sin la intervención del autor, se representó en la corte de Portugal, probablemente en los palacios de Lisboa, ante la reina de Portugal doña Leonor y el consejo del rey D. Manuel en 1521.

(77) Cf. Briesemeister, "Das Mittel-», p. 12-13; Menéndez Peláez, "El teatro escolar», p. 589. 
A pesar de su escasa ejemplaridad y su desenfado, fue utilizada para libro de estudiantes, al que Maldonado, para facilitar la lectura y el aprendizaje de latín, puso escolios y notas en la tercera impresión( ${ }^{(78)}$.

El argumento es como sigue:

Philocondus quam deperit Christiolam Trili astu alloquitur; parasiti technis eadem potitur. Quod cum rescivit Alilpus, cui pater peregre agenti parvulam desponderat Milio, adulterii laesaeque nobilitatis apud regem Philocondum postulavit. Dies certamini constituitur. Verum, re composita per reginam atque transacta, Alilpus Damianam, Philocondi sororem, duxit uxorem, Philocondus suam habuit expetitam Christiolam.

"Filocondo habla con Cristiola, de la que está perdidamente enamorado, con la astucia de Trilo; con los tejemanejes de un parásito la hace suya. Cuando se entera de esto Alilpo, a quien Milión, el padre, la había prometido de pequeña, aunque vivía aquél en el extranjero, acusó a Filocondo de adulterio y de la mancilla de su honra ante el rey. Se fija el día del duelo. Pero, arreglada la cuestión por medio de la reina, y resuelta, Alilpo se casa con Damiana hermana de Filocondo, y Filocondo logra a su amada Cristiola».

Intervienen en ella más de veinte personajes: además de los protagonistas Filocondo, Cristiola, su madre y sus sirvientas, y los antagonistas Alilpo, su padre y Damiana, hermana de Cristiola, otros secundarios, como una serie de criados que vienen a ser como representantes de las diversas regiones de Castilla. La población mora está personificada en la criada Mora. Vándalo representa el criado andaluz, severo y responsable. Cántabro y Trilo a los vascos y navarros, con una filosofía popular acomodaticia, y otros; y al margen de la trama, un fraile que aparece en divertidas escenas, víctima

(78) Es una síntesis parafraseada de Asensio, E. y Alcina Rovira, J. F., "Paraenesis ad litteras" Juan de Maldonado y el Humanismo español en tiempos de Carlos V, Madrid, 1980, p. 28. Para más detalle véase la amplia introducción de Durán Ramas, Ma Ángeles (ed.), Juan de Maldonado, Hispaniola-La Española, Barcelona, 1983, en la que estudia el contexto renacentista en que se desarrolla la obra, el autor y sus circuntancias, y los componentes básicos de la comedia: título, argumento, personajes, composición y precedentes y estilo; y para las características de su estilo narrativo, Prieto, A., La prosa española del siglo XVI, Cátedra, 1986, pp. 342-349. 
de la perfidia del parásito y del propio Maldonado, al ironizar sobre sus pacatas costumbres y frailunas (rezo del rosario, etc.).

\section{- Los Eremitae ${ }^{(79)}$.}

La obra está constituida por un conjunto de diálogos que se desarrollan sucesivamente en el entorno de una especie de locus amoenus que sirve de escenario: primero dialogan entre sí tres ermitaños llamados Alonso, Alvaro y Alfonso. Al margen de ellos y sin hablarlos pasan y dialogan otras tres parejas de personajes secundarios: Rebolledo y Adolfo, un cazador y un prevendado; Lupino y Vulpeyo, un mercader y un porquero; y Gelasio y Flora, un viejo verde y una doncella que provocan escenas graciosas.

En él se entrecruzan distintos elementos cómicos, como la broma que el primer ermitaño Alfonso gasta a su amigo Álvaro al fingir que no lo conoce en el encuentro inicial; la indignación de los ermitaños ante el desprecio de la primera pareja (Rebolledo y Rodolfo) y la breve escena que sucede ante los ojos de los ermitaños (muy próxima al estilo del teatro escolar renacentista), en la que el viejo Gelasio intenta seducir a la joven Flora.

Bataillón definió la obra como «una pequeña comedia en un acto y varias escenas» ${ }^{(80)}$; pero a Peinador le parece la definición demasiado estricta. "La comedia», dice, "es una cosa y el diálogo humanístico otra. Lo que pasa a los personajes en el relato de sus vidas pertenece al campo de la narración; lo que les sucede en el breve período de su encuentro y conversaciones (lo que abarca el marco) no posee entidad suficiente como para convertirse en la trama de una comedia. Es tan sólo un escenario dialogístico perfectamente construido» (p. 45).

(79) Impreso junto a la Linguae latinae exercitatio de Vives, Estella, Adrian de Anvers, ca. 1550? Biblioteca Nacional de Madrid, Ms. R / 7935. Véase Peinador Marín, Luis Jesús, "Apuntes sobre la edición de un texto en latín del siglo XVI: los 'Eremitae' de Juan de Maldonado". Actas del II Seminario Internacional de edición y anotación de textos del Siglo de Oro" (Univ. De Navarra), Madrid, 1991; y su profundo estudio y edición en «Un diálogo del siglo XVI español: 'Eremitae', de Juan de Maldonado”, Criticón, 53, (1991), pp. 41-90.

(80) Bataillon, M., Erasmo y España, México-Madrid-Buenos Aires, F.C.E., 1983, p. 647. 
- El Geniale iudicium, sive Bacchanalia(81).

Es un coloquio escolar en el que se describe la lucha alegórica entre Ingluvies y Continentia, a caballo entre los ejercicios escolares y el drama humanístico ${ }^{(82)}$.

Juan de Valencia. Nineusis y Prodigi Filii Comoedia ${ }^{(83)}$.

El humanista Juan de Valencia, de Loja (Granada), racionero de la catedral de Málaga, escribió entre otras obras, estas dos piezas de Teatro: ${ }^{(84)}$, compuestas las dos siguiendo rigurosamente la ley de los cinco actos propuesta por Horacio, precedidas en cada uno de ellos por sus respectivas praecantiones en cuartetas.

El argumento de Nineusis es la parábola del pobre Lázaro y el rico avariento. Se trata de una pieza típica de teatro escolar por su mezcla del tema, bíblico, clásico y alegórico, y del uso del latín y el castellano, en la que los personajes más importantes se expresan en latín y los secundarios en castellano o en latín macarrónico (García Soriano,14-15).

La Comedia Prodigi Filii consta de 5 actos, con sus respectivas praecantiones y 9, 5, 3, 1 y 2 escenas en cada uno de ellos. El tema es la narración bíblica completa de la parábola del hijo pródigo en lenguaje del siglo XVI imitando a los cómicos romanos, pero adaptándola al ambiente de su época.

Los personajes son los consabidos de la parábola del hijo pródigo, el padre (Erasthius), los dos hijos (Pandochius, el menor, y Philoponus, el mayor) y

(81) Fue editado en Burgos en 1549 en la obra miscelánea Opuscula quaedam docta simul et elegantia y por separado con un pequeño discurso en Geniale iudicium, sive Bacchanalia et oratiunculam dictam in Bacchanalibus, también en 1549, cf. Durán Ramas, Juan de Maldonado, p. 47.

(82) Cf., Briesemeister, "Das Mitell-» p. 13 y nota 33.

(83) Cf. García Soriano, El teatro, pp. 14-15 y nota, 3.; Briesemeister, "Das Mittel-», 18; y López de Toro, J., "Juan de Valencia, escenificador latino de la Biblia", en Homenaje Fichter, Madrid, 1971, pp. 479-503, con la edición de la Comedia Prodigi filii, pp. 490-503.

(84) Nineusis. Comoedia de diuite Epulone... "Comedia latino-hispanica. Imitación de Terencio», según Paz y Meliá, Catálogo, Madrid, 1934, núm, 4468; y Prodigi Filii Comoedia. 
el capataz de porqueros (Centro), a los que se añaden un adulador (Lycus), dos criados del padre (Dromo y Dora) y uno del hijo menor (Sosia).

La pieza, concluye López Toro, es «un elocuente ejemplo de cómo Juan de Valencia adaptaba la parábola bíblica a las necesidades del teatro del siglo XVI con tal acierto y gracia que, si hoy estuviera en boga el teatro escolar, su representación sería un éxito indudable» (p. 503).

En un artículo de 1995 estudié la diferencia que existe en la dramatización del tercer momento de la parábola del hijo pródigo - el correspondiente a su vida lujuriosa y pródiga reflejada en la frase de los versículos 13-14 del evangelio de San Lucas: ibi dissipauit sustantiam suam uiuendo luxuriose - entre las comedias en castellano, los modelos del teatro jesuítico (Asotus y Acolastus) y las obras latinas de colegio de jesuitas y esta humanística(85). En él mostré que, como cabía esperar, el tema amoroso se desarrolla más en las comedias en castellano que en las otras, en las que se prefiere la dramatización del tema rufianesco del despilfarro y la expoliación del pródigo; pero hice notar también cómo, en el desarrollo que se hace del tema amoroso en las latinas, en contra de los esperado, el jesuita Barcelo es más atrevido en su comedia que el humanista Juan de Valencia en ésta suya.

\section{Cuadro resumen}

\begin{tabular}{l|l|c|l|l}
\hline \multicolumn{1}{c|}{ Autor } & \multicolumn{1}{c|}{ Título } & Fecha $\mathrm{i} / \mathrm{r}^{(*)}$ & \multicolumn{1}{c}{ Lugar } & \multicolumn{1}{c}{ Género } \\
\hline Antonio Geraldini & Carmen bucolicum & $1485 \mathrm{i}$ & Roma & Égloga \\
\hline \multirow{2}{*}{ Hércules Floro } & Tragedia Galathea & $1502 \mathrm{i}$ & Barcelona & Tragedia \\
\cline { 2 - 5 } & Comedia Zaphyra & $1502 \mathrm{i}$ & Barcelona & Comedia \\
\hline \multirow{2}{*}{ Joan Parteni Tovar } & $\begin{array}{l}\text { Amor et pudicitiae } \\
\text { Pimenimachon }\end{array}$ & $1503 \mathrm{i}$ & Valencia & Égloga \\
\cline { 2 - 6 } & $\begin{array}{l}\text { Contemplatiuae } \\
\text { uitae Dimachon }\end{array}$ & $1503 \mathrm{i}$ & “ " & " " \\
\hline
\end{tabular}

(*) $\mathrm{i}=$ impresión; $\mathbf{r}$ = representación.

(85) Picón García, V., "El tema del Hijo Pródigo en la dramática del s. XVI en España”, Voz y Letra 6,1 (1995-1997), pp. 73-87. 


\section{Cuadro resumen - Continuación}

\begin{tabular}{|c|c|c|c|c|}
\hline Autor & Título & Fecha i/r ${ }^{(*)}$ & Lugar & Género \\
\hline Juan Bautista Anyés & $\begin{array}{l}\text { Egloga in natiuitate } \\
\text { Christi }\end{array}$ & $\begin{array}{l}\text { c. } 1513 \mathrm{r} \\
1527 \mathrm{i}\end{array}$ & Valencia & Égloga \\
\hline \multirow[b]{2}{*}{$\begin{array}{l}\text { Fray Bartolomé } \\
\text { de Sorió }\end{array}$} & $\begin{array}{l}\text { Colloquium Romani } \\
\text { Paschini, et Valentini } \\
\text { Gonnari }\end{array}$ & $i$ & $i$ & Diálogo \\
\hline & $\begin{array}{l}\text { Oratio litteralis fratris } \\
\text { B[althasaris] Sorio in } \\
\text { christi natiuitate } \\
\text { sanctissima in } \\
\text { conuentu sancti } \\
\text { mathei per quosdam } \\
\text { discipulos recitata }\end{array}$ & c. $1513 \mathrm{r}$ & $\begin{array}{l}\text { San Mateo } \\
\text { (Castellón)? }\end{array}$ & $\begin{array}{l}\text { Sermón } \\
\text { representado }\end{array}$ \\
\hline Juan Angel González & $\begin{array}{l}\text { Perlepidum } \\
\text { Colloquium in } \\
\text { agendum Publii } \\
\text { Terentii Latinissimam } \\
\text { Eunuchum publice } \\
\text { recitatum }\end{array}$ & 1527 & Valência & Diálogo \\
\hline Jaume Romanya & $\begin{array}{l}\text { Noua Tragicomedia } \\
\text { Gastrimargus }\end{array}$ & $1562 \mathrm{r} ?$ & Mallorca & Comedia \\
\hline $\begin{array}{l}\text { Balaguer, Francesc } \\
\text { Satorras }\end{array}$ & Delphinus & $1543 r / 1542 r$ & Perpiñán & Tragicomedia \\
\hline Jaume Cassià & $\begin{array}{l}\text { Sylua de uita et } \\
\text { moribus }\end{array}$ & 1576 & Barcelona & Comedia \\
\hline Juan Cassador & Comoedia Claudius & 1573 & $i$ & Comedia \\
\hline Pedro Sunyer & $\begin{array}{l}\text { Terra, dialogus in } \\
\text { Galiam puerorum }\end{array}$ & 1574 & Barcelona & Diálogo \\
\hline \multirow[b]{2}{*}{ Palmireno } & Dialogus & $1562 \mathrm{r}$ & Valenci & Diálogo \\
\hline & $\begin{array}{l}\text { Sigonia }(1563 r), \\
\text { Thalassina }(1564 r), \\
\text { Octavia }(1564 r), \\
\text { Lobenia }(1566 r), \\
\text { Thebiana }(1567 r), \\
\text { Fabula Aenaria } \\
(1574 r)\end{array}$ & $1563-1574$ & " " & $\begin{array}{c}\text { Comedia } \\
i\end{array}$ \\
\hline $\begin{array}{l}\text { Diego Ramírez de } \\
\text { Villaescusa }\end{array}$ & $\begin{array}{l}\text { Dialogi quatuor super } \\
\text { suspicato Joannis } \\
\text { Hispaniarum Principis } \\
\text { emortuali die }\end{array}$ & $1498 \mathrm{i}$ & Amberes & Diálogo \\
\hline
\end{tabular}

(*) $\mathbf{i}$ = impresión; $\mathbf{r}=$ representación. 


\section{Cuadro resumen - Continuación}

\begin{tabular}{|c|c|c|c|c|}
\hline Auto & Título & Fecha $\mathrm{i} / \mathrm{r}^{(*)}$ & Lugar & Género \\
\hline $\begin{array}{l}\text { Bachiller de la } \\
\text { Pradilla }\end{array}$ & $\begin{array}{l}\text { In laudem } \\
\text { Calagurrita } \\
\text { Episcopi de suo in } \\
\text { episcopatu aduentu } \\
\text { Aegloga }\end{array}$ & 1499 & Pamplona & Égloga \\
\hline \multirow{2}{*}{ Mal-Lara } & $\begin{array}{l}\text { Comedia Locusta } \\
\text { (latín y castellano) }\end{array}$ & 1548 & Salamanca & Comedia \\
\hline & $\begin{array}{l}\text { Absalon? } \\
\text { Otras? }\end{array}$ & 1548 & " " & Tragedia \\
\hline \multirow[b]{2}{*}{$\begin{array}{l}\text { Sánchez de las } \\
\text { Brozas }\end{array}$} & Apollinis Fabula & 1859 & Salamanca? & Mezcla géneros \\
\hline & $\begin{array}{l}\text { Calirrboe (1560), } \\
\text { Achilles inventus } \\
\text { (1566), } \\
\text { Asuerro (1566?), } \\
\text { Bethsabee/Bersabé } \\
\text { (1568), Trepidaria, } \\
\text { David? }\end{array}$ & & Salamanca & $\begin{array}{l}\text { Comedia } \\
\text { Tragedia }\end{array}$ \\
\hline $\begin{array}{l}\text { Bartolomé } \\
\text { Barrientos }\end{array}$ & $\begin{array}{l}\text { De Illiberitanorum } \\
\text { maurorum seditione }\end{array}$ & $1568-1569$ & Salamanca & Tragedia \\
\hline Maestro Vanegas & Tragedia Iudit & 1569 & Salamanca & " " \\
\hline \multirow{3}{*}{ Juan Pérez (Petreius) } & $\begin{array}{l}\text { Ate religata et } \\
\text { Minerva restituta }\end{array}$ & & Alcalá & Diálogo \\
\hline & $\begin{array}{l}\text { Comediae quattuor: } \\
\text { Necromamticus, } \\
\text { Lena, Suppositi, } \\
\text { Decepti }\end{array}$ & $1574 \mathrm{i}$ & Alcalá & \\
\hline & $\begin{array}{l}\text { Chrysonia comedia } \\
\text { ex apuleii Asinii } \\
\text { aureo in dramatis } \\
\text { forma redacta }\end{array}$ & & & \\
\hline \multirow{3}{*}{ Juan de Maldonado } & Hispaniola & $\begin{array}{l}1521 \mathrm{r} \\
1535^{3} \mathrm{i}\end{array}$ & $\begin{array}{l}\text { Lisboa } \\
\text { Burgos }\end{array}$ & Comedia \\
\hline & Eremitae & $1550 \mathrm{i}$ & Estella & Diálogo \\
\hline & $\begin{array}{l}\text { Geniale iudicium, } \\
\text { sive Bacchanalia }\end{array}$ & 1549 & Burgos & Diálogo \\
\hline \multirow{2}{*}{ Juan de Valencia } & $\begin{array}{l}\text { Nineusis. Comoedia } \\
\text { de divite Epulone }\end{array}$ & $i$ & $i$ & Tragicomedia \\
\hline & $\begin{array}{l}\text { Filii prodigis } \\
\text { Comoedia }\end{array}$ & $i$ & $i$ & Comedia \\
\hline
\end{tabular}




\section{VI - El teatro escolar jesuítico}

Una fuente imprescindible para el conocimiento del teatro neolatino en España en el siglo XVI es el teatro escolar jesuítico, que por su entidad merece un amplio y detallado tratamiento imposible de ofrecer aquí, por razones obvias. De ahí que me haya tenido que limitar a recoger algunos de sus rasgos más característicos, como los siguientes: su diferencia con el teatro universitario, su concepción, su reglamentación y la dimensión y carácter de su producción, teniendo en cuenta el vehículo de su expresión(86).

Se le puede considerar una derivación del teatro escolar universitario que hemos visto que se promovía en la Universidad por los humanistas. Comprendido el valor pedagógico que el estudio del teatro clásico de Plauto y Terencio, sobre todo, y su práctica poseía para el aprendizaje del latín, algunos de los primeros padres de la orden educados en la Universidad, aunque con la oposición inicial de S. Ignacio, propusieron introducirlo en sus colegios y lo lograron bien pronto.

\section{Diferencia entre el teatro escolar universitario y el jesuítico}

Entre este teatro y el teatro escolar de tipo humanístico las líneas a veces no son muy precisas; pero hay varios rasgos que los diferencian claramente, entre los que hay que destacar los siguientes:

(86) Para una visión general de este teatro deben consultarse los estudios citados de García Soriano, El teatro; Briesemeister, "Das Mittell-», pp. 19-29; Menéndez Peláez, "El teatro escolar», pp. 591-606, a los que hay que añadir los de González Gutiérrez, C., "El teatro de los jesuitas en la Edad de Oro I y II», Cuadernos para la investigación de la literatura hispánica, 18 (1993), pp. 7-148 y 19 (1994), pp. 7-126; Alonso Asenjo, J., La tragedia de S. Hermenegildo y otras obras del Teatro Español de Colegio, Universitat de Valènce, 1995, especialmente pp. 1-81 y 87-212; y Menéndez Peláez, J., Los jesuitas y el teatro en el Siglo de Oro, Oviedo, Universidad, 1995; y "El teatro jesuítico: sistema y técnicas escénicas. Las raíces del teatro de Calderón de la Barca", en Calderón: sistema dramático y técnicas escénicas. Actas de las XXIII Jornadas de teatro clásico Almagro XXIII, 2001, pp. 33-76; y Picón, V. (Coord.), A. Cascón, P. Flores, C. Gallardo, A. Sierra y E. Torrego, Teatro escolar latino del s. XVI: La obra dramática de Pedro Pablo Acevedo S.I. I: Lucifer Furens, Occasio, Philautus, Charopus, Madrid, Ediciones Clásicas, 1997, pp. 7-41. 
El teatro humanístico y escolar universitario es fundamentalmente didáctico: con él se pretendía incitar al conocimiento del latín y de la retórica y su contenido se hallaba teñido del moralismo característico del humanismo. Comparte con el jesuítico el uso de latín como vehículo lingüístico de comunicación y de expresión en la elaboración de las piezas dramáticas, y provoca, como ha señalado Asenjo para aquél, un vivero de dramaturgos y de actores ${ }^{(87)}$.

Pues bien, el teatro jesuítico recoge esa finalidad didáctica del universitario preocupado por el aprendizaje del latín, aunque eliminando en gran medida el recurso al humor y la risa, pero añade otra más importante de carácter religioso: utilizarlo como instrumento para educar a los espectadores (niños y padres que acuden a las representaciones) en los aspectos más importantes de la doctrina y de la moral cristiana(88), además de la teología dogmática y catequética.

Hay otra diferencia de gran calado entre ambos teatros: el teatro escolar universitario «desde el principio del siglo XVI venía haciéndose en las aulas por influencia indudable de la atención filológica a los autores latinos», algo que no ocurría en el jesuítico. Éste «mira hacia delante, el universitario hacia el pasado. El interés de las representaciones humanísticas en Alcalá y Salamanca es casi arqueológico, si se le compara con el desaliñado teatro de la compañía, de dramaturgos a veces mediocres, pero que deseaban hacer de sus comedias algo lleno de vida y de actualidad"(89).

El jesuítico intenta conjugar la educación del pasado con el desarrollo de unos contenidos más apropiados para vivir la vida presente y futura del cristiano.

(87) Cf. Alonso Asenjo, "Panorama”, donde en las pp. 178-188 señala los cuatro rasgos que considera que caracterizan al teatro escolar humanístico: respecto al vehículo lingüístico, el uso del griego, latín, romance, verso, prosa, latín-romance y romance; la formación moral, atendiendo al mouere "conmover o mover a actuar»; la atención al delectare, para suscitar el humor y la risa; y hacer de esta actividad teatral un vivero de dramaturgos y de actores.

(88) Sobre esta impronta moralizante y la búsqueda del realismo social, cf. Menéndez Peláez, Los jesuitas, pp. 91-93.

(89) Arróniz, La influencia, pp. 27 y 30. 
Atendiendo a los principios clásicos que la poética y la retórica proponían para la composición de las obras literarias, los jesuitas prefieren o priman otros distintos que los humanistas: del prodesse o delectare o de las dos cosas a la vez que proponía Horacio para la poesía, los humanistas ponían un especial interés en el delectare, para lo cual exigían dotar a la obra de un estilo cuidado componiendo el texto con una elocutio más pulcra; a los jesuitas, en cambio, les importaba más el prodesse, es decir, la búsqueda de lo serio y lo útil por encima de la risa y la belleza.

Acevedo precisa muy bien estas ideas en el prólogo del Philautus:

«El grande observador $<$ de $>$ aquesta arte

no me diga: 'aquí faltó el decoro,

mejor estotro fuera bien entiendo:

faltar en mucho y no llegar

con muchas partes al decoro antiguo'.

Mas túvose atención más al provecho

poniéndolo delante de los ojos,

que no al arte servir curiosamente» (Philautus, 105-112) ${ }^{(90)}$.

Y del docere, delectare y movere que proponían los retóricos para la prosa, especialmente para el discurso, los jesuitas preferían para el teatro, que concebían también como un sermón disfrazado, el docere, y el mouere al delectare ${ }^{(91)}$.

\section{Concepción jesuítica del teatro}

La estética barroca, alentada sin duda por la educación jesuítica, vio en el mundo un inmenso teatro en el que se representa la comedia de la vida. Esa idea la expresó plásticamente J. B. Weinix en el retrato que hizo

(90) Cascón-Picón, en Picón, V. (Coord.), Teatro escolar latino, p. 332.

(91) Así se decía en estas líneas de la semblanza de Acevedo „...trocó los teatros en púlpitos, y despidió a sus hombres de sus representaciones más corregidos y más contritos que los excelentes predicadores de sus sermones...». Para más detalle, véase Gallardo, C., "El teatro como predicación: la homilética del P. P. Pablo de Acevedo", Edad de Oro 16 (1997), pp. 161-170. 
a Descartes en el 1647, en la que se lee mundus est fabula. No sabemos si lo hizo o no con su consentimiento, pero el lema refleja, como en ningún otro lugar, el concepto del filósofo de la vida(92), y es congruente con la concepción dramática que imprimió a su obra filosófica(93).

Esto un filósofo. Pero también un dramaturgo como Calderón, educado asimismo en los jesuitas, defiende en El gran teatro del mundo - comedia filosófica que incide sobre la existencia humana —, que la vida no es más que una representación teatral.

Los jesuitas comparten, pues, esa concepción del mundo como un teatro con la de la comedia como imitación de la vida.

Así, Acevedo concibe la comedia Charopus como una imitación y un espejo de la vida social que refleja en ella, al dramatizar los problemas del trío de personajes que sostienen la acción, padre, hijos y esclavos, como las comedias plautinas. Con ello conjuga las dos concepciones clásicas que se mantuvieron sobre la comedia: la de Diomedes (atribuida a Suetonio), que la definía como una conjunción o comprensión de la vida privada y del azar civil»(94), con la de Cicerón que la definió como «imitación de la vida, espejo de la costumbre e imagen de la verdad»(95):
«Ser de la vida humana una imitación
y un espejo do se ve lo que pasa
y una imagen que la verdad bien representa
dixo un sabio definirse lo que nos
comedia, aunque es griega la vox, llamamos.

(92) Cf. García Hernández, B., "Literatura y filosofía. De la inspiración entusiástica de Descartes en Plauto", Silva 2 (2003), pp. 61-80, esp. 63-64.

(93) En esta idea se basa la tesis defendida por el mismo profesor García Hernández, en su estudio Descartes y Plauto, Tecnos, 1997, de que el sistema filosófico cartesiano está inspirado y asentado sobre el argumento del Anfitrión de Plauto.

(94) Comoedia est priuatae uitae ciuilisque fortunae sine periculo comprebensio, cf. Reifferscheid, A., C. Suetonius Tranquillus praeter Caesarum reliquiae, Hildesheim-New York, 1971, p. 7.

(95) Comoediam esse Cicero ait imitationem vitae, speculum consuetudinis, imagenem varitatis, Apud Donatum, Excerpta de comoediae, 5,1. 
Y si esto es ansí, mire cada cual

de todo lo que aquí representaren

qué es lo que le toca...

mas su estudio todo sea conferir

la forma de su vida con la imagen

de aquesta acción... (Charopus, 62-69) ${ }^{(96)}$.

Pero el dramaturgo da un paso más que el filósofo e introduce otra concepción más profunda de la comedia considerándola como un reflejo de la vida interior del hombre y de la batalla que éste libra en ella, como se constata en la trama y la acción de su comedia Bellum y uirtutum et uitiorum(97).

\section{Reglamentación de las representaciones}

Conscientes, pues, de la importancia del teatro para poner ante los ojos de los jóvenes distintos aspectos de la vida humana en su vertiente social e interior y formarlos en la teología y moral cristiana, los jesuitas promueven desde muy pronto las representaciones teatrales en los colegios que se multiplican rápidamente en España, Europa y, más tarde, en ultramar, y las regulan en la Ratio atque institutio studiorum, que proponía la normativa que debía regir los estudios de los colegios de jesuitas.

El embrión de este ordenamiento educativo se halla ya en la Parte Cuarta de las Constituciones de Ignacio de Loyola, de 1556, a partir del cual cada colegio fue desarrollando sus propias normas particulares, hasta que se creó una comisión para recopilar y unificar la normativa existente.

En 1586 se dio la primera redacción que se revisó y modificó en 1591. En ellas se promovía el estudio de la comedia y de la tragedia, se fomentaba la actividad teatral como un complemento importante para la formación de los alumnos y se establecían la frecuencia de las representaciones y ciertas condiciones para realizarlas con decoro.

(96) Gallardo-Flores, en Picón, V. (Coord.), Teatro escolar latino, pp. 449-450.

(97) Cf. Picón García, V., "La Comedia Bellum virtutum et vitiorum de Pedro Pablo de Acevedo: originalidad de su dramatización”, Excerpta philologica 7-8 (1997-1998), pp. 211-222. 
En 1599 se publicó la Ratio studiorum de 1599, en la que, además de insistirse en las condiciones ya propuestas en las anteriores redacciones, se fijaron definitivamente otras nuevas. Así en el apartado 13 de las Reglas del Rector se establecen estas cinco normas: la lengua a emplear en las representaciones, la frecuencia de éstas, el carácter del tema y la prohibición de introducir en ellas nada que no estuviera en latín o no fuera decoroso, ni persona alguna o vestido de mujer:

Tragoediae et comoediae - 13. Tragoediarum et comoediarum, quas non nisi latinas ac rarissimas esse oportet, argumentum sacrum sit ac pium; neque quicquam actibus interponatur, quod non latinum sit et decorum, nec persona ulla muliebris vel habitus introducatur ${ }^{(98)}$.

Evidentemente, estas normativas no se practicaron ni antes ni después de 1581 y 1599 en todos los colegios con la rigidez establecida, salvo quizá la relativa a las mujeres. La transgresión es particularmente importante respecto al uso de la lengua y la frecuencia de las representaciones.

\section{La producción teatral}

Las representaciones se multiplicaron al multiplicarse las ocasiones que se presentaban para ello, como las que ofrecían las fiestas principales del calendario litúrgico (Corpus, santos importantes de la Compañía, patronos de los colegios, etc.), las fiestas del calendario escolar (inicio y final de curso, actos académicos solemnes, etc.), y los acontecimientos excepcionales ocurridos en el colegio o en la ciudad respectiva (visita de personalidades ${ }^{(99)}$, inauguraciones, etc.) $)^{(100)}$.

(98) Cf. Gil, E. (ed.) et alli, La pedagogía de los jesuitas, ayer y boy, Comillas, Madrid, 1999, especialmente, pp. $40-47$ y 82.

(99) Una quizá de las más típicas de las producidas en este subgénero es la titulada In aduentu Regis que compuso del P. Acevedo para celebrar la visita de Felipe II a Sevilla con ocasión de la guerra de las Alpujarras, cf. Picón García, V., "La comedia? Desiderius de P. P. de Acevedo en honor de Felipe II: historia y alegoría", en Ana $\mathrm{M}^{\mathrm{a}}$. Aldama, et alii, La filología latina hoy. Actualización y perspectivas, Madrid, 1999, pp. 1217-1230.

(100) Véase el apartado “Un calendario académico y litúrgico» en Menéndez Peláez, Los jesuitas, pp. 89-91. 
Por ello, la producción de obras fue muy grande ${ }^{(101)}$. Para España y Portugal se ha cifrado nada menos que en varios miles, aunque se ha perdido la mayoría, por el poco aprecio que se mostraba por el texto, que salvo en contadas ocasiones no solía editarse, y por los avatares que sufrió la Compañía de Jesús después de su disolución.

No obstante, conservamos más de un centenar de piezas completas, aunque sólo se ha editado un escaso número de ellas(102), y conocemos los títulos y el argumento de otras muchas.

\section{Del neo-latín al castellano}

La lengua propia en que deberían haberse compuesto todas ellas, como ordenaba la Ratio, era el latín. Y el latín predomina en un buen número, de manera que en este sentido el teatro jesuítico es también un teatro neo-latino. Como en muchos casos los asistentes no entendían las que se representaban en latín o con partes importantes en esta lengua, para hacerlas más comprensibles, se anteponía un prólogo en romance, o se hacía un prólogo bilingüe, con dos intérpretes. Pero este procedimiento fue sólo un compromiso, pues la presión de la lengua vernacular hará que la composición evolucione progresivamente: de hacerse en latín sólo o casi sólo, a hacerse en latín con algunas partes en castellano, en latín y castellano de forma más o menos equilibrada, en castellano con partes en latín y en castellano sólo, incluso insertándose fragmentos en otras lenguas romances, como el gallego y el italiano, o en jergas locales.

De las más salientes por su carácter neo-latino, en mayor o menor proporción, se pueden destacar, entre otras, las de los Padres Acevedo, José, Bonifacio, Barçalo (Barceló), Venegas - español de nacimiento - y las

(101) Véase la nómina que dan García Soriano, El teatro, pp. 232-315; Alonso Asenjo, La tragedia, pp. 54-67; Menéndez Peláez, Los Jesuitas, pp. 441-446).

(102) Cf. Alonso Alonso, J., "Un lustro de ediciones de teatro escolar jesuítico del Siglo de Oro", Diablo texto 4/5 (1997/98), pp. 417-446. 
del códice atribuido a Martín de Roa(103) que ofrezco a continuación, y algunas más, anónimas:

De Pedro Pablo de Acevedo (1522-1573) (RAH 383 ms. 9/2564): In bonorem divae Catherinae [Egloga]; Comedia Metanea; Dialogus M.B.P.C.D. de Iesu nomine; Comedia habita Hispali in festo corporis Christi; Tragedia Lucifer furens in diem Circumcisionis Domini; Actio feriis Solemn. Corporis Christi; Dialogus Feriis Solemnibus Corporis Christi; Comedia occasio acta Hispali anno 1564 [San Lucas]; Comedia Philautus; Comedia Caropus; Athanasia; In aduentu comitis Montis Acutani; Ad distribuenda praemia certaminis litterarii; Oratio in principio studiorum; Dialogus <in> initio studiorum. Ante orationem in comendatione scientiarum; In aduentu regis;

(103) Para Acevedo, véase los estudios de Roux Lucette, E., "Cent ans d'expérience théatrale dans les colleges de la Compagnie de Jésus en Espagne», in Dramaturgie et Société. Rapports entre l'oeuvre théâtrale, son interprétation et son public au XVle et XVIIe siecles, Paris 1968, t. 2, pp. 479-523; Saa, Orlando E., El teatro escolar de los jesuitas en España. La obra dramática de Pedro Pablo de Acevedo, New Bronswick, Slusa,1990); la edición de cuatro de sus obras, Lucifer Furens, Occasio, Philautus y Charopus, en Picón, V. (Coord.), A. Cascón, P. Flores, C. Gallardo, A. Sierra y E. Torrego, Teatro escolar latino..., y los numerosos trabajos realizados hasta ese año por los miembros de este equipo sobre distintos aspectos de la su obra constatados en las pp. 30-31, nota 75, y otros posteriores; la edición de la Metanea en la obra citada de Alonso Asenjo, "La tragedia de S. Hermenegildo» y la tesis de Domingo Mallvadi, A., La producción escénica de Acevedo. Un capítulo en la pedagogía del latín en La Compañía de Jesús, Salamanca, colección «Victor», núm. 69, 2001. **** Para el Padre José, García Soriano, El teatro, pp. 81-83. *** Para el Padre Bonifacio, la transcripción del Códice de Villagarcía de González Gutiérrez, C., El Códice de Villagarcía del P. Juan Bonifacio, Madrid, UNED, 2000; y los trabajos de Gallardo, C., "La Nabalis Carmelitidis de Juan Bonifacio y el sabor de los clásicos», en J.M Maestre Maestre, J. Pascual Barea, L. Charlo Brea (eds.) Humanismo y pervivencia del mundo clásico. Homenaje al Profesor Antonio Fontán, III, 2, Alcañiz-Madrid, 2002, pp. 1201-1223; Flores Santamaría, P., "Teatro escolar latino del s. XVI: la Comoedia quae inscribitur Margarita del padre Juan Bonifación, en J.Ma Maestre Maestre, J. Pascual Barea, L. Charlo Brea (eds.) Humanismo y pervivencia del mundo clásico. Homenaje al Profesor Antonio Fontán, III,2, Alcañiz-Madrid, 2002, pp. 1179-1186. **** Para Barceló, Picón García, V., "Tradición del teatro escolar latino del s. XVI: La Comedia Prodigi fili de Guillermo Barcelón, en J.M Maestre Maestre, J. Pascual Barea, L. Charlo Brea (eds.) Humanismo y pervivencia del mundo clásico. Homenaje al Profesor Antonio Fontán, III,2, Alcañiz-Madrid, 2002, pp. 1235-1248; Sierra de Cózar, A., "El teatro escolar latino en el Colegio de Montesión (Palma de Mallorca) I: historia y documentos", en M. del C. Bosch -M. A. Fornés (eds.), Homenatge a Miquel Dolç, Palma de Mallorca, 1997, pp. 623-626. *** Para Miguel Venegas, Frèches, C.-H., Le théâtre (nota 2), pp. 175-239; Griffin, N., "Miguel Venegas and the sixteenth-century jesuit school drama", Modern language Review 68 (1973), pp. 796-780; y Two Jesuit Ahab Dramas: M. Venegas, Tragoedia cui nomen inditum Achabus and Anonymous, Tragedia Jezabelis, Exeter, Univ. de Exeter, 1976; Miranda, M., "Teatro bíblico novilatino: A Tragédia de Acab de Miguel Venegas", Humanitas 46 (1994), pp. 351-371; y "Música para o Teatro Humanístico em Portugal», Humanitas 55 (2003), pp. 315-339. *** Y para Martín de Roa, Molina Sánchez, M., «El teatro de los jesuitas en la provincia de Andalucía: nuevos datos para su estudio", J. Mª. Maestre Maestre, J. Pascual Barea, Humanismo y pervivencia del mundo cláscio I, 2, Cádiz, 1993, pp. 643-654. 
Dialogus in principo studiorum; In aduentu Hispalensis Praesulis D. Christop. Roxeo ac Sandovalio; Oratio in scientiarum laudem recitata a Gabriel de Mansilla; Dialogus recitatus in hebdomada sancta de passione Christi; Certamen litterarium sacris solemnibusque Christi Corporis Sancti feris celebrandis; [Bellum uirtutum et uitiorum]; [Dialogus Certaminis litterarii]... in ipsa clase.

Del P. Jose (Patris Ioseph -sic-) (RAH 383 ms. 9/2564, fols. 318-335): Iudithis tragoedia tertia. Anno 1578.

De Juan Bonifacio (1538-1606) (RAH 384 ms. 9/2565): Tragedia Namani; Tragoedia Jezabelis; Tragoedia Patris familias de Vinea; Comoedia quae inscribitur Margarita; Tragicomedia Nabalis Carmelitidis; Comoedia quae inscribitur Solomonia; De uita per diuinam Eucharistiam restituta. Actio brevis; Actio de Sanctissima Eucharistia; Actio quae inscribitur examen Sacrum; Introducción en forma de diálogo para unas declamaciones "pro morte contra mortem".

De Martín de Roa (1561-1637 BNM ms. 15404): Parenesia; Acolastus; Demophilea, de vera et ementita faelicitate.

De Guillermo Barçalo (1561-1602) (RAH, 388 ms. 9/2569): Dialogus de Petri martiris. Certamen cum arrianis hereticis et eiusdem mortem continens; Trag<icom>edia de divite epulone; Comedia prodigi fili.

De Miguel Venegas (1531-1567): Saul Gelboaeus; Achabus; Absalom.

Como se puede ver por los títulos, el listado abarca un amplio abanico de géneros (tragedias, comedias, tragicomedias, églogas, etc.) y de temas (dramas teológicos, bíblicos, de vidas de santos, diálogos de distintos temas, etc.) merecedor de una exposición pormenorizada como hemos hecho con el teatro humanistico y escolar universitario en el capítulo anterior; pero deberá esperar una mejor ocasión ${ }^{(104)}$.

(104) Es en la edición crítica, traducción y estudio de las piezas de este teatro neolatino compuestas por los cuatro primeros autores y otros anónimos, en lo que estamos empeñados los integrantes del proyecto de investigación arriba citado. 


\section{REFERENCIAS BIBLIOGRÁFICAS}

Alcina Robira, J. F., "La tragedia 'Galathea' de Hércules Florus y los inicios del teatro neolatino en la Corona de Aragón", en Calamus renascens, Alcañiz-Cadiz, 2000, pp. 13-30.

Alcina Rovira, J. F., "La tragèdia Galathea d'Hercules Florus i els inicis del teatre neollatí a Barcelona i a València (1485-1527)", en Albert Rossich (Coord.) El teatre català dels orígens al segle XVIII, Universitat de Girona, Edition Reichenberger, Kassel, 2001, pp. 145-259.

Alcina Robira, J. F., Juan Ángel González y la 'Sylva de laudibus poeseos' (1525), Universidad Autónoma de Barcelona, 1978.

Almansa Tollante, R., Cuatro diálogos que tratan sobre el infausto día en que murió el Príncipe D. Juan, heredero de España de Diego Ramírez de Villaescusa, Prólogo, edición facsímil del texto latino, transcripción y traducción, Diputación provincial de Jaén, 1997.

Alonso Alonso, J., "Un lustro de ediciones de teatro escolar jesuítico del Siglo de Oro", Diablo texto 4/5 (1997/98), pp. 417-446.

Alonso Asenjo, J. (ed.), La Tragedia de San Hermenegildo y otras obras del Teatro Español de Colegio I, Universidad de Sevilla-Universidad de Valencia-UNED, 1995, pp.1-79.

Alonso Asenjo, J., "Dos mujeres de armas tomar en la Fabella Aenaria de Palmireno", en Edad de Oro, XVI; Madrid, Universidad Autónoma de Madrid, 1997, pp. 29-52.

Alonso Asenjo, J., "Optimates laetificare: la 'Egloga in Nativitate Christi' de Joan Baptista Anyés o Agnesio", Criticón 66-67 (1996), pp. 601-668.

Alonso Asenjo, J., "El teatro del humanista Hércules Floro», en F. Carbó et alii, eds., Quaderns di Filologia (Studis Literaris,1), Homenatge a Amelia García-Valdecasas, Valencia, Fac. de Filología, Univ. De València, 1991, vol. 1, pp. 31-50.

Alonso Asenjo, J., "Los elementos mágicos del teatro de J. Lorenzo Palmireno", en E. J. Blasco et alii, Las Comedias de Magia y de Santos, Barcelona 1992, pp. 33-50.

Alonso Asenjo, J., "Panorama del teatro estudiantil del renacimiento español», en Spettacoli Studenteschi nell' Europa Umanistica, Roma, Edizioni Torre d'Orfeo, 1998, pp.151-191.

Alonso Asenjo, J., Molina Sánchez, M., Jaime Romañá, Tragicomedia 'Gastrimargus', de próxima publicación en http://parnaseo.uv.es/Ars/teatresco/teatresco 1/ (2006).

Alvar Ezquerra, A., Juan Pérez (Petreius) y el teatro humanístico, en Unidad y pluralidad en el mundo antiguo. Actas de IV Congreso Español de Estudios Clásicos, Madrid, Gredos, 1983, II, pp. 205-212.

Arróniz, A, La influencia italiana en el nacimiento de la comedia española, Madrid, Gredos, 1969.

Asensio, E. y Alcina Rovira, J.F., "Paraenesis ad litteras" Juan de Maldonado y el Humanismo español en tiempos de Carlos V, Madrid, 1980. 
Bonilla y San Martín, A., «El teatro escolar en el Renacimiento español y un fragmento inédito del toledano Juan Pérez", Homenaje a Menéndez Pidal, 3, Madrid, 1925, pp. 143-155.

Bonilla y San Martín, A., «Fernán López de Yanguas y el Bachiller de la Pradilla», Revista Crítica Hispano-Americana 1 (1915), pp. 44-51.

Bradner, L., "The Rise of a Secular Drama in the Renaissance", Studies in the Renaissance, 3 (1956), pp. 7-22.

Bravo Villarroel, R., La "Historia Baetica" de Carlo Verardi, drama histórico renacentista en Latín sobre la conquista de Granada, Instituto Tecnológico Monterrey, 1971.

Briesemeister, D., "Das Mittel- und Neulateinische Theater in Spanien", en K. Pörtl (ed.), Das Spanische Theater: Von den Anfängen bis zum Ausgang des 19. Jahrhunderts, Darmstadt, Wissenschaftliche Buchgesellschaft, 1985, pp. 1-29.

Briesemeister, D., «Literatura épico-dramática del siglo de Oro sobre la conquista de Granada: ¿un compromiso político?», Congreso sobre Andalucía en el Siglo de Oro, Córdoba, 1987.

Camón Aznar, J., Sobre la muerte del Príncipe don Juan, Madrid, Real Academia de la Historia, 1963

Casas Homs, J. M"a J. de Vallata, «Poliodorus». Comedia humanística desconocida, Introducción, estudio, transcripción y notas, Madrid, 1953, pp. 37-40.

Codina Mir, G., Aux sources de la pédagogie des jesuites le 'modus parisiensis', Roma, 1968.

Cortijo Ocaña, A., Juan Pérez 'Petreyo', Teatro latino escolar: Suppositi-Los Supuestos de Juan Pérez 'Petreyo' (ca. 1540), Edición, introducción, traducción y notas, Pamplona, 2001.

Domingo Mallvadi, A., La producción escénica de Acevedo. Un capítulo en la pedagogía del latín en La Compañía de Jesús, Salamanca, colección «Victor», núm. 69, 2001.

Domínguez, G.-Sotelo, A.I., "Breves notas sobre la 'Zaphira' de Hércules Floro", Archivo Hispalense, $\mathrm{n}^{\circ}$ 171-173 (1973), pp. 63-70.

Durán Ramas, M‥A. (ed), Juan Maldonado, "Comoedia Hispaniola [1519]" / La Española. Edición, traducción y notas, Barcelona, 1983.

Elizalde, I., "E1 antiguo teatro de los colegios de la compañía de Jesús», Educadores 4 (1962), pp. $667-84$.

Esperabé Arteaga, E., Histoira de la Universidad de Salamanca, Salamanca, 1914, t. I.

Flores Santamaría, P., "Teatro escolar latino del s. XVI: la Comoedia quae inscribitur Margarita del padre Juan Bonifació», en J. Ma Maestre Maestre, J. Pascual Barea, L. Charlo Brea (eds.) Humanismo y pervivencia del mundo clásico. Homenaje al Profesor Antonio Fontán, III,2, Alcañiz-Madrid, 2002, pp. 1179-1186.

Framiñán de Miguel, $\mathrm{M}^{a} \mathrm{~J}$., "Actividad dramática en el Estudio Salmantino del Renacimiento, Plauto y Terencio", en J. Ma Maestre Maestre, J. Pascual Barea y L. Charlo Brea (eds.), Humanismo y pervivencia del mundo clásico. Homenaje al Profesor Antonio Fontán, Alcañiz, Madrid, 2002, III, 33, pp. 1187-1200.

Frèches, C.-H., Le théâtre néo-latin au Portugal (1550-1745), Paris, 1964.

Gallardo Mediavilla, C., "El teatro como predicación: la homilética del P. P. Pablo de Acevedo», Edad de Oro 16 (1997), pp. 161-170.

Gallardo Mediavilla, C., "La Nabalis Carmelitidis de Juan Bonifacio y el sabor de los clásicos", en J. M ${ }^{a}$ Maestre Maestre, J. Pascual Barea, L. Charlo Brea (eds.) Humanismo y pervivencia del mundo clásico. Homenaje al Profesor Antonio Fontán, III,2, Alcañiz-Madrid, 2002, pp. 1201-1223.

Gallego Barnés, A., "La risa en el teatro escolar de Juan Lorenzo Palmireno", en Actes du $3 e$ Colloque du Groupe d'Étude sur le Théâtre Espagnol (Toulouse, 31 janvier-2 fevrier, 1980), París, 1951, pp. 187-196. 
Gallego Barnés, A., Juan Lorenzo Palmireno (1524-1579). Un bumanista aragonés en el "Studi General» de Valencia, Zaragoza, Institución Femando el Católico, 1982.

García-Hernández, B., "Literatura y filosofía. De la inspiración entusiástica de Descartes en Plauto", Silva 2 (2003), pp. 61-80, esp. 63-64.

García-Hernández, B., Descartes y Plauto, Tecnos, 1997.

García Olmedo, Félix, (1944), Diego Ramírez de Villaescusa (1459-1537) fundador del Colegio de Cuenca y autor de los Cuatro Diálogos sobre la muerte del Príncipe don Juan, Madrid, Editora Nacional, 1944.

García Soriano, J., El teatro universitario y humanístico en España. Estudios sobre el origen de nuestro arte dramatico; con documentos, textos ineditos y un catalogo de antiguas comedias escolares, Toledo 1945.

Gil, E. (ed.) et alli, La pedagogía de los jesuitas, ayer y hoy, Comillas, Madrid, 1999.

González Gutiérrez, C., El Códice de Villagarcía del P. Juan Bonifacio, Madrid, UNED, 2000.

González Gutiérrez, C., "El teatro de los jesuitas en la Edad de Oro I y II", Cuadernos para la investigación de la literatura hispánica, 18 (1993), pp. 7-148 y 19 (1994), pp. 7-126.

González-Ollé, F., "El Bachiller de la Pradilla, humanista y dramaturgo», Romanische Jabrbuch 17 (1966), pp. 285-300.

González Roldán, T., Baños Baños, J. M., Saquero Suárez-Somonte, P., El bumanismo cristiano en la corte de los Reyes Católicos: las consolatorias latinas a la muerte del príncipe Juan, Estudio, edición y traducción, Madrid, Ediciones Clásicas, 2006, pp.

Griffin, N., "Miguel Venegas and the sixteenth-century jesuit school drama», Modern Language Review 68 (1973), pp. 796-780.

Griffin, N., Two Jesuit Ahab Dramas: M. Venegas, Tragoedia cui nomen inditum Achabus and Anonymous, Tragedia Jezabelis, Exeter, 1976.

Hermenegildo, A., La tragedia del Renacimiento español, Barcelona, Planeta, 1973.

Hofmann, H., "Point de vue sur les méthodes et les perspectives des etudes néo-latines», Les Cabiers de l'Humanisme'", I (2000), pp. 11-33.

Ijsewijn, J., "Neo-Latin: an historical Survey», en J. Lluís Barona (ed.), Humanisme i literatura neollatina, (Universitàt de València), 1996, pp. 43-62.

Ijsewijn, J., Companion to Neo-Latin Studies. Part I: History and diffusion of Neo-latin Literature, Lovaina, Leuven Univ. Press. 1990.

Ijsewijn, J., Companion to Neo-Latin Studies. Part II Literary, Linguistic, Philological and Editorial Questions, Lovaina, Leuven Univ. Press, 1998.

Lanesi, I., La commedia, en Storia dei generi letterari Italiani, Milán (s./d.).

López de Toro, J., "Juan de Valencia, escenificador latino de la Biblia", en Homenaje Fichter, Madrid, 1971, pp. 479-503, con la edición de la Comedia Prodigi filii, pp. 490-503.

Lucero, Ll., "Sobre un poema d'Antoni Geraldini dedicat a Bernat Margarit", Annals de l'Institut d'Studis Gironins, 31 (1990-1991), pp. 89-98.

Maestre Maestre, J. M⿻. "El papel del teatro escolar en la enseñanza de la Retórica y del Latín durante el Renacimiento: en torno a la Fabella Aenaria de Juan Lorenzo Palmireno", en Los bumanistas valencianos y sus relaciones con Europa: De Vives a Mayans, ed. Jordi Pérez i Durà y José María Estelles, Valencia, Ayuntamiento, 1998, pp. 95-114.

Maestre Maestre, J. Mª, "Valencia y su Studi General en el teatro de Juan Lorenzo Palmireno", El teatre Clàssic al mar de la Cultura Graeca i la seua pervivència dins la cultura occidental, Ed. J. Vicente Bañuls, Francisco de Martino, Carmen Morenilla i Jordi Redondo, Levante Editori-Bari, 1998, pp. 335-367. 
Maestre Maestre, J. Ma ., "En torno a las fuentes del Dialogus de Juan Lorenzo Palmireno, en F. Sojo Rodríguez, F. (coord.), Latinitas Biblica et Christiana. Studia Philologica varia in Honorem Olegario García de la Fuente, Madrid, 1994, pp. 543-550.

Maestre Maestre, J. M ${ }^{\mathrm{a}}$., «La mezcla de géneros en la literatura latina renacentista: a propósito de la 'Apollinis fabula' del Brocense, en Simposio IV Centenario de la publicación de la "Minerva” del Brocense: 1587-1987, Cáceres, 1989, pp.145-187.

Maestre Maestre, J. Ma ., "Formación humanística y literatura latino-renacentista: a propósito de Juan Lorenzo Palmireno", en Los humanistas españoles y el humanismo europeo. IV Simposio de Filología Clásica, Universidad de Murcia, 1990, pp.191-202.

Maestre, J. Ma ., Leal, J. y Sirara, J. L, Juan Lorenzo Palmireno ensaya la "Fabella Aenaria" con sus alumnos del Estudi General de Valencia, Dramaturgia de Juli Leal y Josep Lluís Sirera, a partir de la edición de José María Maestre, con prólogo de Josep Lluís Sirera y Juli Leal, Universitat de València, 2000.

Miranda, M., "Teatro bíblico novilatino: A Tragédia de Acab de Miguel Venegas», Humanitas 46 (1994), 351-371.

Miranda, M., "Música para o Teatro Humanístico em Portugal», Humanitas 55 (2003), 315-339 .

María Bover, J., Biblioteca de escritores baleares, Palma, 1968, II, pp. 291-296.

McCabe, W,H., An Introduction to the Jesuit Theater, (ed. by L.J.Oldani, St Louis, 1983.

Menéndez Peláez, J., "El teatro escolar latino-castellano en el siglo XVI", en J. Huerta Calvo, Historia del teatro español, Madrid, Gredos, 2003, pp. 581-608.

Menéndez Peláez, J., "El teatro jesuítico: sistema y técnicas escénicas. Las raíces del teatro de Calderón de la Barca", en Calderón: sistema dramático y técnicas escénicas. Actas de las XXIII Jornadas de teatro clásico Almagro XXIII, 2001, pp. 33-76.

Menéndez Peláez, J., Los jesuitas y el teatro en el Siglo de Oro, Oviedo, Universidad, I995.

Menéndez Pelayo, M., Bibliografía Hispana-Latina Clasica, Madrid, C.S.I.C., 1951, tomo VII, pp. 416-419.

Mérimée, H., [1913]: El arte dramático en Valencia, Valencia 1985, vol. I, pp. 248-270.

Mesa Sanz, J. F., "Hércules Florus grammaticus: apuntes para una biografía», en E. Sánchez Salor - L. Merino - S. López Moreda (eds.), La recepción de las artes clásicas en el siglo XVI, Universidad de Extremadura, 1996, pp. 147-154.

Molina Sánchez, M., "El teatro de los jesuitas en la provincia de Andalucía: nuevos datos para su estudio", J. Ma . Maestre Maestre, J. Pascual Barea, Humanismo y pervivencia del mundo clásico I, 2, Cádiz, 1993. pp. 643-654.

Morel-Fatio, A., Ate religata et Minerva restituta, comédie de collège représentée à Alcalá de Henares en 1539 ou 1540", Bulletin Hispanique 5 (1903), pp. 9-24.

Mustard, W. P., The Eclogues of Antonio Geraldini, Baltimore, 1924;

Peinador Marín, L. J., "Un diálogo del siglo XVI español 'Eremitae' de Juan Maldonado», Criticón 52 (1991), pp. 41-90.

Peinador Marín, L. J., "Apuntes sobre la edición de un texto en latín del siglo XVI: los 'Eremitae' de Juan de Maldonado". Actas del II Seminario Internacional de edición y anotación de textos del Siglo de Oro (Univ. De Navarra), Madrid, 1991.

Pérez Priego, M. A., El Príncipe Don Juan, heredero de los reyes católicos y la literatura de su época. Lección inaugural del curso 1997-1998, UNED, 1997.

Pérez-Rioja, J. A., "Hernán Pérez de Yangüas, humanista y autor dramático», Celtiberia 36 (1968), pp. 163-182. 
Picón García, V. «El teatro escolar latino en el Colegio de Montesión S. I. (Palma de Mallorca): la obra de Guillém de Barçalo (Barceló), en Homenaje a Miquel Dolç, Palma de Mallorca, 1997, pp. 603-607.

Picón García, V., "El tema del Hijo Pródigo en la dramática del s. XVI en España», Voz y Letra 6,1 (1995-1997), pp. 73-87.

Picón García, V., "La Comedia Philautus de Acevedo: sus deudas al 'Terencio cristiano' (Acolastus de Gnaphaeus y Samarites de Papeus)", Congreso Internacional de Humanismo y Renacimiento, Universidad de León, 1996, pp. 599-609.

Picón García, V., "La Comedia Bellum virtutum et vitiorum de Pedro Pablo de Acevedo: originalidad de su dramatización”, Excerpta philologica 7-8 (1997-1998), pp. 211-222.

Picón García, V., "La comedia Desiderius? de P. P. de Acevedo en honor de Felipe II: historia y alegoría", en Ana M $\mathrm{M}^{\mathrm{a}}$ Aldama et alii, La Filología latina boy. Actualización y perspectivas, Sociedad de Estudios Latinos, Madrid, 1999, pp. 1217-1230.

Picón García, V., "Tradición del teatro escolar latino del s. XVI: La Comedia Prodigi fili de Guillermo Barcelón, en J.M Maestre Maestre, J. Pascual Barea, L. Charlo Brea (eds.) Humanismo y pervivencia del mundo clásico. Homenaje al Profesor Antonio Fontán, III, 2, Alcañiz-Madrid, 2002, pp. 1235-1248.

Picón, V (Coord.), A. Cascón, P. Flores, C. Gallardo, A. Sierra y E. Torrego, Teatro escolar latino del s. XVI: La obra de Pedro Pablo de Acevedo S.I. I: Lucifer Furens, Occasio, Philautus, Charops Madrid, Ediciones Clásicas, 1997.

Prieto, A., La prosa española del siglo XVI, Cátedra, 1986.

Rincón González, Mª Dolores, «El aspecto multiforme del panegírico latino: algunos ejemplos renacentistas", en J. Mª Maestre Maestre, J. Pascual Barea y L. Charlo Brea (eds.), Humanismo y pervivencia del mundo clásico. Homenaje al Profesor Antonio Fontán, Alcañiz-Madrid, 2002, III, 2, pp. 723-729.

Rincón González, Mª Dolores, "Historia Baetica" de Carlo Verardi. Drama humanistico sobre la bistoria de Granada, Granada, 1992.

Romeu i Figueras J., Teatre català antic, Curiel, Barcelona, 1995, pp. 128-131.

Roux Lucette, E., "Cent ans d'expérience théatrale dans les collèges de la Compagnie de Jésus en Espagne», in Dramaturgie et Société. Rapports entre l'oeuvre théâtrale, son interprétation et son public au XVle et XVIIe siècles, Paris 1968, t. 2, pp. 479-523.

Rubió i Balaguer, J., Humanisme i Reinaixement, Barcelona, Publicacions de l'Abadia de Montserrat, 1990, pp. 203-229.

Saa, Orlando E., El teatro escolar de los jesuitas en España. La obra dramática de Pedro Pablo de Acevedo, New Bronswick, Slusa,1990.

Salvadó Recasens, J., "Joan Parteni Tovar, mestre de Vives a la Universitat de València", Studia Philologica Valentina 1 (1996), pp. 125-143.

Sanz Hermida, J., "Literatura consolatoria en torno a la muerte del Príncipe Dn. Juan», Studia Historica-Historia Medieval 11 (1993), pp. 157-170.

Sierra de Cózar, A., "El teatro escolar latino en el Colegio de Montesión (Palam de Mallorca) I: historia y documentos", en M. del C. Bosch -M..A. Fornés (eds.), Homenatge a Miquel Dolç, Palma de Mallorca, 1997, pp. 623-626.

Sojo Rodríguez, F., "Sobre el humanista español Juan Pérez (Petreyo)», Analecta malacitana 9,1 (1986), pp. 27-37.

Vega y Luque, C. Luis de la, "Vida y obras de Juan Lorenzo Palmireno», en Teruel, n 49-50, Instituto de Estudios Riojanos, 1973. 
(Página deixada propositadamente em branco) 
Jesús Menéndez Peláez

Universidad de Oviedo

PROPAGANDA IDEOLÓGICA EN EL TEATRO NEOLATINO Y ROMANCE

DE LOS COLEgIOS DE JESUITAS EN EL SIGLO DE ORO ESPAÑOL

\section{El contexto de la investigación}

Desde 1978, en la Universidad de Oviedo, se viene trabajando, bajo mi dirección, en un amplio proyecto de investigación sobre Los Jesuitas y el teatro en el Siglo de Oro ${ }^{(1)}$; en este proyecto colaboran también las Universidades de Navarra y Toulouse con el asesoramiento, respectivo, de los profesores Ignacio Arellano y Marc Vitse.

La investigación tiene programadas varias fases:

$1^{a}$ Compilación, a través de microfilms o microfichas de todos los manuscritos que contienen las obras dramáticas de este teatro jesuítico que custodian la Biblioteca Real de la Historia, la Biblioteca Nacional de Madrid y las bibliotecas privadas de distintos colegios de la Compañía de Jesús, repartidos por la geografía nacional. Este objetivo está ya cumplido.

$2^{a}$ Descripción, lo más completa posible, de los manuscritos que contienen las obras del teatro jesuítico, con el fin de elaborar un catálogo o inventario real, lo más exhaustivo, de las obras actualmente existentes de

(1) Un avance de este proyecto fue ya publicado: Jesús MENÉNDEZ PELÁEZ, Los jesuitas y el Teatro en el Siglo de Oro, Oviedo, Universidad, 1995. También puede verse una síntesis del teatro latino-castellano, universitario y de colegio, en IDEM, "El teatro escolar latino-castellano en el siglo XVI", en Javier HUERTA CALVO (Dir.), Historia del Teatro Español, Madrid, Gredos, vol. I, 2003, pp. 581-608; más recientemente un estado de la cuestión en IDEM, "Estudios sobre el teatro jesuítico español en el Siglo de Oro: Status quaestionis», Ínsula, 695, 2004, pp. 2-5. 
este teatro jesuítico. Los resultados han sido publicados en la revista Archivum [Universidad de Oviedo], LIV-LV (2004-2005) 421-563.

$3^{\text {a }}$ Distribución y clasificación de las obras por subgéneros dramáticos tomando como criterios aspectos prioritariamente religiosos, ya sea de naturaleza litúrgica o ya de intertextualidad con las Sagradas Escrituras, pues la mayor parte de este teatro se representaba siguiendo el curso del calendario del ritual cristiano: hagiografías (fiestas de los santos), autos sacramentales (Corpus), Navidad, Semana Santa, de inspiración bíblica (Nuevo y Antiguo Testamento), cristianización de elementos paganos y de circunstancias.

$4^{a}$ Elaboración de la nómina de aquellos dramaturgos más representativos del teatro jesú́tico en un intento de ofrecer los datos pertinentes de su biografía. No obstante, este apartado ofrece problemas de atribución, ya que muchas de las obras del teatro jesuítico no llevan atribución de autor, sino tan solo el marbete "Por uno de la Compañía", expresión que quizá derive del voto de humildad de los dramaturgos; de esta manera, se evitaba cualquier tipo de protagonismo que pudiera poner en peligro esa virtud. Es una praxis bastante habitual en los hijos de san Ignacio hasta épocas recientes; en ocasiones un anónimo y posterior amanuense - la caligrafía lo ratifica - escribe el nombre del dramaturgo a quien ese amanuense o lector avisado atribuye la obra, lo que facilita, con ciertos riesgos, el problema de la autoría.

$5^{\text {a }}$ Edición-transcripción individualizada de cada una de las obras, un proyecto en el que están implicados alumnos de los distintos ciclos de la enseñanza reglada de nuestras respectivas universidades.

$6^{\text {a }}$ Creación de una página web destinada a recoger trabajos y ediciones del teatro jesuítico español. Al tratarse de obras, por lo general muy extensas, y siendo un teatro, cuyos textos por el momento no forman parte del canon literario, su publicación a través de la imprenta quizá pueda resultar difícil por su elevado coste; sin embargo, resulta muy sencillo difundir, con una finalidad divulgativa, estas ediciones a través de Internet. El servicio que con ello se hace a la investigación humanística resulta patente. 
$7^{a}$ Uno de los pioneros en el estudio del teatro jesuítico español fue, junto con Justo García Soriano(2), el P. Félix G. de Olmedo, especialista de reconocido prestigio en la oratoria sagrada del Siglo de Oro, quien dejó publicado tan solo una mínima parte de lo que tenía preparado; el Colegio de san Estanislao de Kostka en Salamanca custodia un ingente material inédito sobre la historia de la predicación medieval y del Siglo de Oro, algunos de cuyos trabajos ya estaban terminados para enviar a la imprenta. Junto con la oratoria sagrada, el teatro jesuítico fue otra de sus preocupaciones, dejando igualmente trabajos completos para la imprenta. El P. Olmedo fue un entusiasta admirador del P. Juan Bonifacio que emerge en la cultura del siglo XVI como pedagogo y como dramaturgo y que es el autor del conocido Códice de Villagarcía, una de las compilaciones más importantes y mejor conocidas, principalmente a través de los comentarios analíticos de García Soriano; la personalidad de este pedagogo y dramaturgo nos es bien conocida gracias a los estudios del P. Olmedo(3), quien tenía también preparados unos «Breves apuntes para Historia del teatro en los antiguos colegios de la Compañía", así como la trascripción de varias obras de teatro de Hernando de Ávila, Salvador de León, Pedro de Salas y otros; también había concluido una edición-trascripción completa, sin duda la primera, de la Tragedia de san Hermenegildo; en su archivo se conserva una carta — fechada el 26 de diciembre de 1935 - que le remite desde Roma el P. Dionisio Fernández, a quien el P. Olmedo había consultado aspectos muy concretos de estas obras; esto quiere decir que el P. Olmedo, antes de la guerra civil, ya tenía ultimada las ediciones del "Códice de Villagarcía” y de la Tragedia de san Hermenegildo, así como otras obras de los autores referidos. La falta de sensibilidad hacia esta temática literaria, que caracterizó durante mucho tiempo a la universidad española, quizá haya sido

(2) Justo GARCÍA SORIANO, El teatro universitario y bumanístico en España. Estudios sobre el origen de nuestro arte dramático; con documentos, textos inéditos y un catálogo de antiguas comedias escolares, Toledo, 1945.

(3) Félix G. OLMEDO, Juan Bonifacio (1538-1606) y la cultura literaria del Siglo de Oro, Santander, Publicaciones de la Sociedad de Menéndez Pelayo, 1938. 
la causa de que aquellos materiales no hayan visto la luz de la imprenta. Tan solo dejó publicadas algunas consideraciones sobre la relación entre determinadas obras del teatro jesuítico y La vida es sueño de Calderón de la Barca(4) $^{(4)}$ No obstante, su obra está ahí y en breve se irá dando a conocer, ya que fue uno de los pioneros en los estudios sobre el teatro jesuítico en la España del Siglo de Oro. Con el objeto de hacer justicia a las investigaciones realizadas por el P. Olmedo y evitar expolios se firmó, dentro de este proyecto de investigación, una colaboración con el Colegio de san Estanislao de Kostka en Salamanca, depositario del archivo del P. Félix de Olmedo, para digitalizar sus investigaciones, una tarea ya realizada que se irá ofreciendo a través de la referida página web.

En el año 2003 este proyecto fue galardonado con la «Beca Alarcos» promovida por la prestigiosa Fundación Príncipe de Asturias para premiar trabajos de investigación histórico-literaria. Tal concesión corrobora la importancia que el teatro latino-español, durante mucho tiempo olvidado, está cobrando en la actualidad dentro del mundo del hispanismo. Esta ponencia ha de entenderse, por tanto, en el contexto de este amplio y ambicioso proyecto de investigación.

\section{Metodología y precisiones terminológicas}

Pretender abordar en los límites de una ponencia la "Propaganda ideológica en el teatro neolatino de los colegios de jesuitas en el Siglo de Oro español» es, sin duda, un objetivo inabarcable, por lo que ha de ser una visión incompleta, aunque espero que no condicione las conclusiones, antes bien un análisis más exhaustivo y extenso de los materiales las confirmaría con mayor contundencia argumental. Espigaré, pues, tan solo alguno de los aspectos más relevantes de esta orientación didáctica que dieron los

(4) Félix G. OLMEDO, Las fuentes de "La Vida es Sueño", Madrid, Voluntad, 1928, particularmente las pp. 115-188. 
jesuitas españoles — si bien las mismas conclusiones se podrían extraer quizás de las obras de teatro que los dramaturgos jesuitas escenificaron en otros países tanto europeos como de Hispanoamérica(5) —. Para este propósito me fijaré en uno de los subgéneros dramáticos donde, a mi juicio, aparece con mayor claridad la función propagandística del teatro jesuítico; me refiero a las comedias hagiográficas.

Siguiendo la pedagogía escolástica creo que es necesario explicar el contenido semántico de los términos que aparecen en el enunciado de esta ponencia. Por "propaganda ideológica» entiendo el universo cristiano con que la educación jesuítica reviste sus enseñanzas en los colegios durante ese período de la cultura española que denominamos Siglo de Oro o Edad de Oro. Ese universo cristiano abarca dos aspectos: lo espiritual y lo académico; en este sentido el teatro jesuítico entronca con el teatro universitario renacentista que emerge en Centro-Europa siguiendo el marbete erasmista del Litterae et pietas. El teatro jesuítico español es, por tanto, deudor, en sus orígenes, a una corriente que desde Europa irradia por todo el continente esta singular pedagogía que asumió la Compañía de Jesús. Precisamente las primeras obras escenificadas en los colegios de jesuitas pertenecen a estos humanistas. El Euripus, del franciscano holandés Livino Brecht, y el Acolastus, de Guillermo Gnapheus, y algunas otras son la base sobre las que se apoya el incipiente teatro jesuítico español, unas obras que no estaban exentas de un fuerte contenido ideológico y que en buena medida coincidían con el universo cristiano de los jesuitas; por eso las aceptan. Se puede decir que el teatro jesuítico español, desde el principio, acentuó de manera especial servir a la formación espiritual de las gentes que acudían a

(5) Una simple ojeada al repertorio bibliográfico elaborado por Nigel GRIFFIN (Jesuit School Drama. A Checklist of critical Literature, Londres, 1976) lo corrobora. Particular interés tienen los estudios dedicados al teatro jesuítico en Alemania por Jean Marie VALENTIN; entre sus publicaciones habría que destacar, en este sentido, su Les jésuites et le théâtre (1554-1680). Contribution à l'histoire culturelle du monde catholique dans le Saint-Empire romain germanique, Paris, Éditions Desjonquères, 2001; como 'teatro de evangelización' caracterizó Othon ARRÓNIZ al teatro representado por determinadas órdenes religiosas en la evangelización del Nuevo Mundo; la tercera parte del trabajo (pp. 138-182 está dedicada al 'teatro jesuita' (Teatro de evangelización en nueva España, México, UNAM, 1979). 
aquellas representaciones, unos espectadores que eran en primer lugar los alumnos a los que se unían sus familiares y una buena parte de las gentes de la villa o ciudad donde estaba ubicado el colegio. Este didactismo espiritual tendrá un fuerte contenido moral y dogmático en consonancia con la espiritualidad ignaciana y a la vez siguiendo las orientaciones dogmáticas del Concilio de Trento; por tanto, la idea que pretendo resaltar es cómo el teatro jesuítico es portador de las orientaciones ascético-místicas pergeñadas por san Ignacio en sus Ejercicios Espirituales sin olvidar la orientación contrarreformista que caracterizó a la Compañía de Jesús.

\section{Teatro y púlpito: la obra dramática como sermón disfrazado}

Desde que Horacio asignó a la literatura la doble finalidad de aprovechar y deleitar (prodesse et delectare), la crítica literaria estableció una especie de dicotomía entre el fondo y la forma; el fondo sería el contenido ideológico y la forma el revestimiento donde habría de residir fundamentalmente el arte literario. Pues bien, aprovechar y deleitar van a ser dos categorías que atraviesan la pedagogía del teatro jesuítico. Es más; podríamos decir que el dramaturgo del teatro jesuítico establece, en líneas generales, una primacía del aprovechamiento por encima del deleite. Los dramaturgos jesuitas utilizarán el teatro como un auxiliar pedagógico, un método que ellos heredan del teatro universitario. Y dentro de este aprovechamiento los contenidos doctrinales que configuran el universo cristiano serán los prioritarios. Lo dice muy claramente uno de los primeros dramaturgos del teatro jesuítico español. Es el P. Juan Bonifacio quien lo recuerda en algunos de sus prólogos o argumentos.

Vos seréis el argumento

y el thema de este sermón

disfrazado, Vos, divino sacramento(6).

(6) P. JUAN BONIfACiO, Códice de Villagarcía, Biblioteca Real de la Historia, Ms. 9/2565, fol. $204 \mathrm{v}$. 
En el Prólogo a la Actio quae inscribitur nepotiana, de nuevo el P. Bonifacio advierte que los alumnos de los colegios de Jesús y de san Gil en Ávila son aún principiantes en su formación en las artes sermocinales; a pesar de ello intentarán hacer algo provechoso:

[...] Por tanto, los estudiantes

de Jesús y de san Gil

traen una cosa vil

y propia de estudiantes [...].

Es un sermón disfraçado;

hablan burlando y de veras;

entre cosas plazenteras

el provecho irá mezclado(7).

La preocupación docente la tuvo más clara aún el P. Acevedo, a quien se considera el primer dramaturgo jesuita español; en el prólogo a la Comedia Metanea deja muy explícita su concepción del teatro como género donde el dramaturgo debe preocuparse sobre todo de transmitir una sana doctrina antes que someterse a las leyes de la estética. Para el P. Acevedo el aprovechamiento ascético y doctrinal del universo cristiano ha de anteponerse al deleite, es decir, lo moral tiene prioridad sobre lo artístico.

Contaros he una historia en breve suma, la cual veréis después representada, porque lo que se ve a los ojos mueve mucho más que lo que al oído damos. El grande observador de aqueste arte no me diga: 'aquí faltó el decoro'; 'mejor esotro fuera'; bien entiendo faltar en mucho y no llegar con muchas partes al decoro antiguo, mas túvose atención más al provecho poniéndolo delante de los ojos, que no al arte servir curiosamente ${ }^{(8)}$.

(7) P. JUAn BOnifacio, Códice de Villagarcía, Biblioteca Real de la Historia, Ms. 9/2565, fol. $137 \mathrm{r}$.

(8) P. Pedro Pablo ACEVEDo, «Prólogo» a Philautus, Biblioteca Real de la Historia, Ms 9/2564, fol. 2r; edición de Vicente PICÓN GARCÍA et alii, Teatro escolar latino del s. XVI: La 
La misma concepción del teatro mantiene en el 'Argumento' de la Comoedia Charopus:

[...] Y si esto es ansí, mire cada cual de todo lo que aquí representaren qué es lo que le toca y no imagine ser fábulas de vana Poesía, ni ponga su atención en mirar las peregrinas vestiduras y atavíos, mas su estudio todo sea en conferir la forma de su vida con la imagen de aquesta acción( ${ }^{(9)}$.

De esta manera, el P. Acevedo saldría al paso de las críticas que le podrían venir de círculos academicistas que le acusarían de conculcar las leyes de la poética clásica. El teatro se convierte así en un «sermón disfrazado». Por medio de la representación escénica el dramaturgo pone sobre las tablas ejemplos de conducta, en unos casos para no seguir, en otros para ser imitados. La ejemplaridad se convierte en una de las funciones principales del teatro jesuítico, enlazando con una costumbre también muy jesuítica en sus colegios que se la conocía con el nombre de "predicar el ejemplo»; se trataba de una predicación muy singular que tenía lugar los lunes, miércoles y viernes durante la cuaresma ante un público escolar. El tema era muy sencillo: un ejemplo que estimulaba el ejercicio de la virtud, o un ejemplo de conducta aberrante que había destruido al protagonista por seguir los imperativos de los enemigos del alma, es decir, el demonio, el mundo y la carne ${ }^{(10)}$. Pero, sin duda, el autor que dejó una mayor huella de la piedad

obra del Pedro Pablo de Acevedo. Lucifer Furens, Occasio, Philautus, Charopus, Madrid, Ediciones Clásicas, 1997, p. 332.

(9) Ibidem, fol. 169v-170r; edic. cit. de PICÓN, p. 451.

(10) La Biblioteca Universitaria de Salamanca custodia dos códices que recogen los ejemplos predicados en el colegio jesútico de san Estanislao. En un trabajo publicado hace algunos años propuse la vinculación genética del tema del «don Juan" con un ejemplo que lleva por título "El tema de don Juan" (véase Jesús MENÉNDEZ PELÁEZ, "El tema de don Juan en la predicación de los Siglos de Oro", Archivum, XXXIX-XL (1989-90)365-383). De la asistencia de un público escolar a estas predicaciones da testimonio el estudiante italiano Girolamo da 
jesuítica no solo entre los estudiantes de los colegios de jesuitas del Siglo de Oro, sino entre otras congregaciones religiosas tanto seculares como regulares fue el P. Alonso Rodríguez (1538-1616) con su Ejercicio de perfección y virtudes cristianas; sus pláticas terminan siempre con el epígrafe «En que se confirma lo dicho con algunos ejemplos»; decenas y decenas de ejemplos va refiriendo el jesuita para recordar determinados momentos de la vida de los santos que el autor considera modelos de conducta para ser imitados por los jóvenes estudiantes; su obra puede ser considerada como un verdadero ejemplario.

Es la misma actitud que adopta el P. Acevedo con su teatro; en el Argumento a su Comedia Metanea el dramaturgo actúa como un predicador:

Oiréis exhortaciones a la penitencia veréis sus lágrimas con que la triste suerte de aquellos llora a quien la trina peste - demonio, mundo y carne - oprime y vence ${ }^{(11)}$.

No es de extrañar que los historiadores de la Compañía de Jesús, al referirse al P. Acevedo escriban: «[El P. Acevedo] trocó los teatros en púlpitos, y salían los hombres muchas veces más recogidos y llorosos de sus representaciones, que de los sermones de algunos excelentes predicadores»(12).

Aunque quizá no se pueda aplicar esta concepción del teatro que tiene el P. Acevedo a la totalidad de los dramaturgos de la Compañía, sí nos vale para marcar la orientación que los dramaturgos del teatro jesuítico dieron a sus representaciones escolares: el teatro había de ser un auxiliar de su pedagogía académica y sobre todo espiritual. «Trocó los teatros en púlpitos»;

Sommaia, quien realizó estudios en Salamanca; del impacto que tales ejemplos producían en su espíritu dejó testimonio en su diario (véase Diario de un estudiante de Salamanca, edición e introducción de George HALLEY, Universidad de Salamanca, 1977.

(11) P. ACEVEDO, "Prólogo» a Comoedia Metanea, Biblioteca Real de la Historia, Ms. 9/2564, fol. 201r; edic. de julio ALONSO ASENJO, Comedia Metanea, en La Tragedia de san Hermenegildo y otras obras del Teatrio Español de Colegio, Sevilla-Valencia, UNED, vol. II, p. 115.

(12) P. Pedro DE RIBADENEYRA, Historia de la asistencia, 1, V, c. 12, citado en Antonio ASTRÁIN, Historia de la Compañía de Jesús en la Asistencia de España, Madrid, Razón y Fe, 1914, vol. 2, p. 587. 
esto es, el teatro había de cumplir la función asignada al púlpito, y desde el púlpito el predicador enseñaba las verdades del universo cristiano en su doble aspecto: moral y dogmático.

\section{El teatro jesuítico, la espiritualidad ignaciana y el Concilio de Trento}

Los dramaturgos del teatro jesuítico intentarán expandir este universo cristiano a través de sus creaciones dramáticas, que amenizaban las principales efemérides del calendario litúrgico y escolar; dentro del amplio corpus que conforman el teatro jesuítico español me fijaré, para el objetivo propuesto, en el teatro hagiográfico.

La literatura hagiográfica en sus distintos géneros tiene un fundamento teológico que no se puede obviar si se pretende comprender en su total significación la creación literaria. La hagiografía literaria descansa y se apoya en una teología de los santos. Podemos afirmar, como punto de partida, que el sensus fidelium, esto es la liturgia, primero, la especulación teológica, en segundo lugar, y finalmente la doctrina conciliar atribuyen a los santos dos funciones que servirán de inspiración al hagiógrafo: la ejemplaridad y el poder de intercesión.

La ejemplaridad se fundamenta en el hecho de que los santos, como seres humanos que fueron, estuvieron revestidos de una naturaleza humana herida y dañada por el pecado original, una lacra que ellos supieron superar merced a un programa de perfección ascética impuesto por el imperativo evangélico de "sed perfectos como vuestro Padre celestial es perfecto» (Mat., 5, 48); esta perfección tiene un único modelo de imitación: la figura de Cristo, — «nadie llega al Padre, el tres veces santo, sino por mí» (Jn, 8, 12) - a quien la teología reviste de una doble naturaleza: humana y divina; esta doble naturaleza planteó graves polémicas en los primeros siglos del cristianismo. Recuérdese el arrianismo y sus secuelas en la historia de la teología; porque Cristo es hombre y, por tanto, copartícipe de nuestra 
humanidad, Cristo será el modelo ejemplar que se ha de imitar. De la imitación de Cristo así reza el título de una de las obras de mayor impacto en la piedad popular desde el Siglo de Oro hasta nuestros días; su autor, Tomás de Kempis, un apellido que dio título también a la obra, El Kempis. El ser humano que encarna en su proyecto existencial esta imitación de Cristo se convierte en santo; la teología paulina está llena de imágenes metafóricas y de comparaciones para expresar esta idea: "Revestíos del Señor Jesucristo» (Rom., 13, 14); la vida del cristiano ha de sumergirse en Cristo, como injertada en la suya: "Vivo yo, pero no yo, que es Cristo quien vive en mi» (Gal., 2, 20); la santidad ha de ser, pues, la aspiración de todo cristiano, esto es, imitar a Cristo; el programa que lleva a la consecución del título de santidad está contenido en el sermón de la montaña: son las bienaventuranzas. Este será el programa sobre el que versará el juicio final. Por eso la liturgia, el sensus fidelium, se sirve de este texto evangélico para festejar el día de Todos los Santos (1 de noviembre). El santo se convierte así en el modelo de alumno ejemplar que ha sabido imitar a su maestro y superar con éxito el curso existencial de la vida. Por eso la Iglesia, desde sus inicios, utilizará el santoral como paradigma o modelo del curricullum vitae del cristiano.

El poder de intercesión de los santos fue tratado por la especulación teológica de manera particular por santo Tomás de Aquino en la STh, 22- q. 83, a.12; este artículo lleva por título "Utrum sancti qui sunt in patria orent pro nobis»; santo Tomás responde afirmativamente; los santos tienen poder de intercesión por varias razones:

$1^{\circ}$ Quia cum oratio pro aliis facta ex caritate proveniat, ut dictum est, quanto sancti qui sunt in patria sunt perfectioris caritatis, tanto magis orant pro viatoribus...

$2^{\circ}$ Quod sanctis qui sunt in patria, cum sint beati, nibil deest nisi gloria corporis, pro qua orant; orant autem pro nobis, quibus deest beatitudinis ultima perfectio; et eorum orationes habent efficatiam impetrandi ex praeceptibus eorum meritis et ex divina aceptatione... 
$3^{\circ}$ Quia sancti viventes meruerunt ut pro nobis orarent ideo eos invocamus nominibus quibus bic vocabantur, quibus etiam nobis magis innostescunt...(13)

La argumentación teológica justifica de esta manera el patronazgo que desde el primitivo cristianismo la Iglesia concedió a los santos; el primero de estos patronazgos se refiere al bautismo. La Iglesia, a través del derecho canónico, determina que:

Curent parochi ut ei qui baptizatur, christianum imponatur nomen; quod si id consequi non poterunt, nomini a parentibus imposito addant nomen alicuius Sancti et in libro baptizatorum utrumque nomen perscribant ${ }^{(14)}$.

La misma legislación eclesiástica, basándose en el poder intercesor de los santos, aconseja que las distintas agrupaciones humanas, desde las propias naciones hasta las agrupaciones gremiales, elijan a un santo como patrono a quien invoquen como intercesor ante la divinidad:

Laudabiliter quoque servatis servandis sancti nationum, dioecesium, provinciarum, confraternitatum, familiarum religiosarum aliorumque locorum et moralium personarum eliguntur et, accedente confirmatione Sedis Apostolicae, constituuntur Patroni(15).

El Concilio de Trento, máximo exponente de la Contrarreforma, sistematiza ya de manera mucho más clara la teología de los santos en su intento por salir al paso de las aberraciones de las doctrinas protestantes, cuya historia salutis desconoce el papel soteriológico de los santos; el 3 de diciembre

(13) SANTO TOMÁS DE AQUINO, Summa Theologica, editio cura Fratrum eiusdem Ordinis, Madrid, BAC, III, 1952, pp. 550-551

(14) Código de Derecho Canónico, edic. de Lorenzo MIQUÉLEZ DOMíNGUEZ- Sabino ALONSO MORÁN — Marcelino CABREROS ORTIZ, Madrid, BAC, 1962, art. 761, p. 292.

(15) Ibidem, art. 1.278 p. 484 
de 1563 se aprueba el Decretum de invocatione, veneratione et reliquiis Sanctorum et sacris imaginibus en los siguientes términos:

Mandat sancta Synodus omnibus episcopis et ceteris docendi munus cu109 ramque sustinentibus, ut iuxta catbolicae et apostolicae Ecclesiae usum, a primaevis christianae religionis temporibus receptum, sanctorumque Patrum consensionem et sacrorum conciliorum decreta: imprimis de Sanctorum intercessione, invocatione, reliquiarum bonore, et legitimo imaginum usu fideles diligenter instruant, docentes eos, Sanctos, una cum Christo regnantes, orationes suas pro bominibus Deo offerre; bonum atque utile esse, suppliciter eos invocare et ob beneficia impetranda a Deo per Filium eius Iesum Christum Dominum nostrum, qui solus noster Redemptor et Salvator est, ad eorum orationes, opem auxiliumque confugere; illos vero, qui negant Sanctos, aeterna felicitate in caelo fruentes, invocandos esse, impie sentire ${ }^{(16)}$.

Por tanto, el Concilio sanciona con un «impie sentire» la negativa protestante a considerar que los santos tienen poder de intercesión. El Concilio asimismo justifica el culto que se debe a las reliquias y a las imágenes de los santos con una precisión terminológica que impide establecer equivalencias semánticas con los ídolos paganos, objeción propuesta por los detractores de este culto de dulía.

La iconografía hagiográfica - pintura, escultura, grabados - que caracteriza a nuestro barroco arranca, a mi juicio, de la siguiente disposición tridentina:

Imagines porro Christi, Deiparae Virginis et aliorum Sanctorum in templis prasertim habendas et retinendas, eisque debitum honorem et venerationem impertiendam, non quod credatur inesse aliqua in is divinitas vel virtus, propter quam sint colendae, vel quod ab eis sit aliquid petendum, vel quod

(16) DENZINGER, Henricus- SCHÖNMETZER, Adolfus, Enchiridion Symbolorum Definitionum et Declarationum de Rebus Fidei el Morum, Barcinone, Herder, 1965, p. 419. 
fiducia in imaginibus sit figenda, veluti olim fiebat a gentibus, quae in idolis spem suam collocabant: sed quoniam honos, qui eis exbibetur, refertur ad prototypa, quae illae repraesentant: ita ut per imagines, quas osculamur et coram quibus caput aperimus et procumbimus, Christum adoremus, et Sanctos, quórum illae similitudinem gerunt, veneremur. Id quod Conciliorum, praesertim vero Nicaenae Synodi, decretis contra imaginum oppugnatores est sancitum. (17)

Quiero llamar la atención en otra disposición recogida por este decreto tridentino en relación con la literatura hagiográfica. Es una exhortación a que los obispos y rectores de las iglesias utilicen las artes, tanto literarias como pictóricas, para instruir a los fieles en esta doctrina hagiográfica:

Illud vero diligenter doceant episcopi, per historias mysteriorum nostrae redemptionis, picturis vel aliis similitudinibus expressas, erudiri et confirmari populum in articulis fidei commemorandis et assidue recolendis; [...] quia Dei per Sanctos miracula et salutaria exempla oculis fidelium subiciuntur, ut pro iis Deo gratias agant, ad Sanctorumque imitationem vitam moresque suos componant, excitenturque ad adorandum ac diligendum Deum et ad pietatem colendam. Si quis autem his decretis contraria docuerit aut senserit: anathema sit(18).

Todo esto explica la gran eclosión del culto de dulía con que la liturgia católica venerará a los santos a partir del Concilio de Trento; la riqueza artística que generó la hagiografía durante nuestro barroco es uno de los testimonios más singulares de los países católicos, de manera muy especial en España; la literatura, la música y las artes plásticas, al unísono, crearon un patrimonio cultural que no tiene parangón en ningún otro país.

(17) DENZINGER, Henricus; SCHÖNMETZER, Adolfus, Enchiridion Symbolorum Definitionum et Declarationum de Rebus Fidei el Morum, Barcinone, Herder, 1965, p. 420.

(18) Ibidem, p. 420. 


\section{La espiritualidad ignaciana a través del teatro hagiográfico jesuita}

Que la Compañía de Jesús jugó un papel preponderante en el desarrollo doctrinal del Concilio de Trento es algo bien conocido. Los Papas - Paulo III, Julio III, Marcelo II y Paulo IV - , que presidieron las distintas convocatorias de las sesiones tridentinas, sintieron una predilección y simpatía especiales por la nueva savia que traía aquella nueva congregación; una simple lectura de las sesiones tridentinas lo deja bien claro. Los teólogos jesuitas jugaron un papel determinante en el Concilio de Trento(19). De esta manera la Compañía de Jesús, nacida al calor de las doctrinas tridentinas como órgano oficial de la Contrarreforma, habría de tener muy en cuenta las orientaciones conciliares sobre el carácter modélico de los santos en la vida espiritual y a la vez seguir las singularidades espirituales con que la diseñó su fundador. Los jesuitas dieron un fuerte impulso a la literatura hagiográfica en los distintos géneros literarios; particular importancia tiene la obra hagiográfica del P. Pedro de Rivadeneyra con sus vidas de san Ignacio o san Francisco de Borja y, sobre todo su Flos Sanctorum [a. 1599], una obra de lectura frecuente en la espiritualidad católica desde el Siglo de Oro hasta los tiempos modernos. El teatro hagiográfico jesuítico ha de entenderse, pues, en este contexto de las doctrinas tridentinas y de la espiritualidad ignaciana.

(19) Dos nombres jesuitas van unidos al desarrollo de Trento: los PP. Diego Laínez y Alfonso Salmerón. Son los consultores habituales del Papa y de los obispos en las cuestiones más espinosas, como el tema de la justificación. La discusión entre el P. Laínez y el P. Seripando es uno de los capítulos más significativos de esta impronta del jesuitismo en Trento al dejar su sello en el decreto sobre la justificación frente a la teoría de Seripando que será calificada como la teoría camuflada de Lutero. La misma impronta dejaron los jesuitas en la teoría sacramentaria. El espíritu que se respiraba en el aula conciliar era claramente contrarreformista; lo prueba el "modus operandi" del concilio; todas las sesiones comenzaban con la intervención de los teólogos encargados de analizar la posición protestante para proponer a continuación la doctrina católica. En este análisis preliminar los teólogos jesuitas llevarán con frecuencia la iniciativa. 
Ante la imposibilidad de hacer un estudio individualizado de la propaganda ideológica en las distintas comedias hagiográficas tan solo ofreceré las características generales más significativas a modo de una tipología del santo en el teatro jesuítico donde se ve cómo la Compañía de Jesús utiliza el teatro como instrumento de propaganda ideológica de ese universo cristiano, moral y dogmático, a través de la puesta en escena de la vida de unos santos que resultan ejemplares para ser imitados por la pléyade de alumnos que acudían a sus colegios.

\subsection{Verosimilitud histórica}

La elección del personaje modelo estará condicionada por el espectador al que se dirige, esto es, un público prioritariamente estudiantil. Se trata, por tanto, de un teatro escolar ${ }^{(20)}$. Los modelos que se presentan han de tener un currículo existencial que presente unas condiciones sociales y ambientales que puedan ser verosímiles para unos jóvenes estudiantes del Siglo de Oro. De esta manera el mensaje ideológico que se pretende transmitir se hace creíble. Por ello la primera característica que ha de tener la obra literaria que se presenta, con una finalidad prioritariamente docente, es la verosimilitud histórica. De ahí que las hagiografías del teatro jesuítico tengan un trasfondo histórico que el hagiógrafo y dramaturgo seguirá con bastante fidelidad; téngase presente que algunas de estas hagiografías se escriben muy poco tiempo después de la muerte de los protagonistas; una gran parte de los espectadores habían conocido y tratado a los protagonistas; por tanto, el dramaturgo pretende escribir una biografía dramatizada. De esta manera el mensaje será más favorablemente acogido. Por otra parte, el hagiógrafo y dramaturgo elegirá dentro del santoral aquellos santos que

(20) Sobre la impronta pedagógica de este teatro escolar véase Jesús MENÉNDEZ PELÁEZ, J. Los jesuitas y el teatro... pp. 31-97; también IDEM, "El teatro escolar latino-castellano en el siglo XVI», en Javier HUERTA CALVO (Dir.), Historia del Teatro Español, Madrid, Gredos, vol. I, 2003, pp. 581-608. 
por sus circunstancias ambientales e históricas pudieran mejor adecuarse a la realidad existencial de los espectadores del Siglo de Oro. Si al mismo tiempo esos santos nacieron en el seno de la propia Compañía, la impronta docente y pedagógica será más eficiente. De ahí que una buena parte del teatro hagiográfico jesuítico tenga como protagonistas a beatos o santos salidos de la Compañía, empezando por el su Fundador.

Ignacio de Loyola, Luis Gonzaga, Francisco de Borja, Estanislao de Kostka, alcanzan la aureola de santidad en el seno de la Compañía. Sus vidas fueron utilizadas por el teatro jesuítico del P. Diego Calleja ${ }^{(21)}$. Era algo esperado, por lo que vengo diciendo, que el dramaturgo jesuita utilice sus esquemas existenciales para presentarlos como modelos que podían ser imitados por la pléyade de estudiantes y de jóvenes novicios que recibían aquellas enseñanzas(22); unas enseñanzas que provocaron celos y recelos con la universidad pública; estas pugnas y polémicas son testimonio del gran éxito que alcanzó aquella pedagogía(23). Los dramaturgos del teatro jesuítico aprovecharán esta favorable acogida que tuvieron sus colegios en la España del siglo XVI para, a través del teatro, formarles en letras y en espiritualidad, según el ya conocido marbete de Erasmo del litterae et pietas. En otro lugar ya analicé detenidamente la función docente y las características tipológicas que tiene el teatro jesuítico ${ }^{(24)}$.

(21) Hay dos padres jesuitas que llevan el nombre de Diego Calleja, lo que da origen a confusiones. Ya Cayetano Alberto de la Barrera y Leirado (Catálogo del Teatro Antiguo Español, [1860], edic. facsímil, Madrid, Gredos, 1969, pp. 59-60) advirtió esto; los dos trataron el tema hagiográfico en el teatro. El códice que se conserva en la Biblioteca Real de la Historia lleva en el lomo el título de Comedias del P. Calleja. Este padre, del que no tengo más noticias, es autor de las comedias arriba señaladas. La que se refiere al fundador de la Compañía, está fechada en 1609, y está dedicada a festejar la beatificación del fundador que tiene lugar precisamente el 15 de noviembre de ese año. La comedia referida termina con este colofón: "Acabose de componer a gloria de Dios y nuestro Beato y Padre Ignacio a 20 de Diciembre de 1609".

(22) Bernabé BARTOLOMÉ MARTíneZ, Historia de la Acción Educadora de la Iglesia en España, Madrid, BAC, 1995, p. 663

(23) Biblioteca Real de la Historia, Sección Jesuitas, Legajo 48 s/c citado por Bernabé, 1995 , p. 663.

(24) Jesús MENÉNDEZ PELÁEZ, Los jesuitas y el teatro...[1995] y «El teatro escolar latinocastellano... [2003]. 


\subsection{El santo como modelo de fortaleza}

El título que el P. Diego Calleja asigna a la hagiografía sobre san Ignacio ya es bien significativo: El Triunfo de Fortaleza; la fortaleza como virtud cristiana la prodiga san Ignacio sobre todo para afianzarse en la vocación jesuítica. Con frecuencia el joven que deseaba entrar en religión podía encontrarse con la negativa de su familia, particularmente del padre. El propio san Ignacio hubo de intervenir personalmente en alguna ocasión para resolver un conflicto familiar en que el padre de un muchacho se oponía a que su hijo profesara en la Compañía; en aquella ocasión Ignacio de Loyola escribe una larga carta que es una disertación sobre la fortaleza que los jóvenes han de tener para defender su vocación religiosa frente a los imperativos familiares ${ }^{(25)}$. En los catecismos de la época, tanto en el del P. Astete ${ }^{(26)}$ como en el del P. Ripalda(27) se considera a la Fortaleza como una de las virtudes cardinales y uno de los dones del Espíritu Santo. La Fortaleza será, siguiendo la presencia de personajes alegóricos que prodigó siempre el teatro jesuítico, uno de los personajes centrales de la obra. Los jóvenes novicios que se decidían a entrar en la nueva Congregación necesitaban un modelo a seguir. El hagiógrafo del teatro jesuítico les propone el ejemplo del propio fundador. El hagiógrafo y dramaturgo quiso sazonar esta obra dramática, estructurada en tres largas jornadas, con un acentuado verismo histórico; los personajes representan el entorno existencial en el que vivió Ignacio a partir del cerco de Pamplona por los franceses con que se inicia la obra: Diego Laínez, Salmerón, Francisco Javier son algunos de los personajes que revestidos con el don de la Fortaleza consiguen vencer al Demonio, La Carne, Lutero, La Herejía y la Gentilidad.

(25) SAN IGNACIO DE LOYOLA, Obras Completas, edic. de Ignacio IPARRAGUIRRE- Cándido de DALMASES y Manuel RUIZ JURADO, Madrid, BAC, 1991, pp. 964-965.

(26) P. ASTETE, Catecismo de la doctrina cristina, Madrid, Maeva, 1997, pp. 31-32

(27) P. RIPALDA, Catecismo de la doctrina cristiana, Madrid, Maeva, 1997, p. 42 


\subsection{El santo como modelo de renuncia al estatus social de la familia}

Luis Gonzaga, Francisco de Borja (1510-1572) y Estanislao de Kostka, nacidos a la vida espiritual en el seno de la Compañía, serán referentes constantes en la vida de esta Congregación desde sus inicios hasta los tiempos modernos; la iconografía que adorna iglesias, pasillos y estancias de los actuales colegios de jesuitas no es más que el testimonio del fervor que estos primeros jesuitas suscitaron entre sus correligionarios. Tres vidas muy singulares. Los tres eran de procedencia noble y habían experimentado los loores de la vida cortesana.

Luis Gonzaga era el mayor de los hijos de una influyente familia cortesana en la Lombardía italiana; desde muy joven se sintió atraído por la vida espiritual, lo que ponía en peligro las pretensiones que su padre había depositado en él; en vano intenta halagarle con todos los placeres de la vida nobiliaria europea para disuadirle de aquella vocación religiosa; placeres, honores, seducciones sexuales y glorias no lograron cambiar la decisión de entrar en religión bajo los auspicios de Ignacio de Loyola. La decepción de su padre, que había hecho lo indecible para que su hijo Luis desistiese de entrar en religión, queda patente en la carta que escribe al padre Claudio Acquaviva, General del noviciado jesuítico donde entra Luis: "Hago saber a vuestra señoría reverendísima que le entrego lo que más quiero en este mundo y la mayor esperanza que tenía para la conservación de mi casa»(28). Como puede verse, se trababa de una vida que para los rectores de la Compañía resultaba ejemplar y modélica a través de la cual se podía transmitir una propaganda de las verdades morales y dogmáticas del universo cristiano. De ahí que los dramaturgos y hagiógrafos del teatro jesuítico la hayan utilizado como fuente de inspiración para su teatro. Dos comedias del P. Salas (Coloquio del primer estudiante y mayorazgo trocado, beato Luis Gonzaga y El estudiante soldado que es la niñez del beato Gonzaga)

(28) «San Luis Gonzaga» en AA. VV., Año cristiano, Madrid, BAC, II, 1959, p. 712 
y un diálogo del P. Ximeno del colegio de Aragón (Diálogo del beato Luis Gonzaga) ${ }^{(29)}$, además de poemas sueltos, testimonian el carácter ejemplar y modélico que la vida de Luis Gonzaga tenía para los alumnos y novicios de los colegios de jesuitas. Estas obras recalcan varias virtudes que a juicio de los dramaturgos resultaban modélicas y que, por tanto, habían de imitar los estudiantes de la Compañía. Una de ellas era la castidad, el personaje alegórico quizás más importante en ellas; el padre de Luis, en su intento para que desistiera de entrar en religión y se ocupase de su casa como mayorazgo que era, le había hecho rodear de un ambiente cortesano poco propicio para conservar la virginidad; sin embargo, el joven Luis se mantuvo fiel a sus ideales; de esta manera pasó a ser considerado como modelo de castidad. La segunda virtud que los citados dramaturgos presentan como modélica y ejemplar en Luis Gonzaga es la milicia cristiana, una vieja alegoría bíblica que pasa al cristianismo, bajo la metáfora del miles christianus que defiende el reino de Dios y que tomará cuerpo estamental y social en las llamadas órdenes militares desde la Edad Media hasta la Ilustración. Fue esta una idea muy querida por Ignacio de Loyola. Recuérdese que la Bula fundacional de la Compañía de Jesús de 1540 lleva por título Regimini militantis Ecclesiae y que "cualquiera que entre en nuestra Compañía ha de ser soldado de Dios bajo la bandera de la Cruz" ("Quicumque in Societate nostra, quam Iesu nomine insigniri cupimus, vult sub crucis vexillo Deo militari»; el «miles christianus» será uno de los ingredientes de ese universo cristiano; los miembros de la Compañía han de ser ante todo soldados de Cristo. La ascética ignaciana es una lucha entre dos realidades o fuerzas antitéticas, el Bien y el Mal; son como dos ejércitos, capitaneados por dos jefes militares, Cristo y el Demonio. Es este el núcleo de una de las meditaciones más originales de los Ejercicios Espirituales conocida como «la de las dos banderas». Es, asimismo, la idea motriz que aparece constantemente como el núcleo o leit-motiv de la acción dramática del teatro hagiográfico jesuítico. El escenario es como un campo de batalla en donde lidian dos

(29) Biblioteca Real de la Historia, Ms. 9/2571 
ejércitos que enarbolan su propia bandera para llevarse a su lado al protagonista. Los numerosos personajes de que constan las hagiografías del teatro jesuítico serán militantes de una de estas dos fuerzas o banderas; la alegoría será el recurso dramático habitual para crear unos personajes que representan vicios y virtudes en aquellos escenarios del teatro escolar. Luis Gonzaga fue modelo de «estudiante soldado» bajo la bandera de Cristo.

Estas mismas características presentan las comedias hagiográficas sobre Francisco de Borja y Estanislao de Kostka que omito.

Continuando con las hagiografías del P. Calleja nos encontramos ahora con otros modelos muy distanciados en el tiempo de los santos anteriormente presentados como ejemplos que deben ser imitados. Hasta ahora hemos aludido a santos nacidos al socaire de la Compañía; fueron, sin duda, los más modélicos y ejemplares para transmitir la propaganda ideológica del universo cristiano; pero el repertorio había de ampliarse; por eso el hagiógrafo y dramaturgo elegirá dentro del santoral aquellos santos que por sus circunstancias ambientales e históricas pudieran mejor adecuarse a la realidad existencial de los espectadores del Siglo de Oro; de nuevo nos encontramos con que los santos elegidos para la comedia hagiográfica fueron santos cuya conducta religiosa había provocado un conflicto familiar. El mensaje propagandístico es muy claro: los imperativos religiosos han de estar por encima de los proyectos sociales de la voluntad paterna. Este será el mensaje que el dramaturgo intentará transmitir con dos modelos de santos, cuyas coordenadas existenciales se enmarcan en la Roma Imperial de Teodosio el Grande (347-395) y Honorio (384-423); estamos, pues, a finales del siglo IV y principios del V. La paz de Constantino (306-337) había hecho del cristianismo la religión del Imperio; era la primera célula de lo que después se llamó el nacionalcatolicismo que tendrá en Carlos V y, sobre todo, en Felipe II una verdadera continuación. Mutatis mutandis, el dramaturgo del teatro jesuítico busca un pasado con unas ciertas analogías con el momento en el que él escribe. El santoral recogía dos santos un tanto extraños, uno de la tradición griega y bizantina, San Juan Calibita, mientras 
el otro estaba inserto en la sociedad romana, san Alejo ${ }^{(30)}$. El dramaturgo jesuita situará a la familia de san Juan Calibita en la Roma del emperador Teodosio; la comedia nos presenta a su padre, Eutropio, en diálogo con su esposa, muy preocupados ambos por dar a su hijo un «estado conveniente» (fol. 66v). La llegada de un monje eremita a la casa del noble patricio provocará el conflicto. El joven Juan abandonará su casa para seguir los postulados de la vida eremítica; el trauma familiar resulta claro. Se fuga de la casa paterna, sin saber su paradero. Pasados los años regresará de nuevo como pobre mendigo, pidiendo limosna en su antiguo hogar, no siendo reconocido por los suyos; su propia madre le desecha, mientras su padre le acoge disponiendo una choza para él. La vida penitente que lleva conmueve a cuantos le visitan; finalmente, poco antes de morir refiere a su propia madre su verdadera identidad.

La Vida de san Alejo tiene muchos parecidos con la anterior(31). De nuevo la comedia hagiográfica jesuítica actúa de medio de propaganda de los ideales de la espiritualidad ignaciana. La renuncia a la propia familia fue objeto constante de la espiritualidad jesuítica; el ya citado P. Alonso Rodríguez dedica el Tratado Quinto del Libro II de su Ejercicio de perfección cristiana a "De la afición desordenada de parientes"; son siete capítulos en los que el jesuita habla de los peligros que puede suponer un excesivo apego a la propia familia; su reflexión está entreverada de abundantísimos ejemplos de conducta modélica no sólo de santos sino del propio Ignacio de Loyola que mostraron un cierto desarraigo con su familia. El santo del teatro jesuítico ha de ser también modelo en refrenar esta tendencia innata en el ser humano.

(30) La tradición de estos santos, particularmente de san Alejo, fue estudiada por Carlos Alberto VEGA, La vida de san Alejo. Versiones castellanas, Salamanca, Universidad, 1991. Las comedias jesuíticas referidas se encuentran en Biblioteca Nacional, Ms. 17.288, san Alejo, fols. 1r-62r; san Juan Calibita, fols. 63r-105v.

(31) Véase Jesús MENÉNDEZ PELÁEZ, "El santo peregrino en el teatro jesuítico: La vida de san Alejo, peregrino en su patria", en Homo viator. Errance, pélegrinage et voyage initiatique, Coloquio Internacional celebrado en la Universidad de Caen (Normandía), 27-28 y 29 de mayo de 2004 [en prensa]. 


\subsection{El santo como modelo de firmeza en la fe cristiana}

La espiritualidad jesuítica no podía obviar las particulares circunstancias que rodeaban la historia de la Iglesia durante el Siglo de Oro. El teatro jesuítico nos presenta a santos que han sacrificado su propia vida por defender sus creencias religiosas. Es otra de las parcelas modélicas que presenta el santo del teatro jesuítico. Hasta ahora habíamos visto santos dentro de la categoría de "confesores» o "Vírgenes», ahora nos adentramos en la categoría de los santos «mártires». San Hermenegildo, san Pedro Mártir, santa Catalina de Alejandría, santa Cecilia, san Tiburcio y san Vicente y hermanos son los puntos de mira de los dramaturgos del teatro jesuítico.

En la Tragedia de san Hermenegildo, una de las obras mejor logradas no sólo del teatro jesuítico sino del teatro renacentista español, el mensaje ideológico que se quiere transmitir es muy claro: los imperativos religiosos han de estar por encima de la voluntad paterna. Hermenegildo aceptará el martirio, renunciará a los vínculos familiares antes de claudicar de su fe. Las analogías que planteaba el hecho histórico del siglo VI en el que se evoca el conflicto entre un padre arriano y un hijo que abjura de la religión paterna y se convierte al catolicismo guardaban estrecha relación de verosimilitud para la sociedad de finales del siglo XVI, que vivía la ruptura entre católicos y protestantes. No ha de olvidarse que tal ruptura entre católicos y protestantes fue siempre una de las grandes preocupaciones de la Compañía de Jesús, cuyo testimonio más fehaciente lo dejó el P. Pedro de Ribadeneyra en sus Historias de la Contrarreforma (32).

Dejamos a san Pedro Mártir, cuya vida sirvió de inspiración al P. Guillermo de Barceló para su Dialogus Petri Martiris certamen cum Arrianis hereticis et eiusdem mortem continens ${ }^{(33)}$ cuya finalidad es presentar la fortaleza espiritual de este santo frente a la herejía; evocamos, sin embargo, a

(32) Pedro de RIBADENEYRA, Historias de la Contrarreforma, Madrid, BAC, 1945.

(33) Biblioteca Real de la Historia, Ms. 9/2569, fols. 1r-12v. 
santa Catalina de Alejandría, una de las santas más celebradas en el teatro jesuítico, cuyos dramaturgos no hacen más que continuar una tradición que en los tiempos medievales había alcanzado su máximo apogeo; esta santa, mártir en el Imperio romano del siglo IV, fue considerada como modelo de fortaleza e ingenio en la defensa de la fe cristiana; son muchas las instituciones que ya desde la época medieval se acogieron a su patronazgo: Universidad de París, filósofos, estudiantes, molineros, carreteros... Los colegios de jesuitas celebraron siempre con un cierto boato su festividad. De ahí que los dramaturgos del teatro jesuítico se hayan inspirado en una tradición, envuelta en la leyenda, sobre la discusión que mantuvo con los filósofos gentiles y la aceptación del martirio. El P. Hernando de Ávila, autor principal de la Tragedia de san Hermenegildo, es al mismo tiempo el autor de la Tragicomedia de santa Catalina, Virgen y Mártir (34). El dramaturgo, como indica en el prólogo, pretende presentar a la santa como modelo de "virgen y esposa de Cristo" y de "fortaleza y varonil constancia / que no la puso miedo el cruel tirano / las amenazas dél ni los tormentos» (fol. 107v). A lo largo de la obra se pone de manifiesto una vez más el influjo de la imaginería presentada por san Ignacio de Loyola en los Ejercicios Espirituales bajo la iconografía de las dos banderas. Después de negarse a presentar la ofrenda a los dioses paganos, pues ella solo "a Cristo eterno y celestial esposo/ de mí le hago humilde sacrificio» se le presentan tres ángeles, uno de los cuales sostiene con la santa este diálogo:

$$
\begin{aligned}
& \text { Ángel. - Queréis, sabia Catherina, } \\
& \text { militar como guerrera } \\
& \text { debaxo de la bandera } \\
& \text { de la milicia divina? } \\
& \text { Catalina. - Sí quiero, y bien que quiera. } \\
& \text { Ángel. - ¿Proponéis de pelear } \\
& \text { y con valor conquistar } \\
& \text { por la fe de Jesucristo? }
\end{aligned}
$$

(34) De esta obra se conservan dos manuscritos: Biblioteca Nacional de Madrid, Ms. 17.288, fols. 106r-191v; Biblioteca del Colegio de san Ignacio de Alcalá de Henares, Ms. 325. Las referencias se toman del manuscrito de la Biblioteca Nacional. 


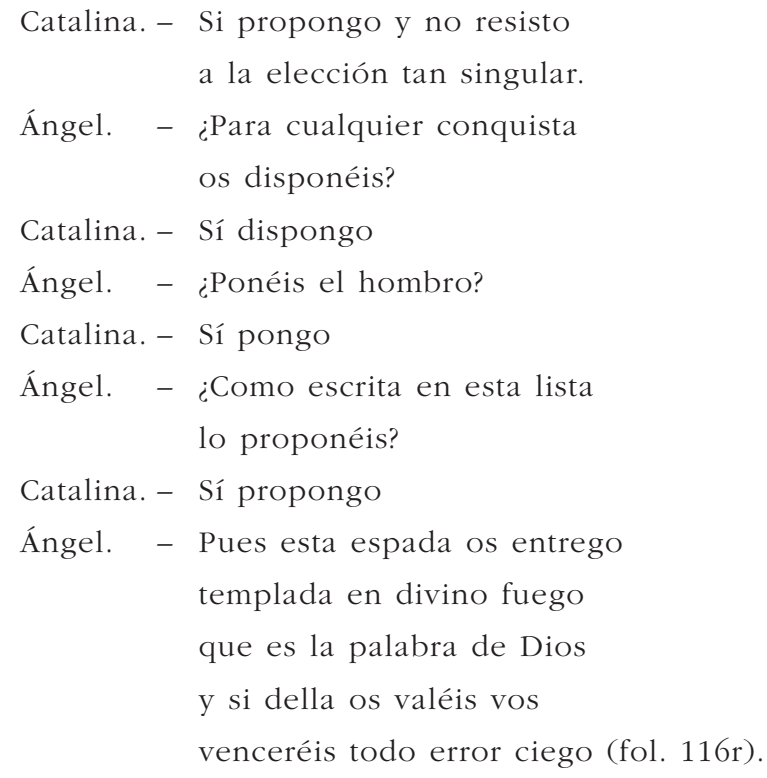

El teatro eleva a la categoría sensible, mediante la representación, una de las ideas básicas de la espiritualidad ignaciana y que forma parte del universo cristiano y caracteriza a los miembros de la Compañía de Jesús: la milicia cristiana, el "miles Christianus».

San Vicente y hermanos mártires. Los ejemplos de los hermanos Vicente, Sabina y Cristena, mártires bajo la persecución de Diocleciano, constituyen la sustancia del contenido dramático de la obra de Juan Bonifacio Tragoedia quae inscribitur vicentina ${ }^{(35)}$. Nacidos en Talavera de la Reina son ejecutados en Ávila, ciudad que los tiene como patronos y donde se levanta la basílica de san Vicente, uno de los monumentos más impresionantes del románico español. El dramaturgo jesuita, en este caso el P. Juan Bonifacio, profesor de Latín y de Retórica durante un tiempo en el colegio jesuítico de Ávila, utiliza el teatro para proponer unos modelos de conducta ejemplar en la actitud de estos tres hermanos que aceptan el martirio antes que claudicar

(35) Juan BONIFACIO, "Códice de Villagarcía», Biblioteca Real de la Historia, Ms. 9/2565, fols. $144 \mathrm{r}-168 \mathrm{r}$. 
de su fe. El universo cristiano exige la renuncia a la propia vida antes que renegar de los principios de la fe. El espíritu contrarreformista aconseja al creyente incluso perder la propia vida antes de claudicar de las propias convicciones dogmáticas; el respeto al dogma puede exigir al cristiano la renuncia a la propia existencia. La naturaleza juvenil de estos protagonistas — jóvenes adolescentes — les hacía más ejemplares y modélicos: modelos de firmeza por la defensa de la fe.

Los dramaturgos y hagiógrafos del teatro jesuítico seguirán buscando modelos en jóvenes mártires de los primeros siglos del cristianismo para presentarlos como espejos en los que habían de mirarse los jóvenes estudiantes del Siglo de Oro por su fidelidad a la nueva religión y a la vez como modelos de castidad. Es el tema en el que se inspira el Diálogo de la gloriosa y bienaventurada virgen y mártir santa Cecilia y santos Tiburcio $y$ Valeriano $^{(36)}$. Es un caso de amor tratado de una manera muy singular. Los protagonistas son tres jóvenes patricios de la Roma Imperial: Valeriano, Tiburcio y Cecilia. La obra dramática comienza con un "romance» a la manera de prólogo donde se cuenta la historia.

Valeriano se enamora de Cecilia desconocedor de que la joven se ha convertido al cristianismo con voto de castidad. La joven no puede hacer público su compromiso religioso, pues estamos en plena persecución religiosa. El casamiento se realiza. Cuando los jóvenes se introducen en la cámara nupcial y Valeriano se dispone a consumar el matrimonio, Cecilia le cuenta su gran secreto; su amor ha de ser puramente espiritual; cualquier atrevimiento será castigado por el ángel que la acompaña el cual está presto a utilizar su espada para defender la fidelidad de la virgen con Cristo su esposo. Valeriano no ve en la habitación más que a su esposa; para ver al ángel - le dirá su esposa — es necesario que te bañes en las aguas sagradas que podrás encontrar en las catacumbas de los cristianos. Allá se dirige;

(36) Biblioteca Real de la Historia, Ms. 9/2568, fols. 144r-175v. 
se encuentra con el Papa quien le cuenta todo el proceso de conversión de Cecilia. Las aguas sagradas serán el bautismo que recibe de manos de Sumo Pontífice; vuelto a casa va al encuentro de su esposa que está en la alcoba; allí la encuentra efectivamente acompañada del ángel que les ciñe a ambos con dos coronas de guirnaldas de rosas. La fragancia de las rosas despierta la curiosidad de Tiburcio, hermano de Valerio, el cual le persuade para que deje la idolatría; de esta manera, los tres afrontarán el martirio. He aquí un argumento más sazonado de leyenda que de historicidad. No importa. Al dramaturgo le interesa recrear dramáticamente unos ejemplos que podían servir de modelos de castidad y de fortaleza, dos de las grandes virtudes del universo cristiano, frente al paganismo.

Una lectura propagandística muy semejante se desprende de la Vida de san Eustaquio. El protagonista y su familia pertenecen al estamento militar romano; una misteriosa aparición de Cristo al joven Eustaquio en una escena cinegética es el comienzo de su conversión; después de una larguísima cadena de aventuras con su mujer y sus hijos, que recuerda el esquema narrativo de la novela bizantina, terminarán aceptando el martirio antes que rendir culto a los dioses paganos. Eustaquio, su mujer y sus hijos son presentados aquí como una familia modélica de firmeza en la fe cristiana. La ambientación del mundo pagano que subyace en todas estas obras no es ajeno a otra preocupación que siempre embargó a los pedagogos jesuitas: el peligro de un excesivo fervor por la Antigüedad Clásica que podía conducir a una paganización; en las obras del P. Acevedo, primer dramaturgo del teatro jesuítico, está muy presente esta idea. Los jesuitas desde sus colegios fueron grandes impulsores de los studia humanitatis, pero a la vez sintieron la zozobra y advirtieron de los peligros de paganización a los que podría abocar un excesivo entusiasmo por los autores clásicos. La expurgación de Terencio es un caso claro. Desde el teatro los dramaturgos jesuitas defenderán la idea de que por encima de la bondad estética del mundo clásico está la bondad moral del universo cristiano. 


\subsection{El santo como modelo de la eficacia en la consecución de la gracia divina}

El P. Cigorondo, uno de los más fecundos literatos de la Compañía, como poeta y como dramaturgo, compuso, entre otras varias obras, una Comedia a la gloriosa Magdalena ${ }^{(37)}$ de "dos mil setecientos versos más o menos", como dirá al final. La historia la recogen los evangelios: María Magdalena vivió cautiva del Amor profano hasta que descubre a Cristo, Amor divino. La gracia divina transformó radicalmente la vida de aquella meretriz hasta convertirla en una santa. La doctrina sobre la justificación fue uno de los puntos de mayor disensión en Trento por su divergencia con los protestantes. El agrio problema "de auxiliis» que convulsionó la espiritualidad del Siglo de Oro está aquí presente según la tesis jesuítica del P. Molina. El dramaturgo desarrolla la obra tomando como núcleo dramático la lucha interior de estos dos impulsos antitéticos, que tomarían cuerpo existencial en aquellos jóvenes estudiantes. María Magdalena se convierte así en un modelo que supo vencer al amor profano. Una de las cuartetas finales es bien explícita:

$$
\begin{aligned}
& \text { Sírvaos María de exemplo } \\
& \text { en ver con la integridad, } \\
& \text { que en sintiendo la verdad } \\
& \text { supo fabricarle el templo (38). }
\end{aligned}
$$

\subsection{El santo como modelo de espíritu misionero}

La vocación misionera, finalidad primera de la Compañía, aparece muy temprano en el teatro jesuítico. La figura de san Francisco Javier, compañero de san Ignacio desde los inicios, partirá como misionero para la India

\footnotetext{
(37) Biblioteca Nacional, 17.286, fols. 13r-87v.

(38) Ibidem, fol. 87r.
} 
en 1540. Sus cartas misioneras dirigidas a los miembros de la orden, en las que contaba los avatares de su evangelización por tierras del lejano Oriente, fueron siempre punto de referencia espiritual para mantener viva la vocación de catolicidad con que nació la Compañía. La Gran Comedia de san Francisco Javier, el Sol en Oriente y el Coloquio de la conquista espiritual del Japón hecha para san Francisco Javier(39) (BRH, 9/2575) son dos hagiografías cuyas características estilísticas de una y otra obra remiten al barroco; las dos son anónimas y presentan al santo navarro como modelo de una catolicidad sin fronteras culturales, étnicas y políticas:

\author{
valeroso adalid contra el infierno, \\ luz de la compañía y ornamento, \\ apóstol que entre bárbaras naciones \\ dio luz donde no alcanzan los Triones ${ }^{(40)}$
}

\title{
A modo de conclusión
}

Los distintos santos que inspiran la comedia hagiográfica del teatro jesuítico son presentados como modelos, cuyo devenir existencial ejemplifica las nuevas orientaciones de la espiritualidad pergeñada por san Ignacio, quien a su vez asume las nuevas prerrogativas que dimanan del concilio de Trento. Contrarreforma y espiritualidad ignaciana, expresada literariamente de manera muy singular por el P. Alonso Rodríguez ${ }^{(41)}$ o el P. Ribadeneira, serían, a mi juicio, los soportes ideológicos que subyacen en el texto dramático, cuyas técnicas escénicas y dramáticas siguen los postulados del carácter docente de este teatro escolar. Como dirá Alonso Asenjo, "la Compañía de

(39) Biblioteca Real de la Historia, 9/2575.

(40) Biblioteca Real de la Historia, Ms. 9/2575, fol. 2v.

(41) Como ya se dijo, el P. ALONSO RODRÍGUEZ (1538-1616) es el autor del Ejercicio de perfección y virtudes cristianas, una de las obras que mayor impronta ha dejado no solo en la espiritualidad y ascesis de los miembros de la Compañía de Jesús, sino que trascendió a otras comunidades religiosas, por lo que se le considera un clásico de la espiritualidad de nuestro Siglo de Oro. 
Jesús centrará sus esfuerzos en la aceptación de la religiosidad católica activa y militante, en la ascética y en la teología»(42). La hagiografía del teatro 126 jesuítico es una manifestación más del arte al servicio de la propaganda ideológica generada por la Contrarreforma.

(42) Julio ALONSO ASENJO, La Tragedia de san Hermenegildo y otras obras del Teatro Escolar Español de Colegio, Sevilla-Valencia, UNED, 1995, Vol. I, p. 27 


\title{
Dietrich Briesemeister \\ Universidade Livre de Berlim
}

\author{
O TEATRO ESCOLAR JESUÍTICO E OS \\ DESCOBRIMENTOS PORTUGUESES: ANTÓNIO DE SOUSA E
}

LA REAL TRAGICOMEDIA DEL REY DOM MANOELL

A aparatosa representação da Tragicomédia do descobrimento e da conquista do Oriente pelo rei Dom Manuel, o Venturoso, da autoria do Padre António de Sousa (1591-1625) no Colégio de Santo António em Lisboa, nos dias 21 e 22 de Agosto de 1619 não teria sido bem sucedida sem uma longa tradição literária e prática dramatúrgica cultivadas pela Companhia de Jesus. O espectáculo, composto em menos de quatro semanas, subiu à cena por ocasião da entrada solene do rei Filipe III da Espanha na capital lusa, no quadro do programa festivo que celebra a primeira visita oficial do monarca ao reino sob o domínio filipino. O texto não se conserva integralmente, uma vez que Sousa, na costumada modéstia dos professores da classe de retórica, se recusou à sua publicação, aliás talvez por motivos políticos. Existe somente uma relação bilingue bastante completa redigida por João Sardinha Mimoso com a aquiescência do próprio autor na base de suas informações e segundo as cópias manuscritas dos papéis distribuídos aos jovens actores.

"Habes carmina a semilaceris actorum chartis eruta, semideletis caracteribus seu caracterum centonibus tradita», disse o compilador no final, pedindo desculpas ao leitor pelas erratas. ${ }^{(1)}$ O título reza em espanhol:

(1) Conheço dois exemplares na Alemanha, um conservado no acervo antigo da Biblioteca Ducal em Wolfenbüttel e outro na Brasilien Bibliothek da empresa Robert Bosch em Estugarda, 
Relacion de la Real Tragicomedia com que los Padres de la Compañia de Jesus en su colegio de S. Anton de Lisboa recibieron a la Magestad Catolica de Felipe segundo de Portugal, y de su entrada en este Reino (Lisboa: Jorge Rodriguez, 1620).

Além do livro publicado um ano depois do evento, circulou com certeza um programa (perioche) — «librito de extracto», f. 63r — do qual o editor se serviu também para a reconstituição do texto representado em presença do insigne espectador (vide f. 4v). O título exacto da peça teatral que articula demonstrativamente a autoconsciência histórica dos portugueses não figura na relação. O editor fornece, à parte de extensos passos métricos em latim, o argumento das cenas em castelhano para a melhor compreensão do Rei e seu séquito, provavelmente menos destro em captar a língua do Lácio, assim como descrições dos bastidores e da vestimenta dos numerosos comparsas e actores colegiais, da cor e do valor das pedras preciosas, dos efeitos figurativos alegóricos, dos símbolos e emblemas pintados, das danças e coros cantados, etc.: tudo isso forma um conjunto de interesse excepcional para a história material do teatro de colégio, o seu equipamento e o dispêndio gastos naquelas circunstâncias para impressionar o monarca malquerido. Mesmo sem ilustrações, podemos imaginar vivamente o luxo incrível espalhado no pátio do colégio, fundado já em 1553 e que, no seu momento de maior esplendor, albergava quase 2.500 alunos. A descrição gráfica que deu João Baptista Lavanha, historiógrafo da Corte na Viagem de Catholica Real Magestade del Rey D. Filipe II N. S. Ao Reyno de Portugall E Rellação do solene recebimento que nele se lhe fez (Madrid: Thomas Iunti, 1622, com uma edição espanhola do mesmo ano), realça o carácter oficial e publicitário do

de aquisição recente. Vide SEQUEIRA, G. de Matos, Teatro de Outros Tempos, Lisboa, 1993, pp. 145 e ss; FRÈCHES, Claude-Henri, "Le théâtre néo-latin au Portugal: histoire et actualité dans les tragicomédies du XVII e siècle» in Euphrosyne, Revista de Filologia Clássica 2 (1968) 87-131; FRĖCHES, Claude-Henri, "Le théâtre néo-latin au Portugal. La Tragicomédie de Dom Manuel» in Aufsätze zur portugiesischen Kulturgeschichte 5 (1965) 108-148; FRÈCHES, Claude-Henri, Le Théâtre néo-latin au Portugal (1550-1745), Paris/Lisboa, 1964. 
precioso volume. ${ }^{(2)}$ Contém 14 gravuras com os arcos triunfais erigidos nas ruas e praças de Lisboa pelos grémios profissionais e pelas comunidades de estrangeiros residentes na capital (entre eles alemães e ingleses). Lavanha menciona também a função teatral no recinto monástico e dá um resumo do itinerário do cortejo real em território português. A arquitectura efémera com o seu imenso desenrolamento emblemático, alegórico e mitológico transforma o espaço público em cenário festivo dum espectáculo barroco total que repete, varia e celebra motivos e momentos centrais do drama panegírico, (3) por exemplo, com as alegorias dos quatro continentes, os cenários de guerra, as figuras e os acontecimentos da história nacional, os heróis Vasco da Gama e Cristóvão Colombo com os atributos simbólicos dos países descobertos, Portugal e Castela como «ministros de la dilatación de la Fe» e defensores da Igreja de Roma contra os infiéis e heréticos. A relação de Lavanha e o livro de João Sardinha Mimoso, que contém a Tragicomédia, constituem dois documentos sumamente ilustrativos para a história das festividades públicas e da dramaturgia barroca em Portugal.

(2) Exemplar no Gabinete de Estampas, Fundação Património Cultural Prussiano, Berlim; vide também o estudo de VETTER, Ewald M., "Der Einzug Philipps III, in Lissabon 1619" in Aufsätze zur portugiesischen Kulturgeschichte 19 (1962) 187-263.

A correspondente écfrase poética encontra-se nos romances de Francisco Rodrigues Lobo, La Iornada que la Magestad Catholica del Rey Don Phelippe III de las Hespañas hizo a su Reyno de Portugal, y el Triumpho, y pompa con que le recibió la insigne Ciudad de Lisboa el año 1619, Lisboa, 1623. António José Saraiva e Óscar Lopes (História da Literatura Portuguesa, Porto, ${ }^{17} 1996$, p. 395) presumem que «talvez Rodrigues Lobo quisesse, com a Iornada, defender-se da acusação de antifilipismo». Lavanha escreveu a relação por ordem do rei. A descrição da Tragicomédia encontra-se na versão espanhola, f. 66v-71r. Além disso, refere-se a dois espectáculos mitológico-alegóricos mudos, montados em honra do soberano: um desfile fluvial e instalações figurativas do desembarque em Belém e no Terreiro do Paço - na Aduana - o Combate dos Gigantes (Titãs) celebrando a expulsão dos mouriscos em 1609. O historiador Lavanha reformou também a Década IV da Ásia que João de Barros deixou inacabada; o volume quarto saiu em Madrid (1615).

$\mathrm{Na}$ descrição do "Arco de los mercaderes alemanes", que exalta as relações hispano-alemãs, Lavanha menciona que Filipe III, ao receber a notícia da guerra na Alemanha que chegaria a durar trinta anos, interrompeu a viagem para voltar a Madrid.

(3) Los architectos designan / Mil cuerpos de varias formas, / Las ingeniosas empresas, /Hieroglíficos, y historias. / Los poetas alabanzas / Letras, versos, motes, glosas, / Los pintores mil batallas, / Figuras, Reys, y Heroas. Rodrigues Lobo, La Iornada; f. 18v-19r. 
Abstraindo das qualidades retóricas e literárias, a Tragicomédia veicula uma séria mensagem parenética. O facto de Sardinha Mimoso, o seu editor, ter inserido no meio dos trechos latinos anotações que explicam figuras e episódios da história de Portugal (biografias panegíricas de Vasco da Gama, Francisco Almeida e Afonso de Albuquerque) é outra prova de que a publicação posterior à data do acontecimento protocolar não corresponde ao interesse do público local e pátrio mas, sim, se dirige inequivocamente aos espanhóis como gesto ostentativo "pera em toda Espanha se conhecer a perfeição Portugueza», como afirma o Prólogo (f. 1v). A sinopse histórica espalhada ante o soberano estrangeiro leva ao mesmo tempo a dedicatória ao Duque de Bragança, Teodósio II, considerado como pretendente legítimo ao trono, um desafio sem rodeios. A Companhia de Jesus favorecia em boa medida a Restauração. De facto, em 1640, D. João, Duque de Bragança, será proclamado rei de Portugal depois de sessenta anos de dominação espanhola. Os espanhóis prosseguiam uma política humilhante para com os vizinhos e rivais. Entretanto, a oposição recrudescia em Portugal. A epopeia Os Lusíadas tornou-se em símbolo literário e manifesto ideológico da resistência patriótica e da identidade nacional. Em ordem a estas atitudes políticas, a tradução neolatina (Lisboa, 1622) que Fr. Tomé de Faria, bispo de Targa, fez daquele poema era um fanal mais visível para lá. Sem mencionar o nome do autor, naturalmente muito célebre, leva a dedicatória ao "Inclito, Invicto ac Illustri Portugalliae Regno". Faria evoca de maneira saudosista e orgulhosa a grandeza passada: "Cum mecum famam qua olim, o fortunatissimum Regnum, in toto terrarum orbe floruisti, infelicemque statum ad quem, ob tua maxima flagitia, quinquaginta ante annos devenisti, perpenderem magnumque inde animi maerorem conciperem, ut mibi esset solamini, animum ad antiquiora Lusitanorum facta, quam alii pedestri oratione conscripserunt, carminibus beroicis, quae non nisi de re seria ac gravi agunt, commendanda applicaui». (4)

(4) BRIESEMEISTER, Dietrich, "As traduções neo-latinas de Os Lusíadas" in Forum Litterarum. Miscelânea de estudos literários, linguísticos e históricos oferecida a J. J. van den Besselaar. Ed. Hans Bots e Maxim. Kerkhof, Amsterdam e Maarssen, 1984, 95-101. 
Só em 1619, trinta e cinco anos depois de ter sido investido como herdeiro do trono de Portugal, Filipe III, nascido no mesmo ano da morte do rei D. Sebastião, se decidiu a visitar o país contra o parecer do Conselho do Estado e do Conselho de Castela. As profecias populares do regresso iminente de D. Sebastião e da subsequente restauração da antiga autonomia de Portugal ligaram-se aos Duques de Bragança.

Tais expectativas messiânicas tinham uma profunda repercussão na mentalidade espiritual e política do povo. Neste contexto, D. Teodósio representava a máxima figura legítima da monarquia extinta, sob a dominação dos Habsburgos. As posturas anti-espanholas e as esperanças sebastianistas confluíam. O teatro neolatino também está decididamente do lado da causa patriótica. Junto com outros confrades, o P. Sousa favorecia, mais ou menos abertamente, o retorno da Casa de Bragança ao trono. Desde a sua chegada, Filipe III viu-se confrontado com a proposta de declarar Lisboa capital do império luso-espanhol, o que explicaria os esforços dos portugueses para preparar ao soberano um acolhimento arrebatador, digno de uma metrópole. A arquitectura triunfalista e a decoração iconográfica põem em evidência a grandeza, o poder e a riqueza sem igual da cidade do Tejo. Lisboa, herdeira de Roma, era já uma ideia muito cara aos humanistas e historiadores do século XVI. André de Resende, em 1534, fez o elogio nestes termos: «Olisipo... quae una nostro aeuo Romanam gloriam et triumphos adaequauit. Regina uasti Oceani, superba Mauretaniae, Atlantidis orae, Aethiopiae, Arabiae, Persidis, Indiae, Taprobanes et innumerabilium insularum domitrix». (5)

Camões exalta Portugal como "quasi cume da cabeça/ De Europa toda» (Lus. III, 2), retomando a imagem alegórico-simbólica da Europa na car-

(5) Numa carta dirigida ao rei D. João II, Angelo Poliziano (apud Fidelino de Figueiredo, A Épica Portuguesa no Século XVI, Lisboa, 1987, p. 95) escreveu em 1489 "Etenim Lusitaniae te regem cernes, hoc est (ut semel dixerim) Romanae multitudinis, cuius olim tam multis (sicut accepimus) coloniis ista potissimum regio frequentabatur. Invoca, ainda antes do descobrimento do Brasil, o rei como "mundi alterius sequester et ianitor, tot illos sinus, tot promontoria, tot littora, tot insulas, tot portus, tot oppida, tot maritimas urbes, uno veluti pugillo concludens et numerosissimas nationes pene sub manu tenens, ad quae antea ne ipsius quidem famae quamlibet praepetes alae pervolarunt». 
tografia do século XVI como princesa (a península dos Apeninos forma o pé) e a Espanha como cabeça do corpo continental. O vate «Via estar todo o Céu determinado/ De fazer de Lisboa nova Roma» (Lus. VI, 7). (6)

O conteúdo histórico-político da Tragicomédia do jesuíta insere-se perfeitamente no quadro e nas intenções das festas organizadas por toda a cidade de Lisboa. Com o seu resumo episódico, teatral, cénico da história portuguesa, faz parte da interpretação por imagens vivas, plásticas e simbólicas que transforma a arquitectura urbana real em bastidores e palco. Faltava pouco para que Sousa tivesse sido expulso da Companhia de Jesus por causa de alguns epigramas dirigidos contra Filipe. Em 1617 já tinha representado outra tragicomédia sobre Dom Afonso Henriques e a legendária batalha de Ourique (1139), que justifica as origens providenciais e divinas da monarquia portuguesa. Só existe um folheto com o argumento. As Parcas anunciam que o futuro rei Dom Manuel irá conquistar os rios da Índia e que o rei D. João III fará apelo aos jesuítas para que eles «ueteres reducant / moribus annos".

A tragicomédia ao rei Dom Manuel evoca, pois, a história dos grandes descobrimentos portugueses, os «novos argonautas». O próprio rei, Vasco da Gama, Almeida e Albuquerque são os protagonistas. O rei lusitano entra em cena três vezes, com toda a pompa e honras. Em conformidade com a função didáctica do teatro e da literatura, em geral, dos jesuítas, Sousa faz uma prédica ao rei espanhol presente, exortando-o a emular as virtudes do rei Dom Manuel, se quer reger bem e conservar a herança dos territórios no Ultramar. Como se sabia, Filipe não se consagrou fervorosamente aos assuntos governamentais e americanos. Perante as ameaças iminentes dos holandeses sobre o Brasil, os portugueses tentavam convencer o rei da

(6) Vide, para o mote "Orbi Europa semper luceat", PINHO, Sebastião Tavares de, "A descrição camoniana da Europa e a cartografia ginecomórfica” in Revista Camoniana 14 (2003) 185-228; STRÄTER, Thomas, "Europas Haupt blickt auf die grosse Weltmaschine: kartographische Metaphern in Luís de Camões' Epos Os Lusiadas", in BRIESEMEISTER, Dietrich; SCHÖNBERGER, Axel (eds), Vielfalt und Heterogenität: Studien zu den Literaturen Angolas, Brasiliens, Mosambiks und Portugals, Frankfurt 2004, 331-356. 
urgência de proteger melhor as possessões brasileiras e orientais. Censuravam-no sobretudo por não ter reforçado a tempo a defesa do Brasil. Em 1622 os portugueses foram obrigados a abandonar Ormuz, posição-chave para o comércio no Golfo Pérsico, cuja conquista ainda se celebra orgulhosamente na Tragicomédia. Em pouco tempo, o Estado da Índia desmoronou-se e só restavam Goa, Diu e Macau, como empórios portugueses. A Tragicomédia passa-se ainda na época gloriosa da expansão no Oriente. D. Manuel é o agente corajoso desta ofensiva. O seu bisneto Filipe, ao contrário, é um monarca estrangeiro inerte. D. Manuel protagoniza os feitos portugueses, Filipe II, o antípoda do Venturoso, arrisca-se a perder o Império criado um século e meio antes. Manuel encarna o modelo das virtudes dum rei cristão, representando na cena e na realidade do passado histórico, juntamente com as figuras grandiosas do capitão Vasco da Gama e dos primeiros vice-reis transfigurados, o destino e a missão da nação portuguesa. Já no século XVI, a historiografia e Os Lusíadas de Camões desenvolviam a mesma visão da história. Neste contexto, seria interessante analisar como a Tragicomédia consegue operar uma transposição ou adaptação teatral, não só do relato de João de Barros na Ásia (Déc. I, livro IV) citado pelo editor como "diligente historiador portuguez» (f. 50), e autorizada testemunha, mas também da epopeia camoniana que precisamente aspirava por apresentar «exemplos a futuros escritores» (Lus. VII, 82). Como Barros dava a preferência ao género panegírico - "por quanto o Panegírico fez sempre fé do que vê e o representa aos olhos» - o P. Sousa escreveu a Tragicomédia como epifania apoteótica do rei Dom Manuel exibindo as façanhas portuguesas opostas ao imobilismo espanhol. A justificação retórica que oferece Sardinha Mimoso ao falar no seu prólogo dos «ingenios Portugueses, cuio natural es, ser tan largos en enprender hechos grandiosos, como cortos en escriuillos", fundamenta-se com certa frequência no humanismo ibérico. Nem o panegírico, nem a tragicomédia admitiriam a menor dúvida quanto à decadência do poder português já evidente aos olhos de todos, ao contrário: na época filipina está na moda o panegírico, por exemplo, os Elogios dos Reis de Portugal de 
Bernardo de Brito (1623). Sardinha Mimoso introduz pequenos discursos biográficos em louvor de altas personalidades portuguesas para explicar a 134 sua intervenção na acção dramática.

A encenação triunfalista e dispendiosa da Tragicomédia, contrária ao espírito austero exigido na Ratio Studiorum jesuítica, visualiza as concepções elevadas de valores e virtudes mediante um aparato alegórico e emblemático, tableaux vivants com procissões, pompas fúnebres e cortejos de triunfo, relatos épicos, descrições (écfrases), teicoscopias, elementos todos emprestados do reportório retórico e literário ensinado nas classes superiores de colégio e praticado nos exercícios dos alunos. Os jesuítas não podiam ficar atrás no concurso renhido com os grémios, corporações e nações que haviam construído magníficos arcos na cidade. A Tragicomédia deve ser considerada também como uma forma de propaganda e manifestação apologética da Companhia de Jesus. Mais de trezentos alunos participaram como actores ou figurantes. A execução da música(7) andou em mãos dos melhores mestres da cidade (prólogo, f. 4r). O espectáculo incluiu ballet e danças (foliões), fogos de artifício, efeitos sonoros, coros, exibição de animais exóticos vivos e simbolizados, índios selvagens, diabos, feiticeiros, momos, etc. Estes elementos circenses e divertidos, a pomposa decoração, as máquinas teatrais deveriam captar todos os sentidos dos espectadores. A direcção da Tragicomédia a grandes efeitos operísticos pressupõe uma experiência técnica sofisticada e enormes despesas. O editor do livro confessa com manifesta admiração: «Los Padres se vencieron assi mismos» (prólogo) e anota no público a sensação de «espanto universal». O monarca espanhol mostrou-se impressionado pelas condições primorosas do ensino no colégio. O P. Sousa pôde, por fim, servir-se do exemplo de Os Lusíadas, onde Camões introduz (Lus. V, 63), dentro da acção épica

(7) LEITE, Serafim, "A música nas escolas jesuíticas do Brasil no século XVI" in Cultura (Rio de Janeiro, $\mathrm{n}^{\circ} 2$ (1949), 27-41. É especialmente interessante o coro brasílico ("musico razonamiento») em tupi, crioulo-português e latim, f. 58r-63r; vide AYROSA, Plínio M. da Silva, Apontamentos para a bibliografia da lingua tupi-guarani, São Paulo, ${ }^{2} 1954$, p. 211. 
Cantigas pastoris, ou prosa ou rima

$\mathrm{Na}$ sua língua cantam, concertadas

Cõ doce som das rústicas avenas.

A Tragicomédia mistura todo o género de espectáculo: elementos trágicos e cómicos, bailado, desfiles (momos), combinando os efeitos musicais, emocionais e visuais com os procedimentos retóricos para criar uma obra de arte total, ao gosto e estilo barrocos. O dramaturgo liga a História universal à história nacional e actual: "Orbi Europa semper luceat». A propagação da fé justifica a expansão com a famosa fórmula: "Fé e Império». Os jesuítas tinham especial interesse em destacar a evangelização no Oriente que eles consideravam seu domínio privilegiado. A alegorização respectiva interpreta a história portuguesa como luta entre Deus e o Demónio, entre o Bem e o Mal, entre cristãos e infiéis. Em visões e profecias manifesta-se a vontade providencial divina que dirige as acções do povo eleito. Assim, a Tragicomédia desemboca em teatro do Mundo que abrange tanto o Além eterno como as realidades terrestres, Ocidente e Novo Mundo, presente e passado. A distribuição do espaço teatral acentua ainda mais o profundo simbolismo religioso: do lado direito do proscénio entra o rei Dom Manuel e tudo o que se refere «a las cosas de Portugal», enquanto que do lado oposto se apinham "los Moros» e «las cosas de la gentilidad».

Os sucessos representados no palco estendem-se entre 1498 - descoberta da rota da Índia - e 1515, segunda conquista de Ormuz. Além disso, António de Sousa alude ao achamento do Brasil (1500) e aos feitos de armas dos primeiros vice-reis portugueses, sobretudo à conquista de Diu e de Goa (1510). A história já não é para o jesuíta uma lição exemplar, mas o próprio motivo de uma apoteose da Pátria. Ante a comitiva espanhola, a Tragicomédia demonstra a perfeição portuguesa apenas com «algumas das muytas prosperidades que a este Reyno trouxe o felicíssimo Rey Dom Manoel». Para o público português, o espectáculo evoca radiosamente o Século de Ouro à luz do saudosismo político: «Estos fueron los Portugueses de aquella edad dorada, que a nuestros tiempos dexaron en herencia una honrosa enbidia, mezclada con dolor de no ygualarlos (f. 123v-124r). 
A acção da Tragicomédia resulta do encadeamento de episódios no decurso cronológico. A Laus Portugalle, exercício convencional de retórica, e a ostentação cerimonial (em cortejos com pompa imperial) em plena cena acentuam de maneira quase provocante a vontade de afirmação duma nação autónoma. Há momentos de exaltação patética, quando o vice-rei dá ordem aos canteiros para esculpirem as proezas orientais (f. 104r-v), o «lusitano feito» (Lus. V, 100), motivo clássico da epopeia, rivalizando, por exemplo, com Virgílio (Eneida, I, 450-494, história de Tróia esculpida nos muros de Cartago; VIII, 626-731, o escudo de Eneias; Camões, Lus. VII, 7476, VIII, 1 ss. A história de Portugal nos estandartes como "pintura fera e muda poesia»). Assim a Tragicomédia torna-se história viva em imagens, um friso monumental de quadros dramáticos que evocam os feitos gloriosos. A acção não se desenvolve estritamente segundo as leis do género dramático, não obstante a sua repartição em cinco actos. As configurações cénicas não fazem desfiles, pelo contrário, uma série de paragens, de peripécias entrelaçadas pelos conhecidos procedimentos técnicos (sonhos, visões, mensagens, presságios, acções paralelas e contrastadas).

Como mestre de retórica o P. Sousa é plenamente consciente dos problemas do género épico, o mais nobre da poesia. No seu prólogo, alude à disputa sobre a definição da tragicomédia, imaginando as censuras indignadas de Sófocles que lhe pergunta: "Quae tua ista actio?» - nem tragédia, nem comédia no sentido clássico do termo. Sousa mantém uma concepção medieval que entendeu a tragédia (ou comédia) em primeiro lugar como "genus narrationis» e menos no seu sentido teatral clássico. A condição das personagens dramáticas, o estilo e o desenvolvimento da acção determinam o carácter trágico ou cómico. A tragédia exige "ingentes personae», "magni terrores», "exitus funesti». A acção começa na alegria para acabar na catástrofe, enquanto que a comédia obedece ao princípio estruturalmente contrário: "exordium triste», "laetus finis». Aqui estamos em presença de "mediocres fortunae bominum", de "parui impetus periculorum». A matéria ("in India gesta») e o rango dos protagonistas (rei, vice-rei, capitães, "general de los Portugueses Argonautas», sultão) requer a nobreza do género e do estilo. 
Camões já o definiu em Os Lusíadas (X, 8): "Matéria é de coturno e não de soco». Os casos terríveis são as batalhas, as mortes (Almeida o "Aleixandro português», f. 117v), os sofrimentos e o medo dos portugueses (durante os tremores de terra, naufrágios, intrigas das forças elementares e diabólicas). Entre os elementos cómicos figuram os entremezes, os disparates dos diabretes, as danças e canções populares, os camponeses ingénuos, pastores, marinheiros, soldados índios que povoam a cena. No proémio, Olisipo - personificação de Lisboa —, Tagus (Tejo) e Cintra, dedicam juntos o espectáculo ao rei Filipe, organizando a festa em honra do soberano. A alegoria de Lisboa como "Domina Mundi» reveste-se duma significação especial. Como sujeito da acção aparece já nas crónicas de Dom João I e de Dom Pedro redigidas por Fernão Lopes. Olisipo introduz o assunto da tragicomédia sob o título próprio duma obra historiográfica: «algunos valerosos hechos de los fortíssimos y invictos capitanes» que actuam em nome de D. Manuel, um dos antepassados de Filipe III.

Uma exposição alegórica abre o primeiro acto explicando - sub specie aeternitatis - a razão teológica dos acontecimentos e conflitos que em seguida vão ocorrer na terra. Idolatria, filha do diabo, Perfidia e Caecitas representam as forças demoníacas que se opõem à missão providencial dos portugueses. Uma cena de sacrifício presidida por um sacerdote bramânico assistido de um "Barbaro Selvatico» (selvagem) introduz simultaneamente um prognóstico e um momento cómico: o próprio Diabo deita abaixo o altar pagão; haruspicium opõe-se a oraculum (profecia angélica do Céu). O paralelismo das acções fortemente acentuado corresponde a um conceito medieval do cenário simultâneo. Enquanto Perfidia cobiça o Império do Oriente a Portugal, Cultus, Fides e Pietas deploram os estragos causados no mundo inteiro pela Idolatria. O anjo da guarda do Oriente desce da Glória no alto dum andaime construído no pátio do colégio para proclamar o encargo divino dos portugueses. Esta instrução celeste determina para sempre a História e sua sucessiva encenação no espaço simbólico teatral. O rei Dom Manuel, eleito de Deus, é chamado para destruir o reino da Idolatria. O Anjo entrega ao soberano luso a Esfera do Mundo, símbolo do brasão 
nacional. Pelo contrário, o Demónio queixa-se do efeito que a chegada de Cultus produz no Oriente. A acção histórica do drama da Salvação universal evolui consequentemente a partir do "prelúdio do Céu».

Em seguida, o jovem rei de Portugal entra em cena triunfalmente no meio dum momo celebrado nas festas cortesãs e recebe as honras em presença do espectador principal, um tributo protocolar audaz. No magnífico quadro central que coloca em cena o interior do mesmo drama em acção, Vasco da Gama entra acompanhado de 40 homens executando um desfile-ballet. Gama presta o juramento ao rei, recebe da sua mão as bandeiras, pronuncia uma arenga e faz-se ao mar com júbilo numa autêntica cena operística. Sonho e partida correspondem aos passos épicos de Os Lusíadas, IV, 68 e ss. e Eneida, VIII, 36-65.

Logo a seguir a esta exposição com intermédios realistas, o segundo acto leva o espectador ao plano cósmico e simbólico: a machina mundi (machina do mundo em Os Lusíadas, VI, 76) é o quadro dos acontecimentos históricos. Camões situa também os eventos nesta perspectiva meta-histórica e sobrenatural. Num ballet dos quatro elementos furiosos, Sousa introduz ao lado dos demónios a força brutal da natureza que põe em perigo a missão dos portugueses no Cabo das Tormentas. O Tritão entra no palco "Como el poeta Camoes le pinta» (f. 89v; Lus., VI, 16). O conselho dos deuses é substituído pelas figuras da Idolatria que convoca os Elementos como executores da sua aversão contra os portugueses. Ao final deste acto sombrio, um marinheiro que se salvou no naufrágio salta para o estrado como mensageiro num relato épico para informar sobre a chegada dos portugueses à Índia. O coro final canta o hino dos valentes marinheiros.

O acto terceiro trata da presença dos portugueses na Índia. Vasco da Gama entra rodeado de quinze províncias que levam oferendas exóticas para celebrar em cantos alternados o rei Dom Manuel e Vasco da Gama. Este triunfo é mais um espectáculo aparatoso com coreografia (folia dos serranos - descoberta do Brasil). "El Brasil sobre un vestido justo de color de negra carne, trahia en la cabeça una guirnalda de pluma de papagayos... Entrò cabalgando sobre un cocodrilo, de diez palmos de largo (mais de 
dois metros) ... acompañante seis papagayos». Os índios cantam em língua tupi e crioulo português. Este entremez de carácter bailado-pantomima-circo constitui um documento linguístico e etnológico único que procede das missões dos jesuítas no Brasil.

Para concluir o primeiro dia da festa, dez danças camponesas (foliões) e coros populares são oferecidos ao rei espanhol como divertimento folclórico, não palaciano e sério.

O quarto acto mostra novamente graves peripécias (deliberações do Sultão e sua "compagnie bizarre») e acções militares turcas para desbaratar o comércio português. Um exército inimigo entra em formatura, mas o rei D. Manuel não se deixa intimidar pelas ameaças recebidas da boca dum mensageiro espanhol, Mauro, ermitão do Mosteiro de Santa Catarina no Sinai, padroeira de Goa, a caminho de Roma para informar o Papa das represálias que põem em perigo os peregrinos da Terra Santa. É, de facto, um detalhe mencionado na Crónica de D. Manuel de Damião de Góis e nas Décadas de João de Barros (I, VIII, 2). O monge espanhol Mauro saiu do Egipto no Verão de 1503 trazendo uma missiva do Sultão dirigida ao Papa contra os reis de Espanha e Portugal. Queixa-se das navegações dos portugueses à Índia que ele havia armado primeiro e, sobretudo, dos Reis Católicos por terem aprisionado os muçulmanos sobreviventes das guerras de reconquista da Andaluzia com a pressão de se converterem ao cristianismo. A carta do Sultão (1503) conserva-se ainda nas versões latina e portuguesa. ${ }^{(8)}$

Na Tragicomédia, o rei Manuel encoraja o espanhol - outro gesto que dá uma forte lição ao rei Filipe — e os portugueses ganham a batalha de Diu. Damião de Góis e Diogo de Teive tratam destes episódios em suas obras históricas latinas.

A morte do vice-rei Almeida é atribuída às maquinações de Incúria, ajudada pelos demónios. O mágico turco que vaticinou a vitória do Sultão

(8) MATOS, Luís de, L'expansion portugaise dans la littérature latine de la Renaissance, Paris, 1991, 321-323. 
encoleriza-se numa cerimónia mântica em que prevê o fim desastroso do vice-rei. Camões (Lus. VIII, 45) fala dos

\author{
Arúspices famosos \\ $\mathrm{Na}$ falsa opinião, que em sacrifícios \\ Antevêem os casos duvidosos \\ Por sinais diabólicos e indícios.
}

Por ocasião desta morte, os portugueses organizam um cortejo fúnebre. São Tomé, apóstolo da Índia, do alto do céu proclama Albuquerque, «otro Sanson lusitano", seu sucessor. ${ }^{(9)}$ De imediato, os gemidos de luto convertem-se em gritos de júbilo. Os reinos asiáticos submetem-se aos portugueses e o "Chorus festivus» canta em hinos os feitos de Almeida. Numa nota Sardinha Mimoso acrescenta que Almeida participou como herói jovem na conquista de Granada.

No acto final a apoteose, já pressagiada, vai-se desenvolvendo com rapidez vertiginosa. Um barco carregado de pimenta, canela e noz-moscada está ancorado numa cena que faz jogo com a saída no início. A alegoria de Portugal dá as boas vindas aos marinheiros com salvas de canhões, e o rei escuta o relato épico-retórico. Ainda ficam por vencer alguns obstáculos, primeiro o terramoto, uma cena inspirada na Ásia de Barros, "donde hallo el Poeta lugar de fingir con fundamento auer temblado la tierra» (f. 89). Albuquerque explica aos soldados espantados o fenómeno natural como uma causa sobrenatural ou moral: treme a terra porque recusa «la carga que leva la dilatacion de su santa ley en aquellas partes tan remotas». Ao surgir uma cruz no alto da Glória (momento misterioso que corresponde à Sphaera Mundi no acto primeiro), os portugueses fazem preces e recobram o ânimo. A conquista de Goa e de Malaca será interpretada como intervenção dos portugueses causada pelo requerimento destes territórios por

(9) «Fueron tales los trabajos, y constancia inuencible de Albuquerque, en peligros por la mar, y por terra, que ni los imaginados de Hercules y Vlisses le hazen ventaja» (f. 122r). 
serem protegidos contra o Islão. A vitória sobre o rei Ceifadino dá ocasião para mostrarem os portugueses a sua generosidade e grande clemência - o que com certeza nem sempre corresponde à realidade colonial. Quando Ceifadino sai do palco, os soldados alçam seus escudos em forma de couraça de tartaruga para protegê-lo. Com a entrada das bandeiras lusas que levam o emblema das Quinas, vai crescendo a exaltação patriótica ante o rei Manuel e Filipe III. O exército português forma frente diante duma tela pintada com os muros de Ormuz: é assim que o autor jesuíta transpõe a teicoscopia (teixoskopia) épica para o tablado. Duas cenas marcam pateticamente o final. Os canteiros talham em pedras as façanhas portuguesas (ao mesmo tempo que três capitães se queixam de estar ausentes na ilustre série). Os escultores de facto representam e perpetuam a memória da história de Portugal numa obra artística de grande vulto:

\author{
Com picões de bronze \\ Em jaspe famoso \\ Esculpir queremos \\ Feito glorioso. (f. 109r)
}

Albuquerque aproxima-se de Portugal sentado sobre um carro triunfal em companhia de Olisipo, Tagus e Cintra, paço e sede simbólicos da Casa de Avis. O triunfo profetizado no acto primeiro chega, por fim, a ser realidade histórico-teatral. O relator Sardinha Mimoso tira proveito do momento frenético para fazer uma detalhada descrição do carro, interpretando o valor emblemático das cores e figuras: "Diosele a Portugal el color encarnado, por ser symbolo del amor y lealdad que a sus Reyes sempre tuuo, el oro es ansi mismo amoroso símbolo, y todo denotaua el mundo que offerecia a su Magestad esta obra; peto, espaldar, gola, y espada, por su señalado esfuerço, corona, y sceptro, por su magnifica y dilatada Monarchia. Tambien el oro denotaua en el su sabiduria, en que entre todos los mas Reynos oy florece, ilustrando com ella los de que triumpha». O rei Dom Manuel sai 
em triunfo como os imperadores romanos. Em homenagem protocolar e gesto conciliante, Portugal faz entrega ao rei espanhol das «victórias de seus filhos". Ao mesmo tempo ressoa uma voz lamentando hiperbolicamente "no hauer mas que un solo mundo para su triunfo, pues muchos fueran poco para el inuencible y fuerte animo de sus hijos».

A Tragicomédia de 1619 é o canto de cisne da época dos grandes descobrimentos. A obra apresenta-se como misto híbrido que amalgama diversos elementos estruturais, géneros e procedimentos retóricos, numa manifestação teatral que apenas oculta seu empenhamento patriótico, diferente da atitude acomodatícia de Francisco Rodrigues Lobo nos romances festivos que celebram La Iornada que la Magestad Catholica del Rey Don Phelippe III de las Hespañas hizo a su Reyno de Portugal, y el Triumpho, y pompa com que le recibió la insigne Ciudad de Lisboa el año 1619 (Lisboa, 1623). O padre jesuíta joga com os argumentos fundamentais da história nacional numa acção dramática que ultrapassa de longe as dimensões tradicionais do teatro de colégio. O juízo de Luciana Stegagno Picchio parece duro demais: «lo sforzo scenico era destinato a mascherare la povertà letteraria e la fredezza d'ispirazione» (obra cit., 119). Não toma em conta nem as circunstâncias sócio-culturais e políticas, nem as características funcionais do teatro escolar jesuítico que se baseiam nos princípios da imitatio e aemulatio e que utiliza um determinado repertório retórico.

Embora esteja escrita em latim, a Tragicomédia fica essencialmente uma peça portuguesa no seu colorido local, nas referências à geografia, história e literatura e, nomeadamente, pelo espírito patriótico que anima o seu conceito da história pátria. Nesta celebração tipicamente barroca - o "gusto dello spettacolo» não é privativo do teatro jesuítico —, a realidade política, as reivindicações messiânicas, o orgulho nacional, o exercício lúdico da inventio e do ornatus retórico, assim como a concorrência das artes plásticas, da música e arquitectura associam-se de maneira importante ao serviço da pedagogia, da parénese e da propagação da fé. 
Manuel José de Sousa Barbosa

Universidade de Lisboa

\author{
TEATRO JESUÍTICO E ESTÉTICA BARROCA: \\ O TESTEMUNHO DUM DRAMA TRUNCADO, \\ ANÓNIMO E SEM TÍTULO (BPE, COD. CVIII/2-7, 61R-85V)
}

Sobre este drama anónimo, truncado e sem título tive já ocasião de me pronunciar uma primeira vez em artigo publicado na revista Euphrosyne onde formulei várias hipóteses sobre a sua autoria e apresentei, em apêndice, um resumo da acção dramática por cenas e a transcrição dos coros. ${ }^{(1)}$ O meu interesse por este texto tem a ver com a questão bem espinhosa do repertório do teatro jesuítico, tão difícil de estabelecer, já que são muitas as notícias nas litterae dos Jesuítas sobre representações teatrais e escassos os textos disponíveis que, nem sempre, como é o caso, permitem estabelecer um elo inequívoco com tais notícias. Não são muitos os casos em que tais repertórios remetam com segurança para os textos. Estes não se conservaram em muitíssimos casos e, dos que se conservaram, nem sempre possuímos um conjunto de referências que salvaguardem o carácter inequívoco da associação notícia - texto.

Esta minha comunicação pretende, pois, antes de mais, apresentar-se como uma achega para o enriquecimento do repertório do teatro jesuítico,

(1) Cf. "Luzes e mistérios no teatro jesuítico. BPE, cod. CVIII/2-7, fls. 61r-85v: o Nabuchodonosor de Stephanus Tuccius? Interpelações de um texto truncado", Euphrosyne 31 (2003), pp. 415-426. Nas citações de versos desta peça, indicaremos os actos em numeração romana e as cenas em árabe. Tais indicações remetem para a edição provisória do texto por nós elaborada. 
projectando luz sobre um drama que, pela situação codicológica do seu texto, se afigura inequivocamente jesuítico, presumivelmente do último quartel do século XVI e provavelmente representado no colégio de Évora. O facto de o texto desta tragédia (ou tragicomédia), aparecer inicialmente truncado terá desviado dele atenções que, é minha convicção, lhe são merecidas, atenções essas que, quem sabe se indevidamente, se centraram noutro drama, este de texto integral e de tema similar, ostentando como título Tragicomoedia Nabucodonosor, inserto noutro códice igualmente da Biblioteca de Évora, de idêntica génese jesuítica. (2)

No artigo da Euphrosyne acima referido expliquei por que razão algumas afirmações de C.-H. Frèches a propósito deste Nabucodonosor de texto integral me pareciam mais susceptíveis de se aplicarem a este drama de texto truncado que, tudo o leva a crer, possuiria título idêntico. Ou seja: o drama analisado por Frèches pode não ter sido o representado em Évora no ano de 1576 , perante o Cardeal D. Henrique, num espectáculo de cinco horas, mas sim este, de que hoje vos vou falar; e o que o estudioso francês do teatro neolatino em Portugal afirmava quanto a «não ser impossível estar-se perante o Nabucodonosor desaparecido de Stefano Tucci», creio eu que poderá afirmar-se igualmente deste drama truncado que até hoje passou praticamente ignorado. (3)

Pretendo hoje com esta minha comunicação dar continuidade à apresentação desta peça teatral duma forma mais profunda, em ordem a evidenciar a estética subjacente a uma imitatio que conferiu à fábula dramática o seu aspecto singular. Não sou especialista em estética do barroco, como o título desta minha comunicação poderá fazer pensar. Tenho do barroco a ideia geral de movimento artístico que, numa ruptura com a estética renascentista, quebra equilíbrios formais e funcionais na abordagem de determinados temas, segundo uma lógica do excesso na representação da realidade, lógica

(2) O códice BPE, cod. CVIII/2-8, fls. 35-68, de características materiais gémeas, reúne igualmente composições em prosa e verso oriundas dos actos académicos da "Academia Eborensi", como se pode ler na lombada de ambos. Cf. Ibid., pp. 416-417.

(3) Cf. Ibid., pp. 422-423. 
essa que confere aos elementos significantes uma forte preponderância, num jogo complicado mas significativo da intencionalidade do artista.

O conhecimento que fui adquirindo gradualmente deste drama, concomitante à leitura e progressiva fixação do seu texto manuscrito, com tradução incluída, convenceu-me de que valia a pena resgatar das trevas e colocar com validade a plena luz este texto ignorado. Os versos iniciais que faltam, ${ }^{(4)}$ felizmente não invalidam a formação duma apreciação global desta dramatização do Livro de Daniel, capítulos 2, 3 e 4. As primeiras impressões recolhidas logo me mostraram que a singularidade desta dramatização se alimentava de toda uma retórica que, não apenas ao nível da elocutio, mas também ao nível da encenação, com toda a sua carga de sonoridades e de visual, veiculava uma ars persuadendi por demais denunciadora dos seus objectivos finais. Talvez seja mais correcto falar, neste caso, de estética barroca de génese jesuítica, no sentido de que o artefacto denuncia a conhecida estratégia de eficácia característica dos seguidores de S. Inácio, ao serviço de propósitos concretos, inseridos em tempo e lugar bem estudados. ${ }^{(5)}$

A abordagem dramática deste passo bíblico, tão multiplicada desde a Idade Média, na Renascença e, concretamente, no teatro jesuítico, da forma como surge aqui concretizada denota a concepção medieval que levava à apreensão dos acontecimentos históricos como representações das forças da consciência, traduzindo a infindável luta entre bem e mal, entre virtude e vício. É esta ideia de embate eterno entre as referidas forças antagónicas que parece estar na base da demarcação bem patente em cena dos dois campos por onde se repartem as personagens de extracção bíblica a que se associam, de acordo com a situação dramática, as de índole alegórica que dão expressão plástica a esse embate de índole psicológica. Assim, o campo das forças do mal (uitia) que manipulam Nabucodonosor surge comandado por Soberba, a senhora do mundo, assessorada pelo príncipe de

(4) Eles conteriam certamente o prólogo e uma ou duas cenas do primeiro acto, de que nos resta apenas uma.

(5) Contra a ideia simplificadora de se chamar à arte jesuítica arte barroca, cf. VICTOR-L. TAPIÉ, O Barroco, trad. de Armando Ribeiro Pinto, Editora Cultrix, Universidade de São Paulo, p. 18. 
seu reino, designado em latim de Cupido e representado na conhecida figura duma criança alada, munida de arco e setas, mas esvaziado de conotações eróticas. As suas setas não levam a Nabucodonosor o fogo do amor, mas o da ambição desmedida. Por isso, optamos por traduzir a designação latina desta personagem por "Ambição». A ela junta-se também a Perfídia.

No campo oposto, ao profeta Daniel e aos três jovens hebreus associar-se-ão as alegorias da Fé, da Esperança e da Constância. As restantes personagens, a saber, os sátrapas, Vilmerodaque e os mensageiros, integram-se com verosimilhança neste quadro dramático marcado pelo antagonismo que referimos atrás, em consonância com o relato bíblico.

\section{A unidade da acção dramática}

Estamos longe aqui do propugnado pela reflexão dos humanistas em torno da poética de Aristóteles, reflexão essa acompanhada da emergência da chamada tragédia regular, assente na observância da lei das três unidades, de que se aponta geralmente como primeiro exemplo a Sofonisba de Giovanni Giorgio Trissino. Pelo contrário, assistimos neste Nabucodonosor a uma pluralidade de acções que, a nosso ver, se interligam e evoluem segundo a dinâmica de dar expressão dramática à ideia de humilhação dos soberbos e, concomitantemente, à de afirmação incontestável do poder divino. A prioridade desta dinâmica explica a sucessão em palco de um conjunto de cenas que mais propriamente designaríamos de quadros justapostos, duma forma que, salvaguardando embora a fidelidade ao passo bíblico, não se move por preocupações de verosimilhança de tempos e lugares.

A acção dramática, no seu todo, apresenta-se polarizada em dois momentos bem diferenciados, assentes na ideia de triunfo. Assistimos primeiramente a uma tentativa de triunfo, conduzida por Soberba, a senhora do mundo ("domina mundi»), como a tratam os seus servidores, frustrada por não ser ainda senhora de Nabucodonosor, para merecer em pleno tal tratamento 
(Acto II, cena 1). Este triunfo da Soberba será incompleto e efémero. Ela apoderar-se-á da mente de Nabucodonosor, mas serão vãos os seus esforços para esmagar Daniel, o seu principal obstáculo. O acto III, com a provação dos três jovens salvos miraculosamente da fornalha, marca o ponto culminante da tensão dramática, se é que se pode falar nesta peça em verdadeira tensão dramática. Soberba realizou efectivamente o seu propósito de fazer Nabucodonosor entregar seu coração à Ambição, mas a salvação miraculosa dos três jovens é já o presságio do triunfo final da Fé no acto V. Este triunfo final da Fé, em que o poder de Deus se afirma esmagadoramente, dá-se após a humilhação extrema de Nabucodonosor que, na sua bybris sacrílega, se elevara até às nuvens, pretendendo tratamento divino. Tal humilhação marca o acto IV onde o castigo do monarca, com o seu exílio do poder durante sete anos, transformado em boi e alimentando-se na companhia de outras alimárias, ilustra as consequências da atitude de orgulho desmedido do monarca e faz reflectir sobre o uso do poder, a questão da sucessão e os perigos antevistos numa situação de vazio de poder.

\section{A figura de Nabucodonosor}

Neste jogo de contrastes com que o dramaturgo caracterizou a sua peça, a figura de Nabucodonosor surge-nos incontornável numa análise sob esta perspectiva. O claro e o escuro demarcam-se aí com nitidez, no que respeita à sua atitude mental antes e após o castigo. Primeiramente temos o tipo de tirano pagão, marcado por atitudes de orgulho, de violência e de impiedade; deparamos depois com um modelo de príncipe enaltecido como sábio e submisso a Deus, sem apego ao poder.

A primeira face de Nabucodonosor enquanto modelo de tirano pagão é-nos dada em grande parte em cenas onde a alegoria está presente. O seu fascínio pela glória surge-nos testemunhado na cena 3 do acto III onde, após dar um beijo à Ambição, exclama: "Oh! Quão doce é o sabor da glória» 
e pede ao jovem que personifica tal vício que lhe permita usufruir muitas vezes de abraço tão doce. ${ }^{(6)}$ Fica regalado com a promessa de tal concessão. Na despedida, Ambição refere-se-lhe como «a ilustração perfeita do seu poder». (7) Outro traço caracterizador do tirano é um excesso de confiança que invade a área do sacrílego. Não acredita que a invejosa fortuna possa contaminar a sua alegria com algum infortúnio. A confiança cega no carácter inabalável da sua felicidade pessoal vai ao ponto de confessar ser também ele um deus. A contemplação do esplendor inigualável do seu poder fá-lo sentir-se o mais ditoso de todos os reis, enumerando, com intuitos comparativos, as limitações dos outros monarcas. Auto-elogia-se numa série de interrogações onde passa em revista os seus grandiosos feitos, sem evitar a blasfémia:

"Mais: ousaria algum deus fazer-me frente?»(8)

Mas na mesma cena em que Nabucodonosor se vangloria da sua glória e poder excepcional, em que confessa sem pejo gostar de fazer-se representar abraçado a todo o globo terrestre, ${ }^{(9)}$ soará a voz do Anjo, plena de autoridade ("Nem uma palavra enquanto falo»), ${ }^{(10)}$ para lhe anunciar o castigo de sete anos de vida errante pelos campos como um boi, castigo que lhe fará saber que é Deus quem reina. Do estado deplorável a que se viu reduzido são múltiplas as referências trazidas à cena, nas intervenções dos dois mensageiros e do próprio filho, Vilmerodaque, que lamenta, inconsolável, a imundície e a sordidez do pai.

Radicalmente diferentes são as novas atitudes do Nabucodonosor convertido, regressado do castigo. Antes de mais, refira-se a submissão a Deus.

(6) «Nabuc. O iucundum gloriae gustum diem / O laetum, dulcem o nimium, et felicem diem! / Liceat amplexu saepius o puer tuo / Tam dulci perfrui.» - III, 2, 805-8

(7) «O felix nostri maximum imperii decus.» - loc. cit., 808.

(8) «Obstare mihi quin ullus auderet deus," - IV, 2, 1163.

(9) "Sic ego me mecum soleo saepe fingere / Totam tenentem machinam amplexu meo." - IV, 2, 1172-3

(10) Nabuc. Miserere, Ang. Nullum, dum loquor uerbum, sile» - IV, 2, 1202. 
Se Daniel the diz que são ordens de Deus, logo ele declara obedecer de boamente ${ }^{(11)}$; realce-se igualmente a profunda renitência em reassumir o poder e que está na base desta viva altercação com Daniel:

\begin{abstract}
Daniel - Recusas fazer o que ordena o Deus supremo?
Nabuco - Recuso fazer o que o Deus supremo proíbe.

Daniel - O Deus celeste ordena que assumas o poder.

Nabuco - O mesmo Deus proíbe o poder aos soberbos.

Daniel - Não governará orgulhosamente quem foi precipitado do alto do trono por causa do seu orgulho.

Nabuco - Esta péssima desgraça acompanha todos os orgulhosos. Expulsos do poder, ostentam um ar humilde, mas se regressarem ao poder, ficam mais orgulhosos do que antes. $^{(12)}$
\end{abstract}

Nabucodonosor cederá, finalmente, confiante de que a mão poderosa de Deus o segurará, para que não resvale dessas receadas alturas. A esta renitência em assumir o poder, acrescente-se, por fim, o desprezo pelo fausto que lhe está associado. Para Nabucodonosor, que agora odeia o ceptro, a púrpura, o trono e tudo o que se lhe associa, aqueles trajes sujos e grosseiros que ostenta em cena dão-lhe a garantia do perdão do seu crime. Acabará por abandoná-los, não tanto por pressão do filho mas porque, como o informa Daniel, "Deos o ordena». Antes porém que esta difícil renúncia se efective, o dramaturgo, num exagero de encenação, coloca Nabucodonosor em cena abraçado aos seus imundos andrajos, chorando em saudosa despedida, com palavras que decalcam as da desesperada Dido, no canto IV da Eneida, sobre as reluzentes armas do guerreiro troiano, já fora do seu alcance para sempre:

(11) «Dan. Huc te reduci caelitum numen iubet. / Nab. Iubet? Libenter subiicio imperio caput.» - V, 2, 1603-4

(12) «Dan. Numen recusas facere quod summum imperat? / Nab. Numen recuso facere quod summum uetat. / Dan. Caeleste, sceptrum capias, Numen imperat. / Nab. Idem superbum, Numen imperium uetat. / Dan. Non imperabit tumide quem semel tumor / Ex alto Regni praecipitem solio dedit. / Nab. Hoc tumidos sequitur maximum cunctos malum / E Regno pulsi, abiectam ceruicem gerunt / Hi Regnum redeant peius quam prius tument.» - V, 2, 1612-1620. 
Doces despojos enquanto o destino e um deus o permitia. Ah! Como seria feliz, feliz por demais, se a minha vida tivesse terminado seus dias no meio dos bosques, para não empunhar, ao invés, os ceptros enganadores, nem ver os reinos perigosos. Porque vos abandonei, ingrato que fui, ó lugares ocultos? Porque vos abandonei, ó agradáveis covis das feras? Como me seria mais doce levar uma vida discreta entre vós, ignorado do mundo e quando, por fim, os dardos da morte me ferissem, sepultar então meu pobre corpo em terra humilde, do que ter de empunhar o ceptro e ostentar a cabeça orlada de pérolas. Ó morte que tardas em chegar, porque me reservas esta sorte?(13)

\section{Os diálogos}

Outra instância do drama onde avulta o contraste, e aqui com uma funcionalidade muito própria do docere, são determinados diálogos conduzidos segundo o esquema típico da disputatio, contrapondo geralmente duas personagens, numa sucessão de réplicas marcadas por um paralelismo antitético, em que um dos interlocutores vai dando resposta às sucessivas e renovadas objecções do outro, promovendo ambos deste modo o esclarecimento da questão em debate. Um caso exemplar é o da cena dos dois sátrapas (IV, 5) que, ao longo de setenta versos, aproximadamente, comentam a situação de vazio de poder gerada com o exílio de Nabucodonosor, incertos quanto ao futuro próximo e receosos da sua sorte nesta rotação da fortuna que colocará no poder Vilmerodaque, filho de Nabucodonosor. Continuarão ou não a beneficiar do favor real? O tipo de resposta prudente e sentenciosa de um deles soa como um sinal de sabedoria acrescida donde manam as lições a reter. Veja-se o seguinte extracto do diálogo em que se conjectura sobre a futura atitude de Vilmerodaque, quando assumir as rédeas do poder:

(13) Dulces exuuiae dum fata, deusque sinebat / Felix ah! Nimium felix si uita fuisset / In syluis finita mihi, ne perfida rursus / Sceptra manu gererem, neque lubrica regna uiderem. / Cur uos ah latebrae, cur ah grata antra ferarum / Deserui ingratus? Quanto mihi dulcius esset / In uobis tacitam ignotum traducere uitam / Et tandem cum me fixissent spicula mortis / Sub uili miserum deponere cespite corpus / Quam sceptrum gestare manu quam tempora gemmis. / Ah mors sera nimis quid me haec in fata reseruas? - V, 2, 1671-1681. 
Sátrapa 1 - Acreditas que a dor e as lágrimas possam durar muito tempo? Mal se veja sentado no trono real, cheio de orgulho, com a cabeça enfeitada de ouro, esquecerá o pai, promoverá outros e banirá estes da sua antiga posição.

Sátrapa 2 - Não venerará o nome do pai ausente?

Sátrapa 1 - Uma vez chegados ao poder, o nome do pai é vil para os reis.

Sátrapa 2 - E não receará gozar da fama de filho ingrato?

Sátrapa 1 - Os que reinam para si próprios pensam que tudo lhes é lícito.

Sátrapa 2 - Temerá a divindade, essa temível divindade, a mando da qual o pai se arrasta expulso do poder.

Sátrapa 1 - O orgulhoso nunca aprende com o exemplo alheio.

Sátrapa 2 - Mas ele não ficará orgulhoso.

Sátrapa 1 - Não empunhará o ceptro por muito tempo.

Sátrapa 2 - Mas ele recusa verdadeiramente assumir a condição real e não deseja reinar com o pai expulso. Odeia o ceptro, a púrpura, o orgulho.

Sátrapa 1 - Finge odiar.

Sátrapa 2 - Ou antes, tu é que receias demasiado.

Sátrapa 1 - É insensato viver na corte sem experimentar o medo.

Sátrapa 2 - Não quem se sente bafejado pelo favor benevolente dos príncipes.

Sátrapa 1 - Pelo contrário, para esse é demasiado enganador o favor dos príncipes.

Sátrapa 2 - Certo é o amor posto à prova durante muito tempo.

Sátrapa 1 - Muitas vezes, o que durante muito tempo foi posto à prova num instante se esvai.

Sátrapa 2 - Que resolução aconselhas então que tomemos neste momento?

Sátrapa 1 - Armemo-nos de coragem para a incerteza da situação. ${ }^{(14)}$

(14) «Satrapa An tu dolorem credis, et lachrymas Diu / Durare posse? Regio ut semel throno / Sceptro superbus sederit, fuluo caput / Ornatus auro, pectore expellet patrem, / Attollet illos, pristino hos trudet gradu / Alius Annon parentis nomen absentis colet / Satrapa Post sceptra uile est regibus nomen patris. / Alius Annon timebit filii ingrati notam? / Satrapa Licere credunt cuncta, qui regnant sibi. / Alius Numen timebit, cuius imperio parens / (Numen timendum) pulsus e regno iacet. / Satrapa Alterius nunquam tumidus exemplo sapit. / Alius At non tumebit. Satrapa Non feret sceptrum diu. / Alius At ille uero capere regalem manu / Virgam recusat, patre nec pulso cupit / Regnare, sceptrum purpuram, fastus odit.

Satrapa Odisse fingit. Alius Imo tu nimium times. / Satrapa Stultum est in aula uiuere expertem metus. / Alius Non cui benignus principum aspirat fauor. / Satrapa Huic imo fallax 
Também para inteirar a plateia do aspecto horrendo de Nabucodonosor no seu exílio de vida selvagem, recorre o dramaturgo a dois mensageiros cujas falas, alternando-se em estilo bem diferenciado, remetem para dois estados de espírito: de um lado, ou seja, do lado de quem viu, há um sentimento de horror, de completo transtorno mental, de desnorte e perplexidade sobre o que fazer com notícia tão horrível, se dar ou não ao filho tal notícia sobre o estado lastimável do pai; no outro, que não viu, a serenidade, aliada a uma curiosidade natural de perceber o que se passa. Os dois mensageiros irrompem em cena. O primeiro com falas em tom veemente, tendencialmente ampliadas com frequentes exclamações e interrogações que entrecortam e quase bloqueiam o fluir das informações aguardadas pelo outro. Este limita-se a intervir inicialmente de forma breve e simples, reclamando do outro a continuação do relato interrompido. Inteirado de toda a situação, é então a vez de também ele elevar o tom do discurso para lamentar a condição actual do tirano, evocando, na figura duma apóstrofe a Nabucodonosor, o seu esplendor de outros tempos. A esta apóstrofe associa-se em paralelo outra, pela boca do outro mensageiro, consagrada aos ardis da fortuna. Esta alteração em cena do estado de espírito dum dos mensageiros tem um efeito amplificador, acentuando o carácter inenarrável do conteúdo da notícia sobre o estado deplorável a que desceu Nabucodonosor. Do desnivelamento cognitivo e afectivo que diferenciava inicialmente os dois mensageiros, passou-se agora a uma consonância de posições extensível ao domínio volitivo. Que fazer? Era a pergunta do mensageiro transtornado, de posse duma notícia terrível. A resposta será dada pelo outro, pelo que não viu a crueza dos factos, mas a eles chegou pela narração do companheiro. O seu conselho final vai no sentido de que uma notícia destas não deverá ser de modo nenhum dada ao filho de Nabucodonosor:

- "retira-te e esconde-te até que ele regresse de novo ao seu reino». (15)

principum est nimis fauor. / Alius Diu probatus certus est amor; Satr. Diu / Probata saepe temporis puncto cadunt / Alius Quid ergo nos nunc capere consilii mones? / Satrap. Paremus animos fortis ad dubias uices.» - IV, 5, 1341-1364.

(15) "Alius Abscede, et dum redeat iterum ad regnum, late." - IV, 6, 1458. 


\section{A alegorização como ilustração do combate psicológico}

O assalto da Ambição: Um dos processos mentais ilustrado em cena tem a ver com a cedência de Nabucodonosor à ambição, tema da cena 2 do acto III, que vale a pena passar aqui em revista. O monarca confessa-se seduzido por Ambição, enredado nos seus laços, disposto a segui-la, arde já nas chamas de Ambição, mas ela adverte-o de que isso tem o seu preço, e dita as suas leis. Para a seguir, o tirano terá de as acatar. Terá de perder a vergonha e não sentir pejo de exprimir às claras o que ocultamente deseja, porque a primeira lei da Ambição é não ter vergonha nenhuma; a segunda, não recear nem os homens nem os deuses. (16) Nabucodonosor hesita, num combate interior que funciona como pretexto para prolongamento do diálogo e sugere uma evolução mental do monarca que o conduzirá a declarar que está totalmente possuído pelas labaredas da ambição e pronto a declarar sem ambiguidades o seu maior desejo, desvanecido já todo o resquício de vergonha: deseja que a multidão o adore de joelhos como um Deus. ${ }^{(17)}$ Desejo reiterado solenemente diante de Ambição a cujo arbítrio se submete e cujas exigências promete satisfazer: ser um servo fiel da glória, arredar do seu caminho, de forma implacável, quantos se lhe opuserem. Este domínio da Ambição sobre o tirano tem a sua tradução simbólica numa linguagem de estilo emblemático. Ambição coloca o seu trono ao lado do do monarca; este pede para ela lhe atar as mãos com nós apertados e lhe prender cadeias ao pescoço. ${ }^{(18)}$ Ambição parte levando consigo o coração de Nabucodonosor e face ao convite deste para que venha visitá-lo a sua casa, ou melhor, corrige Nabucodonosor, à casa dela, responde-lhe esta de forma subtil e engenhosa, patenteando um conceptismo tipicamente barro-

(16) "Cupido Iam regni leges inclytas tradam mei / In nostro regno lex prima est, nullus pudor / Secunda, nec hominem uereri, nec Deum,» - III, 2, 730-732.

(17) "Nabuc. Tanquam Deus / Cupio adorari supplici a turba genu» - III, 2, 752-3

(18) «Nabuc. Arctis Cupido deprecor nodis manus / Vinci, catenas necte ceruici tuas / His esse potius nexibus uinctum iuuat, / Quam liberato currere qua uelim gradu.» - III, 2, 783-6. 
co: «Virei, ou melhor, não virei, pois embora pareça afastar-me é aqui que permaneço. É esta a minha natureza. Geralmente estou mais onde menos pareço estar». (19)

O palácio de Soberba: A abertura de cena no acto II coloca a plateia perante um quadro alegórico representando o palácio de Soberba. Pelas personagens que habitam esse palácio, por duas didascálias na margem e pelo teor dos diálogos, facilmente se conclui que o dramaturgo deixou aqui fortes pretextos para um cenário tipicamente barroco, onde a acentuada carga simbólica anda a par com um esplendoroso fausto, de colorido variado e exótico, proveniente quer da indumentária identificadora de cada personagem quer de outros objectos que, por exigências da encenação ou por mero reforço da verosimilhança, figuravam em cena.

É o diabo quem faz as apresentações de Soberba como «domina mundi» (v. 212), servida por inúmeros criados em toda a terra. A cena exibe alguns dos mais ilustres, diferenciados certamente pelos seus trajes característicos e por outros adereços simbólicos. São eles Rómulo, "O ilustre fundador de Roma," Alcides, "O terror de toda a terra, domador de monstros», Nino, o mítico fundador de Nínive, e Senaqueribe, antepassado próximo de Nabucodonosor. Todos, com excepção de Nino, intervêm em cena professando solenemente o seu comprazimento pessoal em se submeterem ao poder de Soberba. Neste ambiente de completa submissão de todo o mundo às leis da Soberba, a presença de Daniel constitui-se como um elemento dissonante. É ele o porta-voz do poder divino que faz frente a uma Soberba com ânsias de poder absoluto. Soberba conta com os serviços de um Mago, representante dos poderes ocultos, cuja caracterização e actuação em cena se revelariam ricas de sugestão, dada a forma como nas suas falas revela confiança nos seus sortilégios. Assinale-se finalmente a presença dum carro

\footnotetext{
(19) "Cupido Veniam, imo non ueniam, nam gradum / Auferre licet hinc uidear, hic maneo tamen / Nostra isthaec est natura, saepe sum magis / Vbi minus esse uideor, iam felix mane.» - III, 2, 800-2.
} 
em cena, carro esse que Soberba, antes de se voltar em definitivo para a magia, tenta em vão por duas vezes, de acordo com as didascálias, fazer rodar de encontro a Daniel para o esmagar sob as rodas. (20)

Esta cena no início do acto II revela-se estruturante de toda a acção dramática, pressagiando os seus futuros desenvolvimentos. É patente o antagonismo de situação dramática entre esta cena e a cena final que marca o desenlace do drama. Em ambas é a ideia de triunfo que move a acção, nomeadamente através da presença do carro, elemento basilar tradicionalmente associado à expressão alegórica do triunfo. As pretensões falhadas da Soberba de esmagar Daniel, não conseguindo mover o carro, podem tomar-se, pelo ridículo que geram, um prenúncio do desfecho deste combate travado entre a Soberba e o poder divino, aqui representado por Daniel. A cena, entretanto, alimentar-se-á deste triunfo efémero, como o deixam antever as palavras de Daniel. "Parte agora, alegre e sorridente com o teu triunfo. Mas não será por muito tempo que sentirás o gosto de rir».(21) O palco vai animar-se com este confronto entre as trevas e o poder divino. Nabucodonosor deixar-se-á prender por Ambição, filha da Soberba, mas na obtenção do que mais ambicionava, verá o triunfo fugir-lhe no martírio dos três jovens.

O combate pela fé: A condenação à morte na fornalha ardente dos três jovens hebreus, companheiros de Daniel e favoritos de Nabucodonosor, por se recusarem a prestar honras divinas ao tirano, ocupa uma longa cena de duzentos e catorze versos. O interrogatório de Nabucodonosor, dividido entre a necessidade de fazer cumprir o seu édito e a profunda compaixão e simpatia que nutre pelos três jovens; a entrada em cena das alegorias da

(20) "Hic magicus et diabolus in rotas incumbentes mouere currum non potuerunt, quare illos Superbia summa cum indignatione a se reiecit. Abite etc»- BPE, cod. CVIII/2-7, fl. 64r $m g$; "Hic iterum conati sunt irruere, et currum incitare, sed omnis eorum conatus elusus est. Quapropter Superbia. O non ferendum» - Ibid. fl. $64 \mathrm{v} \mathrm{mg}$.

(21) «I. Perage mente quod agitas dudum tua / Sed non licebit diutius facto frui. / I nunc triumpho laetus et ridens tuo / Sed non licebit diutius risu frui» - II, 1, 370-3. 
Fé, da Esperança e da Constância para acompanharem e animarem os três jovens em momento de provação; a tentativa frustrada de Nabucodonosor de aniquilar as três mulheres, isto é, as figuras alegóricas acabadas de referir; o milagre da salvação miraculosa dos três jovens; o espanto de Nabucodonosor e a sua subsequente profissão de fé no Deus de Israel, explicam a duração desta cena central do drama.

A transposição deste episódio para o palco, pelo que o texto sugere, terá proporcionado à plateia uma cena bem decorada e movimentada, plena de artifício, numa conjugação de recursos sonoros e plásticos que, associados à declamação, deram expressão aos temas do heroísmo, da glória e do triunfo. O carácter prodigioso desta cena como que surge anunciado nas palavras da Fé:

«Hoje veremos com que prodígios a verdadeira fé é posta à prova».(22)

É a virtude heróica que aqui é posta à prova nos três jovens às mãos dum tirano que, baldados os seus esforços de os demover com palavras lisonjeiras e promessas de dádivas generosas, se encoleriza e ameaça com a crueldade do suplício. O prodígio encheria a cena. Constância, Esperança e Fé entrariam como personagens ex-machina, deixando os soldados paralisados de espanto ante um tirano encolerizado por não ver cumpridas as suas ordens. ${ }^{(23)}$ As três virtudes tomariam assento num trono cujo brilho e esplendor, de tão intensos, deixariam os soldados novamente confusos e inertes face às ordens que tinham de aniquilar aquelas mulheres. ${ }^{(24)}$ Como estaria representada a fornalha ardente? O texto sugere a sua proximidade, ao alcance verosímil do olhar das personagens, talvez trazendo para a

(22) "Fides Ne nominate mortem, hodie uidebitis / Quantis se uera prodigiis probet fides. - III, 4, 925-6.

(23) "Arripite, quid statis lenti satellites?» - III, 4, 913

(24) «Nabuc. O timidi, lenti, inertes, ignaui milites, / Quo fugitis? Mentes quis tantus terret timor? / An alto flammas creditis ueras iaci? / Ars magica solitis excitat lucem dolis. / Eia iterum ruite, ferte nec retro gradum. / Milites Heu quantus ambit lucidum splendor tronum? / Maiestas quanta fulminat contra minas?" - III, 4, 983-9. 
cena a ilusão do clarão das suas chamas. Nabucodonosor, em cena, dirige a fala aos três jovens na fornalha. ${ }^{(25)}$ O relato da salvação miraculosa é feito por dois mensageiros, em acção conjugada, sobre um fundo sonoro que associa o crepitar das chamas e o som harmonioso do hino de louvor entoado pelos jovens. Do anjo que deteve o avanço das chamas dentro da fornalha, referido pelos mensageiros como todo de luz, com um fulgor de fogo que feria os olhares, ${ }^{(26)}$ o texto não postula necessariamente a sua presença em cena.

Esta cena, que se situa no meio da representação, pode considerar-se uma cena fulcral pela articulação que evidencia com toda a acção dramática, tanto a anterior como a posterior. A recorrência da temática da magia nas palavras de Nabucodonosor, que vê truques de magia nos prodígios que imobilizam os seus soldados, ${ }^{(27)}$ não deixa de evocar os esforços baldados de Soberba de fazer avançar o carro para esmagar Daniel e o seu posterior recurso aos serviços dum mago. A evocação, pela Fé, da venda do coração à vã glória e a promessa da sua restituição, (28) além de aludir à anterior presença de Ambição em cena, antecipa já o desenlace, onde vemos a recondução de Nabucodonosor no poder associada à recuperação dum coração novo, que Esperança lhe dá de presente. (29)

Dos diálogos travados nesta cena repleta de som e cor, com destaque na parte final para a harmonia musical e o brilho esplendoroso que auréola as personagens ex-machina, realce-se o carácter gnómico em algumas fases desses diálogos, com máximas cujo conteúdo se articula com as correspondentes figuras alegóricas:

(25) «Sidrac, Misac, Abdenago, et tu quisquis es, / Tantam corusco lucem, qui uultu iacis, / Et frangis aciem, conspici, nec te sinis...» - III, 4, 1028-30.

(26) «Fulgore quartus igneo totus micat," - III, 4, 1005.

(27) "Ars magica solitis excitat lucem dolis.» - III, 4, 986.

(28) «Tu, cum cor dederis gloriae sic hodie tuum / Nequaquam nos ubi excipere possis, habes / Quod si reduci cor tibi tuum cupis," - III, 4, 1049-51

(29) «Fides Euolue tandem spes soror magnum sinum / Missumque caelo munus. Nab. O uere Deae / Caeleste donum, sumo iam sceptrum manu, / Regnare iam me posse securum puto. / Spes Quid tam laetaris cordis obtentu noui? / Nab. Nil corde maius optimo Reges habent." - V, 4, 1816-21. 
Nabuc - Quem és tu? Procurai algemas bem pesadas, clientes.

Fé _ - Não há cadeias que possam aprisionar a Fé.

Nabuc - Lançar-te-ão às chamas.

Fé _ - Brilharei ainda mais. A fé autêntica refulge muito mais nas chamas. ${ }^{(30)}$

$[\ldots]$

Nabuc - Que ela receie pois aquele a cujas mãos pode morrer.

Esperança - Quem é conduzido pela nossa mão não teme poder algum.

A esperança percorre caminhos penosos com muita alegria.(31)

$[\ldots]$

Fé _ - Vai, ó verdadeira e fiel descendência dos Patriarcas.

Precedidos pela Fé, nada vos é doloroso.

Constância - Vai, avança alegremente com passo firme por entre as chamas.

Comigo a seu lado, ninguém se deixa vencer pelos infortúnios.

Esperança - Avança. Ilustre estirpe de Abraão; ri-te das ameaças.

Ao lado da Esperança, todo o sofrimento se torna agradável.(32)

\section{Conclusão: Matriz jesuítica e estética barroca}

Ainda que o contexto codicológico nos não fornecesse inequívocas garantias da génese jesuítica deste drama, um conjunto de indicações dadas pelo texto far-nos-ia chegar igualmente à conclusão segura de que só

(30) «Nabuc. Quae tu? Catenas quaerite, clientes, graues. / Fides Nullis teneri uinculis fides potest. / Nabuc. Daberis in flammas praeceps. Fides splendebo magis / In flammis uera, clarius fulget Fides.» - III, 4, 927-930.

(31) «Nabuc. Quem igitur timeat, cuius intereat manu. / Spes Nullam horret, nostra quem manus ducit, manum, / Spes per difficiles laetior currit uias.» - III, 4, 937-9.

(32) "Fides I, uera ueterum, i, fidens progenies Patrum, / Antecedente, nihil est asperum, fide. / Constantia I, perge forti laeta per flammas gradu, / Me comite, nullis uincitur quisquam malis. / Spes I, clara proles Abrahae, i ridens minas, / Omnis, spe comite, redditur dulcis labor.» - III, 4, 998-1003 
poderíamos estar perante uma peça jesuítica, encenada com aparato para altura solene (início ou encerramento do ano lectivo, distribuição de prémios, visita de personalidade importante, etc.). O intuito pedagógico, como factor mobilizador das opções privilegiadas no domínio da poética, por demais evidente nos temas e tópicos implicados, testemunha claramente a favor dessa matriz jesuítica.

Esta dramatização, a pretexto do conhecido episódio bíblico da fornalha ardente, oferece-se ao fim e ao cabo como uma ilustração do lema da Companhia de Jesus, "Ad maiorem Dei gloriam», num ambiente de heroísmo que tem como pano de fundo um combate donde derivará logicamente o triunfo de uma das partes à custa da pesada humilhação da outra. Dentro deste esquema linear de que se alimenta a dramatização perpassa um espelho do príncipe. Na personagem Nabucodonosor podemos ver projectado o retrato do monarca absoluto cuja legitimidade dinástica não é posta em causa, mas sim o exercício do seu poder, a que são fixados limites. A cena dramática dá-nos dois modelos bem contrapostos do monarca: primeiro, o tirano pagão, a que se contrapõe, no desenlace, o monarca cristão. No primeiro tipo, temos um Nabucodonosor orgulhoso, sedento de glória, pronto a sacrificar tudo o que de mais precioso possui, a sua pessoa, simbolizada no seu coração. Nesta fase, em que o monarca anseia ser igualado aos deuses, o recurso às forças ocultas da magia, como forma de remover os obstáculos ao acesso ao supremo poder ou à sua manutenção, é a regra. A condição de tais monarcas, porém, como avisa repetidamente o texto, designadamente no coro IV, não os subtrai ao jogo cíclico das forças da fortuna que, na sua rotação cega, vai fazendo tombar no abismo quem antes guindara às maiores alturas. (33)

No Nabucodonosor da segunda fase, que passou por um processo de humilhação e que depois vemos reconduzido ao poder, o dramaturgo parece

(33) "Ardua quisquis tempora gemmis / Condis, et auro, sceptraque gestas, / Altoque sedes solio, cerne / Cerne labantes quomodo gressus / In tam lubrico tramite figas» - Chorus V, $1459-63$. 
ter tido o cuidado de deixar um conjunto de indicações que, contrapostas às do parágrafo anterior, remetem para uma condição qualitativamente diferente do monarca, como homem de poder. Já nos referimos à sua humildade, traduzida em cena com um exagero que se poderá mesmo classificar de barroco e que redunda, funcionalmente, na afirmação do poder divino. Aludi igualmente à profunda renitência em regressar ao poder, um tópico muito frequente nos Jesuítas, onde se dá expressão à consciência aguda dos perigos que espreitam quem detém o poder, o maior dos quais é o de o governante pretender que o adorem como um deus. A esta humildade e fastio pelo poder, junta-se a vergonha por ter despedaçado o seu coração, ao entregar-se à Ambição. Das indicações aqui deixadas sobre a nova condição de um soberano que, na intenção do dramaturgo, talvez possamos qualificar de cristão, a primeira tem a ver com um acto simbólico que se passa em palco, na cena final: Esperança, exortada pela sua irmã Fé, desdobra o seu grande manto e dá-lhe o presente enviado do céu: «um coração novo que nenhum ímpeto de Ambição poderá demover, mesmo que esta estenda os seus dardos ou as suas cadeias». (34) Com esse coração novo Nabucodonosor atinge nova condição como homem de poder. Subtrai-se ao jogo cego das vicissitudes da fortuna em que se vêem enredados os soberanos insensatos. Fé reconhece no Nabucodonosor regressado da penosa humilhação uma pessoa sensata, em condições de empunhar o ceptro, de se revestir do esplendor da púrpura e de, sem medo, subir ao trono, pois nenhum poder o precipitará de lá.(35) A outra indicação, porventura mais significativa da preocupação do dramaturgo em sugerir o perfil do soberano cristão, tem a ver com os limites do poder real. Estamos no final da peça, nos derradeiros versos da última cena, que deixam antever já a magnificente saída de cena, em cortejo festivo, ao estilo dos triunfos renascentistas. Não falta o

(34) "Spes Laetare potius dabimus cor nouum tibi / Quod nulla possit flectere uis cupidinis, / Seu tela, seu catenas intendat suas." - V, 4, 1811-3.

(35) "Ascende pulso iam regium tronum metu, / Iam nulla te uis inde praecipitem dabit." $-\mathrm{V}, 4,1828-9$. 
carro para simbolizar o triunfo, a par de outros motivos alegóricos e uma disposição ordenada dos figurantes, que desfilarão exibindo as têmporas enfeitadas de flores e empunhando ramos de palmeiras, ao som do canto triunfal constituído pelo coro V. ${ }^{(36)}$ Falta, porém, dar o devido castigo à Ambição e à Perfídia. A causa é de Nabucodonosor, mas este entrega-a à Fé, para que seja esta a decretar tal castigo, e, ao fazê-lo de bom grado, explicita as razões:

"Só tu conheces as insídias, só tu as poderás punir devidamente». (37)

Com esta concessão à Fé, Nabucodonosor deixa de si, em momento fulcral da situação dramática, pouco antes de o pano baixar, a imagem modelar do soberano sábio, consciente de que nem tudo lhe é lícito, capaz de auto-limitar-se ante o poder verdadeiramente soberano que é o poder divino, representado ali por Fé, personagem alegórica. Cabe à Fé julgar e punir, a mesma Fé que, em situação dramática bem diferente, fora acusada por Nabucodonosor de ensinar os súbditos a desprezar as ordens dos reis e que na altura lhe respondera:

«- Precisamente quando os reis ordenam o que é contrário a Deus»(38)

É recorrente na dramaturgia jesuítica a emergência deste modelo de governante desapegado do poder, preferindo ao bulício da corte a rudeza e o sossego da vida humilde, em cuja construção convergem, como neste drama, uma série de topoi hauridos dos textos clássicos seleccionados para leitura nas diversas classes. Não é difícil reconhecer nesse modelo, incarnado

(36) "At nunc feramus regiam ad domum gradum / Laeti thriumpho, floribus cincti comas / Ornate, palmas capite, iam regnet Fides, / Fides thriumphet, floreat Fides Fides / Det iura mundo, nemo non colat Fidem. / Praei Michael magne defensor sacrae / Custosque Fidei; ducite currum nobiles / Magnique Vates: laetos uos fundite cantus» - V, 4, 1871-1878.

(37) «Nab. Trado libenter, sola tu nosti dolos / Punire sola tu dolos poteris satis.» - V, 4, $1849-50$.

(38) «Fides Cum nempe Reges contraria iubent Deo.» - III, 4, 934. 
neste Nabucodonosor restituído ao poder, a corrente do anti-maquiavelismo cristão, em que, entre outros nomes, se inclui o do português Jerónimo Osório, teve também como paladinos eminentes jesuítas, de que se destacam Pedro Ribadeneira, Juan Mariana e Giovanni Botero. Foi a partir da obra deste último, Della ragion di stato (Veneza, 1589), que ganhou corpo entre os doutrinadores jesuítas a teoria da razão de estado cristã, caracterizada como "a razão de estado ad maiorem Dei gloriam, que exprime a perfeita harmonia entre os ensinamentos da fé e as exigências inescusáveis do governo dos povos proclamada pela Razão».(39)

Os exercícios espirituais: Outro elemento de matriz jesuítica, facilmente perceptível neste tipo de dramatização do episódio bíblico é a dinâmica dos Exercícios Espirituais que, da mesma forma que marcava singularmente a vida de cada jesuíta, cremos que condicionou aqui de forma ineludível o trabalho do dramaturgo.

É sabido que os Exercícios Espirituais consistiam basicamente numa contemplação interior avivada por técnicas que estimulavam a imaginação do exercitante na recriação de cenários e de situações onde ele próprio se inseria. No caso do presente drama, com a apropriação singular do episódio bíblico nele testemunhada, a plateia era colocada a contemplar em palco uma realidade espiritual a que não é alheia qualquer pessoa. Ainda que não sejamos monarcas absolutos, não estamos ao abrigo de nos confrontarmos, em grande ou pequena escala, com os assaltos ardilosos do orgulho ou da ambição. A cena em que Nabucodonosor é assaltado pela Ambição e o vemos, após um longo e bem imaginado processo de cedências, totalmente rendido, implorando ao vício alegorizado que lhe ate as mãos com nós bem apertados e lhe prenda cadeias ao pescoço, essa cena soa-nos como a compositio loci em que o exercitante era convidado a associar imaginativamente uma situação de pecado a uma situação física como a de estar

(39) NAIR DE NAZARÉ DE CASTRO SOARES, O príncipe ideal no século XVI e a obra de D. Jerónimo Osório, INIC, Coimbra, 1994, p. 203-204. 
numa prisão. (40) A cena do combate pela fé, onde os três jovens recebem o auxílio das três virtudes remete-nos igualmente para outro prelúdio dos Exercícios Espirituais em que o exercitando se contempla a si próprio diante da Corte Celeste e é convidado a ver com força imaginativa como todos os santos intercedem por ele. ${ }^{(41)}$ O binarismo que referi na construção de alguns diálogos onde duas personagens se desdobram em considerações sobre a mesma questão (a cena dos dois sátrapas é o exemplo mais flagrante), parece remeter igualmente para a técnica da exercitação inaciana. Neste caso concreto, sou tentado a ver a génese deste binarismo, tão em voga neste drama, no exercício congeminado por Santo Inácio, das três classes de homens reflectindo sobre o destino a dar a uma grande soma de dinheiro adquirida indevidamente. Aqui cada classe agrupava dois homens. Esta divisão de cada classe em dois facilitaria o desenvolvimento imaginativo de diálogos criados para o efeito, colocando o exercitando mais como observador e não tanto como juiz de si próprio. ${ }^{(42)}$ O binarismo dos diálogos tal como nos surge na referida cena dos dois sátrapas favorece, em benefício da plateia, uma melhor observação da situação dramática, segundo os três pontos da dinâmica contemplativa proposta por S. Inácio: observar as pessoas, escutar o que dizem, ver o que fazem.

\section{Estética barroca}

Pelo tipo de elocutio, testemunhada directamente no texto e pelo aspecto duma encenação que conjecturamos como magnificente, a estética subjacente à imitatio do dramaturgo parece enquadrar-se claramente no movimento do Barroco. Comecemos pela elocutio.

(40) HEINRICH PFEIFFER, S. J., "La radice spirituale dell'attività teatrale della Compagnia di Gesù negli 'esercizi spirituali' di San'Ignazio", in I Gesuiti e i primordi del teatro barrocco in Europa. XVIII Convegno Internazionale del Centro Studi sul Teatro Medievale e Rinascimentale (Roma, 26-30 de Outubro de 1994) Roma, Torre d'Orfeo Editrice, 1995, p. 32.

(41) Cf. loc. cit.

(42) Ibid. pp. 34-36. 
A estratégia de persuasão montada em palco, numa conjugação forte e massiva de elementos de vária ordem, ultrapassa o domínio da elocutio. Esta enquadra-se nessa funcionalidade persuasiva através de um jogo recorrente de figuras de estilo que conferem ao discurso um tom épico e emotivo. Merecem realce as figuras de repetição, de efeito amplificador, não apenas de adjectivos, substantivos e verbos, ${ }^{(43)}$ geralmente em grupos de três, mas também de expressões de horror ou de indignação, de juras e de orações inteiras na figura do isocólon trimembre. ${ }^{(44)}$ A esta repetição acumulante, que funciona no sentido de acentuar a evidência do que se passa em cena, há que acentuar igualmente a recorrência muito frequente da interrogação e da exclamação, numa clara estratégia de acumular para impressionar. ${ }^{(45)}$

Outro aspecto da elocutio digno de menção é o recurso frequente à simetria, muito perceptível nas fases mais vivas dos diálogos, onde a alternância das falas se sucede com rapidez. Isto ocorre sobretudo nos diálogos antinómicos, muito característicos deste drama, onde o paralelismo antitético une algumas vezes na figura do quiasmo dois versos de falas diferentes. (46) Nas tiradas mais longas, o tom declamatório vive sobretudo da anáfora ${ }^{(47)}$, muitas vezes combinada com a metáfora e a perífrase, com efeitos de engrandecimento e de sublimação. ${ }^{(48)}$

(43) Vejam-se só alguns exemplos dos muitos que marcam o texto. a) de adjectivos: "Finire uitam hic liceat, impios Lares, / Infandos postes, funestam intrabo domum.» - V, 2, 1608-9; b) de substantivos: "Cupido Minare poenas horrificas, ferrum, feras / Flammas, catenas, pectines, diras neces / Et quae non tantis uincetur uirtus malis?» - III, 2, 764-6; c) de verbos: "Satrapae Agnosco, fateor praedico, ad pedes cado, / Adoro supplex, pronus inclino caput, / Viuat, diuque uiuat, regnet, imperet / Debellet hostes, proterat, calcet suos.» - IV, 2, 1187-1190.

(44) «Ille est, trisulcas mittit qui manu faces, / Qui uersat orbis uastos immensi globos / Qui sceptra sponte donat, et adimit sua. »- V, 2, 1570-2.

(45) Um exemplo de acumulação de exclamações. "O summa gentis caecitas mortalium! / O error ingens! O tenebrosum genus!» - II, 2, 401-2. Acumulação de interrogações: "Quo enim potest sanari qui sic non potest? / Quid expectas? Quid differs exitium pater? / Quid raptas cogit toties flammas ponere ? / Quid uincit animum? Quid ligat iratas manus? »- II, 2, 486-90.

(46) Vejam-se estes dois casos típicos: «Dan. Numen recusas facere quod summum imperat? / Nab. Numen recuso facere quod summum uetat.» - V, 2, 1612-3; "Habere talem patrem est regno charius. / Nabuc. Habere talem natum est regno pulchrius, - - V, 4, 1739-40.

(47) «Iam non precabor, iam non obsistam Deo,» - IV, 1, 1121.

(48) "Como neste caso, para engrandecer a majestade divina: "Princ. Adoro Numen, Daniel et colo tuum / Ille est, trisulcas mittit qui manu faces, / Qui uersat orbis uastos immensi globos / Qui sceptra sponte donat, et adimit sua. " - V, 2, 1569-72. 
A encenação: A ausência quase total de didascálias impossibilita certezas inequívocas sobre uma encenação que, apenas com base em pistas advindas do texto, se crê ter sido de uma magnificência esmagadora, concedendo grande privilégio ao aspecto visual. Comecemos pelo vestuário. O tipo de personagens que integra a acção dramática fornece amplos pretextos para colorir a cena de requinte, pela variedade de trajes em personagens de condição e proveniência diversa. Pensemos em Nabucodonosor e na sua corte de sátrapas, em Vilmerodaque, seu filho, no profeta Daniel e nos três jovens hebreus. Já conjecturámos como a corte da Soberba, rodeada de vassalos tão ilustres (Senaqueribe, Hércules, Rómulo, Nino...) se deveria impor com uma decoração soberba.

O recurso a técnicas de persuasão extra-racional é um dos aspectos a salientar aqui. Ele tem a ver essencialmente com as personagens de índole alegórica: de um lado a Soberba, a Ambição e a Perfídia, a que podemos associar também o Mago; do outro, a Fé, a Esperança e a Constância, às quais se vem juntar depois o Anjo. Afigura-se-nos plausível conjecturar que na caracterização destas personagens houve um claro propósito de construir um espectáculo total por integração de todas as artes, exagerando as cores negativas de umas e realçando o brilho e o esplendor de outras. Esta estratégia de recorrer à utilização de elementos plásticos que logrem a atracção dos sentidos, favorecendo a acção directa de Deus, segue fins de natureza propagandística e não deixa de se inserir na dinâmica dos Exercícios Espirituais. (49)

Embora o tema hagiográfico, à primeira vista, se preste melhor a um tipo de teatro propagandístico com pretensões de responder a situações concretas, esta dramatização dos capítulos iniciais do Livro de Daniel parece-nos susceptível de enquadrar-se perfeitamente nesse tipo de teatro. Se é esta a tragédia noticiada na Sinopse de Franco como tendo sido representada em

(49) Sobre a utilização dum estilo pictórico por parte do barroco como meio de persuasão extra-racional cf. JOSÉ-ANTÓNIO MARAVALL, "Objectifs sócio-politiques de l'emploi de moyens visuels", Baroque VII (1974), pp. 111-119. 
1576,(50) lembremo-nos de que estamos em plena época de lutas religiosas, vistas do lado católico como lutas contra a heresia. Os acontecimentos recentes em França haviam dado um pungente espectáculo. A tristemente célebre matança de S. Bartolomeu foi tema privilegiado na exercitação escolar jesuítica. O mesmo códice que contém o texto desta tragédia contém igualmente um número razoável de composições poéticas alusivas ao acontecimento. ${ }^{(51)} \mathrm{Na}$ altura, a afirmação da Igreja Católica passava pela aplicação dos decretos do Concílio de Trento, com a ajuda imprescindível do poder temporal. No papel dramático de Daniel enquanto profeta do verdadeiro Deus, conselheiro político, assistente e consolador do povo hebreu, é legítimo ver projectada uma espécie de desejada aliança da Igreja Católica com as monarquias absolutistas, num esforço de catequização maciça visando a adesão ideológica uniforme e ortodoxa da grande massa da população. Assim se conseguiria com eficácia esmagar de forma humilhante a heresia e exaltar em seu triunfo a santa Fé católica, ad maiorem Dei gloriam.

(50) A notícia é a seguinte: "Mense Maio in scenam data tragoedia Nabucho, spectatores morata horas quinque: mirifice recreatus Cardinalis iucundo spectaculo». Cf. ANTÓNIO FRANCO, Synopsis Annalium Societatis Iesu in Lusitania ab anno 1540 usque ad annum 1725 . AugustaeVindelicorum et Graecii, 1726, p. 110, n ${ }^{\circ} 14$.

(51) Eis os títulos de alguns desses poemas: "De caede haereticorum» - fls. 58v, 59r-v; "Haeretici descriptio" - fl. 59v; "In Petrum Ramum in Sequanum demersum» - fls. 59v-60r. 
Jean-Marie Valentin

Universidade de Paris

LES HUMANISTES ALLEMANDS ET LE THÉÂTRE NÉO-LATIN. ENTRE L'HÉRITAGE, LA MORALE ET L'ÉLOGE PRINCIER

Naturellement, le Saint Empire s'inscrit majoritairement dans l'espace ouesteuropéen dont il épouse les grandes tendances. Son étendue, le mélange de populations et de langues, rendent cette réalité évidente. Comme partout, on rêve de faire ce qu'a fait et fait toujours l'Italie. Le discours inaugural du grand Celtis à Ingolstadt fournit la formule clé des humanistes du Nord des Alpes: la migratio musarum. L'imitation est effort conscient pour égaler et, un jour, dépasser le modèle. De plus, comme partout ailleurs, ce sont les chaires d'université, récemment créées, spécialement dans les Facultés des Arts, qui donnent l'impulsion. En ce sens, la date de fondation, le lieu de création, le choix des maîtres sont de puissants indicateurs de l'existence d'une politique nouvelle, mais l'Empire possède aussi de nombreux caractères propres. Ses structures politiques sont variées et révèlent très tôt un polycentrisme qui traversera les siècles. À l'Empereur, lui-même chef d'une dynastie ayant ses territoires patrimoniaux propres, s'ajoutent les princesélecteurs, des principautés, civiles et ecclésiastiques, de toutes sortes et de toutes tailles, des villes, libres ou non, qui ne cessent d'affirmer leur pouvoir, comme les princes, par des jeux d'alliances complexes et instables.

Ce monde est celui d'avant la Réforme et d'avant la rupture confessionnelle qu'elle entraîne. Par exemple, l'Allemagne du Sud, la Germania Superior, ne peut être dissociée de territoires de la Germania Inferior tels que les 
Pays-Bas, membres à part entière de cette grande construction. L'humanisme pour sa part va accroître l'intensité des rapports culturels entre ces deux grands espaces. L'exemple le plus illustre est ici celui que donne Erasme, de Rotterdam, qui passe une grande partie de sa vie à Bâle, séjourne à Sélestat et Strasbourg, rend maintes visites à Londres à son ami Thomas More, chancelier d'Angleterre. Deux voies ont concentré sur elles ces échanges et lieux d'épanouissement de l'esprit nouveau, des méthodes exégétiques récemment introduites, des pratiques d'écriture savantes ou poétiques. A l'axe rhénan qu'Erasme personnifie admirablement ${ }^{(1)}$ mais qui permet aussi de resituer la belle floraison alsacienne dans son vrai cadre, et qui fait de villes comme Bâle, Sélestat, Strasbourg, Tübingen, Heidelberg et, plus à l'est, Nuremberg, puis, dans l'espace du Rhin Inférieur, Louvain, Liège, Anvers, Rotterdam autant de points d'appui vivants, il y a l'axe danubien qui relie les villes souabes à Vienne, capitale de l'Empire, ainsi qu'aux espaces de l'Europe du Centre, encore exempte de Turcs jusqu'en 1526, la Hongrie et la Pologne notamment.

Ce monde est en outre marqué par la mobilité des meilleurs humanistes, Erasme naturellement, mais aussi Celtis. Tous bénéficient du vaste réseau d'universités récemment fondées, du système d'écoles latines (Lateinschulen) qui se substituent peu à peu aux Domschulen, voire aux Klosterschulen plus imbriquées dans les structures ecclésiastiques, cathédrales et monastères. Notons encore deux phénomènes qui contribuent à rendre plus actif et plus solidaire ce tissu: la correspondance entre humanistes, phénomène qui traduit, dans la rémanence, la tendance à remplacer le centre unique (disons: le modèle français en devenir) par le réseau (en langage moderne: le "network») et la création de sociétés, les Sodalitates, qui anticipent, il est vrai sans en avoir les objectifs concrets, le phénomène des académies des $16^{\mathrm{e}}$ et $17^{\mathrm{e}}$ siècles.

(1) Jean-Claude Margolin: Erasme, précepteur de l'Europe, Paris, Julliard, 1995. 
Le dynamisme de ces hommes et des organismes, auxquels ils s'identifient ou appartiennent, se nourrit du sentiment d'œuvrer à l'avènement d'un âge nouveau et de travailler à un renouveau culturel qui tend à se réaliser, en dehors de tout conflit dogmatique, au sein même de l'Eglise-mère de Rome - on mesure ici la différence avec l'humanisme baroque du $17^{\mathrm{e}}$ siècle romain de la cour des Barberini et du pontificat d'Urbain VIII, qui, s'il lui arrive de déborder de son cadre naturel, est substantiellement interne à l'Eglise catholique posttridentine.

Le théâtre n'est qu'une partie de cette grande entreprise de régénération par les lettres. Mais face à une politique de revitalisation du latin, comme langue parlée également, de retour aux auteurs antiques, de réfection de l'enseignement dont le collège secondaire sera le fruit historique, il occupe une place culturelle sans commune mesure avec ce que nous pourrions imaginer aujourd'hui. Pour les commodités de l'exposé, je me centrerai sur trois axes principaux:

- l'héritage

- la morale

- l'éloge princier, ou plus exactement impérial.

\section{L'héritage}

Les humanistes allemands, comme tous leurs frères de combat en Europe, ne s'adonnent pas seulement à l'exégèse philologique, et donc à l'établissement (et à l'édition) de textes sûrs. Ils veulent aussi faire renaître un latin 
vivant, de modèle généralement cicéronien (quelles que soient les nuances), qui serait contre les latins d'Église ou scolastique, la lingua franca de la Respublica litteraria. Il y eut, dans l'Empire également, un effort considérable et systématique, dont l'enracinement progressif fut le résultat d'une lutte constante contre des résistances avant tout théologiques, la scientia sacra se sentant menacée dans son monopole et son statut de regina scientiarum. A Louvain par exemple, l'opposition fut particulièrement vive et se répéta avec une extrême intensité autour de 1520 quand commencèrent les ripostes institutionnelles (voyez au même moment la Sorbonne) et individuelles à la Réforme de Luther. Le cas de Martinus Dorpius ${ }^{(2)}$ est peut-être le plus révélateur, en ce sens en effet que le conflit l'oppose à lui-même en quelque sorte. L'humaniste qu'il est prend rapidement peur face à ce qu'il tient pour d'inacceptables audaces et qui sont, d'abord et avant tout, la suite logique de positions qu'il partageait pleinement peu avant. Il reste que les humanistes universitaires (ou non, comme Erasme) font appel au théâtre pour soutenir et alimenter leur plan de rénovation de la langue par la littérature transmise par la scène. Erasme traduisant en latin l'Iphigénie et l'Hécube d'Euripide, démontre la valeur de la langue de Cicéron comme médiateur culturel, y compris avec la Grèce. Mélanchthon, éditant Térence (1516), suggère la supériorité d'un modèle de langue sérieuse, sensible, noble (celle dont Diderot fera encore crédit à l'Hécyre / Hecyra du même Térence). On voit bien ici que le souci philologique n'est que subalterne face à une ambition étonnante: faire renaître un latin proche de ce qu'il avait été pour le transformer en instrument de ce changement culturel, qui est aussi retour aux sources, sans lequel l'humanisme lettré ne serait que projet savant.

(2) Sur tout ce contexte, voir Jean-Marie Valentin: Aux sources du théâtre néo-latin de la Réforme catholique: l' Euripus" (1549) de Livinus Brechtus, dans: Humanistica lovaniensia 21 (1972), p. 81-188. Repris dans J.-M. V.: Theatrum Catholicum. Les jésuites et la scène en Allemagne au XVI et au XVII siècle, Nancy, 1990, p.131-206. 


\section{La morale}

On peut dire qu'Erasme et Mélanchthon étaient mus par des préoccupations qui reprenaient celles de nombre de leurs contemporains. Ils se demandèrent comment (et auprès de qui) faire fructifier l'héritage, comment actualiser le message, ou encore par quels moyens le christianiser en le faisant servir à l'éducation de la jeunesse - Mélanchthon était d'ailleurs l'auteur d'une rhétorique, Erasme avait fait paraître un programme pédagogique, le De pueris instituendis, ${ }^{(3)}$ qui illustrent leurs préoccupations pédagogiques. Il apparut, comme nous pouvons le constater a posteriori, que trois voies au moins étaient praticables:

1. Celle de Dorpius. Elle se définit par le recours à Plaute, dont le jeune maître louvaniste complète l'Aulularia dont il écrit, dans un style aussi proche que possible de celui de l'auteur latin, les parties manquantes. Il fera de surcroît le même travail pour le Gloriosus (dit Miles Gloriosus).

2. Celle d'Adrianus Barlandus. Ce dernier tente, en latin, de refaire pour la latinité moderne le chemin même que l'on supposait les Grecs avoir parcouru, c'est-à-dire passer de l'épopée nationale fondatrice, en ce cas l'Iliade, aux textes tragiques représentés lors des grandes dionysies. Ainsi tire-t-il de l'Enéide de Virgile une Dido, à laquelle, selon toute vraisemblance, il accordait une valeur de paradigme. Plus tard, N. Frischlin et le jésuite Gretser emprunteront à leur tour ce chemin singulier. (4)

3. Celle, la seconde du même Adrien Barlandus, esprit décidément ingénieux et productif, qui rend concret le rêve sous-jacent aux pratiques des premiers universitaires "latinophiles»: faire rayonner le théâtre en pratiquant, à partir de lui et autour de lui, une irrigation, en favorisant un rayonnement venant féconder des formes en partie anciennes, en partie scolastiques, en

(3) Edition, traduction et commentaires par Jean-Claude Margolin, Genève, Droz, 1966.

(4) Jean-Marie Valentin: Les jésuites et le théâtre (1554-1680). Contribution à l'histoire culturelle du monde catholique dans le Saint-Empire romain germanique, Paris, Desjonquères, 2001, p. 301-334. 
partie nouvelles - mais dans tous les cas pleinement cohérentes avec les idées générales déjà définies.

C'est le développement des concertationes, des dialogues, ${ }^{(5)}$ des colloques et autres progymnasmata. Imités du rhéteur Aphthonius, ceux-ci furent portés à leur sommet à la fin du 16e siècle par le Jésuite Jakob Pontanus. Ces petites formes confortent la primauté de Térence tandis que le succès rencontré par ces dernières, données sous une forme déclamée, et donc "sine scenico apparatu», favorise et la recherche d'un effet de réalité (les petites scènes quotidiennes «en situation») et le développement d'une technique fondée sur le renouveau général de la rhétorique (de Mélanchthon au jésuite C. Soarez). A Strasbourg le travail de Jean Sturm, issu lui-même des écoles liégeoises et admirateur du modus parisiensis, montre comment cette intense pénétration du système pédagogique donne le branle, en l'absence même de l'accord de Sturm, à la pratique théâtrale. Les Jésuites saisiront plus tard le dynamisme inhérent à cet échafaudage premier et le capteront au profit de leur apostolat lié à la rhétorique, à la spiritualité des Exercices et à l'exploitation des affects.

L'idée qui s'impose — redisons-le: au sein même de l'humanisme c'est celle de la pietas litterata, du bonus discipulus face au bonus magister, tous deux devant devenir ou incarner déjà l'bomo bene dicendi peritus, exaltant la morale du travail (contre la pigritia), une éthique de la bonne éducation, des règles de la civilité commençante, de la morale civile, et donc du service de la cité et de la collectivité comme lieu d'accomplissement du chrétien appelé à faire son salut dans le monde. C'est en même temps une théologie des œuvres et de la foi en vue du salut. On ne constate pas alors de conflit véritable entre ces deux voies, de même que règne l'harmonie postulée entre fides et ratio.

(5) Il est toujours utile de se reporter à Louis Massebiau: Les colloques scolaires du XVIe siècle et leurs auteurs 1480-1570, Paris, 1878. 
La limite de ce théâtre est sa tendance à reconstituer un speculum spatii scholastici, ou du moins, à faire de cet espace un abrégé du monde en général selon un didactisme qui protège de l'extérieur et ne fait par exemple pas intervenir l'histoire ou la politique. C'est une morale de l'exemplum par transformation des ouvres antiques selon une conception qui peut rendre conciliables les deux univers culturels, l'antique, païen mais anticipateur du message chrétien (le saint Socrate d'Erasme), et le moderne, chrétien, absolument supérieur et accomplissant l'histoire à travers la Révélation du Dieu d'amour. Cependant: l'écho demeure faible, les initiatives sont dispersées, locales, dépendantes des individus.

Les meilleures illustrations de ce mouvement sont celles relevées à la fin du XVe siècle dans l'espace proprement allemand. Chez les grands auteurs, on constate la valeur fondatrice de ces textes dont la parution coïncide avec la publication de recueils de colloques, ce qui confirme la réalité de ce lien essentiel évoqué tout à l'heure. (6) Il faut mentionner ici le Stylpho de Wimpheling qui passe pour le premier drame néo-latin composé outreRhin. Lu par l'auteur (ou joué par ses élèves) à Heidelberg le 8 mars 1480, ce drame composé par le grand humaniste de Sélestat a un sujet de valeur générale. La technique est celle du contraste qui réapparaîtra plus tard dans les romans, en allemand cette fois, de son compatriote Jörg Wickram au milieu du $16^{\mathrm{e}}$ siècle. Le monde peint est celui de l'école et l'objectif visé se réalise par la mise sur la scène de deux destins opposés, celui d'un étudiant zélé et appliqué qui connaît une ascension glorieuse et celui d'un élève négligent (piger), condamné à une déchéance progressive et qui se révèle être définitive.

C'est là une voie prometteuse marquée par une réelle qualité littéraire. La même remarque s'applique au Codrus de Kerckmeister de 1485... Quant au Henno (1497) du grand hébraïsant Reuchlin impliqué dans une querelle

(6) Paul Bahlmann: Die lateinischen Dramen von Wimphelings "Stylpho" (1480) bis zur Mitte des 16. Jahrbunderts. Ein Beitrag zur Literaturgeschichte, Münster, 1893. 
fameuse, une «affaire» comme l'on a dit, qui mettait en jeu la légitimité de la critique philologique et de la lecture des textes en hébreu, il appelle

quelques brèves remarques particulières. Le titre d'abord: Scena Progymnasmata sive Henno. Reuchlin lie exemplairement ici le dialogue pédagogique venu de l'Antiquité et le théâtre; "sive» terme appelé à une grande fortune, affiche ostensiblement le didactisme, la leçon, inhérente au texte et à la représentation. Enfin le sujet se place dans la proximité de L'Histoire de Maître Pathelin, un des grands textes français du Moyen Âge, sans que l'on puisse fournir toutefois la preuve d'une filiation philologique. Mais le registre est nouveau. C'est celui du comique de la "farce» - comme l'exprimait le texte français. Indubitablement, il y a dans ce cas une ouverture vers des formes de rire indépendantes du monde scolaire dont les frontières les plus strictes sont clairement désormais transgressées. Cette potentialité ne sera toutefois guère exploitée. Mais il est de fait qu'elle existe et suggère, outre une pression du bas-comique déjà présente dans Plaute, un besoin de situations réalistes qui mettent en scène des milieux et des individus ou professions inspirés d'une réalité sociale certes stylisée, mais proche de la vie concrète au sens même de la formule cicéronienne: "comedia imitatio vitae civilis».

\section{L'éloge princier}

Le rapprochement des dates est peut-être artificiel, mais la proximité est parfois révélatrice de l'apparition de mouvements nouveaux. Dès le début du $16^{\mathrm{e}}$ siècle, on voit paraître deux textes dont la publication chronologiquement voisine marque l'émergence d'une nouvelle écriture dramatique que l'on considèrera comme le troisième volet de la production humaniste dans l'Empire. Le premier à pour titre Ludus Dianae, il date de 1501. Le second s'intitule Laudes Maximiliani. Sortis des presses en 1504, tous deux sont de la plume du même auteur, l'archihumaniste Conrad Celtis (ou Cel- 
tes). ${ }^{(7)}$ Cet important représentant des lettres latines en Allemagne eut une audience considérable, d'abord et avant tout dans les territoires impériaux de la maison des Habsbourg. Il fut proche de l'Empereur lui-même et protégé par lui. A Vienne fut fondée à son intention une nouvelle faculté des arts. Celtis était un patriote allemand, comme les Alsaciens Wimpheling et Beatus Rhenanus. Il était préoccupé par la défense du passé des Allemands et soutint le mouvement national qu'avait déclenché la redécouverte de la Germania de Tacite. Il voulait promouvoir la culture allemande et lui donner la première place. C'est à lui que l'on doit notamment la première édition moderne (en 1501) des comédies de Roswitha von Gandersheim, pièces écrites au $10^{\mathrm{e}}$ siècle et dont l'objectif était déjà de fournir un substitut chrétien au théâtre de Térence. L'idée du Terentius Christianus réalisée par Schnonaeus près d'un siècle plus tard, apparaissait aussi grâce à Celtis comme une aspiration actuelle, mais également comme portée par une recherche multiséculaire qui cherchait à fusionner les héritages pour mieux leur conférer l'onction du christianisme.

Celtis était enfin historien et son texte sur Nuremberg, capitale des villes ralliées à l'humanisme (elle fut la patrie de Pirckheimer puis de Dürer), le De origine, situ et institutis Norimbergae libellus de 1502, transplante en Allemagne la tradition italienne (celle de Ludovico Bruni) des éloges de villes. On sait que Celtis fut l'initiateur des Sodalitates. La Danubiana fut de toutes la plus importante, mais il y eut également, en fonction de ses lieux d'activité académique, la Vistulana à Cracovie, la Sodalitas litteraria Hungarorum et la Rhenana. Or, ce rayonnement comme cette présence multiple ne se départissent jamais d'une aspiration à fixer un centre qui ait la force symbolique du pouvoir. L'Empereur en devient donc le cour et de ce fait, Celtis inaugure, au théâtre ainsi que dans l'éloge, un humanisme politique qui rejoint le parti-pris pro-habsbourgeois (et secondairement

(7) Heinz Kindermann: Le théâtre en Autriche au temps de Maximilien Ier, dans: Jean Jacquot (dir.): Le lieu théâtral à la Renaissance, Paris, CNRS, 1964, p. 159-170. 
anti-français) des historiographes alsaciens. ${ }^{(8)}$ C'est un moment nouveau et riche potentiellement d'un courant original: avec Celtis, le théâtre n'est plus confiné aux dépendances et espaces subalternes des universités. Il n'est plus seulement la forme la plus élaborée d'une pratique pédagogique pénétrée de part en part par la pratique des exercitia rhetorica et des progymnasmata. Il change de lieu pour se muer en spectacle virtuel, puis réel, de cour. Si son esprit demeure pleinement chrétien et son idéal, hautement poétique, il est clair qu'il est indissociable de son destinataire suprême, la personne de l'Empereur. Mais il faut encore aller plus avant et rappeler que ce type d'écriture, qui ne se conçoit pas sans le concours des autres arts (peinture, musique, danse, ballet, emblématique) et conduit logiquement à la plurimédialité, établit également le destinataire en protagoniste. Mais comme il n'est pas possible de placer l'Empereur en personne sur la scène, comme on le ferait du roi à la cour de Versailles, l'éloge se doit de mettre à contribution deux modes d'expression qui concrétisent cette volonté de grandeur dont le stylus gravis est le correspondant au sein de la hiérarchie traditionnelle des styles.

Le premier de ces modes est la référence mythologique, traitée souvent à travers le canal de l'adumbratio. A une époque où la répartition future entre mythologie et histoire, vouées, l'une, à structurer l'opéra, l'autre à pourvoir la scène dramatique en sujets, cette pratique n'a rien qui contrevienne à une poétique à laquelle - pour d'évidentes raisons chronologiques — la distinction postérieure entre théâtre parlé et théâtre chanté ne saurait s'appliquer. A quoi il faut ajouter que l'éloge exige des héros positifs qui rehaussent la gloire de l'Empereur (ou de l'Impératrice) et de l'Empire et puissent, dans l'idéal, suggérer une perfection atteinte ou à atteindre. L'éloge, en effet, conserve en lui quelque chose de l'Institutio principis dont on observe justement à cette époque, et très précisément au début du $16^{\mathrm{e}}$ siècle avec Erasme, la naissance prestigieuse - c'est d'elle encore que dérivent le De

(8) Cf. Jacques Ridé: L'image du Germain dans la pensée et la littérature allemandes de la redécouverte de Tacite à la fin du XVIe siècle, Paris/Lille, 3t., 1976. 
Principatu de Machiavel et l'abondante littérature anti-machiavelienne qui suivit surtout chez les jésuites. L'exploitation en situation de la mythologie est ainsi inséparable d'un complexe d'idées convergentes, asymptotique de leur réalisation pleine et entière ou répondant à un jeu d'oppositions frontales. Comme on le sait, si la mythologie pourvoit le drame en figures bien identifiées, elle exige, pour nourrir les dialogues et visualiser les heurts et les conflits, la présence d'allégories. Il ne s'agit pas alors de ressusciter la psychomachie telle que Prudence l'avait conçue pour le Moyen Âge, mais de peupler l'espace théâtral de figures empruntées aux mondes des vices ou des vertus d'une part, d'entités abstraites du discours philosophique grec, et notamment hellénistique, d'autre part.

L'emploi de ces figures, facilement identifiables par le spectateur (elles apparaissent fréquemment avec un bandeau portant leur nom), est puissamment évocateur en raison même des traits figuratifs qui les définissent de longue date. Elles s'insèrent en outre dans une histoire de la pensée qui va privilégier la sophistique et le stoïcisme, tous deux relus à la lumière de la patristique, et ce depuis les écrits de Basile de Césarée et de Justin Martyr aux premier et deuxième siècles. (9)

Celtis innove donc en composant, à trois ans de distance, son Ludus Dianae et ses Laudes Maximiliani. Il produit là en effet les deux modes, modernes à l'époque, de la littérature encomiastique, le dramatique et le poétique, qui ont dès lors légitimement leur place à côté de la narration historique. Mais son autorité est aussi à la source d'une lignée qui connaîtra son acmé avec les formes majeures de l'art de cour baroque que sont, dans la seconde moitié du $17^{\mathrm{e}}$ siècle, les ludi caesarei jésuites, la festa teatrale d'inspiration italienne et l'opéra vénitien implanté dans la Vienne impériale et dont Il Pomo d'oro (1667) de Sbarra et Cesti constitue la réalisation inégalée. ${ }^{(10)}$

(9) Sur ces filiations, se reporter à Jean-Marie Valentin, supra, note 2.

(10) Jean-Marie Valentin: "Il Pomo d'oro" et le mythe impérial catholique à l'époque de Léopold $I^{e r}$, dans: J.-M. V.: L'Ecole, la ville, la cour. Pratiques sociales, enjeux poétologiques et répertoires du théâtre dans l'Empire au XVII siècle, Paris, Klincksieck, 2004, p. 507-528. 
Pour l'heure, l'entreprise humaniste demeure enclose dans un cadre nettement plus modeste. Toutefois, elle apporte, à travers l'exploitation dramatique du "mythe" d'Hercule à la croisée des chemins, un mode de théâtralisation efficace à travers le dialogue, la symbolique puissante de personnages antagonistes, une symbolique par ailleurs facilement transposable au plan de l'éloge. ${ }^{(11)}$ Hercule, tel que le présente Prodicos de Ceos dans la version qu'en donnent les Mémorables de Xénophon, la seule qui nous soit conservée, est, et va demeurer, une figure que son statut de demi-dieu pare d'une aura renforcée par son apothéose ultime. Mais même dans sa jeunesse, période de sa vie que privilégie Prodicos et que devaient moraliser les Pères de l'Église, Hercule est traité en exemple inégalé pour cette raison que son choix en faveur d'Arété (la Vertu) contre Kakia (la Volupté) fait de lui le triomphateur, le «domitor monstrorum» ou "domitor ferarum», le "pacator orbis», toutes qualités que lui applique Sénèque le tragique. Celui à qui le "princeps tragœdorum» accorde la récompense suprême sur terre (le trône, solium) et au ciel (l'admission à l'Olympe, et donc au Paradis chrétien) est en toute certitude une figure propre au discours hyperbolique. Concédons au passage que l'allusion à Sénèque se réfère davantage au $17^{\mathrm{e}}$ siècle, mais il est indiscutable que dès le $16^{\mathrm{e}}$ siècle, elle fournit une caution prestigieuse (celle de la tragédie de l'Hercules CEtaeus) à l'exploitation de ce sujet par la scène.

Quelles en sont (il est temps d'en parler) les manifestations textuelles les plus remarquables à l'époque des humanistes ?

A la Renaissance, l'Hercules Prodicius supplante, sans le faire passer entièrement à l'arrière-plan, le Pâris du célèbre jugement (qui fournit cependant encore la trame d'Il Pomo d'oro de Sbarra-Cesti). Mais les humanistes ne sont pas les premiers à développer ce sujet. Avant eux, ce sont des tableaux avec «inscriptions» dans les langues vernaculaires, où l'on recourt

(11) Voir Jean-Marie Valentin, supra, note 2. 
à la structure "pythagorique» de l'Y et évangélique des deux chemins selon la parabole rapportée par l'évangile de Matthieu.

On en rencontre par exemple dans les entrées solennelles de Bruges en 1468 pour le mariage de Marguerite d'York et du Téméraire, puis de Paris en 1486 pour la venue d'Anne de Bretagne, future épouse de Charles VIII. Ce n'est cependant qu'en 1490 à Vienne (en France, au sud de Lyon), que le choix d'Hercule adolescent fait l'objet d'un traitement dont l'allégorie de l'Entendement donne la clé morale et politique. Le bon prince choisit la voie escarpée, avec son lot de difficultés et d'amertumes. Il y gagne son salut, le secours de Dieu, maître des royaumes et des empires, et permet ainsi à ses sujets de faire à leur tour leur salut. En novembre 1497, l'Hercules in bivio est porté au théâtre par un humaniste du cru, Joseph Grünpeck. Son texte fut publié en cette même ville (Augustae Vindelicorum) en 1498 sous le titre (explicatif et poétologique) suivant: Comoedia utilissima, omnem latini sermonis elegantiam continens... qui ne renseigne pas vraiment, on le voit, sur le protagoniste. Mais il s'agit bien de l'Hercules adulescens qui opère le choix attendu. Grünpeck inaugure ainsi la pratique, très répandue en Allemagne jusqu'à l'époque moderne, du "drame de la décision" (Entscheidungsdrama). D'autre part, il imagine une inversion de la situation de départ, qui le conduit à montrer Hercule s'effaçant dans la scène ultime devant l'Empereur Maximilien et lui offrant le trône que lui avaient gagné ses travaux. C'est l'alliance de «solium» et de «virtus» qui continuera à alimenter les diverses formes de l'épidictique à l'époque du baroque impérial triomphant. En 1509, à Augsbourg encore, Pinicianus, l'ami de Jakob Locher, à qui l'on doit la traduction du Narrenschiff (devenu en latin la Stultifera Navis), met en scène une Virtus et voluptas qui reprend le schéma exposé dans la Divina Institutio de Lactance. C'est, cette fois, le jeune Charles, alors âgé de neuf ans, le futur Carlos Primero d'Espagne devenu plus tard empereur sous le nom de Charles Quint en 1519, qui tranche le débat - l'élément d'institution princière revient ainsi en force dans cette adaptation panégyrique du motif. 
Il apparaît à travers ces exemples que les humanistes n'empruntent plus seulement ici aux auteurs et aux traditions antiques. La sortie hors des espaces universitaire et scolaire, le rapprochement avec le pouvoir politique suprême et le système, contrôlé par celui-ci, des poetae laureati, favorisent une circulation des motifs entre milieux et donc entre espaces linguistiques. On peut y voir une rivalité, mais aussi, comme dans le cas de Brant-Locher, une complétude motivée par la nature du public et celle de l'espace social retenus. Le chapitre 107 de La Nef des fous, intitulée Von Lon der Wisheit (Le salaire de la sagesse), expose en vers allemands rimés, à quatre accents, l'épisode qui nous occupe. Et c'est ce texte qui a servi de base à la représentation donnée en allemand en 1512 à Strasbourg, non loin de la cathédrale, ce qui en souligne assez l'esprit religieux. Locher, qui assura par sa version latine la fortune européenne de la Nef dans les pays voisins (c'est elle qui fut traduite dans diverses langues, non l'original), adapte ce Lon der Wisheit dans le style humaniste. Il l'orne de gravures et il lui donne pour titre Concertatio virtutis cum voluptate. Il met ainsi en évidence aussi bien l'aspect structurel (le débat rhétorique de la concertatio) qui paraît l'emporter ici sur la référence à Hercule (mais le cadre est urbain, patricien, c'est celui d'une ville libre d'empire), que la dimension morale, très typique de Brant. Ce défenseur des belles-lettres gardait, en juriste et en administrateur (Syndikus) de la ville, un attachement profond, et actif, au bon ordre des choses: avec lui, Hercule et ses déesses, qui traduisent ses hésitations, confortent en définitive, et sans le moindre doute, la vision d'un Ordo Christianus collectif tout-puissant, qui s'impose à chacun, selon le principe organisationnel de la hiérarchie terrestre et cosmique.

Du point de vue dramatique cependant, c'est Chelidonius qui a fourni la version la plus étoffée de ce schéma. Sa Disceptatio, pièce-hommage, tout en autonomisant l'éloge du prince à l'aide d'une préface flatteuse, multiplie le nombre des personnages. Ainsi, les versions scolaires et aristocratiques du théâtre humaniste néo-latin montrent avec lui qu'elles révélaient des potentialités comparables quant à une évolution vers une structuration 
plus complexe du jeu scénique. Le nombre de personnages, la possibilité d'actions fondées sur la péripétie aristotélicienne (et non plus sur les seules linéarité ou exploitation par la variation d'une situation unique), l'insertion d'épisodes secondaires et de scènes de guerre indiquent une évolution contrastant avec le statisme qu'implique l'éloge. L'interférence des formes, des langues et des lieux de spectacles ainsi que le fait voir, entre autres, le texte de Brant, suggère en outre la lente édification d'une vie théâtrale à la recherche de cadres propres à en favoriser l'éclosion.

Dans l'Empire, la Réforme et la Contre-Réforme ne permirent pas pendant longtemps une véritable apparition du théâtre moderne, laquelle passait par l'affirmation des troupes professionnelles et la victoire de l'bistrio sur le rhetor. Chacune des Églises voulut maintenir la scène dans son orbite. En 1534, commence l'ère, durable, du théâtre luthérien. En 1549, est jouée la première "comœedia" catholique d'esprit déjà tridentin, l'Euripus de L. Brechtus. Le développement prodigieux de cette grande invention du $16^{\mathrm{e}}$ siècle que fut le collège, libéra les universités du fardeau qu'était la mise en place effective d'un système complexe de représentations régulières. Le lien avec l'humanisme fut réel et partout constatable. Mais il passa après 1530-1550 par une christianisation (les Hiéronymites) qui déborda à son tour sur la confessionnalisation. Le didactisme fut commun aux uns et aux autres, mais les deux systèmes rivaux furent, pour l'essentiel, imperméables l'un à l'autre jusqu'après 1650. En revanche, le mode encomiastique s'épanouit à Vienne et cette fois dans les seuls territoires catholiques gouvernés par les Habsbourg. Les grands spectacles néo-latins, le faste des ludi scenici orchestrés par les jésuites, constitueront une référence durant la période qui va de la fin de la guerre de Trente Ans à l'échec turc devant Vienne en 1683. Leur moindre poids coïncide à cette date avec le recul du néolatin dont l'emploi devait être réservé désormais aux idiomes universitaires techniques. L'allemand s'imposa alors dans la tragédie silésienne, et l'italien devint jusqu'à Mozart le langage de l'opéra. Le théâtre néo-latin, introduit par les humanistes, perdit alors définitivement sa place d'exception. 
(Página deixada propositadamente em branco) 


\section{A TRAGÉDIA DO PRÍNCIPE JOÃO (1554) DE DIOGO DE TEIVE, PRIMEIRO DRAMATURGO NEOLATINO PORTUGUÊS}

O teatro, sobretudo a tragédia, conheceu grande vitalidade e um novo fulgor no ambiente universitário de Coimbra com a chegada dos «Bordaleses». Assim eram designados os mestres que vieram do Colégio da Guiena, a Schola Aquitanica, em Bordéus, com o seu Principal, André de Gouveia, fundar o Colégio das Artes, em Coimbra, a 21 de Fevereiro de 1548. Entre estes mestres figuram autores eminentes de tragédias neolatinas, o escocês George Buchanan, o francês Guillaume de Guérente e o português Diogo de Teive,

O reconhecimento do papel pedagógico do teatro - manifestado por alvarás régios de D. João III que prescreviam a realização de representações na Universidade, à semelhança do que acontecia nos diversos colégios da Europa ${ }^{(1)}$ - , presidiu ao espírito da definição curricular dos Regulamentos elaborados por André de Gouveia, para o Colégio de Bordéus e para o Colégio das Artes. É sobretudo com a criação deste colégio em Coimbra que a produção dramática e a sua representação fazem parte integrante da ratio studiorum, como elementos fundamentais na formação retórica e moral dos alunos.

(1) Cf. Mário Brandão, Documentos de D. João III, Coimbra, Universitatis Conimbrigensis Studia ac Regesta, vol. II, 1939, pp. 47-48. 
A encenação teatral de peças de autores antigos ou da autoria de mestres ou de alunos, no acto de graduação em Artes, empresta cor e brilho à vida estudantil e ultrapassa os limites da comunidade académica, envolvendo, no entusiasmo pelo espectáculo, os familiares dos alunos-actores, e o povo da cidade. Estas representações que se impõem pela qualidade do texto dramático, pela música dos coros, pela espectacularidade cénica tornaram-se assim um fenómeno cultural e social.

A presença, no meio académico, dos dramaturgos «Bordaleses» e a experiência destes mestres como autores e encenadores de peças de teatro, que amiúde representavam, iriam favorecer o espírito de iniciativa literária de novas gerações e condicionar os seus gostos estéticos.

E nem só em Portugal, por toda a Europa, se exercita a arte dramática, com a mesma finalidade, nos colégios universitários, alfobres de ideas novas e centros de irradiação de cultura. O intercâmbio intelectual, favorecido pelo magistério de mestres comuns nos vários colégios europeus — onde a língua de comunicação e de ensino era o Latim - , desempenha um papel de relevo nas origens e evolução da arte dramática, no século XVI.

Compreende-se assim que, nesta época, o discurso dramático e mesmo o discurso literário, em geral, qualquer que seja o género cultivado, revele profunda influência da retórica escolar ${ }^{(2)}$.

A pedagogia retórica que visa a perfeição do discurso, a partir do estudo aturado dos autores clássicos, no original, assenta na prática da memória e na ars combinatoria. Estas, sendo postas ao serviço da multiplex imitatio, tão defendida pelos humanistas desde Petrarca, permitem que as exercitationes não sejam meras repetitiones e se tornem muitas vezes esboços, senão mesmo sólidos alicerces de obras literárias ${ }^{(3)}$. Os próprios themata escolares, de carácter predominantemente celebrativo, a que o género demonstrativo

(2) Vide J. Lecointe, L'idéal et la différence. La perception de la personnalité littéraire à la Renaissance, Genève, 1993, p. 88-99.

(3) Ibidem. 
dá o tom, influíram nas diversas formas literárias e de sobremaneira na dramaturgia quinhentista, maneirista e barroca.

Serve de exemplo o teatro bíblico, em que a constante referencial do mythos é a luta do bem e do mal, antinomia de singular importância nos themata das exercitationes escolares, a que naturalmente se agrega o assunto religioso que a Reforma e as guerras de religião actualizavam.

A tragédia - que combina a sublimidade do estilo com o lirismo das odes corais - vai ser um género privilegiado no Renascimento.

Dirigida a despertar emoções num público receptor, a tragédia define-se como experiência emocional e intelectual, com uma função emotiva, um valor didáctico(4).

Instrumento sedutor da mimese dramática é a linguagem, a palavra, a que a Poética e a Retórica, com seus recursos estilísticos, conferem força e vigor expressivos. Através do debate e do confronto de ideias das diferentes personagens, a tragédia combina o discurso ético e o agonístico, e os três géneros retóricos, demonstrativo, deliberativo e judicial, com predominância do primeiro.

Apesar da dependência dos modelos clássicos que a retórica escolar privilegia, no Renascimento, é visível a preocupação de cada autor em imprimir à sua obra a marca da actualidade, e em criar um estilo novo. Este não poderia colidir com a tradição antiga, nem com a preceptística, que empenhava tantos humanistas, designadamente em Itália. Essa Itália, herdeira de um passado que a todos atraía, iria revelar ao mundo das letras, não só teorias mas também novas experiências teatrais. Umas e outras dariam fruto entre nós com a desaparecida Cleópatra de Sá de Miranda. O próprio António Ferreira para elas voltaria os olhos e a sensibilidade.

Giovan Giorgio Trissino e Giovan Battista Giraldi Cinzio, pioneiros do teatro regular europeu e coriféus da tragédia grega e senequiana, respec-

(4) Vide S. Halliwell, Aristotle's poetics: a study of philosophical criticism, London, 1986, p. 62-81; N. T. Croally, Euripidian polemic. The Trojan women and the function of tragedy, Cambridge, 1994, p. 23-33. 
tivamente, foram determinantes, com a sua produção dramática e a sua teorização, na fixação de modelos trágicos, no Renascimento(5).

A tendência marcadamente moralizadora, em tempos de Concílio de Trento e de Contra-Reforma, impõe o modelo trágico de Séneca, que é visível mesmo em obras que seguem preferencialmente o modelo grego, de que é exemplo a edição definitiva da Castro.

A própria teorização dramática não se alheia da sensibilidade do tempo. Robortello, no seu comentário à Poética, de 1548, que marca o início do aristotelismo científico, embora não se conte entre os comentadores preocupados em dar um significado moral à poesia, refere-se à tragoedia ethice, à tragédia de caracteres, em termos que não escondem as concepções da época, no que toca ao carácter moral e educativo da poesia(6).

Assim desde a Sofonisba de Trissino, composta em 1514 e impressa em 1524, que inaugurou o teatro trágico do Renascimento - e é modelada segundo as tragédias gregas, difundidas pelas edições aldinas, mais do que sobre as quase desconhecidas teorias aristotélicas — até às tragédias de acentuada influência senequiana, de que é exemplo acabado o teatro escolar, jesuítico e reformista, toda a poesia trágica denuncia, pelo tom retórico e a reflexão ética, a evolução sofrida pelo gosto clássico nos meios cultos de então. Pode mesmo afirmar-se que em Portugal e em todo o teatro europeu, a pureza do estilo clássico foi revestida de cores senequianas.

A tragédia de Séneca defendida, em nome de um aggiornamento dramático, pelo teorizador e poeta trágico Giraldi Cinzio, marcaria de forma indelével a orientação seguida pelo teatro europeu, designadamente pelo teatro da época isabelina, de que Shakespeare é o maior expoente(7).

(5) Sobre a teorização e a obra trágica destes autores, vide Nair de Nazaré Castro Soares, Teatro clássico no século XVI. A Castro de António Ferreira. Fontes - Originalidade. Coimbra, 1996, p. 126 e sqq.

(6) Vide Francisci Robortelli Vtinensis in librum Aristotelis de arte poetica explicationes. Florentiae, in officina Laurentii Torrentini Ducalis Typographi, 1548, p. 210-211.

(7) Em Discorso ovvero lettera di Giovambattista Giraldi Cintio, intorno al comporre delle commedie e delle tragedie a Giulio Ponzio Ponzoni, in Scritti estetici, Milano, 1864, parte seconda, p. 12, Cinzio reconhece como prioritária a função educativa da tragédia e preocupa-se 
É, no entanto, numa espécie de oscilação entre a temática histórica, a mitológica e a religiosa e entre o modelo de teatro de Séneca e de teatro grego - de que as duas edições da Castro são exemplo acabado - , que muitas obras ganham individualidade própria e firmam a sua originalidade.

Conhecida é a atitude do pensamento português no século XVI, a nível filosófico e doutrinário, que privilegia o sentido valorativo da existência e se compraz no observar do acto humano, sua análise e comprensão(8). Percebe-se assim o grande acolhimento que teve entre nós a tragédia do Cordovês.

O tom retórico e sentencioso do seu discurso, de pendor moralizante, de acordo com a filosofia estóica, adequava-se na perfeição aos gostos desta época. E não só o teatro de inspiração religiosa e bíblica, com raízes medievais, mas ainda o teatro profano, de assunto mitológico ou nacional tinham sido absorvidos por esta tendência da dramaturgia latina, que animava as tragédias renascentistas.

Maioritário na produção quinhentista, quer protestante, quer jesuítica e contra-reformista, é o teatro de tema bíblico. Sem deixar de ser sobretudo um "poema sacro», na esteira da herança medieval, e de acordo com os padrões de sensibilidade da época, a tragédia transpõe para as figuras da Sagrada Escritura todo um realismo simbólico que as identifica, no seu comportamento, no seu agir consciente ou involuntário, com personagens do mundo real contemporâneo, com suas paixões, conflitos e problemas muito actuais.

Não quer isto dizer que a história e a mitologia não continuassem a servir de inspiração aos poetas dramáticos quinhentistas, em latim e em língua

com a sua novidade de conteúdo e de forma. Neste sentido firma o conceito de catarse e, ao interpretar o phobos do texto aristotélico como "horror" e não como "terror», teoriza sobre a vantagem de apresentar cenas sangrentas coram populo: "Col miserabile e col terribile purga gli animi da vizi e gl'induce a buoni costumi».

(8) Vide Joaquim de Carvalho, Estudos sobre a cultura portuguesa do século XVI, vol. I, Coimbra, 1947, p. 2-3; J. Borges de Macedo, "Livros impressos em Portugal no século XVI. Interesses e formas de mentalidade", Arquivos do Centro Cultural Português, IX - Homenagem a Marcel Bataillon. Paris, F. C. Gulbenkian, 1975, p. 214 e sqq. 
$\operatorname{vulgar}^{(9)}$. Os modelos da Antiguidade e os seus mitos cativaram dramaturgos da dimensão de George Buchanan que à tradição do teatro de carácter alegórico, ainda dominante, quis ver substituído o gosto da inspiração nos modelos clássicos. Foi com esse objectivo, e para fazer brotar nos escolares o amor da Antiguidade - como abertamente o declara na Buchanani uita scripta ab ipso (10) — que ele compôs as suas tragédias. Representadas no Colégio de Bordéus, como testemunha o então aluno Michel de Montaigne (Essais, I. 26), foram-no muito provavelmente em Paris, Coimbra e Cambridge, onde Buchanan ensinou.

A produção dramática do humanista escocês, marco importante nas origens do teatro moderno europeu - é considerado o mestre dramático da Plêiade - inclui duas tragédias de assunto bíblico, Baptistes, menos rica e movimentada do que Jephtes, modelada sobre a Ifigénia em Áulide, que vai servir de fonte de inspiração ao teatro posterior, de que é exemplo a Castro de Ferreira(11). São ainda da sua autoria as traduções livres de Eurípides, Medea e Alcestis, em que a temática amorosa, tão ao gosto renascentista, entra como elemento do conflito. Buchanan será uma referência notável para toda a produção dramática do século XVI.

Significativo, entre nós, é, no entanto, Diogo de Teive, o português que percorrera os diversos centros intelectuais da Europa, onde adquirira uma dimensão de saber e mentalidade verdadeiramente humanistas, autor, como Buchanan, seu colega e amigo, de duas tragédias bíblicas David e Judith e da Ioannes Princeps tragoedia, de assunto nacional contemporâneo. Mestre de Prima do Colégio das Artes, a classe mais avançada de Retórica, que incluía a composição poética, nele permaneceu e ensinou até 10 de Setembro de

(9) São prova disso, entre nós, a desaparecida tragédia Cleópatra de Sá de Miranda, a Ioannes Princeps Tragoedia - a Tragédia do Príncipe João - de Diogo de Teive e a Castro de António Ferreira.

(10) Georgii Buchanani Vita ab ipso scripta biennio ante mortem in Opera Omnia, Lugduni Batauorum, apud Iohannem Arnoldum Langerak, (1725) §§ 30-37.

(11) A. Irvine Watson, "George Buchanan and Antonio Ferreira's Castro", in Bulletin of Hispanic Studies, 31 (1954) 65-77. 
1555, data em que, por sua mão, este Colégio foi entregue solenemente à jurisdição dos jesuítas.

A tragédia David, sobre o episódio de Golias que David abateu com a sua funda, foi levada à cena em Santa Cruz, no claustro da Portaria, em 16 de Março de 1550, por ocasião do bacharelato em Artes de D. António, o famigerado Prior do Crato, filho do Infante D. Luís — irmão de D. João III.

Mais de um século havia decorrido e ainda se conservavam na memória os coros das moças de Israel, acompanhados de música suave, que saudavam o regresso do herói vitorioso: percussit Saul mille, et David decem millia "Saul matou mil, e David dez mil»(12).

Perderam-se ambas as tragédias bíblicas de Teive cujos temas inspiraram famosos pintores renascentistas. Exercício de adestramento da língua latina, da eloquência e das boas maneiras, decerto Teive as escreveu para serem interpretadas pelos seus discípulos. À semelhança do que acontecia nos grandes centros intelectuais da Reforma, que contava com pedagogos como Johan Sturm e Philip Melanchton, a temática bíblica era privilegiada, no teatro europeu e português.

A apresentação em cena de figuras do Antigo Testamento, ou da hagiografia cristã, ou de parábolas do Evangelho permitia ao poeta trágico, pedagogo humanista, fazer o paralelismo entre o passado bíblico e o presente e debater os problemas mais prementes da sociedade contemporânea, de índole política, social e religiosa, numa assimilação perfeita dos temas da Sagrada Escritura aos temas do Humanismo.

Se há uma clara continuidade entre os temas destas obras e os do teatro medieval de inspiração religiosa tem que ser realçada uma diferença significativa, nesta produção humanista — que cativou os «Bordaleses» e os pedagogos reformistas europeus e veio a dar o tom e a especificidade ao

(12) Nair de Nazaré Castro Soares, Tragédia do Príncipe João de Diogo de Teive. Introdução, texto latino, tradução e notas, Lisboa, F.C.T.-F.C.G., ${ }^{2}$ 1999, p. 20. 
teatro jesuítico —, o seu valor estilístico e estético, onde a música e a riqueza cénica se impõem, a conferir dimensão espectacular à encenação(13).

A Ioannes Princeps tragoedia de Diogo de Teive, redigida em 1554, só em 1558 veio a lume, na edição dos Opuscula aliquot ${ }^{(14)}$.

Aspecto marcante desta tragédia é a intenção de se reportar a um assunto, nacional e histórico, com implícitas reflexões políticas em que se espelha, para além dos factos, o pensamento humanista.

Muito embora a tragédia de carácter tópico se encontre já na literatura grega e latina - a Octauia pertencia no século XVI ao cânone senequiano - no entanto, a mitologia foi, na Antiguidade, e continuou a ser no Renascimento, a par do Antigo Testamento, a grande fonte de inspiração trágica. Albertino Mussato, precursor do humanismo italiano, já tinha, no entanto, composto a tragédia Ecerinis, de assunto nacional. Diogo de Teive, na Ioannes Princeps, segue-lhe o exemplo.

O acontecimento fulcral da tragédia neolatina de Diogo de Teive é a morte do Príncipe João, ocorrida dezoito dias antes do nascimento de seu filho, o futuro D. Sebastião, O Desejado.

Verdadeiro treno à morte do último dos filhos de D. João III e de D. Catarina, único herdeiro do reino e única esperança da salvação da pátria, a Tragédia do Príncipe João será uma referência e uma fonte de inspiração para a dramaturgia quinhentista em Portugal(15).

(13) Vide P. ${ }^{\mathrm{e}}$ Luís da Cruz, Tragicae comicaeque actiones a Regio Artium Collegio Societatis Jesu datae Conimbricae in publicum theatrum. Auctore Ludovico Crucio ejusdem Societatis Olisiponensi. Nunc primum in lucem editae et sedulo diligenterque recognitae, Lugduni, Apud Horatium Cardonium, 1605. No Praefatio benevolo amicoque lectori (p. 8), afirma: Chori sunt in omnibus istis, actionibus. Sine harmonia theatrum non delectat. Et praeter tibias, quae nunquam defuerunt, semper apud nos cantus expectatus est - "Os coros existem em todas as peças. É que sem música o teatro não agrada. E além de flautas, que nunca faltam, entre nós espera-se sempre o canto".

(14) Vide Iacobi Tevii Bracarensis Opuscula aliquot in laudem Ioannis Tertii Lusitaniae regis, et principis eius filii, \& fratris Lodovici, atque item Sebastiani primi regis eiusdem nepotis [...]. Salmanticae, Excudebant haeredes Ioannis à Iunta Florent. 1558.

(15) Refiram-se, designadamente, a Castro de Ferreira e o teatro bíblico jesuítico. Sobre a Ioannes Princeps tragoedia de Diogo de Teive como fonte da Castro de António Ferreira, vide Nair de Nazaré Castro Soares, Tragédia do Príncipe João cit., p. 97-132. 
Escrita por um professor do Colégio das Artes, A Ioannes princeps não é uma tragédia de escola. Este facto não a arranca, contudo, do contexto poético-dramático em que se insere e não invalida o seu significado social, na contextura emocional e política da nação portuguesa.

Personagens são os monarcas portugueses, a esposa do Príncipe, D. Joana de Áustria e sua Aia, o Médico que assistiu o príncipe moribundo, na doença, e dois cortesãos, com seus nomes simbólicos, Fílanax, «O amigo do rei» - que se revela como preceptor do Príncipe e pode com segurança ser identificado com Francisco Sá de Meneses(16) _ , e Eubularco, "O chefe do bom conselho», a quem o Rei dá ordens e instruções para que em tudo providencie. Na figura de Eubularco se adivinha o Secretário de D. João III, Pero de Alcáçova Carneiro, Conde de Idanha ${ }^{(17)}$.

O Príncipe João, personagem invisível no decorrer da acção cénica, é quase um símbolo do destino - símbolo da tragédia do reino. Distante, e até algo transcendente, é ele que determina a tragédia, e, embora constitua o eixo da intriga, como que apaga no próprio ocultamento, o aspecto individual que a revelaria como personagem trágica.

Esta ausência do Príncipe, requerida pelo decorum, em virtude da gravidade do seu estado de saúde e da sua morte iminente, justifica que a acção trágica se oriente mais no sentido da reflexão do que da representação viva do drama.

(16) Encarna a personagem Fílanax (philos "amigo»; anax "rei») o preceptor do Príncipe (v. 904-914), identificável, por isso, com Francisco Sá de Meneses, que foi poeta elegíaco-amoroso, o cantor do rio Leça, filho do famoso humanista João Rodrigues de Sá de Meneses. Elogiam-no ou dedicam-lhe composições poéticas Sá de Miranda (Soneto XXV), António Ferreira (Carta XII do livro II), Diogo Bernardes (Carta XVI do Lima), que o faz também encarnar a figura do pastor Franco na Écloga Adónis, dedicada à morte do Príncipe João. Entre outras composições poéticas, que aludem a esta figura, são dignas de nota as que lhe dedicam, por ocasião da morte do príncipe, Pêro de Andrade Caminha (Elegia II) e António Ferreira (Ode III e Elegia I).

(17) Eubularco (eu- "bom», boulê "conselho", archos "chefe»), conselheiro do Rei, uma espécie de primeiro-ministro, o seu secretário, é Pêro de Alcáçova Carneiro, a quem António Ferreira dedica a Carta II. Temos motivos para acreditar que esta personagem com funções de Secretário e de Conselheiro inspire a personagem da Castro, que se define nestes termos (acto I, cena III, v. 282-283): D’ua parte me tens por secretário / mas d'outra me hás-de ter por conselheiro. 
O Coro não tem uma função explícita de personagem. No entanto, quando, no meio do acto V, se desdobra em primeiro, segundo, terceiro e quarto coros, que falam uns após outros em trímetros iâmbicos, notamos que houve uma tentativa de personificar um Coro que, até então, só se fizera ouvir no fim de cada acto. Assim, embora o Coro não seja mais do que um elemento convencional que, pelo seu lirismo, dá beleza à peça, no acto $\mathrm{V}$, assume uma dimensão algo diversa, e como que se personifica para representar a nação que sofre e se lastima com a morte do Príncipe e com a perdição do reino.

Numa palavra, no aspecto dramático, a intriga em pouco se resume, já que a morte do Príncipe se dá como certa, logo a partir do acto II (vv. 373-374).

Toda a peça, portanto, se apresenta como uma espécie de reflexão, em forma de diálogo, onde o lirismo e a atitude de uma expressão moral, nas diversas personagens, em face do acontecimento, se substituem ao movimento dramático propriamente dito.

A tragédia Ioannes Princeps de Diogo de Teive, como toda a produção novilatina da época, é profundamente influenciada, na forma, na ideologia, na linguagem e na concepção trágica pelo teatro de Séneca. Nela dominam a análise psicológica, os monólogos, as confidências, a afirmação constante dos sentimentos dos protagonistas, que se revelam em plena maturidade desde o início, o que vai retardando a acção e lhe confere uma certa passividade de movimento dramático. Era o gosto, corrente na época, por um estilo empolado, cheio de retórica e sentenças morais, bem característico da obra do Cordovês, então muito divulgada e conhecida.

Não quer isto dizer, todavia, que a Ioannes princeps, por ter Séneca como modelo, não se apresente como uma obra com o seu valor próprio, a sua originalidade.

A cultura literária e o próprio magistério docente de Teive, que o mantinham em contacto permanente com as letras clássicas, permitiam-lhe utilizar 
os autores da Antiguidade de tal modo que os traços imitados se afiguram, por vezes, como puras reminiscências. É assim que se encontram disseminados por toda a obra passos de Virgílio, Horácio, Ovídio, Lucrécio. Além disso, muitos dos aspectos pertencentes à tradição clássica e nomeadamente senequiana, enquadram-se de tal modo na própria ideologia do humanismo renascentista, que é difícil avaliar até que ponto Teive teve intenção de imitar ou simplesmente procurou exprimir a mentalidade do tempo.

Ao teatro de Séneca foram os dramaturgos renascentistas buscar situações, personagens, lugares-comuns e mesmo figuras de estilo. Como ele, quiseram dar às suas peças um sentido moral, bem expresso nos ensinamentos, que iam ministrando no decorrer da acção e no seu desfecho.

Não podia Teive fugir à regra. Aliás, num passo da carta de Pedro Sanches a Inácio de Morais, Teive é caracterizado, nestes termos ${ }^{(18)}$ :

\begin{abstract}
Tevius attolit speciosae frontis honorem
Qui Senecam verbis, et multo pondere rerum

Pene pari sequitur gressu, paribus cothurnis.

"Teive ergue o prestígio da sua ornada fronte, ele que imita Séneca nas palavras e na muita

[gravidade dos temas, no ritmo quase igual, no igual estilo trágico.»
\end{abstract}

Ao analisarmos a tragédia loannes Princeps notamos que, na concepção trágica, na ideologia, na forma, na linguagem, no ritmo, na harmonia, no canto é bem vincada a presença de Séneca.

Examinemos a sua estrutura: o prólogo introduz-nos no ambiente em que a intriga se inicia, insinua já o argumento da peça e caracteriza os sentimentos dominantes das personagens centrais que nele figuram, o Rei D. João III e a Rainha Catarina, pais do Príncipe D. João, moribundo.

(18) Cf. P. e António dos Reis, Corpus illustrium poetarum Lusitanorum, vol. I., Lisboa, 1745 , p. 17. 
O segundo episódio é também, nesta tragédia, aquele que prepara o drama propriamente dito - o médico afirma que toda a esperança lhe parece perdida e que o Príncipe vai morrer.

O terceiro acto, como em geral acontece nas tragédias de Séneca, apresenta uma nova peripécia da acção - a tristeza e os receios manifestados pela Princesa, que há tantos dias é impedida de ver o seu querido esposo.

É então, no acto seguinte, que a catástrofe se consuma e se realizam todos os pressentimentos e temores que atormentavam as personagens.

Finalmente, o acto V revela-se-nos como uma conclusão dos anteriores. Nele se comenta a resignação que os Reis manifestaram e todos choram a morte do Princípe.

A ordem por que as personagens aparecem em cena obedece a um certo paralelismo quiástico, à maneira senequiana. Assim, no acto I, dialogam o Rei e a Rainha. Seguem-se-lhe, no acto II, Fílanax e Eubularco, cuja conversa é por momentos interrompida com uma intervenção do Médico. No acto IV, voltam de novo Fílanax e Eubularco, cujo diálogo ainda se prolonga no acto V. Neste último acto, assistimos finalmente ao aparecimento das duas figuras centrais - o Rei e a Rainha — que tinham ocupado a cena durante todo o acto I. No meio da peça, o acto III, a conversa da Princesa Joana com a Ama constitui uma espécie de episódio intercalar que, pela sensibilidade e frescura, pela expressão amorosa, marca a separação entre as duas partes do quiasmo.

É muito natural que Teive, ao estruturar a sua tragédia, ao modo senequiano, a ring composition, tenha intencionalmente utilizado um recurso oratório que teria a vantagem de sistematizar de forma mais clara o processo reflexivo sobre a morte do Príncipe e a própria situação política. Nesse sentido ainda poderá entender-se que, em vez de misturar ao longo da peça as diversas personagens, o autor tenha preferido apresentar dois a dois os seus interlocutores, o que nos faz quase adivinhar um esquema ideológico que é possível manter para cada personagem, com um mínimo de variação dramática. 
Importante, para a análise formal da peça, é o papel desempenhado pelo Coro. À semelhança do que geralmente se observa em Séneca, o Coro não intervém activamente nos acontecimentos, mas interessa-se por eles: têm os seus cantos ligação com o assunto que acabou de ser exposto, nos episódios que os precedem. Poderemos assim defini-lo como um porta-voz da opinião pública, que desempenha o papel da multidão, no drama moderno(19).

No entanto, tal como nas tragédias de Séneca, não podem considerar-se apenas cantica líricos as tiradas que o Coro entoa, na Ioannes Princeps, no fim de cada episódio - que se podem separar da obra e cantar separadamente como certas árias de ópera — , mas ainda as monódias tipicamente líricas, de ritmos variados, postas na boca de personagens individuais, que declamavam ao som da flauta(20).

Vários passos de tragédias senequianas são apontados como manifestações líricas na acção do drama, a tal ponto que declamação e canto se interpenetram, passando-se insensivelmente de um ao outro ${ }^{(21)}$.

Neste segundo tipo de cantica, incluem-se também as intervenções do Coro em trímetros iâmbicos ${ }^{(22)}$ que, pelo ritmo e pelo facto de serem executadas por um só membro do coro, se assemelham às referidas falas, com conotação lírica, de personagens individuais.

É interessante notar que esta união perfeita entre diuerbia e cantica existe também, muito provavelmente, na tragédia Ioannes Princeps.

(19) Definiu o Coro das tragédias de Séneca, nestes termos, L. Herrmann, Le théâtre de Sénèque, Paris, 1924, p. 381.

(20) Ritmos das monódias líricas são, geralmente, trímetros iâmbicos, tetrâmetros trocaicos, hexâmetros dactílicos, anapestos.

(21) De referir as falas de Medeia (Medea, v. 670, etc; vv. 740-848), de Cassandra (Agamemnon, v. 659 etc.; v. 695 etc.; v. 759 etc.; v. 867 etc.), de Teseu (Phaedra, v. 1201 etc.), de Creonte (Oedipus, v. 233, etc.), de Tiestes (Thyestes, v. 920, etc.), de Íole (Hercules Oetaeus, v. 173, etc.; v. 1476, etc.), de Alcmena (Hercules Oetaeus, vv. 1863-1938; vv. 1944-1962; vv. 1977-1982) e de Andrómaca (Troades, v. 705, etc.). Vide o estudo de L. Herrmann, Le théâtre de Sénèque cit., p. 222-225.

(22) Vide e.g. Agamemnon, vv. 710-719 e vv. 775-781. 
Introduzindo o segundo acto, aparece Eubularco, personagem nova que, em longo monólogo, reflecte sentenciosamente sobre a lealdade verdadeira e o amor sincero, que se não movem por interesse algum e permanecem para além da morte. Por estes sentimentos se sente ligado ao seu bom rei, que confia nele inteiramente e agora se consome com a doença grave que prostra o seu único filho.

Perfeitamente integrada na acção, esta cena tem, no entanto, um carácter lírico. É um canto à lealdade dos portugueses ao seu rei e à sua pátria, um dos valores da alma lusíada(23). Comparando esta cena com outras de Séneca, que lhe são equivalentes, julgamos bem provável que fosse musicada e formasse um canticum, que continuaria, num ritmo diferente, a intervenção do Coro que a precedeu. Sendo assim, o monólogo ganharia em vida e em movimento, e a melodia do primeiro Coro, que ainda estava no ouvido, não seria quebrada tão subitamente.

Digna de menção é ainda a segunda cena do acto V. Este inicia-se pelo diálogo entre Fílanax e Eubularco que, tendo já preenchido todo o acto IV, se prolonga, nesta primeira cena do V (até ao v. 1196) que, tematicamente, continua ainda o acto anterior.

A nova aparição destas personagens, que vêm continuar, depois da intervenção do Coro, a conversa deixada em suspenso, tornar-se-ia talvez fastidiosa aos olhos do público. Mas é bem verosímil que a cena seguinte, introduzida além disso por um treno da Rainha, cativasse a atenção pelo ritmo que a música lhe imprimiria.

A Rainha exprime a sua dor e o Coro - que agora se individualiza em quatro elementos, intervindo cada um por sua vez - corrobora as suas lamentações. Esta cena seria, por certo, também declamada ao som da flauta, como depreendemos pelo tom das palavras da Rainha, pelo ritmo em trímetros iâmbicos, que possuem as tiradas dos Coros e ainda pelo confronto

(23) A este propósito, vide Nair de Nazaré Castro Soares, "Gratidão e lealdade: dois valores humanistas", II parte da Miscelânea em honra dos Doutores Walter de Medeiros e Manuel Pulquério - Humanitas 46 (1994) 245-258. 
com cenas idênticas das tragédias de Séneca, onde também figuram apenas personagens e coro, em circunstâncias análogas(24).

Ora numa peça onde, à semelhança das de Séneca, domina a análise psicológica, aparecem, por vezes, os monólogos, as confidências, a afirmação constante dos sentimentos dos protagonistas, que se revelam em plena maturidade desde o início, o que vai retardando a acção, conferindo-lhe certa passividade. Então, grande seria o efeito que a música causaria numa representação teatral deste género.

Muito embora a tragédia Ioannes Princeps, por falta de oportunidade, não chegasse a ser representada(25), podemos pôr como hipótese que Teive se preocupou, ao escrevê-la, com o êxito do espectáculo, possibilitando uma teatralização cheia de efeitos musicais. É o que depreendemos da sua semelhança estrutural com as tragédias de Séneca, em que era fundamental o papel da música. Tal acontecerá com o teatro jesuítico que Teive $\operatorname{prepara}^{(26)}$.

Além destas múltiplas afinidades entre a Ioannes Princeps e as tragédias do Cordovês, note-se ainda a sua linguagem, onde as interjeições abundam e se conservam certos arcaísmos, o próprio vocabulário, a gravidade e o patético do seu estilo trágico, o emprego - por vezes exagerado - de certos processos estilísticos, o seu tom sentencioso e retórico ${ }^{(27)}$.

(24) As suas intervenções seriam declamadas e acompanhadas ao som da flauta. Cf. designadamente, as cenas do Agamemnon (vv. 695-781), do Hercules Oetaeus (vv. 173-230), e da Phaedra (vv. 1201-1280).

(25) Na oração panegírica de D. João III, talvez proferida em I de Setembro de 1554, decorridos já uns meses após a morte do Príncipe, Teive afirmou: Haec omnia uobis ante oculos proposui ea tragoedia, quae aliquando exbibebitur, in qua pro nostra uirili parte immaturum et acerbum principis obitum tractauimus. (Opuscula aliquot, Salamanca, 1558, fl. $14 \mathrm{v}^{\circ}$ ) - "Todos estes factos os coloquei diante dos vossos olhos naquela tragédia que será representada um dia. Nela se narrou, da melhor maneira que nos foi possível, a morte prematura e cruel do príncipe». No entanto, a sua aspiração não chegaria a realizar-se - pelo menos não há notícia disso - pois, passada a comoção que tão trágico acontecimento ocasionara, não teria surgido oportunidade de a levar à cena. (Vide Mário Brandão, A Inquisição e os professores do Colégio das Artes, II vol. Coimbra, 1948 e 1969: vol. II, p. 900.)

(26) Cf. supra n. 13.

(27) Vide Nair de Nazaré Castro Soares, A tragédia do príncipe João, cit.: o capítulo dedicado ao estudo do estilo, pp. 133-137. 
Poderá dizer-se da tragédia de Teive o que Pierre Grimal afirmou da obra dramática de Séneca: desculpa-se a retórica em nome duma musicalidade, que Ihe atenua a ênfase e a afectação, e imprime aos passos líricos o tom poético que as caracteriza(28).

Definida por Aristóteles como mimese da acção humana, da conduta de grandes figuras míticas ou históricas, capaz de provocar o terror e a piedade e estimular a catarse ${ }^{(29)}$, a tragédia é um género privilegiado à expressão da vida humana e seus valores essenciais. Instrumento capaz de suscitar o prazer e enriquecer o pathos, é a linguagem, na perfeição estilística e eficácia oratória do estilo sublime - com seus recursos estéticos, ritmo, harmonia e canto ${ }^{(30)}$.

Se o discurso poético trágico foi elaborado pelos autores da tragédia ática do século V a. C., encontra a sua expressão, na língua latina, na poesia trágica de Séneca. Foi através do logos dramático senequiano, da forma como o poeta da Roma de Nero modelou, na língua latina, a res e os uerba, o pensamento e a expressão nas suas tragédias, que os dramaturgos quinhentistas plasmaram o seu discurso, a sua ars scribendi tragica.

Nesta perspectiva, se o teatro de Séneca se impõe como modelo, sempre presente, e manancial de reminiscências e alusões literárias clássicas, que o seu discurso veicula, é sobretudo porque se lhe deve a fixação da língua trágica latina.

Teive, como os dramaturgos do seu tempo, ao dar voz à experiência trágica, acolhe e assimila as formas, os temas, a linguagem, as imagens e os motivos das tragédias senequianas, que, depurados até à essencialidade, foram fonte perene de inspiração.

Pelo poder da linguagem, o actor, no desempenho do seu papel, é introduzido na dinâmica do jogo cénico. É através da linguagem teatral ou

(28) Vide Jean Jacquot, "Sénèque, la Renaissance et nous", in: Les tragédies de Sénèque et le théatre de la Renaissance, Paris, 1964, p. 271-307, designadamente, p. 272.

(29) Aristóteles, Poética, 1449b 24-28.

(30) Aristóteles, Poética, 1449b 28-30. 
através dos actos, em palavras, que a dramatis persona constrói a sua própria identidade, a sua autenticidade, que depende da autenticidade do seu discurso. Nele intervêm os recursos estilísticos, os efeitos retóricos e acima de tudo o carácter moral da personagem que fala, que é capaz, através da linguagem, de despertar no público a confiança.

Adequado à realização do pathos, de acordo com a alta estatura social das personagens, é o estilo sublime, que representa ao mesmo tempo a perfeição estética e a eficácia oratória(31). Na obra trágica, a teoria da afectividade converge assim com a doutrina do sublime(32). A expressão lapidar, informada de imagens e motivos poéticos, é posta ao serviço da exaltação da grandeza de alma e da virtude, numa apropriação do ethos ao pathos, essencial a uma tragédia que se pretende morata recte, no dizer de Horácio(33).

A valorização da frase ou do dito sentencioso, o recurso a lugares comuns, à máxima, à sententia imprimem força expressiva ao discurso, com vista à plena realização do pathos (34). A multiplicação das sentenças, para caracterizar comportamentos, definir sentimentos fundamentais da alma humana, ou mesmo desenvolver reflexões de natureza abstracta, tais como considerações de carácter político herdou-a Teive de Séneca, que por sua vez a colheu no teatro de Eurípides ${ }^{(35)}$. Séneca revelou nas suas tragédias o gosto pelos mesmos temas e motivos, pela mesma expressão poética, que iria tornar-se numa das características do seu estilo dramático e da sua fortuna, que Shakespeare emblematicamente configura.

(31) Aristóteles, 1449b 21 sqq..; 1453a7-11; Horácio, Arte poética, vv. 95ss e vv. 220-250.

(32) Vide J. Lecointe, L'idéal et la différence. cit., p. 388 sqq. ("Rhétorique et linguistique. L'ethos et le pathos comme instances de l'énonciation").

(33) Horácio, Arte Poética, v. 319. Em traços gerais, o ethos é a manifestação da qualidade moral do sujeito no discurso e o pathos o apelo às paixões do público com vista à persuasão (cf. e. g. Cícero Orator 37, 128 e sqq.). Vide, supra n. ${ }^{\circ}$ 6, a interpretação de Robortello no comentário à Poética de Aristóteles, de 1548.

(34) Vide J. Lecointe, L'idéal et la différence cit., p. 696-697 sqq.

(35) Vide Jacqueline de Romilly, "Patience, mon coeur!». L'essor de la psychologie dans la littérature grecque classique, Paris, 1984, p. 144-147) 
Aliás, independentemente dos modelos seguidos, das influências conscientes ou inconscientes, da criatividade individual, há como que um discurso trágico, próprio de cada época. Este permite que a tragédia se realize como experiência emocional e intelectual, a theatrokratía(36).

Assim se compreende que a tragédia renascentista se defina pelas marcas impressivas de um código poético comum, que informa a poiesis deste período histórico, salvaguardando-se embora os traços genológicos essenciais.

Através do valor poético das imagens, metáforas, comparações, similes, uma das exigências do estilo clássico, característica da literatura do século XVI - em que, por vezes, se conjugam a imagética de origem homérica e a petrarquista - revela-se o sentido da vida física, o gosto e a admiração pela actividade concreta, o sentimento naturalista-panteísta típicos do Renascimento ${ }^{(37)}$.

Tendência particularmente cara ao estoicismo é a divinização da natureza e dos fenómenos naturais, o que justifica o recurso insistente a estes elementos - presentes já na tragédia grega.

No século XVI, num tempo em que o estoicismo se revigora como uma ética do comportamento e em que a experiência abre novos horizontes na observação e conhecimento do homem, do mundo e da natureza, multiplicam-se as analogias cósmicas, as referências aos elementos, as imagens náuticas dos ventos e das tempestades, que comunicam uma espécie de grandeza épica à sinceridade patética(38).

Por outro lado, tornam-se recorrentes as imagens de delicadeza, ternura, beleza frágil, colhidas na natureza, nas paisagens idílicas, a acentuar a tonalidade elegíaca de certos passos.

Trechos expressivos dos referidos registos poéticos surgem na Ioannes princeps tragoedia de Diogo de Teive, como parte integrante da inuen-

(36) Cf. Aristóteles, Poética, 1455a 24-27.

(37) Vide Henri Weber, La création poétique au XVI. ${ }^{e}$ siècle de Maurice Scève à Agrippa d'Aubigné, Paris, 1955, p. 635-636; 738 e sqq.

(38) Desde Petrarca que se assiste, no Renascimento, ao ressurgir do neo-estoicismo, que muito deve a Séneca - poeta tragicus e maximus morum philosophus e mestre de espiritualidade - e à divulgação do Manual de Epicteto, através da tradução latina de Ângelo Policiano. 
tio e da elocutio do seu estilo: servem de exemplo o início do Acto I, o prólogo da peça; o acto III, em que a Princesa Joana exprime, em termos petrarquistas, o cuidado e a saudade que lhe inspiram a ausência do seu marido muito amado; e o acto IV, onde se consuma a catástrofe, a morte do Príncipe João.

A abrir esta tragédia neolatina, o rei D. João III dialoga com a rainha D. Catarina. Ele que vira morrer sucessivamente filhos e irmãos, defronta-se agora com a agonia do único filho que lhe resta, o herdeiro único do reino e única salvação de um Portugal livre e independente - restava ainda a centelha, a luz ténue, o nascituro D. Sebastião.

A solenidade do tom, própria de um prólogo de tragédia clássica, não mitiga a retórica e o gosto empolado das imagens, tão caros ao estilo de Séneca. Essas imagens e motivos de influência clássica, a lembrar sobretudo a poesia de Horácio, que Séneca recolheu e assimilou (39) - tal como os trágicos gregos tinham feito em relação aos seus poetas líricos - adequam-se aos gostos de um povo, herói da gesta marítima, e ao estilo de um poeta que foi seu historiador. ${ }^{(40)}$ Assim inicia a tragédia, com uma fala de D. João III $^{(41)}$ :

"REX: Vt parua saeuis cymba iactatur Notis/ furente ponto, stare nec loco potest/concussa, sic pusillus animus pellitur/curis acerbis et dolore saucius,/ sic nulla requies pectori infirmo datur/ nullumque maesta mens capit solacium./Verum illa firmi pectoris constantia,/ quam nulla tempestatis ira aut impetus/ immanitate saeuus obruere potest,/ scopulo tenaci similis esse ducitur,/ quem fluctuantes haud mouent undae loco,/ non Libycus Auster nec grauis Notus imbribus/ nimbisque frendens nec trahens cuncta impetu/

(39) As imagens náuticas usadas para descrever os sentimentos da alma humana encontram semelhanças com as empregadas, em contextos diversos, por Cícero, Virgílio, Horácio, Ovídio, Séneca. Vide a análise feita in Nair de Nazaré Castro Soares, Tragédia do Príncipe João de Diogo de Teive, cit., p. 257-259.

(40) Diogo de Teive é autor de uma obra histórica que exalta os feitos dos portugueses no cerco de Diu de 1546, intitulada Commentarius de rebus in India apud Dium gestis anno salutis nostrae MDXLVI. Iacobo Teuio Lusitano Autore. Conimbricae apud Ioannem Barrerium, et Ioannem Alvares, 1548.

(41) Nair de Nazaré Castro Soares, Tragédia do Príncipe João de Diogo de Teive, cit., p. $144-145$. 
Strymonius Aquilo lata concutiens freta,/ sed eis resistit mole constanter sua./ Haec una uirtus inclitos reges decet,/ qui uelut in altis montium sedent iugis,/ ubi semper acres proelium Euri concitant,/ ubi caeca rerum domina praecipue explicat/ Fortuna uires sceptraque ostentat sua» (vv. 1-15).

"Como o pequeno batel, na fúria do mar, é joguete dos cruéis Notos e, à força de baldões, não consegue manter a linha de rumo, assim um ânimo débil e ferido pela dor se agita em pungentes cuidados, assim nenhum repouso se oferece ao coração inseguro e nenhuma consolação recebe a alma entristecida. Mas a constância de um peito firme que nenhum arremesso de tempestade ou ímpeto cruel pode, em sua ferocidade, aniquilar, é comparável ao duro rochedo que nem as ondas revoltas conseguem remover, nem o Austro líbico, nem o Noto que range, carregado de chuvas e borrascas, nem o estrimónio Aquilão que tudo arrasta nos seus ataques, sacudindo a amplidão dos mares — antes lhes resiste com a perseverança da sua inteireza. Esta é a virtude capital que convém a reis gloriosos, que estão, por assim dizer, sentados nos altos cumes dos montes, onde sempre os agrestes Euros impelem à luta, onde, senhora cega das coisas, a Fortuna mais aplica as suas forças e ostenta o seu ceptro».

Imagens náuticas, nomes dos ventos, das regiões do orbe, da cosmologia, evocados no seu sentido concreto ou no seu sentido poético, para exprimirem a dimensão de sentimentos que transbordam o mêden agan, são de expressão latina, e predominantemente senequiana, na sua adaptação ao momento trágico. ${ }^{(42)}$

Exemplificativo das tendências estilísticas da tragédia neolatina, próxima do modelo dramático de Séneca pela linguagem, este passo revela ainda os padrões de sensibilidade da literatura, no Portugal de Quinhentos, em que a própria "natureza é coberta pelas exigências do sentir, do apreciar, do avaliar, muito menos pelo descrever, quase nunca do medir». (43)

(42) Expressivas estas longas comparações que abrem a Ioannes princeps de Teive (vv. 1-15). Cf. as fontes clássicas destes versos, ibidem, p. 257-258. Vide ainda M. Armisen-Marchetti, Sapientiae facies. Étude sur les images de Sénéque, Paris, 1989.

(43) Sobre os padrões de sensibilidade lusa, expressos nas obras dos diversos géneros, na época de Quinhentos, vide J. Borges de Macedo, "Livros impressos em Portugal no século XVI», cit., p. 214 e sqq. 
Ainda no prólogo da tragédia, a acentuar a dualidade da alma humana e os seus sentimentos contraditórios que se desencadeiam entre o medo e a esperança, metus et spes, estados de alma próprios da tragédia, surge a resposta da Rainha D. Catarina que, na sua insegurança e fragilidade, se opõe à constância e firmeza de D. João III e faz sobressair o êthos de sapiens estóico do Rei. O locus horrendus, a visão de um fantasma, motivo recorrente na poesia de Séneca(44) — que desde a tragédia grega, geralmente em contraste com o locus amoenus, se adequa à criação e enriquecimento da peripécia ${ }^{(45)}$ - é descrito por esta personagem feminina que encarna o papel de Rainha, mas sobretudo de Mãe. Este locus horrendus, que integra a primeira intervenção de D. Catarina e contribui para adensar a tristeza com um cenário de pesadelo (vv. 27-93), surge em ligação com o sonho profético, de fonte esquiliana, presságio trágico da catástrofe e da consumação do pathos:

"[...] Sed dira nostrum femina premebat latus./ Quid feminam dixi? Horribile portentum erat, / squalore, macie foeditateque efferum,/ prae se furorem immanitatemque indicans; excelso ab umero pharetra pendebat grauis,/ immane robur foeda gestabat manus/ arcus superbi, quem furore percita/ (talis erat oris forma prodigio truci)/ in nostra dirigebat atrox lumina/ et singulis singula adimebat ictibus; quotiesque lumen aliquod auferebat, heu!/ toties putabam ui mibi cor erui./» [...] "Sed illa nullis precibus, ut tigris fera,/ pietate nulla commouetur: unicum,/ quod reliquum habebam lumen, abstulit mibi./" [...] "Sic diu maestissimis/ iacui tenebris consepulta, paruula/ scintilla donec lumine exit ultimo,/ quod lucis expers tum iacebat pristinae./"

(44) Note-se, em Séneca, por exemplo, no drama dos Pelópidas, ou dos Atridas, o simbolismo do fantasma de Tântalo, no início de Thyestes, ou do fantasma de Tiestes, a abrir Agamemnon, ou o significado estrutural e poético da aparição de Aquiles e de Heitor, em Troades.

(45) Note-se, na edição definitiva da Castro (1598), a beleza estrutural e poética da entrada lírica, em pseudo-estrofe de canção, em contraste com a visão medonha do bosque escuro, povoado de feras, atacantes, no acto III, e o enriquecimento da peripécia dá decorrente. Sobre a definição de peripécia - passagem da felicidade à infelicidade e vice-versa - e seu papel na construção dramática, vide Aristóteles, Poética, 1452a 22-24 e 1453a 12-16, com os comentários de 1548 de Robortello (ed. cit., p. 105-108 e 133-135); e os de Giovan Battista Giraldi Cinzio (ed. cit. p. 62). 
"Haec me refecit et tenebrarum chaos/ densissimum illud orbe toto depulit,/ sed alia facies luminis primi fuit/ aliusque lucis fulgor. His insomniis nimium molestis praeterii noctem integram; et adbuc (fatebor uera) pectus territant/ stupidamque mentem tristibus curis premunt." (vv. 53-64; 72-74; 83-93).

«Mas uma mulher terrível oprimia-me o flanco. Porque disse uma mulher? Era um monstro horrendo, selvático em sua imundície, magreza e fealdade, que nitidamente exprimia crueza e furor; do alto do ombro lhe pendia uma pesada aljava e a mão repelente empunhava a robustez imensa dum arco soberbo. Assaltada pela raiva (medonho era o aspecto da face deste portento brutal), apontava-o cruelmente aos meus olhos e em cada disparo me tirava um; e, todas as vezes que me arrancava algum dos olhos, ai! outras tantas eu julgava que o coração me era arrancado à força.» [...]. "Mas ela, como um tigre feroz, por nenhuns rogos, por nenhuma piedade se deixa comover: e o único olho que me tinha ficado - tirou-mo.» [...] "Assim por muito tempo fiquei sepulta nas trevas de desolação, até que uma pequenina centelha sai do último olho que já estava privado da luz antiga.»

"Esta centelha animou-me e afastou de todo o universo aquele caos insondável de trevas: mas outro era o aspecto da claridade primitiva e outro o fulgor da luz. Nestas fantasmagorias tão penosas passei a noite inteira: e ainda, direi a verdade, elas vêm semear o terror no meu coração e oprimem o meu espírito aturdido de tristes preocupações.»

O simbolismo do sonho torna-se evidente, quando pelas palavras da Rainha sabemos que está gravemente enfermo o único filho que, de tantos sobrevivera. A paruula scintilla, a "pequenina centelha" que sai do último olho, que já estava privado da luz antiga, era D. Sebastião que iria nascer a 20 de Janeiro de 1554, dezoito dias depois da morte de seu pai.

Muitas são as afinidades ideológicas e vocabulares entre este sonho da Ioannes Princeps e os das Troades e Octauia(46) e é lícito reconhecer que o nosso tragediógrafo tinha presentes as descrições senequianas, muito embora no domínio do lugar comum as semelhanças de autor para autor adquiram um significado muito relativo.

(46) Vide a análise destas semelhanças in Nair Castro Soares, Tragédia do Príncipe João de Diogo de Teive, cit., p. 259-262. 
Um outro registo, adequado à sensibilidade poética do Renascimento, tem lugar no acto III da Tragédia do Príncipe João: a Princesa Joana, em diálogo com a ama - um expediente euripido-senequiano para apresentar o alter-ego da personagem trágica - exprime o negrume da sua alma, em termos de sympátheia tôn óllôn, de cariz estóico ${ }^{(47)}$ :

"Nec aliud ista temporum mutatio/ tam saeua prodit, quam grauem omnium/ mutationem rerum. En aspicis Notis/ permista rapidis omnia. En micantia/ euomere flammas astra scindique aethera/ et confragosis motibus caelos quati/ nutareque atris cuncta tempestatibus,/ adeo ut ruinam comminentur omnia/ terris creata nec suas seruent uices./ Mutata rerum est forma, nox diem occupat/ Phoebusque terris occulit iubar suum/ et cuncta tristes pollicentur exitus/ duramque cladem.» (vv. 629-641).

«E a mudança tão cruel dos tempos não revela outra coisa senão uma penosa mudança de toda a situação. Olha, tu vês que tudo se revolve sob a acção dos Notos violentos. Olha os astros brilhantes a vomitarem chamas, os ares a fenderem-se, a abalarem-se os céus com estrondosos movimentos e tudo a oscilar com negras tempestades, a tal ponto que ameaça ruína quanto na terra se cria e não mantém a sua regular sucessão. A beleza das coisas mudou, a noite triunfa sobre o dia e Febo oculta ao mundo a sua luz e tudo promete um triste fim e uma cruel destruição.»

Segue-se a confissão amorosa da Princesa Joana por seu marido, numa sugestiva imagética da interioridade, em que a própria expressão lírica e os seus recursos e ingredientes servem para acentuar os contrastes da alma humana, verdadeiro diapasão da essencialidade dramática.

O lirismo petrarquista, no seu jogo intelectivo de antíteses abstractas e assente numa estratégia da reduplicação do sujeito da enunciação, em relação ao sujeito do enunciado, e na valorização das capacidades perceptivas, em que avulta a prevalência da luz, do ver e do olhar, de inspiração plotino-ficiniana, está presente na Ioannes princeps, nestas falas da princesa, grávida de D. Sebastião e por isso afastada do seu príncipe, moribundo. Vejamos este passo $^{(48)}$ :

\footnotetext{
(47) Ibidem, p. 190-193

(48) Ibidem, p. 192-195.
} 
"O care coniux, care plus quam lumina/ quibus solebam te videre, te ut iubar/ conspicuum Olympi, qui potes per tot dies/ abesse praesens? Aula cum te regia/ haec teneat, oculos fugere tu meos potes? conspectu abesse tandiu a meo potes?/ Non id uoluntate, auguror, facis tua; nec dubito ob oculos quin tuos semper meos/ uidere cupias [...]» (vv. 651-659).

"Sed uos, uidere lumina infelicia/ dum non potestis uestra clara lumina/ iubarque uestrum iubare Phoebi clarius,/lugete semper ac perennes fundite/ lacrimas». (vv. 665-669)

"Ó querido esposo! Querido mais do que os olhos com que eu costumava ver-te, a ti, brilhante como o resplendor do Olimpo! Como podes tu estar ausente - embora presente - durante tantos dias? Vivendo tu neste mesmo palácio, podes tu escapar à minha vista? podes há tanto tempo estar afastado do meu olhar? não é da tua vontade, eu o pressinto, nem duvido que os teus olhos desejem ver sempre os meus diante dos teus» [...]

"Mas vós, ó olhos infelizes, enquanto não podeis ver o vosso claro olhar e o vosso esplendor mais brilhante que o esplendor de Febo, chorai sempre e derramai lágrimas sem cessar.»

De um lirismo comovedor é a ternura-paixão que a princesa Joana exprime pelo seu amado ausente, no acto central da obra. Em diálogo com a ama, a princesa pressagia, em termos de identificação com o ser amado, a sua própria morte ${ }^{(49)}$. A sensibilidade amorosa da princesa Joana, e o profundo amor por seu marido, confirmado pela história, que exprime na imagética linguagem petrarquista, é como que projectada no cantar do coro do final deste acto III, em estrofes sáficas, que, à maneira do coro I da Phaedra de Séneca, entoa a invencibilidade e o poder cósmico do amor ${ }^{(50)}$.

(49) O amor que unia os príncipes - à data da morte de D. João, ele não tinha ainda dezassete anos (nasceu a 3 de Junho de 1537) e a esposa tinha dezanove incompletos (nasceu a 24 de junho de 1535) - é cantado pelos poetas de Quinhentos (vide e. g. Sá de Miranda, Elegia à morte do Príncipe D. João; António Ferreira, Écloga Jânio; e Camões, Écloga I, onde a Princesa, tal como na Ioannes Princeps, confessa a sua paixão pelo marido. Há cartas do Príncipe, dirigidas à noiva, onde ele manifesta dedicar-lhe verdadeiro amor. A Princesa Joana, depois da morte do Príncipe João, fez-se freira.

(50) Vide Nair Castro Soares, Tragédia do Príncipe João de Diogo de Teive, cit., p. 201-205: o Coro final do acto III entoa um hino ao Amor e ao seu poder cósmico. Embora este tema coral já se encontre no terceiro estásimo da Antígona de Sófocles, há migrações textuais e alusões literárias colhidas por Teive na obra de Séneca, designadamente em Phaedra, no Hercules Oetaeus, no Agamemnon e ainda na Octauia e (cf. a análise deste coro, feita ibidem, 
Duas espécies de amor — as duas Afrodites, Urania e Pandemos, da doutrina platónica(51) — dominam os corações enamorados, acentua esta ária, que exprime as mesmas ideias que Fílon e Sofia, ao longo dos dois primeiros «diálogos» dos Dialoghi d'amore de Leão Hebreu ${ }^{(52)}$, atentemos num trecho da ode coral entoada no final do acto III:

"Cuncta si victor superat Cupido

corda uictorum, licet illa duris

ac feris gestent truculenta setis

cinctaque ferro,

molle cur pectus nequeat domare

uirginum, molles iuuenumque mentes?

Sed repugnantes trabit et uolentes

ducit amice

Omnium uictor deus est Cupido, sed magis molles animos domare

uirginum nouit iuuenumque blandis

urere flammis.

Hunc uocant quidam rabiem ac uenenum,

bunc luem, pestem, scelus et furorem

milleque immani maledicta lingua

turpia iactant.

Haud tamen norunt geminum esse Amorem:

alterum caecum, furibundum, acerbum,

qui sua ceruos leuitate uincit,

uincit et auras:

alterum castum, moderatum, amicum,

prouidum, mitem, placidum, quietum,

cui fides semper probitasque grata

pectori adhaeret."

(vv. 773-796).

288-291). A caracterização da figura do Amor é feita tal como aparece em Anacreonte e Mosco, o que se tornara já lugar-comum, na poesia e na pintura do Renascimento.

(51) Platão, Banquete, 180 d-e.

(52) Leão Hebreu (Iehudais Abrabanel), Diálogos de amor. Texto fixado, anotado e traduzido por Giacinto Manuppella, 2 vols., Lisboa, INIC, 1983: I, p. 3-143; II, p. 5-149. 
"Se Cupido vencedor triunfa sobre todos os corações

dos vencedores, por violentos que sejam

e providos de duras e bravias cerdas

e cingidos de ferro,

como não há-de dominar o tenro peito

das donzelas e os tenros espíritos dos jovens?

Aos que resistem, arrasta-os; e aos que consentem,

amorosamente os conduz.

De todos é vencedor o deus Cupido,

mas sabe melhor dominar os corações sensíveis

das donzelas e abrasar os dos jovens

com as chamas da sedução.

Chamam-lhe alguns fúria e veneno,

flagelo, peste, crime e desvario,

mil ditos ultrajantes lhe arremessam

com língua truculenta.

Não sabem, todavia, que há dois Amores:

um cego, furioso, cruel,

que em sua ligeireza os próprios cervos vence,

e vence até as brisas;

outro, casto, morigerado, amigo,

prudente, doce, aprazível, sossegado,

a quem são gratas sempre a lealdade e a justiça,

está ao peito bem ligado.»

No acto IV, ao consumar-se a tragédia, já anunciada desde o início da peça e reflectida no sentir individual das diversas personagens - que representam também o sentimento colectivo do povo e da pátria, na sua identidade —, há trechos paradigmáticos da sensibilidade e da linguagem poética que caracterizam o discurso dramático no século XVI ${ }^{(53)}$ :

"Vt sole discedente nox caligine/ obscurat orbem et nubibus spissis tegit/ sic nostra lux, sic splendor omnis ac iubar/ micans Iberae gentis obscurum latet/ tanti recessu Principis neque enim adeo/ intra minora luna fulgens sidera/ emicat, ut ille Principes clarissimos/ praeluxit inter.» (vv. 829-836).

(53) Vide Nair de Nazaré Castro Soares, Tragédia do Príncipe João de Diogo de Teive, cit., p. 206-207. 
"Tal como, em baixando o Sol, a noite envolve no seu negrume o universo e o recobre de nuvens espessas, assim a nossa luz, assim todo o esplendor e brilho intenso dos povos ibéricos se esconde na obscuridade com o desaparecimento de tão grande Príncipe; e nem a lua brilha tão radiosa entre os astros menores como ele refulgiu entre os mais ilustres príncipes.»

E surge a imagem pictórica do príncipe jazente ${ }^{(54)}:$ :

"Ille animam Olympo reddidit, corpus gelu/frigidius intus lectulo in paruo iacet." (vv. 868-869).

«Ele entregou ao Olimpo a sua alma; o corpo, mais frio do que o gelo, jaz lá dentro deitado em leito exíguo».

A morte na flor da idade, a vida cortada em flor, pela mão de Deus ou pela vontade dos homens, reveste-se, em todos os tempos, de poesia, emoção e transcendentalidade. Adequam-se-lhe imagens em que se interpenetram fontes escriturísticas com fontes clássicas, a exprimir a efemeridade da vida ${ }^{(55)}$

"Quis cuncta, quamuis fronte prima appareant/ stabilia, prorsus non caduca deputet, / et proxima esse occasui non iudicet,/ cum noster ille flore primaeuo uigens,/ ille, ille Princeps uiribus firmis ualens,/ instar recessit aurae ab oculis omnium/abiitque ueluti somnus aut fumus leuis,/ ut laeta uerno tempore exiens rosa,/ quae mane flore pulchra conspicuo nitet,/ uespere decorem prorsus amittit suum?/ O quanta in ore gratia ac decor inerat,/ in mente uirtus grataque moderatio!/ Nisi os uideres, quod simile fulgentibus/ micabit astris, ac loquenti aures dares,/ audire magnum te putares Nestorem.» (vv. 874-888).

(54) Ibidem, 210-211.

(55) Ibidem, p. 210-212. Estes versos da Ioannes princeps tragoedia de Diogo de Teive encontram eco na Castro, obra prima da nossa literatura dramática quinhentista (Castro, acto I, v. 52; acto IV, v. 174-175). As imagens repetem-se, em expresssiva permeabilidade entre a mensagem dos livros do Antigo Testamento, nomeadamente os Salmos e o Livro de Job e a dos poetas clássicos, desde a Ilíada, Mimnermo, Semónides de Amorgos, Catulo, a Eneida de Virgílio, Ovídio, Séneca. Nos autores quinhentistas, estas imagens povoam a lírica, a épica, a tragédia, a prosa de carácter moralizante, de que é exemplo expressivo, sobretudo pela sua recepção, o De contemptu mundi de Erasmo. Vide Nair de Nazaré Castro Soares, "Martírio e sacrifício voluntário na tragédia humanista e no mito inesiano: em António Ferreira e Eugénio de Castro", Humanitas 48 (1996) 205-222. 
"Quem há que não considere todas as coisas, ainda que à superfície pareçam estáveis, como inteiramente caducas e as não julgue próximas do ocaso, quando o nosso querido Príncipe, na sua frescura de flor amanhecente, ele, sim, no pleno vigor das suas forças, desapareceu, como uma brisa, dos olhos de todos, e se foi como um sono ou fumo leve, como a alegre rosa que desabrocha na Primavera, rosa que de manhã brilha na sua beleza de flor atraente, à tarde perde por completo a sua formosura? Oh quanta graça e beleza havia no seu rosto, virtude na sua alma e graciosa moderação! Se não visses o seu rosto, que resplandecia semelhante aos astros fulgentes, e apenas escutasses as suas palavras, julgarias ouvir o grande Nestor».

A mestria da frase sentenciosa e a facilidade em manusear o léxico latino com seus recursos estilísticos — que vai desde a expressão do sentimento melancólico e elegíaco à representação das paixões violentas, ou à aplicação da mitologia e da terminologia pagã a conceitos cristãos — são formas diversas de construir o discurso mimético dos modelos clássicos, referente absoluto de perfeição genológica da poesia trágica.

A assimilação dos conceitos bíblicos à altura do discurso clássico pagão reflecte-se, ao longo de toda a Tragédia do Principe João, na forma de designar Deus e os seus atributos, e toda a escatologia cristã, referente ao céu e ao inferno.

Deus é Parens Dium, Moderator orbis, Opifex rerum, o rei do Olimpo, o criador de todas as coisas, que rege o lago estígio, detentor do tríplice raio. Emprega-se Caelitum, Caelicolae, Superi, os habitantes do céu, as potestades da mitologia pagã, para designar os santos e outros bem-aventurados. O Além é designado de diversas formas: o céu é o Olimpo; o Orco, os Lagos Estígios, as funduras do Tártaro são os infernos(56).

Os próprios deuses surgem como metonímias e personificações de conceitos abstractos: Marte identifica-se com a própria guerra; Febo ou Apolo,

(56) Vide e.g. vv. 115; 141; 149; 160-161; 170; 202; 228; 248, 272-273. A fraseologia mitológica clássica, aplicada a conceitos religiosos cristãos, largamente utilizada pelos humanistas, remonta já aos primórdios do Cristianismo. Vide Nair de Nazaré Castro Soares, Tragédia do Príncipe João de Diogo de Teive, cit., e. g. p. 265-266. 
com o seu carro, é a figuração do dia, como Febe, irmã de Febo, é a da Lua, da noite; Témis ou a Justiça personificada - que desde Hesíodo, preside ao ideal da Idade do Ouro - permanece na terra nos áureos séculos de Saturno, nos Regna Saturnia, que o governo de um bom rei propicia, mas abandona a terra, assolada pelo mal, pela desgraça(57).

Imagens náuticas, nomes dos ventos, das regiões do orbe, da cosmologia, evocados no seu sentido concreto ou no seu sentido poético, para exprimirem a dimensão de sentimentos que transbordam o mêden agan, são de expressão latina - e predominantemente senequiana, na sua adaptação ao momento trágico ${ }^{(58)}$.

Tendência particularmente cara aos estóicos era a divinização da natureza e dos fenómenos naturais, o que justifica o recurso insistente a estes elementos - presentes já na tragédia grega.

É sobretudo nos coros que complementam, com a sua função hedonista e emotiva, a função intelectiva e cognitiva do mythos, que o poietes recorre ao mito, a imagens e motivos clássicos, por vezes através da reminiscência e da arte alusiva(59).

Sem deixar de aflorar a temática religiosa que a Reforma e as guerras de religião actualizavam(60), a tragédia renascentista vai incidir preferencial-

(57) Ibidem. Vide e.g. a ode coral que termina o acto I, muito expressiva, neste particular, p. $155-161$.

(58) Vide ibidem, vv. 1-15. p. 144-145 e 257-258. Expressivas as longas comparações que abrem a Ioannes princeps de Teive (cf. supra n. 39).

(59) Vide Nair de Nazaré Castro Soares, «Mito e imagens clássicas na poesia trágica Renascentista, em Portugal", in Actas do Symposium Classicum I Bracarense, "Mitologia clássica e a sua recepção na Literatura Portuguesa" (Faculdade de Filosofia da Universidade Católica Portuguesa, Braga, 21 de Maio de 1999), Braga, 2000, pp. 67-93.

(60) Vide, neste particular, a fala da Rainha, no V acto, vv. 1200-1218, em que invoca os conceitos de culpa e o castigo da terminologia trágica grega, para os associar à morte do Príncipe, sentida como expiação pelos pecados públicos. Digna de referência é a questão da predestinção e da liberdade ontológicas, debatida no De seruo arbitrio de Martinho Lutero, e em resposta a este libelo, no De libero arbitrio de Erasmo e, de forma acabada, na doutrina da justificação e da graça, prolongada na disputa De auxiliis dos jesuítas. Reflexos desta problemática encontram-se de forma velada nas tragédias de Buchanan, na Castro e com maior abertura nas tragédias jesuítas. Vide e.g. Nair de Nazaré Castro Soares, "Martírio e sacrifício voluntário na tragédia humanista e no mito inesiano: em António Ferreira e Eugénio de Castro", Humanitas 48 (1996) 205-222, maxime 210-212. 
mente, ao modo senequiano, na res politica e suas múltiplas implicações - com relevo para o tema do Amor em conflito com a Razão de Estado

- de acordo com os tempos em que surgiu a doutrina de Maquiavel e se afirmou a ciência política com Jean Bodin(61).

A Ioannes princeps tragoedia integra-se nesta tendência temática da sua época: drama individual e familiar é acima de tudo um drama colectivo, nacional, de tema predominantemente político. Nela se debatem temáticas clássicas, com imagens e motivos históricos e mitológicos da tradição literária, de grande interesse e actualidade ${ }^{(62)}$ : a verdadeira realeza, mais atingida pela infelicidade, dada a sua posição eminente, mais exposta às viragens da fortuna; o rei ideal, o bom governante, pastor e condutor de povos, em que o modelo homérico de Agamémnon se combina com o modelo bíblico; e, em contraste com este, a figura do tirano, caracterizada, na sua crueza, pelo recurso a animais selvagens; o valor da lealdade e da amizade verdadeiras, exemplificado em Aquiles - Pátroclo, Teseu - Pirítoo, Orestes - Pílades; a vida áulica com seus perigos de adulação; os trabalhos do rei, em contraste com o ideal da vida simples, da aurea mediocritas e do beatus ille horacianos (em que a filosofia epicurista de tom lucreciano, se une com a poética dos Salmos e o ideal evangélico); a instabilidade e fragilidade da vida humana; a labilidade da fortuna, senhora cega das coisas; o amor sagrado e o amor profano; o poder cósmico do amor, a transcendentalidade do amor e da morte(63).

(61) Vide Nair de Nazaré Castro Soares, O príncipe ideal no século XVI e a obra de D. Jerónimo Osório, cit., p. 260-261.

(62) Para se perceber que Séneca é a principal fonte de inspiração trágica, no que toca a estes motivos e imagens, recorrentes na sua obra dramática, vide Mireille Armisen-Marchetti, Sapientiae facies. Étude sur les images de Sénéque, cit.

(63) A arte da composição e da representação dramática, com um papel fundamental na preparação retórica, na formação integral dos cultores dos studia bumanitatis, contribui para que o século XVI europeu se possa considerar uma verdadeira respublica litteraria. A produção literária de Quinhentos, desde os tratados de educação de príncipes, à poesia lírica, trágica e épica, à comédia, ao panegírico, à parenética, à obra histórica, à oratória escolar manifesta os mesmos gostos de uma cultura enciclopédica cuja fonte de saber é a Antiguidade clássica. Vide, a este propósito, G. Savarese e A. Gareffi, La letteratura delle immagini nel Cinquecento, Roma, 1980. 
Todos estes temas, com seus motivos mitológicos, imagens poéticas, tópoi literários - que facilitam a permeabilidade genológica do género trágico com o lírico, tão ao gosto da sensibilidade poética do tempo ${ }^{(64)}$ — são reveladores da cultura literária humanística do dramaturgo Diogo de Teive e do seu conhecimento directo dos autores latinos que o enriqueceram com a mensagem espiritual e humana e a lição de elegantia linguae latinae.

A aemulatio e a imitatio da Antiguidade clássica documentam a preferência de motivos estéticos e ideológicos, veiculados, muitas vezes, pelo teatro de Séneca, referência genológica privilegiada. Num tempo em que o estoicismo se revigora como uma ética do comportamento conciliada com a moral cristã, conceitos metafísicos e de doutrina estóica, típicos do discurso senequiano, conhecem a maior divulgação e são assimilados pelos autores quinhentista(65). Aliás, a ênfase acentuadamente retórica, que combina a filosofia estóica, característica do êthos das personagens, com o tom epicurista e o lirismo dos coros, agradava à sensibilidade dramática do século XVI. No entanto, os tragediógrafos desta época, e entre eles Diogo de Teive, ao retomarem a expressão, a uox tragica de Séneca, não sacrificam as suas convicções, a sua inspiração e a sua criatividade.

É que a tragédia, mímesis práxeos, imitação da acção humana, tem necessariamente de estar de acordo com os padrões de sensibilidade da sua época, com os gostos do auditório, do leitor/espectador, motivação primeira da obra dramática(66). Além disso, dentro dos princípios aristotélicos do verosímil e do decorum, que as muitas edições comentadas da Poética do

(64) Vide Nair de Nazaré Castro Soares, "Contaminatio genológica na Castro de António Ferreira", Boletim de Estudos Clássicos - Homenagem a C. A. Louro da Fonseca 24 (1995) 87-99.

(65) Neste sentido, é modelar, na Ioannes princeps tragoedia, a caracterização da figura do rei D. João III, encarnação perfeita do ideal do sapiens estóico - a impassibilidade na dor, a constância, a firmeza, a ataraxia. Este êthos trágico do Rei traduz a realidade histórica. Conforme à personalidade que aqui se retrata e elogia é a Carta I, livro I, de António Ferreira que tem por título "Congratulação de todo o reino a el-Rei D. João III, na morte do Príncipe D. João, seu filho, que sofreu pacientissimamente".

(66) Vide definição de Tragédia em Aristóteles, Poética, 1449b 24-28. Sobre a influência de Séneca no teatro do Renascimento e, a partir dele, nas diversas experiências teatrais europeias, vide Georges Uscatescu, Séneca nuestro contemporáneo, Madrid, 1965, p. 130-143. 
Estagirita fizeram reviver, o texto humanista impõe-se pela clareza da sequência discursiva, motivada e coerente, com as suas marcas enunciativas e originalidade própria(67).

É nesta afirmação genológica da tragédia, a que convém a sublimidade, a grandeza de estilo, adequada à sua função emotiva, que Teive tem o seu quinhão como poeta trágico, a abrir caminhos novos à dramaturgia de seu tempo ${ }^{(68)}$.

Em 2 de Janeiro de 1554 morre o Príncipe D. João, único herdeiro do trono, chorado por todos os artistas da palavra, poetas e prosadores. À margem do teatro escolar, compõe Diogo de Teive a Ioannes Princeps tragoedia, a primeira tragédia de assunto nacional, onde dá voz, em versos latinos inspirados, à dor, à angústia colectivas.

Afirma Federico Garcia Lorca: "O teatro é uma escola de choro e de riso e uma tribuna livre de onde os homens podem [...] explicar com exemplos vivos normas eternas do coração e do sentimento do homem».

Drama político, por excelência, a Ioannes Princeps é também um drama "do coração e do sentimento", da alma do homem português, que ainda hoje, à distância de quatrocentos e cinquenta anos da sua elaboração e dos acontecimentos que informam o seu mythos, consegue provocar a catarse, agradar e comover.

A prova é a representação feliz que foi feita neste Congresso.

(67) Vide B. WEINBERG, Trattati di poetica e retorica del Cinquecento, a cura di..., 3 vol., Bari, 1970-1972.

(68) Federico Garcia Lorca, "Charla sobre teatro", Obras Completas, Madrid, Aguilar, ${ }^{18} 1973$, p. 1178 . 
Santiago López Moreda

Universidade de Extremadura

TEATRO, POÉTICA Y RETÓRICA:

LA FABELLA AENARIA DE J. L. PALMIRENO

La importancia que el teatro clásico grecolatino adquiere en el siglo XVI está fuera de toda duda, sobre todo desde que a comienzos de siglo Aldo Manucio publicara los textos de Aristófanes, Sófocles y Eurípides, y fueran dadas a conocer, incluso en versión castellana, las comedias de Plauto en sucesivas ediciones a partir de la traducción de Francisco López de Villalobos primero y de Hernán Pérez de Oliva más tarde. De hecho, las versiones españolas son, tras las italianas, las más numerosas, ya desde finales del siglo XV en que hay traducción castellana de las ocho tragedias de Séneca, según consta en el Registrum de don Fernando Colón, y la edición unos años después de Juan de Timoneda, además del Anfitrión y los Menecmos, que circulaba junto con el Milite Glorioso en una traducción anónima atribuida a Juan de Verzosa(1).

Y si por teatro clásico entendemos también el procedente de la Edad Media, en la medida que contribuyó a propagar los temas bíblicos y la ejemplaridad de los santos, especialmente tras la creación de la Compañía de Jesús, pero sirviéndose de la concepción dramática de los clásicos paganos y el modelo platónico-ciceroniano de los diálogos, está fuera de

(1) Una buena aproximación a la recepción y difusión de Plauto y Terencio en España la tenemos en L. Gil Fernández, "Terencio en España: del medievo a la ilustración», en Estudios de bumanismo y tradición clásica, Universidad Complutense, Madrid, 1984, pp. 95-125. 
toda duda que, como ocurriría en la latinidad tardía, ambas formas de concebir el drama, y muy especialmente la finalidad de las representaciones con su doctrina moral, estaban llamadas a enfrentarse. El teatro escolar de los jesuitas y el teatro de las universidades y centros de estudios civiles necesariamente habían de perseguir fines morales, y hasta métodos pedagógicos, diferentes. Al atavismo de las representaciones religiosas, fieles a los principios poéticos clásicos, el teatro civil responde con nuevas poéticas que se dejan ver especialmente en Juan del Enzina y Lope de Rueda en un primer momento y concluyen con Cervantes y el Arte nuevo de Lope de Vega como culminación de un proceso que otros muchos preceptistas habían ido modelando a lo largo del siglo XVI (Escalígero, Vives, Palmireno, Simón Abril y un largo etcétera).

Este interés por el teatro, que no es un hecho aislado ni al margen de otros intereses culturales, hay que encuadrarlo en el desarrollo creciente de los colegios y las universidades y la necesidad de hacer llegar a los estudiantes la lengua y los contenidos del mundo clásico. A tal fin se escriben numerosas gramáticas para enseñar latín, pero también lenguas vulgares, especialmente para profesionales de otras disciplinas del saber no estrictamente gramaticales, como médicos y científicos, para quienes se realizan traducciones de Dioscórides, Hipócrates, Galeno y Plinio, entre otros.

Estas gramáticas tienen todas como señas de identidad, más allá de los meros contenidos, la preocupación didáctica para hacer llegar a los estudiantes los conocimientos mínimos que le faciliten el acceso a los textos clásicos, pero también una serie de principios estéticos para gustar de las fuentes clásicas bajo cualquiera de sus manifestaciones: oratoria, poesía, drama, filosofía moral... Un ejemplo: La Philosophia vulgar de Juan de Mal Lara, editada en Sevilla en 1568, difunde en castellano poemas de Catulo, Horacio, Ovidio, Marcial, Juvenal, Persio y otros, pero también de Plauto y Séneca, lo que denota no sólo interés poético, sino también doctrinal y moral, al margen de la finalidad estricta del género literario al que se adscribe cada uno de los autores y sin que ello implique una jerarquía de acuerdo con las poéticas clásicas. 
Son, pues, intereses varios, como los científicos, didácticos, morales, estéticos e incluso retóricos los que se dan cita en la actividad docente de las universidades y hacen de la práctica teatral un excelente ejercicio que satisface a todos ellos a la vez que exige una poética del drama que dé forma y razón de ser a dicha práctica.

En este contexto hay que entender los Poetices libri septem de Julio César Escalígero, editados en 1561, que introducen una serie de reflexiones sobre el hecho literario en general y el dramático en particular. Porque, como ocurre con las poéticas clásicas, las normas nacen de la literatura existente y no a la inversa, pero también, si un género literario no está presente en una poética, es como si no existiese o existiese de manera circunstancial y periférica. Por otra parte, la proliferación de manifestaciones dramáticas tan heterogéneas como las representaciones de églogas, la fiesta de los locos, del «obispillo», los misterios en torno a la Navidad y la Eucaristía, las farsas de estudiantes o la costumbre de abrir el curso académico con alguna representación de Plauto o Terencio, exigía un ordenamiento poético canónico que fijara las normas de estas representaciones e incluso estableciese una jerarquía, como había sucedido en la literatura clásica grecolatina.

¿Cuál era, pues, la situación del drama a efectos poéticos?

A la manera aristotélica, Escalígero establece una gradación de géneros en la que tragedia y comedia ocupan una posición intermedia; por lo tanto, no muy digna, o si se quiere, menos digna que en las poéticas clásicas donde el criterio de la mímesis es fundamental en la jerarquía de géneros:

"Los géneros más nobles son los himnos y peanes; en segundo lugar las odas y escolios que versan sobre las gestas más notables de los héroes; en tercer lugar la épica... Le siguen después la tragedia y la comedia... Y por último la sátira, los cantos corales, himeneos, elegía, monodia, canciones y epigramas» (2).

(2) J. C. Escalígero, Poetices libri septem, apud Petrum Santandreanum, 1581, p. 14. (BNM$-3-33265)$. 
Entre otras diferencias, señala Escalígero que la tragedia tiene un comienzo tranquilo y un final terrible, mientras que la comedia empieza de manera enrevesada para concluir de manera feliz, además de un estilo popular, frente a la grandilocuencia de la tragedia.

Pero lo que pretendemos ahora no es hacer una exhaustiva descripción de la teoría dramática de Escalígero, sino dejar constancia de otros valores que los humanistas supieron ver en las representaciones teatrales, tales como la pedagogía de la doctrina moral, el aprendizaje de vocabulario latino y romance, los conocimientos lingüísticos y gramaticales, y sobre todo, la importancia de la actio, como parte imprescindible de la Retórica. Sobra recordar la formación de Cicerón y otros oradores al lado de los grandes dramaturgos y actores para insistir en la estrecha relación existente entre drama y oratoria.

Siguiendo con la reflexión anterior, aceptada una poética propia para el drama, nada menos que de la pluma de un insigne representante de la historia de la gramática, como es Julio César Escalígero, es pertinente que analicemos los rasgos de esta poética para ver en qué medida se ajusta o difiere de las poéticas clásicas y tratemos de observar los fines con que se concibe la producción dramática del siglo XVI, que por razones obvias, no persiguen la mímesis de manera prioritaria.

En efecto, lo primero que llama la atención en la abundante producción dramática del citado siglo es la aceptación de nuevas formas poéticas que rompen el rigor de las poéticas clásicas, especialmente de la aristotélica y horaciana. El fenómeno ni era nuevo ni exclusivo de este siglo, sino que se había dado de manera constante en la evolución del drama; por ejemplo, la historia de la tragedia está llena de innovaciones.

1. - Sófocles lo hizo aumentando el número de actores a costa del papel que desempeñaba el coro.

2. - Eurípides ahondó en este proceso y además, "humanizó» la tragedia restando importancia a los dioses. Era la actitud agnóstica y racionalista 
emanada de los sofistas y de los primeros síntomas de descomposición de la polis.

3. - Séneca «actualizó» en la Roma de Nerón los temas míticos sugiriéndonos que podían leerse en clave política. Renacieron los Tiestes, Atreos, Fedras y Medeas. Es, sobre todo, la tragedia de la sugerencia y de la reflexión de hasta qué punto es lícito eliminare gradus, esto es "cruzar el umbral», «innovar», como se desprende de su polémica con Curiacio Materno.

4. - La Edad Media introdujo dos aportaciones de éxito: la tragedia mítica fue sustituida por la tragedia bíblica y el fatum por el providencialismo, lo que supuso que el castigo se vinculara al comportamiento en desacuerdo con la ley divina. Parásitos, esclavos, meretrices, matronas y otros personajes de la comedia plautina y terenciana dejaron paso a ejemplares santos, personajes bíblicos y truhanes para adoctrinar sobre la Biblia y la moral de la nueva sociedad medieval.

También en el siglo XVI se aceptó la importancia del teatro y la actualización de su papel educador con las correspondientes innovaciones. Dos ejemplos:

Alonso López Pinciano, médico y helenista vallisoletano, a finales del siglo XVI en su Philosofía Antigua Poética, escribía:

"La tragedia fue hecha para limpiar el ánimo de las pasiones del alma por medio de la compasión y miedo. Así que la misma fábula que turba el ánimo por espacio poco, le quieta y sosiega por mucho... Cuando el hombre se acuerda de un Edipo y Hércules Eteo, tórnase muy consolado en sus miserias porque ve que, aunque las suyas son grandes, no lo son tanto como las de Hércules y Edipo, y así queda más fuerte para sufrir más y más trabajos y desventuras».

Cervantes, en su vejez, partidario de innovaciones dramáticas, en $E l$ rufián dichoso abre la segunda jornada con el siguiente diálogo de dos figuras alegóricas, la Curiosidad y la Comedia: 
COMEDIA: "¿Qué me quieres?

CURIOSIDAD: Informarme

qué es la causa porque dexas

de usar tus antiguos trajes, del coturno en las tragedias, del zueco en las manuales comedias, y de la toga en las que son principales: Cómo has reducido a tres los cinco actos que sabes que en tiempo, te componían ilustre, risueña y grave. Ahora aquí representas y al mismo tiempo en Flandes. Truecas, sin discurso alguno, tiempos, teatros, lugares.

Véote y no te conozco.

COMEDIA: Los tiempos mudan las cosas y perfeccionan las artes y añadir a lo inventado, no es dificultad notable. Y en éstos, si los mirares, no soy mala, aunque desdigo de aquellos preceptos graves que me dieron y dexaron en sus obras admirables Séneca, Terencio y Plauto y los griegos que tú sabes He dejado parte de ellos y he también guardado parte, porque lo quiere así el uso que no se sujete al arte».

Siempre hubo, pues, una legitimación para innovar y adaptar a los nuevos tiempos las nuevas manifestaciones dramáticas, y así lo entendieron Cervantes, Anchieta, Juan Lorenzo Palmireno y hasta el mismísimo Padre Juan Bonifacio, por poner sólo algún ejemplo. El primero, poco dado a los milagros en el teatro, critica las comedias de santos (comedias divinas) 
e introduce en su Quijote (I, 48) la famosa discusión entre el Cura y el Canónigo:

«QQué de milagros falsos fingen en ellas, qué de cosas apócrifas!»

(El Quijote, I, 48).

El último, catedrático de Griego y de Retórica en el Studi General de Valencia durante los años 1561 a 1579, a lo largo de su docencia no dejó de publicar obras con fines pedagógicos fundamentalmente, convencido como estaba de la importancia de la educación para sacar de su ostracismo al poble menut del que él, como hijo de herrero, procedía. Es en este contexto donde vamos a situar la primera finalidad del teatro escolar: enseñar de manera sencilla lo que resulta sumamente arduo en los manuales de gramática y de retórica.

En El estudioso de la aldea y El estudioso cortesano, arremete contra los métodos docentes, la gramática de Nebrija, Despauterio y los gramáticos en general:

"Quando me acuerdo de los açotes que me dieron por la significación de limes, pes, fames, cum, palmite, trames, querría morder al camello de mi maestro, que era tan gran asno que sólo quería que el sábado le diéssemos todas las significaciones de los vocablos del texto, mas aun que le repitiéssemos todas las significaciones de popa, venter, y partiéssemos limes, pes en limen infernum et superum...»(3)

"Quien no me cree, póngase un ratillo a la puerta de una ciudad y verá que de moços entran cada un año en ella; unos aprender officios, otros a gramática, de los quales, aunque sean mil, no buelven a sus casas seys que no sepan su officio de sastre, çapatero, etc... pero de quinientos grammáticos no salen treynta. ¿Qué lo causa, sino esta piedra que luego espanta? Si no miren los preceptos de Antonio como hombres ya exercitados. Acuérdense el espanto que le causauan quando niños y verán cuánta

(3) Palmireno, El estudioso de la aldea, p. 107. (Cita tomada de J. Ma Maestre Maestre, El humanismo alcañizano del siglo XVI. Textos y estudios de latín renacentista, Cádiz, 1990, p. LXIV). 
obligación tenemos de dolernos de los cuytados. Lo que Antonio escrivió en prosa claro es, pero sus versos, ¡Dios me libre!...»(4).

"Tales como éstos [Despauterio] corrompen los ingenios de los niños, y con carretones de preceptos los espantan de tal modo que estiman más aprender qualquier officio, que no letras»(5).

"Sólo los grammaticos con açotes tratan, con açotes baratan y con ellos triunfando reciben y despiden. Si preguntáis a un cavallerizo: «¿Con qué domáys un caballo?». Responde: "Con siete cosas que son boz, vara, freno, pantorrillas, estribo, espuelas, buelta». Si preguntamos a un grammático: “¿Con qué instrys a un niño?». Responde: "Con açotes». - "¿Y a un mochacho?». — "Con açotes». "¿Y a una monja?» — «Con açótes». Miren aquí, a qué bestiales encomendamos nuestros hijos»(6).

La fama le llegó con El latino de repente, manual que, siguiendo las pautas de las Elegancias de Valla y Paulo Manucio, a partir de una palabra latina, proporciona al alumno una serie de frases construidas con esa palabra y sus posibles traducciones. Todo ello denota la preocupación por enseñar y es en este objetivo donde se insertan las siete obras que se le conocen, aunque sólo se conservan, y de manera fragmentaria, un Dialogus, cinco comedias (Sigonia, Thalassina, Octavia, Lobenia y Trebiana) y una fábula, la Fabella Aenaria, que es la única que ha llegado hasta nosotros en su integridad.

Como ocurre con Anchieta y Juan Bonifacio, son obras escritas en latín, valenciá y castellano con fragmentos incluso en griego, italiano y portugués; "piezas retóricas de su propia cosecha en las que el latín se mezclaba con el castellano, la prosa con el verso» - dice el profesor Maestre Maestre —.

(4) A. Gallego Barnes, «Un plan de estudios para las escuelas de Alcañiz en la segunda mitad del siglo XVI: el razonamiento que hizo Palmyreno a los regidores de su patria de la orden de enseñar y las reglas que Lorenzo Palmyreno puso a la puerta de su auditorion, Boletín del Centro de Estudios Bajoaragoneses 1 (1981), p. 80.

(5) Palmireno, El estudioso de la aldea compuesto por Juan Lorenzo Palmireno, Valencia, en casa de Ioan Mey, 1568, p. 95 (Madrid, BN, R/7920).

(6) A. Gallego Barnes, art. cit. pp. 83-84. 
Buen exponente del teatro contemporáneo, deja de lado la preocupación erudita para acercarse a los postulados de sus contemporáneos Timoneda y Lope de Rueda, en formas y gustos, que son los de su época; pero sobre todo en la casi obsesiva convicción de que el teatro era el mejor medio de enseñar frente al rigor de las aulas convencionales. "La finalidad - señala el profesor Luis Gil - era familiarizar a los estudiantes en el uso hablado de la lengua latina, la de quitarles el temor a hablar en público y conferirles la necesaria soltura en la actio, es decir, en la manera de adecuar los gestos a la declamación. Se trataba también de apartar a la juventud con honestos entretenimientos de vicios como el juego y de adoctrinarla con mensajes morales y religiosos" ${ }^{(7)}$.

Esta nueva forma de concebir el teatro, en abierta discrepancia con el teatro de los jesuitas, más moral que pedagógico, con el teatro exclusivamente en verso y con el teatro que mantenía las tres unidades clásicas, naturalmente provocó la reacción de no pocos detractores. Por eso, en el prefacio de su comedia Lobenia, tal como recuerda el propio Palmireno en la «última parte de la retórica, en que trata de la memoria y de la actio», sale al paso de las críticas de sus colegas con las siguientes palabras:

«Muchos me acusarán por descender a estas niñeces y tratar cosas poco importantes en fábulas milesias... Pero de ejercicios como éste, en mi modesta opinión, emanan no pocas ventajas: los niños ejercitan la memoria, no están ociosos, corrigen la actio, como rústicos que son, se olvidan de la vergüenza de actuar en público y, sin darse cuenta, como que no hace la cosa, guardan en la memoria las expresiones de Cicerón que previamente les expliqué»(8).

Palmireno se refiere a una de las reglas que puso a la puerta de su auditorio y que se publicaron al final de su Segunda parte del latino de repente, en que hacía alusión a la importancia del teatro como actividad

(7) Luis Gil Fernández, «El humanismo valenciano del siglo XVI», en J. Mª Maestre Maestre, J. Pascual Barea y L. Charlo Brea (eds.), Humanismo y pervivencia del mundo clásico. Homenaje al profesor Antonio Fontán, III.1, Alcañiz-Madrid, 2002, p. 129.

(8) Palmireno, Lobenia, Praefatio. 
lúdica, pero sumamente provechosa, especialmente cuando las condiciones climatológicas de Valencia eran demasiado duras:

"Al tiempo que los días crecen y el calor es pesado, no sólo les compongo comedia para que reciten y se recreen, más aún, les doy modo como ellos mismos saquen Diálogo de dos Epístolas ad Atticum» (9).

Las críticas de Domingo Andrés, a quien sustituyó en la Academia de Alcañiz, fueron especialmente ácidas; pensamos que más por despecho que por convicción. Éste, en la línea doctrinal de la Contrarreforma y de los jesuitas, había escrito contra una representación del Eunuco y del Formión los siguientes versos:

Turpiter, insulse, temere, imprudenter, inepte,

Incaute, inculte, ridicule, insipide,

Intempestive atque omni incondita lepore

Non acta Eunuchus, dilacerata fuit.

Et Pudor et Musae et Charites liquere thetarum,

Avertit vultus casta Diana suos;

Virgineae rubuere genae, rubuere seniles.

opposuit fronti femina virque manum.

Dejando, pues, de lado estas críticas, que responden más a diferentes formas de entender la enseñanza y el drama, y a la consabida oposición a cualquier novedad didáctica, aunque sólo sea inicialmente, de las palabras de Palmireno que citábamos hace un momento, deducimos al menos cuatro ventajas de las representaciones dramáticas.

En primer lugar, los alumnos se igualan en su condición social y pierden el complejo de rusticitas. En el reparto de papeles no se tiene en cuenta la condición social. Séneca en sendas cartas a Lucilio (la 76,31, y la 80,7) y más tarde Poggio Bracciolini en su Oratio ad reverendissimos patres ponen

(9) Palmireno, Segunda parte del latino de repente. Valentiae, excudebat Petrus a Huete, 1573. Madrid, BN, R/308. 
de manifiesto esta ventaja en el tópico que supone la vida como el gran teatro del mundo:

«Cuando en la representación de una obra ven a uno que anda con paso majestuoso, que pronuncia palabras solemnes, grandilocuentes, soberbias y dignas de un rey; cuando lo ven dando órdenes a su séquito, y con el cetro en la mano, inmediatamente se creen, sin saber lo equivocados que están, que lo que están viendo es un rey. Pero quítenle el ornato, el atavío de sus ropajes y la máscara que lleva, y te aseguro que lo que queda es un esclavo y acaso el más necio de todos»(10).

En segundo lugar, no están ociosos (a lusu revocantur). Les recuerdo que la representación de Aenaria se abre con el grupo de estudiantes jugando a los naipes, bebiendo y haciéndose acompañar de músicos. Sobra decir, que parecidos fines siguen teniendo vigencia en la enseñanza actual y que todos hemos sido actores ocasionales en nuestros estudios de bachillerato o universitarios, manteniendo una vieja tradición que propiciaba, e incluso exigía estatutariamente estas representaciones ${ }^{(11)}$.

En tercer lugar, ejercitan y corrigen la actio y la memoria, tan necesarias en profesiones para las que se están formando, tales como la abogacía, la enseñanza y la administración. No en vano, una vez dejadas las aulas, los alumnos de Palmireno están llamados a formar parte de la cada vez más pujante clase intelectual que nutre la floreciente Alcañiz y sobre todo Valencia.

Y por último, aprenden la doctrina de los clásicos, previamente impartida en el aula (phrases quas in orationibus M. Tulli me praelegente obseruarunt). Al menos en este punto hay coincidencia con los jesuitas, aunque, como es natural, discrepan en el canon de autores selectos, salvando sólo los diálogos filosóficos y retóricos del Arpinate, "para hablar con elegancia»(12).

(10) Oratio, ed. de Ricardo Fubini, en Umanesimo e secolarizzazione. De Petrarca a Valla. Roma, 1990, p. 323.

(11) Cf. E. Esperabé de Arteaga, Historia de la Universidad de Salamanca, Salamanca, Imprenta de Francisco Núñez, 1914-1917.

(12) A propósito de Os Estrangeiros de Sá de Miranda, señala certeramente Thomas F. Earle: "The achievement of amplificatio by the accumulation of sententiae, memorable and impressive quotations which illustrate and develop moral or psychological truths. The technique was 
A todo ello habría que añadir una quinta ventaja, la que se deduce del tema de la comedia en cada caso, la enseñanza moral, ventaja a la que no es ajeno su contemporáneo Pedro Simón Abril, como pone de manifiesto en su "Prólogo al lector» en las Seis comedias de Terencio, en clara alusión a la censura de Juan Bonifacio, para quien Terencio era reprobable «porque mezcló el veneno con la miel para que la juventud bebiese con más gusto el tósigo mortal». En estos términos se expresa el rétor valenciano:

"Aunque algunos buenos y píos ánimos tienen por perjudicial la comedia para leerla a los mancebos, porque se representan allí algunas liviandades de mozo... es cierto de preciar mucho su buen ánimo y piadoso celo, pero la cosa no tiene en sí esa falta, si el que la declara es hombre discreto y que la entiende; antes bien, de allí sacará muy vivas razones y ejemplos para inducir a los oyentes al aborrecimiento del vicio, pues les podrá mostrar por la experiencia cuan acosados trae el vicio a los vanillos mozos, cuán perjudiciales son para las haciendas los deleites y cuán mezclados andan con mil descubrimientos y enojos, a cuán pesados amos sirven los que se van tras sus deseos y cómo no gozan de un punto de la verdadera vida y libertad»(13).

Y también Poggio Bracciolini en su De varietate fortunae:

«Ensoberbecidos por los favores recibidos, los poderosos suelen despreciar la virtud, y no temen salir al escenario del teatro de la Fortuna para mostrar al pueblo las mejores imágenes de su buena suerte. Pero la Fortuna, haciendo valer sus derechos, primero hace bajar del pedestal a sus favoritos y luego descubre su necedad"(14).

Pero lo que aquí nos interesa no es tanto la difusión de doctrina moral, cuanto la importancia de la actio y de la memoria, como partes de la retórica, y la ventaja que a tal fin tienen las representaciones dramáticas.

known to ancient rhetoricians and is discussed by Quintilian amongst others. In consequence, it had an important place in the educational practice of the Renaissance». Thomas F. Earle, "Rhetoric and drama: The two versions of Sá de Miranda's Os Estrangeiros", en Nigel Griffin et alii (eds.), Culture and Society in Habsburg Spain, Tamesis, London, 2001, p. 37.

(13) Pedro Simón Abril, Seis comedias de Terencio. Prólogo, Zaragoza, 1577; ed. de L. de Cañigral, Pedro Simón Abril. Textos de humanismo y didáctica, Albacete, 1988.

(14) Poggio Bracciolini, De varietate Fortunae, ed. R. Fubini, Roma, 1990, p. 2. 
El hecho en sí no es más que el reflejo de las enseñanzas de las nuevas retóricas, especialmente la de Luis Vives, sin duda el humanista de más influjo en lo que podríamos llamar la Escuela Valenciana, con insignes representantes de la talla de Fadrique Furió Ceriol, Sebastián Fox Morcillo, Alfonso García Matamoros, Pedro Juan Núñez, Andrés Sempere y nuestro Juan Lorenzo Palmireno.

Vives en el libro IV de su De causis corruptarum artium a propósito de la comedia completamente en latín o griego dice que difícilmente se entiende "porque siendo muertas aquellas lenguas sólo se conservan en los libros». Y en el libro II De causis corruptae eloquentiae declara que las obras dramáticas de su tiempo son superiores por el interés del argumento y por la utilidad moral, a las de los antiguos griegos y romanos: In argumento potiores sunt hoc tempore vulgares fabulae quam antiquae latinae et graecae.

Como hará más tarde Cervantes, Vives es partidario de introducir personajes alegóricos y, en cuanto a la lengua, se ve con buenos ojos la presencia de latinajos cuando éstos sirven para caracterizar a los personajes, como ocurre con el Clérigo y Cruz en El Rufián dichoso.

Pues bien, la importancia que tienen las representaciones dramáticas desde el punto de vista de la enseñanza de la Retórica, tal como propone Vives, aparece claramente en las obras de Palmireno y más concretamente en la Fabella Aenaria, tal como puso de manifiesto Menéndez Pelayo en sus Ideas estéticas en España:

"Nadie busca hoy la Retórica de Palmyreno por su doctrina, sino por varias curiosidades que contiene, de las cuales la mayor son ciertos fragmentos de comedias hechas para ser representadas por sus discípulos, curiosa muestra del teatro escolar del siglo XVI»(15).

Como sucederá más tarde en el Brocense, para Palmireno sólo la elocutio y la actio son puramente retóricas, la inventio y la dispositio corresponden

(15) M. Pelayo, Historia de las ideas estéticas en España, IX, Teoría literaria de los siglos XVI y XVII, Madrid, C.S.I.C., 1994, vol. I, p. 655. 
a la dialéctica y la memoria es una facultad humana que trasciende los límites estrictos de la retórica. En otras palabras, la actio y la elocutio son los dos componentes que más hay que cuidar y nada mejor que el teatro para satisfacer esta necesidad.

La elocutio, sólo es útil si se hace inteligible a los espectadores y de poco sirven las complejas reglas de las retóricas clásicas respecto al ornato; por lo tanto, el mejor medio de llegar a los espectadores es hacerlo en lengua vernácula (castellano o valenciano), sirviéndose sólo del latín accesible al común de los espectadores y adaptando siempre la lengua a los personajes. La práctica totalidad de humanistas alzan su voz contra quienes prescriben la obligatoriedad de enseñar las lenguas clásicas en la misma lengua objeto de estudio, como se desprende del siguiente pasaje de Luis Vives:

«Hablen primero en su propia lengua materna, en la que a su vez también el maestro debe corregir los posibles errores; después, vayan hablando poco a poco en latín. Aprenderán lo que hayan podido oír de su maestro o de sus lecturas, para que así en la escuela se vayan mezclando la lengua materna y la latina...»(16).

La conciencia de que el latín estaba en franco retroceso es compartida por la práctica totalidad de humanistas; incluso alguien tan partidario de conservar las formas de la poética clásica, como el padre Juan Bonifacio, reconoce, a propósito de la lengua, que el latín ya sólo servía "para engañar un par de labradores» y que «en el tiempo en que vivía / el Séneca cordobés / no querían entremés / que latín bien se sabía».

En cuanto a la actio, dada la imposibilidad de presenciar y comprobar la doctrina en una representación del siglo XVI, seguiremos las indicaciones dadas por el propio Palmireno, autor y director de sus obras.

(16) Loquentur primum sua lingua, quae illis est nata, in qua si quid peccent emendabit praeceptor; dehinc paulatim latine. Admiscebunt ea quae de praeceptore hauserint vel si ipsi legerint, ut inter primordia mixtus sit sermo in schola ex patrio et latino... (J. L. Vives, De disciplinis libri XX, excudebat Antuerpiae Michael Hillenius, 1531, fol. 100v. Madrid, BN $\mathrm{R} / 30562$ ). 
Veámoslo en la fabella Aenaria.

La fabella Aenaria, publicada en febrero de 1574 dentro de las Phrases Ciceronis. Hypotiposes clarissimorum virorum. Oratio Palmyreni post reditum. Eiusdem Fabella Aenaria, Valentiae, ex officina Petri a Huete, 1574 (BNM$\mathrm{R} / 17209$ ), trata los consabidos temas del amor entre dos jóvenes, el cambio de fortuna y la anagnórisis, a los que se suman temas más actuales como el del honor y la venganza(17).

Como novedad destacada en comparación con el teatro convencional, Palmireno aumenta el número de personajes: llegó a introducir 29 actores a los que se suma el propio autor. Tan excesivo número obedece a dos razones; la primera, de índole pedagógica: la práctica totalidad de sus alumnos intervienen en la representación o entre bambalinas; la segunda razón tiene que ver con la moda imperante en la que figuran personajes nuevos como el galán, el bobo, el estudiante y sobre todo, personajes femeninos muy activos.

La implicación Teatro-Retórica es el hilo recurrente a lo largo de la obra y da la impresión de que a Palmireno le importa más esto que la propia trama y el desenlace. Un buen ejemplo de ello lo tenemos ya en el Prefacio en boca de tres estudiantes: Daniel, de familia burguesa conversa, Guillem, el estudiante por antonomasia, que tras repetir varios cursos, es el mejor conocedor del maestro, y Jeroni, antiguo alumno de los Jesuitas en Gandía.

El primero de ellos simboliza la concepción estoica de la vida como una representación dramática, al margen del papel que a cada uno se le asigna:

"Os pensáis que porque vivo en la calle del Mar a mí se me puede desplumar como si fuera el bobo de una farsa de Timoneda».

(17) Para las citas del texto que sigue hemos adoptado la edición de Juli Leal, J. M Maestre, Josep Lluis Sirera, Juan Lorenzo Palmireno ensaya "la fabella Aenaria" con sus alumnos del Studi general de Valencia. Dramaturgia de Juli Leal y Josep Lluís Sirera a partir de la edición realizada por J. M Maestre Maestre. Valencia, Servicio de Publicaciones de la Universidad de Valencia-Instituto de Estudios Humanísticos, 2000. 
El segundo (Guillem), a la pregunta de Arnau, músico a su servicio, sobre los años que lleva acabando sus estudios (perficiens non perficiendo), responde:

"Ego, sequutus laudabile hoc divini philosophi exemplum, praelectiones meas aetate hac ingrauescente praefationibus quotidianis exorno, nibil veritus criticorum iudicia... Palmirenus dixit».

En realidad, Guillem lleva cinco años interpretando los prefacios de Palmireno y por eso habla por boca del maestro:

"Muchos hay en el Studi General que se alegrarían de que su deseo de hacer del teatro un medio para la enseñanza del latín y de la Retórica fracasasen".

El tercero, rebotado de los jesuitas de Gandía, critica la desproporción económica entre la enseñanza de sus antiguos preceptores, que se podían permitir ensayos durante todo un curso, y la enseñanza pública del Studi General, con ensayos escasos de sólo unos días, lo que da pie a Guillem y otros estudiantes a recordar la discriminación que padece la enseñanza civil frente a la de los jesuitas, así como la importancia del teatro para ejercitar la memoria, conmover al auditorio (motus animi) y encontrar los argumentos de la inventio y la peroratio:

«Jeroni - Es lo que yo digo. En Gandía los padres nos hacían ensayar muchas semanas seguidas.

Guillem - Eso es porque los estudios de los jesuitas tienen más ingresos que los públicos.

Ricard - ¿Sabes cuáles son las primeras normas para un buen comediante?

Marc - Saberse de memoria el papel.

Ricard - Satis non est.

Daniel - Ya está. Animi motus tibi quaerendus est.

Jeroni - ¿Una motivación...? ¿Y eso, qué es?

Guillem - Yo te lo explico, que tengo experiencia: verás, cuando salgas al escenario has de preguntarte de dónde vienes y para qué vienes... Lo demás, sigue solo. 

Gaspar - Imagínate que tienes que hacer de árbol. Piensa: tus pies son raices, tus brazos son las ramas...
Lluisot - Y los frutos ... son...»(18).

Al final de la escena segunda el propio Palmireno vuelve a recordar la importancia del teatro. Más allá de la práctica retórica o de las representaciones de los clásicos, su comedia es un buen medio de preparación para la vida diaria y para ejercitar la memoria, como pone de manifiesto con la introducción del Eco para formar palabras encadenadas ${ }^{(19)}$ y con la presencia de Jeroni, el interlocutor crítico procedente de los jesuitas:

"¿Y por qué no me demuestras tu interés en este momento tan difícil? Sabes que me juego el premio. Quizá mi futuro. Mi vida. Y yo os enseño que la práctica teatral os ayuda a ejercitaros en la vida cotidiana».

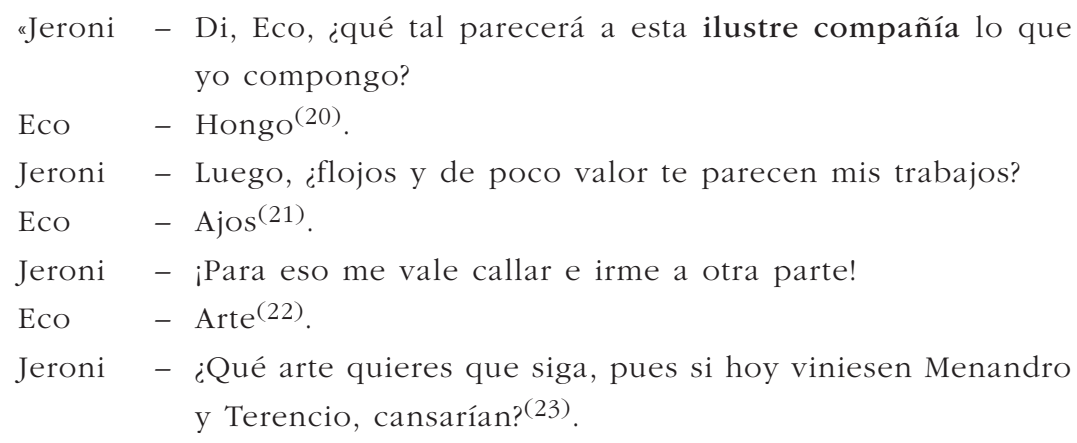

(18) La alusión al aprendizaje per locos et imagines lleva implícita también una buena dosis de erotismo.

(19) Entendemos que la introducción de este personaje alegórico cumple una función crítica contra el aprendizaje memorístico que reproduce palabras sin sentido; más o menos lo que hacían quienes recitaban de memoria el Doctrinale o el Antonio sin saber ni entender lo que decían.

(20) El fungus latino es «tonto» en Plauto, y es también una excrescencia de la carne y del olivo.

(21) Es decir, «huele mal», o también «es uno más».

(22) Sobra ver en este término la alusión al Arte reformado de Nebrija, que como recuerda el perro Berganza en El coloquio de los perros de Cervantes «... Era tiempo de invierno, cuando campean en Sevilla los molletes y mantequillas, de quien era tan bien servido, que más de dos Antonios se empeñaron o vendieron para que yo almorzase...».

(23) Sólo unos años después, Lope de Vega, en la Égloga a Claudio, vv. 40-44, escribiría: 
Eco - Rían.

Jeroni - ¿Cómo quieren que rían, si la buena comedia no obliga a decir gracias? ¿Cómo me echas tan cruelmente en la boca del lobo?

Eco - Bobo.

Jeroni - El bobo siempre es más escuchado, pero ¿cómo lo harán o representarán niños, pues ni la edad ni el cuerpo les ayuda en alguna cosa?

Eco - Osa.

Jeroni - Osar donde no se espera suceso, parece dislate de modorro; por tanto, dame alguna cosa con que tan sabia congregación contente.

Eco - Tente $^{(24)}$

Jeroni - No está en mi mano, porque me lo han mandado, y detenerme no puedo; desviarme no me es concedido; creo que será más fácil camino ayuntar el lenguaje latino con el castellano.

Eco y Palmireno - Llano ${ }^{(25)}$

Palmireno - Pues esto te parece llano seguiré tu consejo, consolándome que, si es fría mi comedia, no es ese mi oficio, y que por divertir a mis discípulos del naipe en estas vacaciones, les he ejercitado la acción y voz en esto, que es ni comedia ni farsa, sino entretenimiento. Y porque me quitaron la joya de terciopelo carmesí, hará seis meses, diciendo que toda mi obra iba latina, pongo en esta mucho romance. No sé si habré acertado.

Jeroni - Pues claro que habéis acertado, maestro. Toda la nobleza valenciana valora vuestro saber. Y los estudiantes admiramos vuestros métodos didácticos. No hay en España mejores estudiantes de Retórica que los que salen de vuestra clase».

"Y cuando he de escribir una comedia encierro los preceptos con seis llaves: saco a Terencio y Plauto de mi estudio para que voces no me den...». sús)".

(24) Pensemos en el juego de palabras: "Abstente de contentar a la Compañía (de Je-

(25) Es decir, mucho mejor el lenguaje llano, al alcance de todos, que los latines que pocos entienden. 
El fragmento es particularmente ilustrativo de la nueva función dramática por los siguientes aspectos:

En primer lugar muestra a las claras la enconada resistencia de la enseñanza en los centros civiles frente a la creciente implantación de los jesuitas. No olvidemos que éstos fundaron en Gandía, en 1546, su primer colegio y que cuarenta años más tarde había ya nada menos que 45. Certeramente señala el profesor Luis Gil que "Allí donde se establecían los jesuitas, hacían una competencia ruinosa a las universidades"(26). Cuando fueron expulsados por Carlos III, sólo se habían salvado de la quema Salamanca y Alcalá. El caso de Portugal es semejante: en 1555 el Real Colegio de las Artes de Coimbra pasa a manos de los jesuitas y Juan III prescribe la obligación de representaciones dramáticas con fines pedagógicos ya desde 1548, fecha de creación del Colegio al frente de André de Gouveia, como parte integrante de la Ratio Studiorum para la enseñanza de la Retórica y el adoctrinamiento moral ${ }^{(27)}$.

En segundo lugar, rompe con la tradición dramática del siglo en los medios escolares. El siglo XV había sido el siglo del descubrimiento de la comedia latina, especialmente desde que en 1429 Niccolo Cusano encontró el códice Orsiniano con las doce comedias desconocidas de Plauto y en 1433 Aurispa hizo lo propio con el comentario de Donato a las comedias de Terencio. Por esta razón, en el siglo XVI los comediógrafos latinos son ampliamente difundidos, incluso en traducciones de las que dábamos cuenta al comienzo de la exposición.

Pero el caso de España es diferente, sobre todo desde que triunfa el espíritu de la Contrarreforma y el modelo educativo de la Compañía de Jesús. Sirvan dos datos: primero San Ignacio ordenó en 1553 que se suprimiera en

(26) Luis Gil, Estudios de Humanismo y tradición clásica, Editorial de la Universidad Complutense, Madrid, 1984, p. 63.

(27) Para saber de la importancia que las representaciones dramáticas tienen en la ratio de los jesuitas, remito al excelente prefacio de A. Martins Melo, Teatro Jesuítico em Portugal no sécolo XVI. A tragicomédia Iosephus do Padre Luís da Cruz, S.I. Fundação Calouste Gulbenkian, Braga, 2004, pp. 9-14. 
los colegios de la Compañía la lectura de Vives, Erasmo y Terencio; poco después, el famoso padre Juan Bonifacio, como buen serrano salmantino (San Martín del Castañar, 1538-1606), de convicciones firmes, en la Christiani pueri institutio, sale al paso de los que, desde la Universidad de Valladolid, se le habían quejado del abandono de Terencio porque, en opinión de éstos, el comediógrafo latino era una buena fuente para leer latín y los argumentos de sus obras no eran objetables desde el punto de vista moral; alegaban, entre otras cosas, que «los niños no reparan en cosas de amores». Pues bien, el buen padre Bonifacio responde en los siguientes términos:

"Los muchachos, sobre todo los españoles, no son tan ingeniosos y tan precoces que puedan imitar desde luego el estilo de Plauto o idear una comedia digna del Menandro latino».

"La impureza está adherida a las cunas de los niños y nace con ellos del vientre de sus madres. ¿Por qué, pues, no tomar toda suerte de precauciones?».

«La Compañía arroja de su casa todos aquellos autores, cuya doctrina es sospechosa, o cuyo lenguaje es lascivo, para que no se manche la pureza ni reciba menoscabo alguno la religión. Por eso no pueden entrar en nuestras casas Erasmo ni Terencio, porque el primero parece poco sincero en la fe, y el segundo es enemigo tanto más peligroso de la castidad cuanto mayor es el número de sus partidarios»(28).

El resultado fue nefasto incluso allí donde se opuso una resistencia más seria a la corriente reaccionaria, como ocurrió en las universidades de Salamanca, Alcalá y Valencia: los clásicos fueron revisados, unas veces mediante adaptaciones (en los Menecmos de Juan de Timoneda la acción se sitúa en Sevilla), otras rompiendo con las tres unidades, y con frecuencia se mezclaron el latín con el vernáculo, aunque salvando siempre el tufillo del mundo clásico y reivindicando el valor educativo de las representaciones, como ocurre en la Aenaria:

(28) F. G. Olmedo, S.I., Juan Bonifacio (1536-1606) y la Cultura literaria del Siglo de Oro, Santander, 1938, pp. 157-160. 
«Si es fría mi comedia no es esse mi officio y que por divertir a mis discípulos del naype, les he exercitado la action y boz en esto». (Prefacio).

«Manifesté ya en otro tiempo, cuando era joven, cuán útiles eran estos ejercicios escolares para embellecer el discurso con una pronunciación elegante. Hoy sigo pensando exactamente igual, pero el encomendar esta misión a un anciano, dico esse boui clitellas imponere. O sea: digo que esto es como poner albardas al buey». (Prefacio).

«Y yo os enseño que la práctica teatral os ayuda a ejercitaros en la vida cotidiana» (Escena II).

La acción de Aenaria transcurre en tiempos de Vespasiano y en varios escenarios geográficos: Julio Sabino, insurrecto en la Galia, hace creer a todos que ha muerto, se esconde en el campo y allí es visitado a hurtadillas por su esposa Epónima. Como es natural, con tanto ir y venir queda embarazada de gemelos (Petronio y Lauredana), que con el transcurrir del tiempo se hacen buenos guerreros y salen en busca de su hermano Alberto, enamorado de Aenaria, princesa de Dinamarca, por la descripción que le habían hecho de su belleza. Alberto se encuentra en prisión por haber dado muerte al noble Tarvisio, que a su vez había violado a Gibelina.

Por su afición a la cetrería, Aenaria se enamora de Alberto, lo saca de la cárcel y, al no poderle quitar los grilletes, lo lleva a hombros huyendo de su padre que ha puesto a todo el reino tras sus pasos.

Vulpino, montero del rey, encuentra a la pareja y quiere violar a Aenaria, pero, es engañada por ésta, que le quita la espada y pide a Alberto que lo mate. Dos caballeros que pasan accidentalmente por el lugar descubren al muerto y, siguiendo el código de caballería, quieren vengarlo. Retan a Alberto y descubren que es el hermano al que buscan.

El rey perdona a la pareja si uno de los dos caballeros vence al contrincante señalado por la corte danesa; caso contrario serán descuartizados los dos enamorados que están encerrados en el castillo de ¡Xàtiva!. Lauredana vence y todos son felices. 
La trama está repleta de excursus, síntoma evidente del valor de las declamaciones retóricas, especialmente relativas a loci amoeni, la vida rústica, las cárceles de África, historias marginales, como la violación de Gibelina que recuerda a la de Lucrecia, pero también relatos caballerescos y romances, como el de la Serrana (la Chata) del libro del Buen Amor que se echa a la espalda al Arcipreste para pasar los arroyos.

Pero, para concluir, me parece de justicia recordar dos valores más del teatro renacentista, el del léxico y los recursos cómicos a él asociados:

Aenaria es un nombre parlante, "aena", "de bronce», porque es una mujer de armas tomar.

Lauredana es la "guerrera laureada", no en vano tras ella hay toda una heroína que combate y vence en duelo.

Vulpinus es astuto como un zorro, aunque termine mal.

Pantálabo, es el estudiante que no hace ascos a nada...

Ecelino, criado de Lauredana y Petronio es "quien cuida en exceso" de sus amos.

Las descripciones, o écfrasis, sirven para enseñar todo un repertorio de términos propios de un campo semántico; así ocurre en la descripción del naufragio, tópico épico y novelístico. Ecelino en la escena I, describe así el naufragio y la caída en manos de los piratas:

Nam inusitata et plane fatali ventorum coniuratione adeo mare commotum intumuit, $u t$ toto littore iactatae naves; deinde, fervente aestu in altum abreptae, mergerentur. Mox elapsi magna difficultate et labore ex isto naufragio in eos, quos dixi, Vulcani ministros incidimus.

[...] In sylvis delitui ne inexorabili rabie barbarus ille me flammis absumeret. Errabam in nemore, cum magno casu a praedonibus Massilensium captus sum, et, post durissimos maritimi cursus errores in Galliam devectus, fuga mibi salutem comparavi.

El léxico de la incertidumbre aparece de manera magistral en la descripción del estado de ánimo de Vulpino:

In hac vita omnia sunt incerta, anxia, brevia, turbulenta, suspicionibus plena, solaque mors non dubia cervicibus imminet (Escena VIII). 
Y como recursos cómicos tenemos:

Los juegos de palabras a los que aludíamos con motivo de las palabras encadenadas, "ayuntar el lenguaje latino con el castellano" y el valenciá y el italiano.

La parodia virgiliana del libro II de la Eneida, verso 3, en que compara la dificultad de un actor (Fumanus) con la de Eneas cuando ha de rememorar en la corte de Dido la caída de Troya (Infandum, regina, iubes renovare dolorem).

La parodia de la lógica y dialéctica medievales a cargo de Soleta para probar la inexistencia de cosas nuevas: «En el mundo no hay cosa nueva. Yo soy el bachiller Soleta y este señor es el bachiller Pantálabo, y él mismo sabe que le probaré que en el mundo no hay cosa nueva: cosa nueva se dice la que nunca fue tal como ella, mas no hay en mundo cosa que no haya sido tal como ella, ergo sequitur que no hay cosa nueva en el mundo. En baroco, en baroco, mi señora. Item, si alguno pudiese hacer alguna cosa nueva buena, seguirse hía que el que la hiciese sería más sabio que los antiguos. Y esto es imposible, ergo sequitur, domine doctor, a., b., c., d.» (Escena IV).

La crítica a la mala pedagogía: "dígoos que los estudiantes de todas las Facultades dejan las licciones por oír las farsas».

Los resabios anticlericales, sobre los que no es preciso insistir.

La alusión a la Valencia contemporánea, verdadera captatio del público, pero con reminiscencias virgilianas:

Videsne quam sint omnia mutata in melius? Iam nulla est cura de patria; bic sedes quietas invenimus: Alberto duce, Alberto vivente, omnia fausta et laeta succedent. In hac urbe erit verae virtutis domicilium perpetuique splendoris hospitale diversorium cunctis gentibus patebit: invehentur buc omnes artes Italiae et cultus ille ex humanitate aulica promanans. Huius gentis mores ad arma et latrocinia natae ita mutabit Albertus, ut regnum ex plumbeo aurum detersaque rubigine splendidum redditum esse fateamur. (Escena XII). 
Y por último, el elogio final de la importancia del teatro compartida por actores y director:

Guillem - Pues claro... Esa es la magia del teatro. Nos hace parecer cultos a los que no dominamos ni la tercera declinación...

Alonso - Y a quienes son de humilde origen, nos hace nacer en palacio.

Daniel - Y lo fingido hace parecer verdadero...

Lluisot - E ilusorio lo que de puertas afuera no es sino la pura verdad.

Palmireno - Tenéis razón. Esa es la fuerza del teatro. Y gracias a ella, sin darse cuenta, se aprende más que en muchas clases...

... Ne mihi vitio vertat benignus spectator non servatas esse comoediae leges, quandoquidem farsas Hispanicas, non Terentii gravitatem, in gratiam vulgi imitatus sum.

... Este saludo de los alumnos de esta mi primera clase de retórica es en honor vuestro. 
Sebastião Tavares de Pinho

Universidade de Coimbra

\section{BUCOLISMO NO TEATRO NOVILATINO PORTUGUÊS}

Uma das características da poesia bucólica clássica, reconhecida desde longa tradição, é a sua "vis dramatica", a sua capacidade de ser representada em palco, como aconteceu em particular com as Éclogas de Virgílio, a fonte mais abundante e mais directa do bucolismo moderno.

São conhecidos os testemunhos dos primeiros biógrafos do Mantuano, entre os quais se destaca o conhecido Sérvio Mário Honorato, que no comentário à obra virgiliana distingue as Bucólicas das Geórgias e da Eneida, classificando as primeiras como um género «humilde em razão do conteúdo e das personagens, uma vez que estas são, aqui, personagens campestres: bumile, pro qualitate negotiorum et personarum, nam personae bic rusticae sunt. E o mesmo comentador acentua a preocupação do Virgílio bucólico em respeitar a verosimilhança, como os dramaturgos, levando a pensar que as suas éclogas são afinal modelos de poesia comparáveis a uma espécie de mimos lírico-dramáticos. É ainda o mesmo Sérvio que, no comentário à Bucólica VI, dá notícia de ela ter sido lida em público pelo próprio Virgílio com grande aplauso dos espectadores, e também cantada no teatro pela meretriz Citéris na presença e para espanto de Cícero, que quis saber quem era aquele jovem autor. Do mesmo modo, na Vita do biógrafo Donato, se recorda que Virgílio tivera tal sucesso com a edição das Bucólicas, que estas eram, até, frequentemente apresentadas em cena por cantores (Bucolica eo successu edidit, ut in scaena quoque per cantores crebro pronuntiarentur), 
testemunho confirmado quase ipsis verbis também por Filargírio na sua biografia de Virgílio.

Não admira que a poesia bucólica virgiliana tivesse sido posta em cena mais ou menos teatral, porquanto a sua feição dramática manifesta-se, à evidência, em muitos dos principais aspectos da sua composição. Entre eles ressaltam a dimensão de espaço e tempo, os cenários e o décor ambiental; a coreografia do movimento e da música com seus ritmos diversos em função do variado sistema estrófico, por vezes acompanhado de refrão; a estrutura dialógica externa, no caso do canto à desgarrada — o famoso canto amebeu - e mesmo no diálogo interno, manifesto nos monólogos; bem como as justas e certames poéticos entre os pastores, no cenário dinâmico de um tribunal; e enfim o ambiente rústico e todas as formas do seu travesti que definem a poesia lírica pastoril e que se enquadram no vasto campo do disfarce, igualmente presente nas várias modalidades do teatro.

Compreende-se, pois, a razão por que o teatro moderno recorreu com frequência ao disfarce da roupagem pastoril para dar corpo dramático a muitas das suas peças. Isso verifica-se, como é sabido, em grande parte das literaturas europeias de língua vernácula.

Era, também, natural que a inclusão da poesia pastoril se tivesse verificado no teatro neolatino em geral e, muito em particular e de uma forma sistemática, na produção dramática jesuítica, designadamente em Portugal. Em primeiro lugar pelo carácter dramatúrgico do bucolismo greco-latino, sobretudo o virgiliano, como vimos, e em segundo lugar porque os dramaturgos portugueses de línguas vernáculas também desde há décadas o praticavam de uma forma assumida e com grande efeito cénico. O caso de Gil Vicente é paradigmático, pois, de entre as suas 40 peças, 17 são textos de estrutura basicamente pastoril ou incluem figuras de pastores ou pastoras. Quanto ao teatro desenvolvido pelos jesuítas, nos seus colégios, especialmente em Coimbra, convém recordar que o público desta cidade estava afeito ao teatro vicentino, porquanto algumas das suas peças foram aqui representadas, por exemplo em 1526 e 1527. E algumas tiveram mesmo 
por objecto principal do seu conteúdo a própria cidade universitária, haja em vista, por exemplo, a Comédia sobre a divisa da cidade de Coimbra.

O teatro neolatino surge em Portugal, como é sabido, com a reorganização dos estudos clássicos à sombra da Universidade Portuguesa, reformada e definitivamente estabelecida em Coimbra em 1537, e em particular com a fundação, em 1548, do Real Colégio das Artes aqui instituído, cujo corpo docente incluía dramaturgos já consagrados vindos do Colégio da Guiena, em Bordéus, a convite e na companhia do seu director André de Gouveia, que veio exercer as mesmas funções no novo colégio coimbrão. Entre eles contavam-se os nomes do francês Guillaume de Guérente e do escocês Jorge Buchanan, cujas tragédias latinas haviam feito grande sucesso em Bordéus e impressionaram o jovem aluno Montaigne, segundo o seu testemunho deixado no capítulo XXV do Livro I dos seus Essais, quando afirma, começando por citar, curiosamente, um verso da Bucólica VIII de Virgílio:

"Alter ab undecimo tum me uix ceperat annus, j'ai soutenu les premiers personnages ez tragédies latines de Bucanan, de Guerente et de Muret, qui se représentaient en notre collège de Guienne avec dignité. En cela, Andreas Goveanus, notre principal, comme en toutes autres parties de sa charge, fut sans comparaison le plus grand principal de France [...].

Este passo, por um lado, revela a prática habitual e o interesse que o teatro tinha na pedagogia das instituições de formação e ensino do século XVI, e, por outra parte, destaca o grande prestígio do humanista português, André de Gouveia, que logo depois veio a ser encarregado por D. João III de organizar o grande colégio público e de fundação régia em Coimbra, o Real Colégio das Artes, do qual foi o primeiro director ou principal, como então se dizia.

Mas não sabemos se o teatro daqueles dois dramaturgos - Guérente e Buchanan - que com ele vieram para Coimbra terá sido, depois, representado também aqui, durante a sua permanência como professores do Colégio das Artes. Temos, porém, o exemplo do português seu compa- 
nheiro e seguidor, Diogo de Teive, a quem se deve uma notável actividade dramatúrgica de mestre, autor e encenador, da qual se conservou, pelo menos, a conhecida Tragoedia, Quae inscribitur, Ioannes Princeps (a Tragédia intitulada Príncipe João), cujos 450 anos se pretendem evocar com a realização deste colóquio.

Desta obra e do título e assunto das peças bíblicas teivianas que se perderam — David e Judith —, parece podermos concluir que a poesia bucólica não terá sido contemplada na sua estrutura. A ser assim, teremos de esperar pelo trabalho pedagógico dos Jesuítas, que pouco depois se instalaram nos meios culturais portugueses, especialmente em Coimbra, Lisboa e Évora, para detectarmos a presença do teatro neolatino pastoril em Portugal.

Como fontes de informação temos basicamente a correspondência epistolar e os relatórios da época, os estudos modernos já realizados e muito em particular os textos manuscritos da produção dramática jesuítica. Neste domínio, os responsáveis pela formação intelectual, pedagógica, científica e literária dos colégios da Companhia, instalados em Portugal desde 1542, tiveram a laudabilíssima preocupação de copiar e guardar em arquivo a produção literária dos seus mestres e colaboradores composta por ocasião e motivo de variadas circunstâncias e actividades, como a abertura do ano escolar, a concessão de graus, a atribuição de prémios, as celebrações festivas sobretudo da Rainha Santa Isabel (no caso do Colégio de Coimbra), a visita de alguma notável personalidade e outros acontecimentos sociais ou académicos.

No caso do primeiro colégio dos jesuítas, em Coimbra, e do Colégio das Artes, que a partir de 1555 passou também para a sua direcção, grande parte de tal produção ficou sistemática e sucessivamente arquivada, dando origem a pelo menos seis grossos códices manuscritos de que se conhecem até agora os tomos I e II, e V e VI, e que ostentam o título quase comum de Rerum scholasticarum, quae a patribus, ac fratribus huius Conimbricensis Collegii scriptae sunt, Tomus primus, e Rerum scholasticarum quae a patribus ac fratribus buius Conimbricensis Colegii scriptae sunt, Tomus 
$2^{u s}$, ou Rerum scholasticarum quae a Patribus huius Conimbricensis Colegii scriptae sunt, Tomus quintus; ou, ainda, Thesaurus rerum scholasticarum, quae a Patribus, ac Fratribus Collegii Conimbricensis scriptae sunt, ab Anno Domini 1631. Tomus $6^{u s}$.

São sobretudo estes códices e também algumas cópias miscelânicas relativas quer aos referidos colégios de Coimbra, quer de Lisboa ou de Évora, que contêm a principal informação manuscrita sobre o conteúdo da produção literária neolatina (e mesmo grega e hebraica) dos jesuítas em Portugal. Tal produção abrange as áreas da poesia, em variados modelos, da oratória em grandes orações de sapiência ou em simples oratiunculae de curta dimensão, bem como do teatro, tanto em peças de ampla estrutura, como sob a forma de pequenas declamações, em monólogos ou em diálogos.

É aqui que encontramos o teatro bucólico neolatino de que pretendemos falar. Este aparece umas vezes disfarçado em textos que não se apresentam como formalmente pastoris mas que têm conteúdo bucólico no seu todo ou em parte; outras vezes trata-se de peças de modelo assumidamente pastoril, confirmado com o título de Ecloga.

As primeiras notícias da representação de uma peça teatral com esse título aparece, tanto quanto sabemos, numa carta quadrimestral do Padre Frutuoso André datada de 31 de Dezembro de 1555 com um relatório acerca da cerimónia inaugural do Colégio de Évora em 1 de Outubro daquele ano, precisamente na data em que em Coimbra a mesma Companhia de Jesus assumia a direcção do Real Colégio das Artes, passando assim a dirigir não apenas o seu colégio particular de Coimbra e primeiro da Companhia mas também o maior colégio público do País.

Na descrição da cerimónia de Évora, o P. Frutuoso fala dos muitos discursos académicos ornamentados com as variadas cores da literatura, da composição de epigramas escritos por mestres e alunos e dedicados à Virgem e a outros santos, bem como ao cardeal-infante D. Henrique, num total de cerca de 1.800 versos, afixados nas colunas e paredes; e também da representação de um certo diálogo escrito em prosa, cheia de humor e 
elegância e que causou nos ouvintes o maior deleite. À tarde «Foi representada uma écloga composta em hexâmetros, de conteúdo adequado e claro, e mesmo em versos de grande beleza e musicalidade e adornada com abundância de sábios conceitos, de tal maneira que, dado o modo como foi representada pela actuação e declamação dos garotos, é inacreditável o enorme prazer que ela a todos causou" (Post hanc, ecloga quaedam acta est, carminibus bexametris conscripta, facilis et perspicua, et ipso carminibus sonitu admodum uenusta atque multis sapientibus sententiis ornata, quae puerorum actione et pronuntiatione quodam modo expressa incredibile est quantum omnibus placuerit). O relator acrescenta ainda que o cardeal-infante D. Henrique, ao ter conhecimento do facto, manifestou o desejo de a ver, e que por isso ela foi representada poucos dias depois na sua presença ( $D e$ ea igitur cum Princeps Cardinalis certior factus esset, eam se cupere audire dixit; quapropter paucis post diebus coram eo acta est) ${ }^{(1)}$.

Igual notícia se pode colher de uma carta quadrimestral do P. Diogo de Barros a respeito do Colégio de Santo Antão de Lisboa, onde, por ordem do Prefeito de Estudos, o mestre da segunda classe compôs uma écloga de Natal e a fez representar pelos seus alunos no Dia da Circuncisão, isto é, a 1 de Janeiro, no ano de 1557. A descrição do conteúdo confirma que se trata de um auto pastoril, pois nele intervêm como actores Maria e José, um anjo e quatro pastores. Tal como no caso anterior de Évora, também aqui o êxito desta Bucólica foi tão grande e tão aplaudido por gente letrada, da nobreza e da corte, que, a pedido do rei D. João III, ela foi pouco depois reposta em cena no próprio paço diante e para admiração da família real(2).

Temos ainda conhecimento de outras bucólicas neolatinas, representadas por motivo da distribuição de prémios escolares, designadamente em Évora

(1) Vd. Monumenta Historica Societatis Iesu, Litt. Quadr. IV, p. 771. Cfr. Jesús Menéndez Peláez, Los Jesuitas y el Teatro en el Siglo de Oro, Oviedo, Universidad de Oviedo, Servicio de Publicaciones, 1995 , p. 504.

(2) Vd. Monumenta Historica Societatis Iesu, Litt. Quadr. V, p. 15. Cfr. Jesús Menéndez Peláez, op. cit., p. 506, e Maria Margarida Lopes de Miranda, Miguel Venegas S. I. e o Nascimento da Tragédia Jesuítica. A Tragoedia cui nomen inditum Achabus (1562). Edição crítica, tradução, comentário e notas, Coimbra, 2002, p. 31 (tese dactilografada). 
(1561), em Braga (1564), em Bragança (1571), entre outras. Mas em todos estes casos, como nos dois anteriores de Évora e Lisboa, dos quais existe apenas alguma notícia acerca do tema ou das circunstâncias de representação, tudo o resto - título, conteúdo e texto - continua desconhecido.

Todavia, para a apreciação objectiva do teatro pastoril neolatino em Portugal temos felizmente o abundante acervo dos códices manuscritos atrás referidos, onde podemos encontrar mais de uma dezena de obras dramáticas que ostentam, mais ou menos formalmente, a sua marca bucólica.

Entre as de maior dimensão e de estrutura mais orgânica, incluindo a divisão em actos, encontram-se a Egloga quae inscribitur Gerion da autoria de Lucas Pereira e representada em Coimbra em 1612; a écloga Marsyas, de João da Rocha, talvez encenada também em Coimbra, cerca de 1616; o David Pastor, de Domingos Teixeira, em 1618 em Coimbra; a «Declamatio» Dares et Entellus, de Pedro de Vasconcelos, Coimbra, 1629; e Eustachius Venator, de André Fernandes, representada em Évora em 1635. O estudo destas cinco peças é fundamental para a apreciação do bucolismo no teatro neolatino em Portugal. Mas não o vamos fazer aqui, sem sequer sumariamente, porquanto já foram estudadas por Claude-Henri Frèches num extenso capítulo da sua tese sobre o teatro neolatino em Portugal(3) e porque sobre elas já tive também ocasião de falar em outra ocasião ${ }^{(4)}$. Aqui tratarei apenas de outras composições dramáticas igualmente bucólicas mas de menor dimensão e que ainda não foram objecto de um estudo em particular.

Um dos primeiros exemplos é a de Manuel Pimenta que foi posta em cena em Coimbra em 1564 e que tem por título simplesmente Dialogus in praemia, que a identifica como sendo destinada à cerimónia de entrega de prémios académicos. Apesar de não se intitular como "Écloga», ao contrário do que acontece com outros exemplos que veremos, a inspiração do

(3) Vd. Le théâtre néo-latin au Portugal (1550-1745), Paris-Lisbonne, 1964, pp. 447-498.

(4) Vd. Sebastião Tavares de Pinho, "Literatura humanística inédita do Colégio das Artes da Universidade de Coimbra no século XVI", in Universidade(s), História, Memórias, Perspectivas, Actas do Congresso "História da Universidade» no $7^{\circ}$ Centenário da sua Fundação, Coimbra, 1991, vol. 4, pp. 67-86, e «O Colégio das Artes da Universidade de Coimbra, agente da tradição clássica no início do século XVII», Biblos 68 (Coimbra, 1992) 49-76. 
bucolismo clássico manifesta-se desde logo pela presença de conhecidos pastores virgilianos no elenco dos seus actores, como "Palaemon", ou forjados na onomástica do Mantuano, como «Maenalus». Trata-se de um diálogo de 444 versos, sendo os primeiros doze em dísticos elegíacos, equivalentes ao Prólogo, e todo o resto em hexâmetros dactílicos, em que intervêm os interlocutores Faburnus, Maenalus, Ortalus, Lycota, Palaemon e Megadorus, num certame de rivalidades poéticas e num curioso processo dinâmico de progressão dialógica crescente: primeiro o despique verifica-se entre Faburno e Ménalo (vv. 15-199); depois entre Licota e Órtalo (vv. 200-267); a seguir rivalizam estes quatro em simultâneo (vv. 268-378); depois (vv. 379-425) junta-se-lhes o juiz Palémon, o mesmo que na Bucólica III de Virgílio preside ao concurso entre Menalcas e Dametas; por fim cantam todos juntamente com Megadoro, a conhecida figura plautina, que aqui também serve para acentuar a ideia de que este poema do jesuíta Manuel Pimenta tem estrutura intencionalmente dramática.

Além dos nomes de pastores, são muitas as outras marcas de evocação virgiliana que percorrem este Diálogo no campo da linguagem, das imagens e de outros variados estilemas. E nem falta, a terminar, o quadro do entardecer (vv. 440-444), que recolhe elementos das Bucólicas I, 83; II, 67 e III, 108-111, do Mantuano:

Levantai-vos rapazes: já nos montes se prolongam as sombras Já o Héspero orvalhado mostra seus ardentes luzeiros.

Fechai agora, meus rapazes, fechai agora os touros nos currais. A mim cabe-me, no tempo da bruma, pôr termo às disputas. Vivei felizes, vivei e conservai-nos na vossa lembrança.

Pimenta, 440-44:

Surgite iam, pueri, duplicant montibus umbrae

Hesperus ardentes ostendit rosidus ignis.

Claudite iam, pueri, stabulis iam claudite tauros.

Ipse ego brumali compono tempore lites

Viuite felices, memores et uiuite nostri. 
Virgílio,

B. I, 83:

Maioresque cadunt altis de montibus umbrae.

B. II, 67:

Et sol crescentis decedens duplicat umbras.

B. III,108-111:

Non nostrum inter uos tantas componere lites;

Et uitula tu dignus et hic, et quisquis amores

Aut metuet dulces, aut experietur amaros.

Claudite iam riuos, pueri: sat prata biberunt.

E para prova de que se trata de uma bucólica levada ao tablado teatral, temos as próprias palavras do clássico Prólogo, que ocupa os primeiros 14 versos, compostos em dísticos elegíacos, para o distinguir do diálogo da peça propriamente dita, toda escrita em hexâmetros, e que, no exercício da sua tradicional função, assim adverte o auditório, personificado nos padres-mestres e nos jovens estudantes do Colégio de Coimbra:

Augusta grauitate, patres, conuertite mentes,

Atque Castaliis gnaua iumenta choris,

Non ueniet fuso lacrimosa tragoedia uelo,

Callida nec uafris comica turba Getis.

Carmina bucolico pecudum canet ore magister,

Vitat inhumani rusticus ora lupi.

Illum Musa leuat terra sublimis, at ille

Exuit hirsutis pectora uelleribus.

Ortalus urbanae memorat mala commoda uitae,

Sedulus agrestes laudat arator opes,

Gramine considet Iudex frondente Palaemon,

Pastor inaequali dum canit ore modos.

Rustica iam ueniet pubes; aduertite undique

Auraque tentatum fausta secundet iter.

Prestai atenção, padres, com augusta gravidade,

E vós, ó juventude industriosa nos coros de Castália.

Não é a lacrimosa tragédia que, de vela solta, vai aparecer aqui,

Nem a malta cómica treinada nas malandrices getas. 
Aqui o maioral dos rebanhos entoará canções com sua bucólica voz,

O camponês foge da boca do desumano lobo.

Àquele, a excelsa Musa o levanta do chão; e este

Desnuda seu peito dos hirsutos velos.

Órtalo relembra as maléficas comodidades da vida urbana,

O dedicado lavrador louva os recursos do campo.

No frondente relvado toma assento o juiz Palémon

Enquanto o pastor entoa seus versos em voz alternada.

Em breve chegará a juventude campestre. Reparai à vossa volta,

E que uma aura propícia favoreça o caminho já tentado.

No mesmo ano de 1564 e também em Coimbra, é encenada uma peça da autoria do P. Júlio Fácio ${ }^{(5)}$, que se assume como uma verdadeira bucólica, porquanto ostenta o título de «Ecloga de Nataliciis Domini». É uma composição já de maiores dimensões, com 713 versos, e que apresenta uma divisão orgânica em três partes, equivalentes a três actos de uma normal estrutura dramática. Conta com um variado elenco de «interlocutores», que inclui a Sybilla Cumaea, que faz de Prologus; Meliandrus pastor senex, Corillus puer eius filius, Floricus adolescens, Axillus puer, Phylomelus grandis natu, Faustulus adolescens, Zephyreus grandis natu, Lycota iumenis, todos pastores; um Angelus nuntius, juntamente com o Chorus Angelorum e um

\section{Chorus Prophetarum.}

Não é apenas o título desta composição e a personificação de pastores assumida pela grande maioria destes interlocutores que lhe concedem um carácter bucólico. É sobretudo o conteúdo ideológico e formal do seu texto que o confirma, pelo uso dos mesmos recursos literários da poesia bucólica clássica, sobretudo virgiliana. É a referência à vida dos pastores e à paisagem e flora do seu ambiente, expressos em vocabulário, sintagmas e estilemas característicos da literatura pastoril.

Intervém em primeiro lugar a Sibila de Cumas, que expõe num Prólogo de 53 hexâmetros a ideia central desta bucólica, anunciando o nascimento

(5) Sobre este jesuíta (Fácio? Fassio? ou Fazio), vd. Francisco Rodrigues, S. J., História da Companbia de Jesus na Assistência de Portugal, Porto, 1931, Tomo I, Volume I, p. 521, nota 1. 
de um salvador, que virá restabelecer a nova ordem de um novo século de felicidade e paz, glosando e adaptando aos conceitos cristãos o conteúdo e as formas literárias do bucolismo do Mantuano em geral, e sobretudo o texto e a mensagem da sua famosa Bucólica Messiânica. O autor não hesita em chamar "Saturnia regna" à nova idade regenerada pela vinda de Cristo, nem em designar o Menino-Deus da era cristã como a «cara descendência do Tonante», num contexto (vv. 19-26) directamente decalcado naquela Écloga IV virgiliana:

Scilicet haec aetas, haec sunt Saturnia regna,

Qua quondam populis cecini uentura futuris.

Ter felix nobis aetas, qua cara Tonantis

Progenies caelo tandem demissa supremo

Adueniet nostris finem latura ruinis,

Qua duce Tartareis serpens imbuta uenenis

Occidet, et ueteris subito contagia culpae

Irrita, praeclusi reserabunt limen Olympi.

É claro que é esta a idade, são estes os reinos de Saturno

Que outrora anunciei que haviam de vir para os povos futuros.

Três vezes feliz para nós a idade em que a cara progénie

Do Tonante, finalmente enviada do Céu supremo,

Há-de chegar para pôr fim à nossa ruína,

E sob cujo império a serpente embebida nos venenos do Tártaro,

há-de cair morta, e, subitamente, os contágios da antiga culpa, anulados, hão-de abrir as portas do encerrado Olimpo.

A primeira parte da peça (Pars Prima, vv. 54-221) contém o diálogo dos pastores Meliandro, Corilo e Flórico, que desenvolvem o tema anunciado no prólogo sibilino, glosando e adaptando à circunstância da moderna celebração cristã, muito do conteúdo dos diálogos dos pastores de Virgílio, designadamente o confronto das suas preferências sobre os dons da natureza, a troca de presentes e o despique da sua qualidade. O diálogo é entrecortado de partes cantadas por todos em simultâneo. 
Na segunda parte (vv. 222-469) intervêm, além do velho pastor Meliandro, os outros pastores Filomelo, Zefireu, Fáustulo e Axilo, em texto umas vezes declamado, outras cantado, quer em diálogo, quer em monólogo, onde continuam os tópicos do bucolismo clássico em que não falta a evocação de outros pastores como Menalcas e Amintas. Um dos temas desenvolvidos é o da exaltação da modesta vida do campo em contraste com a complexidade do bulício urbano, expressa num longo e belo canto alternado que Meliandro, o pastor mais velho, convida os mais jovens a entoar enquanto ele os acompanha com sua flauta e cujo sentido se resume neste refrão sucessivamente repetido (vv. 295-324):

O felix pastor uicinae nescius urbis, O felix paucis pastorum uita capellis.

Oh, feliz o pastor que não conhece a vizinha cidade!

Oh, feliz a vida dos pastores com um pequeno rebanho de cabras!

Meliandro dá por findo este tema, ordenando a seus companheiros:

Cantatum satis est, alio iam uertite mentes

Nam defessa meo delabitur ore cicuta.

Basta de cantar, voltai agora vossas mentes para outro lado, Que a minha flauta, cansada, já da boca me descai.

A terminar a Secunda Pars intervém o Coro dos Profetas em versos glicónios (glosando o poema litúrgico "Rorate caeli desuper, etc." segundo a didascália do manuscrito), seguido do Anjo mensageiro, que anuncia o nascimento de Cristo, e do Coro da Anjos em versos anapestos e adónios, em contraste com todo o resto da estrutura métrica dactílica desta Écloga.

Na terceira e última parte (vv. 470-705) intervêm todos os oito pastores num diálogo em que expressam a sua alegria pela notícia do nascimento do Deus-Menino, naquela noite em que uma estranha luz veio iluminar as trevas. A convite do velho Meliandro todos os oito pastores se dirigem em cortejo para o presépio, cantando um poema compassado por este refrão: 
Visite siderei cunabula, visite, Regis

Ferteque uimineis redolentia dona canistris.

Venham ver, venham, o berço do Rei sideral,

E trazei-lhe dons perfumados, em vossas cestas de vime.

Chegados ao presépio preparam-se para adorar o Deus-Infante, declamando cada um o seu hino pessoal e apresentando-lhe suas oferendas. Tal como acontece com o pastor Menalcas da Bucólica V, 4, de Virgílio, também aqui é dada prioridade a Meliandro por ser o mais velho, conforme adverte o jovem pastor Licota:

Tu Meliandre graui cum sis maturior aeuo Accede, et puero senior da munera primus

Tu, Meliandro, pois que és mais maduro em idade e ponderação, Avança e, como mais velho, sê o primeiro a oferecer teus presentes [ao Menino.

Os pastores desdobram-se em rivalizar com seus cantos, em que se cruzam altos pensamentos teológicos dos pastores mais velhos sobre o mistério da incarnação com expressões de poética e ingénua graciosidade, como esta com que o pequenino pastor Axilo se dirige ao Menino-Deus:

O mihi formosis infans formosior agnis,

Pulcrior haediculis, dulcique iucundior uua.

Ó infante para mim mais formoso que os formosos cordeiros, Mais belo que os cabritinhos e mais jucundo que a doce uva.

A écloga termina com um típico quadro do anoitecer, de sabor virgiliano, (... iam proxima uagas nox duplicat umbras) seguido de um cântico final entoado e acompanhado pela flauta de dois tubos de Meliandro e pela dança dos restantes pastores, que fecha com a exaltação da vida pastoril e campestre e da nova idade regenerada pela incarnação do Verbo, comparável à mítica idade de ouro dos tempos de Saturno: 
En amat in siluis infans habitare remotis.

Nemo mibi urbanas nunc, o nunc, iactet honores!

Rustica simplicitas, tenuisque triumphat egestas.

Nemo mibi urbanas nunc, o nunc, iactet honores!

Hic uiget alma quies, uiget hic secura uoluptas.

O felix aetas, felicia gaudia ruris!

o felix aetas rutilo formosior auro!

Eis que o Menino deseja habitar nas florestas remotas.

Ninguém me venha agora, oh! agora, com honras urbanas.

Triunfa a rústica simplicidade e a frugal privação.

Ninguém me venha agora, oh! agora, com honras urbanas.

Aqui reina a pura tranquilidade, reina o sossegado prazer.

Ninguém me venha agora, oh! agora, com honras urbanas.

Ó feliz idade, felizes alegrias do campo,

Ó feliz idade mais formosa que o ouro esplendoroso.

Pelo ano de 1567, de novo Manuel Pimenta escreve outra composição pastoril, igualmente representada em Coimbra, a que dá o nome de Aepolus

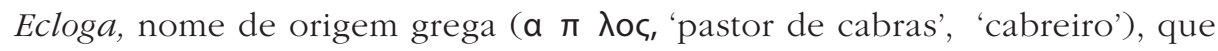
evoca o bucolismo siciliano de Teócrito. Trata-se de um diálogo compacto de cerca de 550 hexâmetros, precedido de um prólogo de 13 dísticos elegíacos, no qual cinco pastores confrontam seus amores, paixões, rivalidades e sonhos sob o disfarce da vida e das preocupações da pastorícia, para gáudio e divertimento dos espectadores. O prólogo é encarnado pela figura do Rumor, o Boato, cuja autodescrição com que ele se apresenta acumula várias reminiscências virgilianas do desenho da Fama, do canto quarto da Eneida. Diz o Rumor de Manuel Pimenta:

Si quis centum oculos cinctum fulgentibus Argum

Me putat, aspectu fallitur ille meo,

Nexa uidet quicumque meis talaria plantis,

Me si Mercurium credulus esse putat.

Rumor ego Hesperiis, et Rumor notus Eois,

Rumor ad hibernos cognitus usque Getas;

Tot mibi sunt aures, tot in omni corpore plumae,

Lumina pro pluma uersicolore latent. 
Se alguém me julga um Argo, de cem olhos fulgurantes

Cingido, esse co'a minha aparência se engana,

E quem quer que veja meus artelhos atados nas plantas dos pés,

Se credulamente julga que eu sou Mercúrio.

Eu sou o Rumor conhecido nas Hespérias, conhecido nas Auroras,

O Rumor reconhecido até pelos Getas hibernais.

Tenho tantos ouvidos quantas, em todo o corpo, as penas;

Por detrás da pluma versicolor estão escondidos meus olhos.

As outras personagens, que são os verdadeiros interlocutores, têm nomes de origem ou formação grega, como Aepolus, Comatas, Galanther, Battus e Aegon, como acontece com os pastores de Virgílio, mas com a particularidade de que, quase todos eles, com excepção de Aegon, não figuram no elenco do Mantuano, mas sim nos Idílios de Teócrito. Isto leva a concluir que o jesuíta Manuel Pimenta se terá inspirado muito provavelmente também no bucolismo greco-siciliano.

Outra particularidade desta Bucólica é a sua integração na cultura e no espaço português, porquanto os pastores, no seu longo canto amebeu de permanente disfarce, acabam por localizá-lo não apenas na dimensão topográfica da tradição greco-latina, mas no espaço e no tempo real e contemporâneo portugueses. A Arcádia geográfica de Teócrito ou a idealizada por Virgílio nas margens do Míncio, ou as regiões da mais antiga tradição clássica, dão lugar aos campos do Mondego, às lezírias do Ribatejo, às águas do Minho e às terras escarpadas do Douro, por exemplo quando o pastor Bato, fazendo eco e adaptação da Bucólica IV de Virgílio, assim responde a Épolo, ocupado nos elogios da fertilidade dos campos de Tróia e da riqueza do seu rei, num texto que é ao mesmo tempo a exaltação de Coimbra como centro de formação e cultura do Portugal de Quinhentos:

Aepole, magna canis, sed nos maiora canemus.

Cantas grandiosa matéria, Épolo, mas nós cantaremos ainda maior.

Monda ubi per campos, et roscida prata uolutus

Argutos inter uolucrum certamine cantus

Perspicuas ducit lucenti gurgite lymphas,

Ardua Castaliae posuere sedilia Musae. 
Vndique discipulos uocat in sua tecta Minerua,

Conueniunt populi uaris e partibus orbis.

Auriferi trans alta Tagi quae flumina gentes

Pinguibus aspiciunt florentia messibus arua,

Quique Tagum, Miniumque bibunt, Duriumque sonorum

Inter inaccessas uoluentem flumina rupes.

Ciuis Vlyssaea properat generosus ab urbe.

Ver ubi purpureum florentia protulit ora

Continuo pubes armis accincta Mineruae

Pieriis certamen init memorabile castris.

Lá onde o Mondego, voluteando pelos campos e prados orvalhados

Por entre o arguto canto dos pássaros em desafio,

Conduz suas águas transparentes em cintilante remoinho,

Colocaram as Musas de Castália seu altaneiro assento.

De toda a parte, para sua casa, chama seus discípulos Minerva,

Aí convergem os povos de variadas partes do orbe.

As gentes que, para lá das fundas correntes do aurífero Tejo,

Contemplam os campos florescentes de nutridas cearas,

E os que bebem as águas do mesmo Tejo, do Minho e do Douro sonoro

Que suas torrentes revolve por entre inacessíveis escarpas.

Apressa-se o nobre cidadão da Ulisseia Urbe.

Mal a primavera de púrpura ostenta seu rosto em flor

Logo a juventude, cingida co'as armas de Minerva,

Inicia o memorável combate dos acampamentos das Piérides.

Por vezes, os textos de carácter pastoril do teatro neolatino português são de muito menor dimensão e apresentam, naturalmente, também menor número de interlocutores, como acontece com a Ecloga in Natali Virginis Augustissimae, composta pelo jesuíta António de Morais provavelmente na viragem do século XVI para o XVII e que consta de um dos tomos dos supracitados manuscritos do Colégio de Coimbra(6).

(6) Vd. Arquivo Nacional da Torre do Tombo, Ms. 1963, Thesaurus rerum scholasticarum, quae a Patribus, ac Fratribus Collegii Conimbricensis scriptae sunt, ad Anno Domini 1631. Tomus $s^{u s}$, fls. 104v-105v. Sobre este códice, vd. o nosso recente estudo «Um códice latino da literatura jesuítica quase desconhecido: o Cód. 1963 da Livraria dos Manuscritos dos ANTT", Humanitas 57 (Coimbra, 2005) 351-382. 
Trata-se de uma composição de apenas 45 versos, com as personagens bíblicas de José — o jovem que viria a ser o pai putativo de Jesus - e do rei David, ambos na figura de pastores dialogando acerca do nascimento da Virgem Maria, numa junção anacrónica de gerações que denuncia desde logo o disfarce característico da poesia bucólica.

O enredo começa com um encontro casual entre os dois pegureiros, ao estilo bucólico virgiliano, quando, ao raiar da madrugada, o pastor José conduzia o seu rebanho para as pastagens paternas e lhe aparece o pastor David, que o saúda, e logo os dois se dirigem para as aprazíveis margens do rio Jordão (vv. 1-7). À pergunta de José sobre as últimas novidades da cidade, David traz a notícia do nascimento de uma filha de Joaquim, aquela que, oriunda do próprio ramo de David, viria a ser um dia a esposa do seu companheiro cénico (vv. 8-12). José recorda agora que, afinal, os seus cordeiros, "com seus trémulos balidos" (tremulis balatibus, v. 13), e todo o rebanho sentiram e anunciaram esse singular nascimento, revelando assim o carácter da sua predestinação divina; e convida o seu amigo a preparar as flautas e a iniciar um canto de desgarrada - o canto amebeu das Bucólicas de Virgílio - para tecer os louvores daquela santa Virgem (vv. 13-17). David responde (vv.18-23), apontando o novo astro que surgiu no céu - o astro da Virgem, que enche de alegria todo o ambiente da natureza pastoril e cuja formosura de corpo e alma superam o perfume das flores e a brancura da neve. A sua beleza vence a «áurea [estrela]», isto é, a própria Lua ou Febe, a irmã de Apolo, como reza a mitologia e os poetas repetem, entre os quais se conta Virgílio (vd. Geórgicas, 1, 431: "aurea Phoebe»), e como ela vem expressamente identificada (Phoebe) em nota marginal do manuscrito desta Écloga renascentista.

O pastor José continua o despique poético felicitando os pais que tal Filha geraram, invocando de forma implícita o famoso casal bíblico de São Joaquim (aliás explicitamente mencionado no começo do poema, v. 8) e Santa Ana, e convida o seu rival cantor a atapetar o chão com rosas, lírios 
e ramos de oliveira, para celebrar o anunciado nascimento desta "Áurea Virgem» (vv. 24-30).

David, o rei-pastor, reporta a figura desta Virgem às antigas profecias dos textos messiânicos, salientando a sua função medianeira no plano salvífico de Cristo e recorrendo, para isso, aos símbolos de salvação que acompanharam a história do povo judeu do Antigo Testamento: ela é a flor do tronco de Jessé, donde provém a genealogia de Jesus; é a cestinha que salvou Moisés nas águas do Nilo (vv. 31-35). José continua esta linguagem figurativa, fazendo identificar a mesma Virgem com o velo que apareceu a Gedeão como sinal de vitória sobre os madianitas; com a prodigiosa vara de Aarão que possibilitou a Moisés a libertação do seu povo do Egipto; com o arco íris que assinalou a aliança de Deus com Noé e seu povo após o Dilúvio; enfim, ela é a escada de Jacob e «a cândida nuvem em cujo manto de ouro se escondeu o próprio Deus» (vv. 35-40).

O carácter bucólico desta cena dialogada, que está, aliás, assumido no seu próprio título, é, ainda, confirmado pelo clássico quadro do entardecer com que ela termina e em que David evoca o lento declinar do sol e o inverso alongar as sombras que deslizam do alto dos montes, como acontece nas composições virgilianas (vv. 41-45).

É curioso notar que este diálogo constitui uma espécie de "Anunciação" no masculino, isto é, a notícia dada pelo rei David da chegada de uma virgem prenunciada pelos profetas e destinada ao matrimónio do futuro pai putativo de Jesus.

Finalmente, e à maneira também de algumas bucólicas do Mantuano, acresce a presença de refrães que se repetem ao longo do poema, marcam o ritmo musical e coreográfico do canto amebeu e acentuam algumas das ideias do seu conteúdo, designadamente a metáfora que faz identificar a Virgem Maria recém-nascida com uma nova Aurora de luz anunciadora do Cristianismo, como se pode ver no próprio texto, que a seguir transcrevemos na íntegra, acompanhado de uma proposta de tradução (o destaque, a negro, dos refrães é nosso): 


\section{AECLOGA IN NATALI VIRGINIS AVGVSTISSIMAE}

Pastores: Ioseph et Dauid

Cum patrias ductaret oues ad pascua Ioseph

Constitit obscuroque attolens lumina caelo,

"Exsere", ait, "nitidos, o Lucifer, exsere uultus".

Obuius huic Dauid dulcis - "Iosephe saltem,

5 Pastor, aue». - "Mi Dauid, aue. Quo tendis?"

DAVID

- Ad undas

Iordanis.

IOSEPH - Quam laetor! Aquas properamus ad undas.

Exsere iam nitidos, o Lucifer, exsere uultus.

Ecquid in Vrbe noui?

DAVID - Natam Ioachimus, auitae

Ille heres pietatis habet. Gratare roganti

10 Namque eodem de fonte fluit mibi sanguinis unda,

Grata unda.

IOSEPH - Optatos nimium tibi gratulor ortus.

Obrue nigrantes iam, Lucifer, obrue uultus.

Scilicet hoc nuper tremulis balatibus agni,

Hoc niuei sensere greges. Ergo illa per orbem

15 Exspectata uenit. Calamos aptemus, et almae

Virginis alterno modulemur carmine laudes.

Huc noua sidereas conuerte Aurora quadrigas.

DAVID - Ecce nouum caelo consurgit Virginis astrum,

Astrum quo pecudes gauderent fetibus, et quo

20 Grata coloratis redolerent floribus arua.

Forma index animi superat candore pruinas.

Nigra tibi collata forent tibi cederet aurea [Phoebe]

Obrue nigrantes iam, Lucifer, obrue uultus.

IOSEPH — Felices qui te talem genuere parentes,

25 Felix prole parens et felix tu quoque mater,

Num felix mater magis an pater inclitus ille?

Inclitus ille parens et felix tu quoque mater.

Huc noua sidereas conuerte Aurora quadrigas,

Sparge nouos flores et oliuis lilia mixta.

30 Alba rosa, o Dauid, nascitur aurea Virgo. 
DAVID - Hunc illum esse reor Iessaea ex arbore florem Quem super auratis requiescet Spiritus alis.

Haec illa est fiscella udo quae uimine texta Clausum Niliacis Mosem seruauit ab undis.

35 Obrue nigrantes iam, Lucifer, obrue uultus. IOSEPH - Ecce tuum uellus Gedeon, tua floribus Aron Virga nitens, cognosce tuae Noe Iridis arcum, En scalas Iacobe tuas, haec candida nubes Cuius in aurato Deus inuolutus amictu.

40 Huc noua sidereas conuerte Aurora quadrigas.

DAVID - Sed iam praecipitant altis de montibus umbrae. Coge pecus, Iosephe, ulmis dum Infantis honores Incido, accrescent ulmi, crescetis honores. Obrue nigrantes, o Lucifer, obrue uultus,

45 Aethereas posthac regat aurea uirgo quadrigas.

\section{ÉCLOGA NO NASCIMENTO DA VIRGEM AUGUSTÍSSIMA}

Pastores: JOSÉ e DAVID

Conduzia José as ovelhas aos pastos de seus pais, Quando parou e, erguendo os olhos à escuridão do céu, Diz: «Desvela, Estrela d'Alva, a tua luminosa face». Vindo ao seu encontro, o doce David lhe diz: — "Deus te salve

5 Pastor José». - «Eu te saúdo, amigo David. P’ra onde vais?» DA. - Para as águas

Do Jordão.

JO. - Quanta alegria! Vamos pressurosos às correntes das águas.

Desvela já, Estrela d'Alva, a tua luminosa face.

E que há de novo na Urbe?

DA. - Joaquim, o conhecido herdeiro

Da piedade avoenga, tem uma Filha. Congratula-te com tua pergunta,

10 Pois é da mesma fonte que flui a corrente do meu sangue, Uma grata corrente.

JO. - Muitíssimos parabéns pela tua invejável origem.

Acaba depressa, Estrela d'Alva, com a tua negra face.

Está claro que os cordeiros, com seus trémulos balidos, o sentiram; Sentiram-no os níveos rebanhos. Portanto, Ela chega esperada 
15 Através do orbe. Aprontemos as flautas e vamos tocar

Em canto alternado os louvores da santa Virgem.

Volve para aqui, ó nova Aurora, as tuas siderais quadrigas.

DA. - Eis que surge no céu o novo astro de uma Virgem,

Um astro tal, que com ele se alegram os gados com suas crias,

20 Com ele os campos exalam o perfume de suas coloridas flores.

Sua beleza, indicadora da alma, supera a candura da neve.

Tivessem sido negros teus dons, e ceder-te-ia o lugar a Áurea Estrela.

Acaba depressa, Estrela d'Alva, com a tua negra face.

JO. - Felizes dos pais que assim te geraram,

25 Feliz o pai com sua prole, e feliz também tu, ó mãe.

Acaso será mais feliz a mãe, ou aquele ínclito pai?

Feliz é aquele ínclito pai, e feliz também tu, ó mãe.

Volve para aqui, ó nova Aurora, as tuas siderais quadrigas.

Espalha, David, frescas flores e lírios misturados com ramos

30 De oliveira: como alva rosa nasce a Áurea Virgem.

DA. - Estou certo que esta é aquela flor do rebento de Jessé

Sobre a qual repousará o espírito de asas douradas.

Esta é aquela cestinha que, de vime molhado tecida,

Guardou e salvou Moisés das águas do Nilo.

35 Acaba depressa, Estrela d'Alva, com a tua negra face.

JO. - Eis o teu velo, Gedeão; eis, Aarão, a tua vara

De flores ornada; reconhece, Noé, o arco da tua Íris;

Eis, Jacob, a tua escada, esta é a cândida nuvem

Em cujo manto de ouro se escondeu o próprio Deus.

40 Volve para aqui, ó nova Aurora, as tuas siderais quadrigas.

DA. - Mas já, do alto dos montes, se precipitam as sombras.

Junta o rebanho, José; enquanto eu cravo nos olmeiros as honras

Da Infante, crescerão os olmeiros, e vós, honras, crescereis também.

Acaba depressa, Estrela d'Alva, com a tua negra face.

45 Que doravante a Áurea Virgem conduza suas etéreas quadrigas.

O bucolismo do teatro neolatino manifesta-se também, com frequência, de forma parcelar, em grandes peças, na medida em que estas contêm partes, mais ou menos amplas, com intervenção de figuras de pastores. Podemos citar, a título de exemplo, as duas obras dramáticas sobre a vida de São Paulino de Nola, contidas no Ms. 1963 do Arquivo Nacional da Torre do Tombo, já atrás referido. Uma ocupa as fls. 145r-171r e tem por título Tra- 
gicomoedia quae inscribitur Paulinus Nolae Episcopus, Conimbricae anno D[omini] 1604, e a sua autoria, registada à margem do texto manuscrito, é do jesuíta Afonso Mendes ${ }^{(7)}$, futuro patriarca da Etiópia. A outra preenche as fls. 58r-88r e, embora sem folha de rosto e por isso sem indicação de autor, poderá ser do mesmo Afonso Mendes, uma vez que trata do mesmo tema, apesar das suas grandes diferenças de texto e de estrutura.

Com efeito, no caso da Tragicomoedia, o acto IV apresenta um diálogo (fls. 160v-161v ) entre os pastores Damon, Montanus, Siluius, Glaucus e Hortulans; e, quanto à outra peça, uma boa parte do Acto V é preenchida com a actuação dos pastores Menalcas, Amintas, Meliboeus e do Pastor minimus Daphnius.

Com a apresentação e análise, ainda que sumária, destas éclogas podemos, pois, concluir reconhecendo que o bucolismo é um facto recorrente no teatro neolatino e lhe concede virtualidades acrescidas na sua função de docere et delectare. O carácter pastoril do teatro deleita e reforça a diversão, pelo exotismo e extravagância das suas personagens; favorece o veículo da crítica de costumes pela aparente ingenuidade e permanente ambiguidade. O poder instalado aceita mais facilmente a censura provinda da boca de um ingénuo pastor, porque ela parece diluir-se por detrás da sua suposta simplicidade e inocência. A feição pastoril deleita de modo particular pela variedade coreográfica da dança e da música vocal e instrumental que acompanha a poesia declamada ou cantada. Enfim, a pastorícia poética do bucolismo propicia ao teatro uma particular capacidade de docere, pela frugalidade e simplicidade de vida que simboliza.

(7) O nome de Baltasar Méndez citado como autor desta tragicomédia por Cayetano Alberto de la Barrera y Leiradi, no Catálogo bibliográfico y biográfico del teatro antigo español desde sus orígenes hasta mediados del siglo XVIII [1860], edic. facsímil, Madrid, Gredos, 1969, citado por Jesús Menéndez Peláez, Los Jesuitas y el Teatro en el Siglo de Oro, Universidad de Oviedo, 1995, p. 456, pode ser um problema de confusão de nomes. Sobre Afonso Mendes, vd. Diogo Barbosa Machado, Biblioteca Lusitana, Tomo I, Coimbra, ${ }^{2} 1965$, p. 41-45, e Baltasar Teles, História Geral da Etiópia a Alta, ou Preste João, e do que nela obraram os Padres da Companhia de Jesus [...], Coimbra, 1660, p. 696. 
António Maria Martins Melo

Universidade Católica Portuguesa

O ELEMENTO FEMININO NO TEATRO JESUÍTICO

EM PORTUGAL NO SÉCULO XVI

A Companhia de Jesus é uma ordem religiosa masculina, sem ramo feminino $^{(1)}$. Este facto, que os tempos têm confirmado, aliado a algumas deliberações de Inácio de Loiola, tem projectado sobre a Companhia uma imagem de misoginia. Para tal ideia, ocupa lugar de relevo a comparação do demónio à mulher, que o fundador apresenta nos Exercícios Espirituais, nas regras para o maior discernimento de espíritos: "O inimigo porta-se como uma mulher: fraco ante a resistência, e forte, ante a condescendência. Porque assim como é próprio da mulher, quando briga com um homem, perder ânimo e pôr-se em fuga, quando o homem lhe mostra rosto firme; e, pelo contrário, se o homem começa a fugir e perde a coragem, a ira, a vingança e a ferocidade da mulher é muito grande»(2). A importância deste pensamento deve-se à particularidade de este ser o livro fundacional da

(1) A única mulher jesuíta foi D. Joana de Áustria, filha de Carlos V de Espanha e de Isabel de Portugal. Casada com o malogrado príncipe D. João Manuel, filho de D. João III e de Catarina da Áustria, daria à luz o futuro rei D. Sebastião. Após decisão tomada em Outubro de 1554, Inácio de Loiola aceita admiti-la a "título experimental» e em segredo absoluto. Recordemos que já tinha havido a tentativa de Isabel Roser, natural de Barcelona, se transformar na primeira mulher jesuíta, pretensão negada pelo fundador da Companhia em missiva datada do primeiro dia do mês de Outubro de 1546. JEAn LACOUTure, Os Jesuítas - 1. A Conquista, tradução de Maria Fernanda Gonçalves Azevedo, Lisboa, 1993, pp. 187-215; HUGO RAHNER, Ignace de Loyola et les femmes de son temps, Paris, 1964, pp. 104-110.

(2) INÁCIO DE LOIOLA, Exercícios Espirituais, tradução do autógrafo espanhol por Vital Cordeiro Dias Pereira, S. J., organização e notas por F. de Sales Baptista, S. J., Braga, 31999 , pp. 167-168, n. ${ }^{\circ} 325$. 
Companhia. Nasceu de uma experiência mística vivida numa gruta em Manresa, junto ao rio Cardoner, em Agosto de 1522. A sua última redacção terá ocorrido quase vinte anos mais tarde, em 1541.

Embora tenha sido esta a visão a prevalecer na Ratio, é bom recordar que Inácio de Loiola trocou abundante correspondência não só com damas de estirpe nobre mas também com as de origem mais humilde. Desse universo nos dá conta a obra do Padre Hugo Rahner, Inácio de Loiola e as mulheres do seu tempo. Mas deste assunto ocupar-nos-emos mais tarde. De momento, e porque a nossa reflexão tem por objecto as realizações teatrais desenvolvidas pelos jesuítas nos seus colégios, em Portugal, durante o século XVI, uma actividade profundamente influenciada pelos autores clássicos latinos, afigura-se-nos prudente algumas palavras introdutórias acerca das primeiras manifestações desta reiterada repulsa mórbida do homem às mulheres.

Tema caro à literatura ocidental, é em Hesíodo que se encontra o seu primeiro testemunho. Com efeito, a história de Pandora, narrada na Teogonia (vv. 565-593) e nos Trabalhos e Dias (vv. 50-99), explica a origem do sofrimento de que a humanidade padece. Perspectiva semelhante se apresenta no fr. 7 de Semónides de Amorgos, datado provavelmente da primeira metade do século VII a. C., e conservado na Antologia de Estobeu (séc. V d. C.). Numa perspectiva de entretenimento, com sabor lúdico, este autor da poesia arcaica grega traça-nos dez retratos femininos, todos eles indesejáveis, excepto um: o da mulher da raça da abelha, ela que dá felicidade ao marido, sendo a única que não merece reprimenda(3). Na Comédia grega abundam os dislates contra as mulheres, nomeadamente em algumas comédias de Aristófanes: a Lisistrata, As mulheres que celebram as Tesmofórias ${ }^{(4)}$ ou em

(3) Vide Francisco ReBelo GONÇALVES, "Simónides de Amorgo, Sátira contra as Mulheres. Notícia literária, tradução do texto grego e comentário filológico", in: FRANCISCO REBELO GONÇALVES, Obra Completa, Vol. I, Lisboa, 1995, pp. 5-69, especialmente p. 41; MARIA FERNANDA BRASETE, "A crítica às mulheres no fr. 7 de Semónides de Amorgos" in: CARLOS DE Miguel MORA (coord.), Sátira, paródia e caricatura: da Antiguidade aos nossos dias, Aveiro, Universidade, 2003, pp. 39-56.

(4) Desta comédia se transcreve uma passagem exemplificativa (vv. 384-405), que tem a particularidade de transferir para a tragédia euripidiana o hábito de dizer mal das mulheres: 
As mulheres na Assembleia. Mas também na tragédia é possível encontrar indícios de espírito semelhante: Creonte, em face da argumentação de Hémon, seu filho, que faz a apologia de uma governação em sintonia com o povo e as leis divinas, para salvar Antígona, atira ao rosto de seu filho palavras ignominiosas que jamais algum homem grego esperaria ouvir: «Tu, que és escravo de uma mulher, não estejas com blandícias»(5).

A misoginia foi igualmente tema versado na literatura latina. Célebre havia de ficar o adágio virgiliano Varium et mutabile / Semper femina!...(6) Naturalmente, os humanistas do Renascimento dariam continuidade a este pensamento. Uma das obras mais representativas desta corrente de opinião é a Silua Nuptialis (1516), do jurista italiano João Nevizano, onde se inspirou Lopo Serrão, para escrever principalmente os Cantos VIII e XIII do seu Poema da Velbice ${ }^{(7)}$.

"Mas há já muito tempo que eu - pobre de mim! — fervo de nos ver enxovalhadas por Eurípides, esse filho de uma hortaliceira, e de ouvir toda a casta de injúrias. Haverá algum insulto com que esse tipo nos não tenha brindado? E calúnias? Seja onde for, desde que haja uma meia dúzia de espectadores, actores e coros, lá começa ele a chamar-nos levianas, doidas por homens, bêbadas, traidoras, tagarelas, uns zeros, a desgraça completa dos maridos. De tal maneira que eles, mal saem do teatro, põem-se a olhar para nós com desconfiança e logo a ver se descobrem algum amante escondido em casa. Já não podemos fazer nada do que fazíamos antes, tais foram as misérias que esse fulano ensinou aos nossos maridos. Assim se uma mulher entrelaça uma coroa, pensam que está apaixonada; se, na lida da casa, deixa cair qualquer coisa, o marido põe-se a perguntar: "Em quem estavas tu a pensar, quando deixaste cair a panela? No hóspede de Corinto, não pode deixar de ser"”. ARISTÓFANES, As mulheres que celebram as Tesmofórias, introdução, versão do grego e notas de Maria de Fátima de Sousa e Silva, Coimbra, ${ }^{2} 1988$, pp. $63-64$.

(5) V. 756: SÓFOCles, Antígona, introdução, versão do grego e notas de Maria Helena da Rocha Pereira, Coimbra, ${ }^{2} 1987$, p. 70 . Sintomática ainda a ausência da mulher nos trinta retratos definidos por Teofrasto nos Caracteres, a que correspondem outros tantos defeitos da natureza humana. MARIA DE FÁTIMA SILVA, "Dinheiro e sociedade (Teofrasto, Caracteres)», in: CARlos DE Miguel MORA (coord.), Sátira, paródia e caricatura ... cit., pp. 91-104, especialmente pág. 92. Ainda a propósito da misoginia helénica, vide ANTÓNIO FREIRE, Humanismo Clássico, Braga, ${ }^{2} 1996$, pp. 75-88.

(6) VIRGílio, Eneida, IV.569-570. Frases com pensamento idêntico podem ler-se em Catulo (Carmina, LXX), em Propércio (III.19), em Ovídio (Amores, III. 1-16; Arte de Amar, II.372-382) ou em Séneca (tragédia Fedra, vv. 559-564). A propósito da presença feminina na obra de Séneca, vide MARIA CRISTINA PIMENTEL, «Estoicismo e figuras femininas em Séneca», Brotéria, 158 (2004) 251-268.

(7) Vide Sebastião TAVARES De PINHO, O poema da Velhice de Lopo Serrão, introdução, texto e aparato crítico, tradução e notas, Coimbra, 1987, pp. 220-225. 
O humanista valenciano Luís Vives, no De institutione foeminae christianae, um tratado de educação feminina com grande difusão no século XVI, não se coibiu de escrever que a formação moral da mulher se alcança com um número reduzido de preceitos, pois é pertença exclusiva da mulher a pudicícia; recomendava, ainda, que a donzela se fizesse acompanhar sempre pela mãe, ainda que permanecesse em casa; aí deve estar recatada do mundo, conhecida de poucos, pois a vida em sociedade é ocasião permanente de maldades e crimes ${ }^{(8)}$.

Portugal assistia, impotente, a momentos de aguda crise familiar: a ausência prolongada do chefe de família, motivada pelo afã das descobertas, conduziu à dissolução de costumes. Houve manifestações de bigamia e elevou-se assustadoramente o número de meninos enjeitados e órfãos ${ }^{(9)}$. A Igreja portuguesa vivia afogada pelas preocupações mundanas, como denuncia André de Resende no sínodo eborense de $1534^{(10)}$; os sacerdotes

(8) Vide J. MANUEL RODRÍGUEZ PEREGRINA, «Mujer, humanismo y sociedad en la Granada del XVI», Florentia Iliberritana, 4-5 (1993-1994) 487-507, especialmente 488-489.

(9) Cf. Johquim Romero magalhães, "A Sociedade», in: História de Portugal, direcção de José Mattoso, Vol. III - «No Alvorecer da Modernidade (1480-1620)», Lisboa, 1993, especialmente pp. 469-475. A propósito, vide RENÉ P. GARAY, "Proto-feminismo no Auto da Índia de Gil Vicente», Brotéria, 158 (2004) 479-486.

(10) «Também a Igreja se prostitui quando, por empenhos, por dinheiro, por favores, por simpatia ou por qualquer defeito moral, mercadeja com gente indigna as funções sagradas, que não podem ser coisa venal, para já não falar em outras formas de prostituição que o mundo bem conhece e que, neste momento, melhor me parece silenciar»: SEBASTIÃO TAVARES DE PINHO, "André de Resende e o Cardeal-Infante D. Afonso: em torno do sermão pregado no sínodo de Évora de 1534”, Eborensia, 1-2 (1988) 66. Ao humanista eborense, religioso dominicano, há-de impor-se, contudo, um certo comedimento, deixando que seja a própria Igreja a corrigir tais abusos, como escreve no Aegidius Scallabitanus: «- Ou melhor — acrescentei -: para não caíres em erro, deves é dizer que "possui para cima de trinta»! Sobre estes assuntos, no entanto, é mais do que aconselhável não murmurar sequer. Esta situação abusiva aguarda a intervenção do braço sinodal, o que acontecerá em Trento - talvez até já tenham começado as sessões - sob a direcção do actual Pontífice Máximo, Júlio III, pois que esta questão tem sido objecto de repetidas queixas por parte de muitos doutoresn: VIRGínIA SOARES PEREIRA, Aegidius Scallabitanus. Um diálogo sobre Fr. Gil de Santarém, estudo introdutório, edição crítica, tradução e notas, Lisboa, 2000, p. 312. Para mais pormenores, vide SEBASTIÃO TAVARES DE PINHO, "André de Resende: o manuscrito do sermão do Sínodo de Évora (1534) e outros autógrafos", in: Cataldo E André de Resende: Congresso Internacional do Humanismo Português (Coimbra-Lisboa-Évora, 25 a 28 de Outubro de 2000), Lisboa, 2002, pp. 219-256. Para a transcrição do texto latino do sermão, vide ISAÍAS DA ROSA PEREIRA, "Sínodo diocesano de Évora de 1534", Anais da Academia Portuguesa de História, II série, 20 (1971) 171-232; JOAQUIm CHORÃo LAVAJO, "André de Resende e a História Religiosa de Portugal", in: Cataldo E André de Resende... cit., pp. 172-173. Testemunho idêntico pode ler-se em ROQUE DE ALMEIDA, Para 
padeciam de uma vida moral censurável, a ponto de Fr. Bartolomeu dos Mártires, recomendar, nas Petições $(1562)^{(11)}$, que «se renovem as decisões dos concílios e as determinações contra os concubinatários»(12). E acrescentava: "que os sacerdotes não prestem serviço a ninguém em actividades menos decentes"(13). No Estímulo de Pastores, obra redigida durante a última fase dos debates conciliares (1561-1563)(14), o Arcebispo de Braga parece retomar este assunto, a propósito da solicitude digna de um bispo. Segundo ele, para se «impedir que o tropel das preocupações e negócios irrompa com repetidos golpes contra a porta do coração e perturbe o sossego da oração e da santa união com Deus», a primeira coisa a fazer é «apartar o coração do amor sensual das criaturas: deita fora os amores sensuais, e ver-te-ás livre de perturbações. Não ames nem desejes nada que não seja em Deus e por amor de Deus, e nenhuns cuidados te afligirão, nem te afastarão de

ler a História da Igreja em Portugal, Porto, 1996, pp. 75-76. Acerca da presença portuguesa no Concílio de Trento, vide Fortunato De Almeida, História da Igreja em Portugal, Porto, Vol. II, 1968, pp. 531-534, que nos dá conta das sessões em que se tratou a questão da residência dos bispos; DAVID SAMPAIO BARBOSA, "Portugal em Trento: Uma presença discreta", Lusitania Sacra, 2. ${ }^{a}$ série, 3 (1991) 11-38; JOSÉ DE CASTRO, "Os Portugueses em Trento», Lumen, 25 (1961) 739-762; para o ambiente que marcou o acolhimento, entre nós, das primeiras orientações conciliares sobre matéria pastoral, vide AMÉLIA M. POLÓNIA DA SILVA, "Recepção do Concílio de Trento em Portugal: as normas enviadas pelo Cardeal Henrique aos Bispos do reino, em 1553", Revista da Faculdade de Letras — História, Porto, II série, 7 (1990) 133-143.

(11) Alguns extractos podem ser lidos em Documenta Bartholomaeana Tridentina. Intervenções conciliares, leitura e tradução de Aires A. Nascimento e Arnaldo do Espírito Santo, introdução de Fr. Raul A. Rolo, O.P., Braga, 1990.

(12) Na Autobiografia de Santo Inácio de Loiola, que o P. Luís Gonçalves da Câmara acabou de redigir em Génova, no mês de Dezembro de 1555, já se regista idêntica preocupação em orientar os costumes em Azpeitia, aquando da sua passagem por ali em 1535: "Había allá otro abuso, que consistía en lo siguiente: en aquel país es costumbre que las muchachas vayan siempre con la cabeza descubierta y que no se la cubran hasta que se casen. Pero hay muchas que se hacen concubinas de los sacerdotes y de otros hombres y les son fieles como si fuesen sus mujeres. Y esto es tan frecuente, que las concubinas no tienen vergüenza en decir que se han cubierto la cabeza por alguno; y por tales son conocidas": El peregrino. Autobiografía de San Ignacio de Loyola, introducción, notas y comentario por Joseph M. ${ }^{a}$ Rambla Blanch, S. J., Bilbao y Santander, ${ }^{4} 2003$, p. 88.

(13) Ibid., p. 37.

(14) A 26 de Janeiro de 1564, pela bula Benedictus Deus, Pio IV daria aprovação a todos os decretos conciliares. O Concílio foi convocado por Paulo III e os trabalhos iniciaram-se, com algum atraso, a 13 de Dezembro de 1545, tendo sido suspensos a 3 de Fevereiro de 1548, numa altura em que o concílio já decorria em Bolonha. De Junho de 1551 a 28 de Abril de 1552, os trabalhos conciliares regressam a Trento, agora sob o patrocínio de Júlio III. 
Deus»(15). Para o bracarense, a par da integridade moral, interessava-lhe propiciar uma sólida formação intelectual ao clero, co-responsável com o bispo no bom andamento da igreja local e diocesana, como indicia esta afirmação registada nas actas conciliares: «Se se não começar pelo exame dos bispos e pela instituição dos seminários, não sei por onde iniciar a reforma, pois estas hão-de ser os dois pilares dela"(16). A esta luz se compreende a fundação do Seminário de S. Pedro, em 1569; nove anos antes, o Arcebispo já havia confiado o Colégio de S. Paulo à Companhia de Jesus(17).

Torna-se clara, deste modo, a importância de um dos vectores fundamentais da intervenção dos jesuítas no âmbito da Reforma Católica: a formação moral e intelectual do clero. Mas também à juventude iria oferecer uma educação humanista dentro dos princípios da ortodoxia católica.

À luz destes factores se deve compreender a intervenção da Companhia de Jesus, mormente as finalidades didácticas da actividade dramática desenvolvida nos seus colégios em Portugal e por toda a Europa(18).

(15) BARTOlOMEU dos MÁRTIREs, Estímulo de Pastores, tradução portuguesa por P. José Barbosa Pinto, S. J. e P. António Freire, S. J., introdução de P. Fr. Raul A. Rolo, O.P., Braga, 1981, p. 149. Para uma análise circunstanciada desta obra, vide DAVID SAMPAIO BARBOSA, "Stimulus Pastorum: texto e contexto de uma proposta de renovação", Lusitania Sacra, 2. série, 15 (2003) 15-41.

(16) RAUl De Almeida Rolo, Bartolomeu dos Mártires. Obra social e educativa, Braga, 1979, p. 49; DAVID SAMPAIO BARBOSA, "Stimulus Pastorum..." cit., p. 26; Documenta Bartholomaeana Tridentina... cit., p. 37.

(17) Para mais pormenores, vide RAUl DE ALMEIDA ROLO, Bartolomeu dos Mártires. Obra social... cit., p. 146.

(18) Sobre a acção cultural da Companhia de Jesus em Portugal, vide ANTÓNIO LOPES, "A educação em Portugal de D. João III à expulsão dos jesuítas, em 1759", Lusitania Sacra, 2. ${ }^{a}$ série, 5 (1995) 13-41. Apesar da dispersão dos missionários pelos novos mundos, a unidade manteve-se e fortalecia-se graças, sobretudo, a uma meticulosa correspondência que assume a feição de relatórios circunstanciados das viagens que empreendiam e dos problemas que enfrentavam em terra de missão: JOÃO PEDRO FERRO, "A epistolografia no quotidiano dos missionários jesuítas nos séculos XVI e XVII", Lusitania Sacra, 2. ${ }^{a}$ série, 5 (1995) 137-158. Na oitava parte das Constituições escreve-se: "Concorrerá também de maneira muito especial para esta união a frequente correspondência epistolar entre súbditos e Superiores, com o intercâmbio de informações entre uns e outros, e o conhecimento das notícias e comunicações vindas das diversas partes. Este encargo pertence aos Superiores, em particular ao Geral e aos Provinciais. Eles providenciarão para que em cada sítio se possa saber o que se faz nas outras partes, para consolação e edificação mútuas em Nosso Senhor." INÁCIO DE LOIOLA, Constituições da Companhia de Jesus... cit., p. 176, n. ${ }^{\circ} 673$. 
Vai ocupar-se esta nossa reflexão de dois mestres jesuítas que leccionaram aqui em Coimbra, no Real Colégio das Artes: de Miguel Venegas e do seu discípulo, Luís da Cruz. Podem considerar-se os mais lídimos representantes do teatro escolar dos jesuítas em Portugal, com importantes repercussões a nível europeu.

Miguel Venegas, natural de Ávila, estreou a tragédia Achabus em 1562, no Real Colégio das Artes, pouco tempo antes de partir para Roma, a 6 de Novembro. Inspira-se sobretudo no Primeiro Livro do Reis (17-19 e $21-22)^{(19)}$.

Sob o reinado de Acab, Israel vive um período de grande prosperidade económica graças, sobretudo, a uma política de proximidade com os Fenícios. Esta amizade consolida-se com o casamento do soberano com Jezabel, filha de Etbaal, rei e sumo sacerdote de Sídon. Com esta união se protegia a ascensão do culto a Baal, divindade fenícia, pois grande era a influência da rainha junto do rei. Mas a idolatria de Israel viria a ser castigada com uma prolongada estiagem, sinónimo de fome. Na verdade, Acab havia ignorado os avisos do profeta Elias.

Três anos volvidos, regressa o profeta à presença do rei, procurando pôr termo ao castigo divino e, simultaneamente, desencadear uma perseguição aos falsos profetas. A acção dramática inicia-se precisamente com o regresso de Elias, do exílio. Confiante na protecção divina, o profeta demanda Acab, auxiliado pelo servo Abdias. Inesperadamente, dá-se o reencontro, marcado por um aceso debate verbal. Às ironias do rei, responde o profeta com um desafio: no Monte Carmelo, em presença do povo, os sacerdotes de Baal e o profeta Elias hão-de invocar o poder do seu deus. Aquele que primeiro consumir a vítima sagrada com fogo será o Deus verdadeiro e enviará chuva sobre a sequiosa terra. Javé está com Elias e o povo, enfurecido, dá a morte aos falsos profetas.

(19) O episódio da morte de Acab vem repetido no Segundo Livro das Crónicas (18). 
Jezabel toma conhecimento do massacre e fica enfurecida; tomada de desvario, irrita-se com a sua congénita fragilidade e com a frouxidão de Acab:

"Ignaua leuium, o feminarum pectora,

Queis fortiores parca naturae manus

Inuidit artes, tela, loricam, tubam,

Largita lanam sordidam et inertem colum!

Nouerca dura, praegrauis, auara, inuida,

Vt dona sorte diuidis iniqua omnibus!

Fecisse tanti fuerat inuictum uirum,

Me Iezabelem feminam! Forsan comes

Sequerer ministros meque sequerentur ducem,

Vir quando nimium residet oblitus domi.

Nunc, eiulatum cogor indignum edere,

Irrisa, inulta, unius opprobrium senis,

Heu misera, nimium nupta patienti uiro."

"Ó corações brandos de mulheres sem audácia,

a quem a escassa mão da natureza quis privar dos ofícios vigorosos,

dos dardos, da couraça e da tuba militar,

e a quem deixou a lã mesquinha e a inábil peneira!

Madrasta cruel e dura, cobiçosa e inimiga,

Com que desigualdade tu repartes entre todos os teus dons!

Tão caro te foi criares invencível o homem,

E a mim, Jezabel, me criaste mulher?

Talvez eu pudesse ao menos ir na companhia dos meus servos,

E eles me seguissem como seu guia,

Já que em casa fica um homem assim tão fraco.

Mas agora tenho de fazer desaparecer esse indigno desgraçado,

Já que fui escarnecida, desonrada, pobre de mim,

Casada com um homem que tolera afrontas vindas de um velho.»(20)

(20) MARIA MARGARIDA LOPES DE MIRANDA, Miguel Venegas S. I. e o nascimento da tragédia jesuítica. A Tragoedia cui nomen inditum Achabus (1562), edição crítica, tradução, comentário e notas, Coimbra, 2002, pp. 466-467, II.03.900-912. Dissertação de doutoramento dactilografada. 
Estas suas palavras insinuam o retrato de um marido submetido aos caprichos da esposa. A ele naturalmente Miguel Venegas vai opor a imagem ideal da relação entre homem e mulher no casamento: a esposa submissa expõe-se às leis do marido (Leges subacta iam maritales subi) ${ }^{(21)}$, proclama o profeta Elias; mais à frente, acrescentará que aos maridos se impõe que dominem, ainda que pela força, a arrogância das suas esposas (Et arrogantes coniugum fastus manu) (22).

Representa esta rainha um papel pouco simpático, como vemos. Trata-se do símbolo da perdição do homem, que atinge o seu clímax quando os impropérios do profeta Elias a identificam com a doce serpente que impeliu a mão de Eva até ao fruto proibido, no paraíso(23). Embora a sua intervenção fique restrita à cena III (761-932), do Acto II (564-1201), nas palavras de Margarida Lopes de Miranda, "para o melhor e para o pior, a Jezabel criada por Venegas em 1562 foi assim a primeira e talvez a mais poderosa personagem feminina do teatro escolar do século XVI»(24).

Já na tragédia Saul Gelboeus ${ }^{(25)}$, que se inspira no Primeiro e no Segundo Livro dos Reis, que foi representada a 9 de Julho de 1559, durante as festas da Rainha Santa Isabel, havia sido dado um primeiro sinal das intenções de Venegas. Talvez se possa afirmar que a entrada em palco da Pitonisa, no Acto IV, tenha sido um ensaio premonitório.

A presença feminina na obra dramática do seu discípulo, Luís da Cruz, oferece-nos uma história semelhante. A tentativa mais ousada encontra-se na Iosephus, uma tragicomédia inspirada na história bíblica de José do Egipto,

(21) Achabus, I.01.161.

(22) Ibid., v.186. A mesma ideia é reiterada pelo seu servo, Abdias, mais à frente: "Cohibenda mentis ira feminae est uiris"; na tradução de Margarida Miranda: "Dos maridos é dever coibir as iras do ânimo feminino" (op. cit., p. 509).

(23) Vide Achabus, I.01.

(24) Miguel Venegas..., cit., p. 308.

(25) A Tragoedia Absalon, como demonstra Margarida Miranda, afinal não é de Miguel Venegas. A sua notoriedade explica que lhe tenham sido atribuídas peças bíblicas anónimas, como esta ou a comédia Tobias. Cf. ibid., p. 221. 
narrada no Génesis $(37-50)^{(26)}$, o primeiro livro da Bíblia e, portanto, do Pentateuco. José é o filho predilecto de Jacob (inter tuos / Fratres amore

primus $^{(27)}$, o primogénito de Raquel(28), que havia de morrer durante o parto de Benjamim(29).

Por causa do sonho da ceifa - que lhe concedia a primazia entre os seus irmãos - José tornou-se odiado pelos irmãos(30), que o venderam como escravo a uns comerciantes ismaelitas. Levado para o Egipto, foi revendido ao intendente do Faraó, Putifar. A perfídia da sua esposa arrastará José até aos calabouços egípcios.

Situa-se este episódio no início do Acto III, que abre com uma reflexão sobre os caprichos da fortuna. Na verdade, coube a Putifar por sorte (sors) e não pelos seus méritos (ob merita) este escravo distinto:

"Haud dubito, crediderim a caelo quaedam Bona

Quibusdam impertita esse, quae nec meruerint

Nec dii dedere ob merita, sed quia sors tulit.

Placuitque diuis, his potius quam illis dare.

Id longe apud me est factum testatissimum

Cuinam deorum meritus sum integerrimum

Mancipium, amore mei et fide clarissimum?

Temeraria est profecto res felicitas.

$V t$ caeci sunt eventus, ut ludibria

Fortunae, uel caeleste donum, industria

Nequaquam comparandam uel pecunia."

(26) Contudo, o argumento cénico não faz referência aos capítulos 38, 48, 49 e 50.

(27) Iosephus, I.01.264-265: " ...entre os teus / Irmãos, no amor o primeiro...”. Todas as citações são feitas a partir da edição crítica desta tragicomédia: ANTÓNIO MARIA MARTINS MElO, O P.e Luís da Cruz, S. J., e a tragicomédia Iosephus. Tomo II - Edição crítica, Braga, Faculdade de Filosofia, 2001. Dissertação de doutoramento dactilografada.

(28) Cf. Gen. 30, 22-24. Raquel era irmã de Lia, ambas filhas de Labão (Gen. 29, 16).

(29) Cf. Gen. 35, 16-20.

(30) No Coro do Anjos do Acto I, o Anjo da Guarda de José dirige-lhe estas palavras (Iosephus, I.Chor.916-918):

"... $\quad \ldots \quad \ldots$ casus

Plangis ne tuos, an fraternae

Scelus inuidiae nobile defles?»

... $\quad \ldots \quad \ldots$ as tuas desgraças

acaso choras ou porventura da fraterna

inveja, crime bem conhecido, é que te lamentas?» 
"Sem dúvida, estaria em crer que pelo céu alguns bens

a alguns foram concedidos, os quais nem o mereceriam

nem os deuses lhos deram pelos seus méritos, mas porque

[a sorte assim o quis.

E agradou aos deuses dar mais a uns do que a outros.

Isso há muito, para mim, é facto comprovadíssimo.

$\mathrm{Na}$ realidade, a qual dos deuses fui eu merecedor de tão perfeito

escravo, que tanto se distingue no amor e fidelidade para comigo?

Coisa bem caprichosa é de facto a sorte feliz!

Cegos são não só os acontecimentos fortuitos, como os caprichos

da fortuna, quer se trate de dádiva celeste, a diligência,

que não se deve comparar, quer se trate de dinheiro.»(31)

Comprado a uns árabes (Mihi uendiderunt Arabes seruum)(32), este escravo de aspecto nobre e de carácter modesto (forma et pudore ingenii) (33), em quem o intendente confia mais que nele próprio (sane illi fido magis quam mibi) ${ }^{(34)}$, é fonte de felicidade (sum beatus) ${ }^{(35)}$, pois que se revelou um excelente administrador na economia doméstica:

"Et sum beatus. Prandeo, ceno, accubo

Sine solicitudine quippe rem curat, domum

Moderatur unus, seruatque, mibi familiam:

Locupletat etiam. Fons honorum in aedibus

Perenitate clarus exundat meis.

Vnde nibil unquam gratius aut iucundius

Putiphar habebit, illum quam seruum sibi.»

"E sinto-me feliz. Almoço, janto, deito-me,

sem preocupações, pois cuida ele dos haveres,

sozinho dirige a casa e cuida da minha família:

e até a enriquece! Uma fonte clara de honras

na minha casa jorra permanentemente.

Daí que nada mais agradável ou mais aprazível

Putifar terá do que possuí-lo como escravo.»(36)

(31) Iosephus, III.01.1774-1784.

(32) Ibid., v. 1785.

(33) Ibid., v. 1786.

(34) Ibid., v. 1789.

(35) Ibid., v. 1790.

(36) Ibid., vv. 1790-1796. 
Este vínculo amistoso assume a natureza de vassalagem prestada pelo servo ao seu senhor, regida por princípios de fidelidade. Não é propriamente amizade, pois não se estabelece entre iguais e, por isso, não há liberdade. É a utilitas a determinar esta relação afectiva. Segundo Aristóteles, este é um exemplo de uma amizade imperfeita, que buscou o seu próprio interesse (Ética a Nicómaco, 1156 a 6-30). Por isso, não obstante o deslumbramento deste escravo virtuoso,

"Verum ipse mecum saepe miror cogitans

Quae tanta uirtus illa sit uel gratia

Vnius adolescentis erga caelites,

Vt quicquid ille dicat, recte dixerit,

Et quicquid ille faciat, recte fecerit.

Iurabo, nostrum diligit seruum Deus,

Et carus homini iure multo maximo est.

Fas est amare quos amant ipsi Dei.”

"Muitas vezes me ponho eu a admirar, pensando cá comigo mesmo, como há-de ser grande a virtude e a aceitação

deste adolescente para com os habitantes celestes.

Como tudo o que ele diz, está bem dito

e tudo o que ele faz, está bem feito,

hei-de jurar que Deus ama este nosso escravo

e é justamente muito querido ao homem.

É lícito amar aqueles que os próprios deuses amam.»(37)

É sobre ele que Putifar, sem hesitação, faz recair a acusação de atentado ao pudor da sua esposa. Depois de conversar com ela, regressa ao exterior da casa e profere estas palavras:

"Vbi ille qui me perdidit? Proh! Quid tibi

Ingrate reddam par sceleri tanto? Domum

Totam ne iuris esse permisi tui,

Vt crimen ausus pessimum deluderes?

Taces?

(37) Ibid., vv. 1797-1804. 
"Onde está aquele que me perdeu? Ah! O que é que te pagarei, ingrato, que seja proporcional a semelhante a tamanho crime? Permiti eu que tu estivesses em toda a casa como senhor dela para tu ousares ludibriar-me com crime tão hediondo? Tu calas-te?»(38)

As invectivas sobem de tom. Repentinamente, de homem mais amado, José transforma-se num monstro, aos elogios sucedem-se as acusações mais infamantes:

"...... ... PV. Culpa est mea.

Nam saepe monitus pauca mancipiis fore

Credenda, fidei cuncta commisi tuae.

En quo recidit istius illa sanctitas?

Simulata uirtus? Fraude tecta castitas?

Perfidia fuerat. Plorat: en ingenium, ea

Quoties fefellisti arte? Quae modestia

Oris pudici?

$« \ldots \ldots \quad$.... A culpa é minha.

Na verdade, muitas vezes fui avisado de que poucas coisas aos escravos deviam ser confiadas; confiei tudo à tua lealdade.

Vês no que veio a dar a santidade deste?

Seria virtude fingida? Castidade acobertada pela fraude?

Perfídia houve. Agora chora: eis a astúcia.

Quantas vezes enganaste com esta arte? Qual é a dignidade

dum rosto honesto?

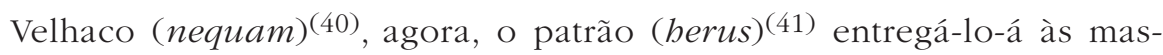
morras reais (in carcerem quo coercet rex suas custodias) ${ }^{(42)}$ :

"Properate, quaenam tanta uos tardat mora?

Eat in opacum carceris tetri specum

Ibi queratur teste se falso premi."

\footnotetext{
(38) Iosephus, III.03.1843-1847.

(39) Ibid., vv. 1848-1855.

(40) Ibid., vv. 1858.

(41) Ibid., vv. 1788.

(42) Ibid., vv. 1867-1868.
} 
"Apressai-vos! Que demora vem a ser essa?

Que vá para a caverna escura do lôbrego cárcere,

que aí se queixe de ser oprimido por falsas testemunhas.»(43)

José acaba de ser vexado publicamente, se bem que esteja inocente. E, contrariamente ao que seria de esperar, aceita o desfecho com resignação. É Cacodémon quem o confidencia ao espectador:

".... $\quad$... Doleo quod uadat lubens,

Quod non repugnet."

«..... Custa-me que vá com gosto, que não ofereça resistência.»(44)

A humildade aprende-se no exercício quotidiano ${ }^{(45)}$. Nas Constituições, constantemente se é interpelado a provas de humildade e de abnegação, pois do seu exercício advém a verdadeira humildade que, a par da caridade para com o próximo, e em particular para com a Companhia, há-de resplandecer no Prepósito Geral e torná-lo amável, tanto a Deus como aos homens ${ }^{(46)}$.

(43) Ibid., vv. 1890-1892.

(44) Ibid., vv. 1869-1870.

(45) No $6^{\circ}$ dia da Segunda Semana dos Exercícios Espirituais, Inácio de Loiola propõe ao exercitante, imediatamente antes da eleição, três maneiras ou modos de humildade "para a pessoa se afeiçoar à verdadeira doutrina de Cristo, nosso Senhor». São uma síntese da $1^{\text {a }} \mathrm{e}$ $2^{\mathrm{a}}$ Semanas, assim elaborada na pena do mestre jesuíta, António Freire: «1 $1^{\mathrm{a}}$ semana: ódio ao pecado, de maneira que nem por tudo o que é criado, se venha a deliberar em cometer um pecado mortal ou venial. Desejar, além disso, e escolher o que mais conduz ao fim para que fomos criados ( $1^{\circ}$ e $2^{\circ}$ graus ou maneiras de humildade). $2^{\text {a }}$ semana: escolher sempre o que Jesus Cristo escolheu, como o escolheu, e movido pelo amor ao mesmo Jesus Cristo $\left(3^{\circ}\right.$ grau de humildade)». ANTÓNIO FreIRE, Retiro espiritual, Braga, 1989, cap. 9 "Purgatório», pp. 74-84.

A eleição é o momento da escolha do estado de vida por que o exercitante há-de optar, tendo em vista o louvor de Deus e a salvação da alma. Há duas espécies de eleição - a eleição imutável (o matrimónio, o sacerdócio...) e a eleição mutável (tomar ou renunciar a bens temporais ou benefícios...) - , mas ambas convergem num fim último: a eleição da vida e da paixão de Jesus Cristo. INÁCIO DE LOIOLA, Exercícios Espirituais, tradução do autógrafo espanhol pelo P. ${ }^{\mathrm{e}}$ Vital Dias Pereira, Porto, ${ }^{2} 1983$, pp. 87-90, n. ${ }^{\text {os }} 169,171-174$.

(46) INÁCIO DE LOIOLA, Constituições da Companbia de Jesus, anotadas pela Congregação Geral 34 e Normas Complementares aprovadas pela mesma Congregação, Lisboa-Braga, 1997, p. 190, n. ${ }^{\circ} 725$. 
Para se alcançar a virtude da humildade e da abnegação(47) de todo o amor sensual e de toda a vontade e juízo próprio, o caminho para o conhecimento e amor de Deus( ${ }^{(48)}$, implica estar "pronto e decidido a aceitar e a sofrer pacientemente, com a graça de Deus, todas as injúrias, escárnios e opróbrios que andam associados à libré de Cristo Nosso Senhor, ou quaisquer coisas deste género, quer venham de alguma casa ou da Companhia (onde pretende obedecer nesta vida, humilhar-se e ganhar a vida eterna), quer de alguém de fora, não retribuindo a ninguém mal por mal, mas bem por mal» $(49)$.

José sofre pacientemente a humilhação de Putifar, sem resistência; de forma semelhante havia já recebido o opróbrio da escravidão.

Mas neste episódio, um dos grandes louros de José é a vitória da castidade ${ }^{(50)}$. Com efeito, resiste aos intentos da esposa de Putifar:

" $\ldots \ldots \ldots \quad \ldots \quad \ldots \quad$.... Illa pallium

Tenuit, reliqui fugiens; o ingens scelus!

Habeat. Pudorem malo seruare, ut uiri

Doceant mulieres iura sacrosancti tori.

Egone idoneus ad stuprum uisus? Mei

Mores ne facinus illud audendum, mibi

Prae se tulerunt? Quo expiabo flumine

Factum scelestae feminae? Iniecit manum,

Fugi, stetit animus integer, sed non fero

Polluta tactu. Pallium abripuit, sibi

Habeat, cremassem. Nile qui pleno alueo

Campis inundas, tolle te insolentius,

Me parte si qua polluit, fluctu ablue."

(47) A propósito, vide CARLOS PALMÉs DE GENOVER, S. J., La obediencia religiosa ignaciana, Barcelona, 1963; MANUEL MARIA ESPINOSA POLIT, S. J., La obediencia perfecta. Comentario a la carta de la obediencia de San Ignacio de Loyola, Quito, 1940.

(48) Ibid., p. 135, n. ${ }^{\circ} 516$.

(49) Constituições da Companhia de Jesus... cit., p. 43, n. ${ }^{\circ} 102$.

(50) O humanista italiano Paolo Vergerio, no seu tratado De ingenuis moribus et liberalibus studiis adolescentiae, também se refere à importância da castidade na juventude: "Bisogna badare perciò con somma cura che i giovanetti si mantengano soprattutto casti; infatti l'amore gustato anzitempo contamina anima e corpo. È dunque opportuno tenerli lontani dai balli e dagli spettacoli di simile genere, e così pure da eccessiva familiarità con donne...”. Apud E. GARIN, Educazione umanistica in Itália, Roma-Bari, 1975, p. 71. 
«..... $\quad \ldots \quad \ldots \ldots . .$. Ela o manto

me agarrou, deixei-lho, fugindo. Oh! que enorme crime!

Que fique com ele. A minha castidade prefiro conservar,

[para que os homens

ensinem às mulheres os direitos do sacrossanto leito nupcial.

Como é que eu lhe pareci idóneo para cometer adultério? Os meus

Costumes, porventura, terão mostrado diante de si que aquele crime

se devia tentar? Com que água hei-de purificar

a acção desta criminosa mulher? Lançou-me as mãos;

fugi; o meu coração permaneceu íntegro; mas não suporto

a poluição do seu tacto. Levou o manto, que fique com ele;

antes eu o tivesse queimado. Ó Nilo que com as tuas cheias

inundas os campos, levanta-te mais alto

se ela me poluiu com alguma parte, lava-me com as tuas águas.»(51)

Apesar de uma perfídia bem condimentada com as traquinices de Cacodémon, a inocência de José, espelha-a o seu rosto:

\section{Putiphar \\ Iosephe quid clamoris? Albes, pallidus \\ Cur ora muta?}

\section{IOS. Ora mutauit pudor.»}

Putifar

"Oh! José, que barulho é esse? Estás branco, pálido;

por que razão mudas o teu rosto?

José

O pudor mudou o meu rosto.»(52)

(51) Iosephus, III.02.1805-1817

(52) Ibid., vv. 1820-1821. Pelos trechos transcritos supra, José torna-se, assim, um exemplum do sucesso educativo prescrito pelos humanistas, com ecos também no tratado Famiglia de Leon Battista Alberti (1376-1422). As palavras que transcrevo são pronunciadas pelo principal interlocutor do diálogo, Lionardo: "- Non ti niego che i padri soprattutto, più che gli altri, debbono colle mani e co' piedi, con tutti i nervi, con ogni industria e consiglio, quanto possono, sforzarsi, che i figliuoli siano costumati ed onestissimi, sì perché fanno l'utile de' suoi (il costume in uno giovane non è meno che la ricchezza stimato), sì etiam perché rendono ornamento e pregio alla casa, alla patria sua ed a se stesso» (Apud E. GARIN, Educazione umanistica..., cit., p. 137). E não falta a exortação a um trato mais humanizado, neste calvário da educação - no dizer de Miguel Torga (Bichos — Contos, Coimbra, 131983, p. 16) - pois os filhos deviam ser levados, de preferência, pela razão: "E vogliono i fanciulli essere correcti con modo e ragione, e anche talora con severità: non vi si accanire però suso, come alcuni rocti e furiosi padri fanno; castigarli sanza ira, senza passione d'animo..." (Apud E. GARIN, Educazione umanistica... cit., pp. 153-154). 
Mas nem sempre a castidade saiu vitoriosa. Rúben manteve relações com Bilha, a concubina de seu pai, Jacob, que o veio a saber. Este ignominioso crime (turpe flagitium) deitou a perder o direito de progenitura(53). Judá há-de cometer incesto com a nora e tornar-se um pai infame (infamem patrem) (54). Contudo, a castitas era uma das virtudes a imitar pela mulher, como já verificámos em o De Institutione foeminae christianae, do humanista espanhol Juan Luís Vives (1492-1540)(55). Também a mensagem paulina é clara ao condenar as imoralidades na forma de incesto (I Cor. 5.1-5) e da fornicação (I Cor. 6.12-19).

Entre a devassidão que a tantos vence, qual farol se ergue a virtude de José, a sua pureza de espírito e de sentimentos, traduzida na recusa, até à prisão e mesmo até à morte, em se envolver com mulher alheia. De profundo significado são estas palavras proferidas pelo demónio que se revela incapaz de alcançar os seus intentos:

CACODAEMON

Nibil tamen mibi dari cupio, prae tua Anima, Iosephe. Posse credideram capi Amore dominae, restitit: castum piget Tentasse iuuenem, ne multi exemplum probent:

Et abstinere turpi a congressu uelint.

Qua re ditatur o reus et ditabitur

Magis quotidie, quippe fomentum rogi

Quo tartara ardent, est libido: plurium

Est illa domitrix sola, quam superbia,

Ira, gula, auaritia, inuidia, socordia, Septena quae sunt cornua quibus Lucifer

Et grex Auerni pallidi orbem uentilat."

(53) Iosephus, I.01.195-197.

(54) Iosephus, III.05.1916.

(55) Cf. JUAN LUÍS VIVES, The education of a Christian woman: a sixteenth century manual, Edited and Translated by Charles Fantazzi, Chicago \& London, 2000, p. 116. 


\section{CACODÉMON}

"(...) Para mim nada quero, senão a tua

alma, José. Julguei que podia deixar-se levar

pelo amor da senhora, mas resistiu. Envergonho-me

de ter tentado um jovem casto, pois muitos hão-de aprovar tal exemplo

e querer abster-se de relações torpes.

Oh! Com isto o réu é enriquecido e enriquecer-se-á

ainda mais quotidianamente, pois o que alimenta a fogueira

em que os infernos se consomem é a devassidão:

ela sozinha é mais dominadora do que a soberba,

a ira, a gula, a avareza, a inveja, a preguiça,

que são os sete chifres com que Lúcifer

e a grei do pálido Averno atormenta o mundo.»(56)

A luxúria é um dos vícios verberados por Dante, n'A Divina Comédia. A dissoluta rainha da Assíria, Semirâmis, encontrou-a Dante quando baixava ao segundo círculo, no Inferno, penalizada pela negra aura: «(..) foi a sabida / imperatriz de numerosas falas. / Em vício de luxúria tão rompida, / que o líbito fez lícito por lei, / contra a censura a que era conduzida.»(57). Seu mestre, Virgílio, havia ainda de nomear Cleópatra, a luxuriosa, e mais de mil sombras «a quem amor tirou da vida hostil» (58). No círculo oitavo se encontra outra famigerada mulher, a esposa de Putifar, "... a falsa que acusou José»(59).

A encerrar este acto, o coro, em verso sáfico, vai cantar a vitória de José sobre a luxúria, enaltecer o pudor sincero deste jovem, coluna de Israel e exemplum para as gerações vindouras:

"O pudor castae generose mentis,

Mentis o praeceps furor impudicae!

(56) Iosephus, III.05.1920-1931.

(57) Dante Alighieri, A Divina Comédia, tradução de Vasco da Graça Moura, Mem Martins, 1998 , p. 58 , vv. 54-57.

(58) Ibid., p. 60, v. 69.

(59) Ibid., p. 215, v. 97 
Quando iam mundo seniore tellus,

Prona laxarit uitiis habenas:

Dicet, o magnum iuuenem, periclo

Qui suo, uicit dominam pudore

Et lacessitus timuit iugalem

Rumpere nodum."

"Ó nobre pudor dum espírito casto!

Ó furor vertiginoso dum espírito impudico!

Quando a terra, já num mundo envelhecido,

der rédea solta aos vícios,

dirá: ó grande jovem, que com perigo

para a sua vida, venceu a senhora pelo pudor

e, provocado, temeu romper o laço conjugal!»(60)

É o canto triunfal da castidade, com raízes no Trionfo della castità, de Petrarca. A perseverança, o medo da infâmia e o desejo da honra e da pureza são virtudes cultivadas por este jovem que se celebrizaram neste triunfo ${ }^{(61)}$. É de novo a exaltação da temperantia, da modestia. Este triunfo simboliza ainda uma outra virtude, a fortitudo: forte na adversidade, teve ânimo suficiente na luta contra a intriga, para que a verdade fosse imposta. É a prática da temperança que conduz à morigeração nos costumes(62).

Semelhante atitude de José recorda-nos o usus aconselhado pelo Bispo de Silves: "A qualidade indispensável aos grandes frutos da honestidade é o desejo da glória (371.59-61) ${ }^{(63)}$, dentro dos limites da recta razão (367.32-40), a que se deve aliar o culto da vergonha (367.44-47), o medo da infâmia, o ódio à vilania (493.48-494.11). É tarefa dos educadores cultivar na alma dos seus discípulos o estímulo destes dois princípios (368.39-44)»(64).

(60) Iosephus, III.Cor.2481-2482; 2502-2507.

(61) Francesco Petrarca, Opere. Canzoniere, Trionfi, Familiarum Rerum Libri. Firenze, 1975, pp. 208-212, vv. 76-90 e v. 193.

(62) ARISTÓTELES, Ética a Nicómaco, 1105a 17-21.

(63) Neste sentido é interessante o passo do De gloria: H. OSORII Op. omnia, I, 122.47-52. Vide sobre este tema A. HAURY, "Cicéron et la gloire: une pédagogie de la vertu», in : Mélanges Boyancé. Paris, 1974, pp. 401-417.

(64) NAIR De NAZARÉ CASTRO SOARES, O Príncipe ideal no século XVI e a obra de D. Jerónimo Osório, Coimbra, ${ }^{2} 1999$, p. 428. 
A castidade é um tema que a mitologia consagrou no desenlace trágico do herói Hipólito, vítima da infâmia de Fedra, que o acusa a Teseu, seu esposo: o assunto seria imortalizado na Phaedra de Séneca, que já havia sido glosado por Eurípides (Hipólito, 429 a. C.).

A par da virtude da castidade, emerge, como vimos, um tema fundamental, a defesa do matrimónio, ou do $7^{\circ}$ sacramento, como the chamou Erasmo (Enchiridion septimum sacramentum), em defesa dos valores morais. A primeira expressão do amor familiar decorre da relação entre marido e esposa.

Como sabemos pela história bíblica, Jacob desposou duas mulheres — as irmãs Lia e Raquel - e as suas duas escravas, Zilpa e Bilha, respectivamente. De ambas as escravas teve filhos, mas por razões de ausência de fecundidade, no caso de Lia, e de esterilidade, no caso de Raquel: assim se tornaram mães por intermédio das criadas, pois a esterilidade era um grande opróbrio para a mulher casada. Com efeito, era interpretado como castigo de Deus. Já assim havia acontecido, no passado, com o patriarca Abraão que concebeu Ismael da escrava egípcia Agar (Gen. 16.2). A bigamia, a poligamia ou a sua forma mitigada no concubinato são práticas entre os povos vizinhos e toleradas entre os israelitas. Mas o ideal da família monogâmica já nos é proposto no Génesis (2.23-24). Neste particular, assume especial significado, nas Sagradas Escrituras, o Cântico dos Cânticos, poema atribuído ao rei Salomão. Prefigura-se aqui a aliança de Deus-esposo com Israel-esposa, à luz do Antigo Testamento; à luz da revelação cristã, configura o "matrimónio" da Nova Aliança, a união mística de Jesus Cristo com a Sua Igreja. São Paulo, na Carta aos Efésios (5.22-33), actualiza esta mensagem à luz de Cristo, renovando o apelo de fidelidade mútua no casamento.

O Iosephus, num contexto de diálogo entre várias culturas e povos, faz apelo à castidade no casamento, como vimos no episódio da esposa de Putifar. Serve ainda este exemplo para condenar a poligamia, frequente entre os povos indígenas. Acresce, ainda, o exemplum de Jacob. Em pleno Egipto, presos pelo grande senhor, Judá esclarece o pai que o governador 
"Existimauit perduelees, liberos

Vnius esse nos parentis diximus."

«julgou-nos inimigos

e nós dissemos que éramos filhos de um só pai.» (65)

A mulher de Putifar, como sabemos, não se mostrou ao público, isto é, não entrou em cena, mas podia estar em palco, embora protegida pelo cenário. Também ela revela uma notória ascendência sobre o marido, que acaba ridicularizado, pois se deixou seduzir pela destreza feminina. Não obstante este papel recatado aos olhos do público, a presença feminina torna-se determinante na economia da narrativa. Com efeito, a desordem que se abateu sobre a casa de Putifar, aliada à interpretação, com verdade, por influição divina, dos sonhos do padeiro e do copeiro, levam ao reconhecimento das suas virtudes junto do carcereiro, que o vai nomear prefeito da prisão. O copeiro, que havia sido restituído às suas antigas funções, vai aconselhá-lo ao Faraó. De facto, as visões de que padecia não as decifraram satisfatoriamente os áugures egípcios. Deste modo, em sinal de reconhecimento, o primogénito de Raquel vai ser nomeado Administrador do Egipto. Providencial este cargo, pois assim vai salvar a sua família do extermínio certo, às garras de uma fome que se estendia a todo o globo terrestre.

Quatro anos antes, Luís da Cruz já havia feito uma primeira tentativa para introduzir um papel feminino, na tragédia Sedecias, também de inspiração bíblica, essencialmente no Livro de Jeremias do Antigo Testamento(66). Estamos a falar da mãe de Sedecias, a Amital. Precisamente oito anos depois de Mestre Venegas incluir uma figura feminina no enredo da tragédia Achabus, como vimos acima.

(65) Cf. V.02.3248-3249.

(66) Para mais pormenores, vide MANUEL JOSÉ DE SOUSA BARBOSA, Bíblia e tradição clássica: a tragédia Sedecias do P. Luís da Cruz, S. I., na convergência de uma estética e de uma pedagogia. Dissertação de doutoramento dactilografada. Tomo I - Estudo Literário. História do texto e critérios ecdóticos. Lisboa, 1998, p. 67. 
Esta data revela-se importante, pois estamos num tempo em que não se acha indecoroso a introdução de donzelas ou rainhas na representação de tragédias ${ }^{(67)}$. Desta opinião é o crítico e pedagogo messanense Giovanni António Viperano (1535-1610) que, por esta altura, quando ainda pertencia à Companhia de Jesus, havia de escrever o tratado De poetica libri III.

Esta mentalidade havia de ser contida, pela primeira vez, na Ratio de 1586, ao proibir-se a presença de figuras femininas em palco, excepto nas províncias transalpinas ou se os costumes locais o exigirem(68). Tenhamos presente que nestas representações teatrais tomavam parte apenas actores masculinos, ainda que os papéis fossem femininos. E mesmo entre os espectadores não era bem-vinda a presença feminina (69). A versão definitiva da Ratio atque Institutio Studiorum Societatis Iesu, em 1599, proibiria, definitivamente, a presença feminina no âmbito dos concursos dramáticos ${ }^{(70)}$. Mas não foi acatada da mesma forma em todas as províncias, como sucedeu numa das províncias da Alemanha. Invocando o princípio de adaptação aos tempos e lugares ${ }^{(71)}$, o P. Geral Cláudio Acquaviva concede-lhe regime de excepção, desde que fossem personagens femininas graues et modestiae ${ }^{(72)}$.

O espírito desta regra já se pressentia nas Constituições, redigidas por Inácio de Loiola e aprovadas na 1. ${ }^{\text {a }}$ Congregação Geral da Companhia de

(67) Ioannis Antonii Viperani De Poetica Libri Tres, Antuerpiae, ex officina Christophori Plantini, Architypographi regii, MDLXXIX, p. 99: Ne censemus indecore puellas et reginas induci, cum res grauis in augusto loco agatur. Cf. MANUEL JOSÉ DE SOUSA BARBOSA, Bíblia e tradição clássica..., cit., p. 30.

(68) Cf. Ratio Studiorum 1586/B, in: Monumenta Paedagogica Societatis Iesu, vol. 5, Roma, 1986, p. 205.

(69) Vide, a propósito, a carta de Baltasar Barreira que dá notícia da representação de uma tragédia por ocasião da inauguração da Universidade de Évora, a 1 de Novembro de 1559. Litterae Quadrimestres ex universis praeter Indiam et Brasiliam locis in quibus aliqui de Societate Iesu versabantur Romam missae, Vol. 6, Madrid - Roma, 1928, p. 312. Cf. MARIA MARGARIDA LOPES DE MIRANDA, Miguel Venegas..., cit., p. 309.

(70) Cf. Monumenta Paedagogica Societatis Iesu, vol. 5, Roma, 1986, p. 371.

(71) Cf. INÁCIO DE LOIOLA, Constituições da Companhia de Jesus anotadas pela Congregação geral 34 e Normas Complementares aprovadas pela mesma Congregação, Braga, 1997, pp. 103 e 123, n. ${ }^{\text {os }} 351$ e 462 .

(72) Cf. F. Charmot, S. J., La pédagogie des Jésuites, Paris, 1951, p. 242. 
Jesus em 1558, onde se apelava aos Superiores para que não permitissem, aos jovens, a leitura de livros que ofendessem os bons costumes. Na sequência desta proibição, menciona-se o nome de Terêncio, o único autor clássico identificado(73), pois, segundo ele, nas aulas, que houvesse, enfim, a preocupação de lhes incutir hábitos dignos de cristãos ${ }^{(74)}$. Trata-se de integrar, em termos inacianos, "virtude e letras, vida e ciência, conduta e saber» $(75)$.

Mas nem sempre estes princípios rigorosos se observaram. As antologias dos Jesuítas, que sobrevalorizaram a castidade, não deixam de acolher frases que nos podem surpreender, como esta da comédia plautina Stichus, claramente na defesa dos direitos da mulher; são palavras que saem da boca de Pânfila, opondo-se, deste modo, aos caprichos paternos:

"Stultiast, pater, uenatum ducere inuitas canes.

Hostis est uxor inuita quae uiro nuptum datur."

"É uma insensatez, pai, mandar as cadelas caçar contra vontade.

Uma mulher casada sem o seu consentimento é uma inimiga

para os maridos.» $(76)$

(73) INÁCIO DE LOIOLA, Constituições da Companbia de Jesus..., cit., p. 124, n. ${ }^{\circ}$ 469: "Se alguns, como Terêncio, não puderem de modo algum ser expurgados, mais vale não se lerem, para que a natureza dos assuntos não ofenda a pureza dos corações».

(74) Ibid., p. 126, n. ${ }^{\circ} 481$.

(75) José MANUEl MARTins LOPES, Projecto Educativo da Companhia de Jesus: Dos Exercícos Espirituais aos nossos dias, Braga, 1997, p. 100. Cf. INÁCIO DE LOIOLA, Constituições da Companbia de Jesus..., cit., p. 124, n. ${ }^{\circ} 307$.

(76) Plauto, P, vv. 137-142, citado por AgOSTINHO DE JESUS DOMINGUES, Os clássicos latinos nas antologias escolares dos jesuitas nos primeiros ciclos de estudos pós-elementares no século XVI em Portugal, Porto, 2002, p. 214. Dissertação de doutoramento dactilografada. Agostinho Domingues, no entanto, não deixa de chamar a nossa atenção para o pensamento misógino da Companhia a propósito da alteração dos versos 121 e 122 desta comédia. Com efeito, enquanto ali se pode ler este diálogo entre Antifão e Pânfila ("AN. Qui potest mulier uitare uitiis? PAM. Vt cottidie / Pridie caueat ne faciat quod pigeat postridie»: "AN. Como pode uma mulher evitar os seus defeitos ? PAM. Evitando em cada dia fazer o que, no dia seguinte, lamentará ter feito.»), na antologia a deturpação desta passagem é evidente, havendo um só interlocutor ("Qui potest uitare, uitet: ut cottidie / Pridie caueat, ne faciat quod pigeat postridie»: "Quem pode evitar as mulheres, evite-as: de modo a precaver-se a tempo para não fazer aquilo de que possa vir depois a arrepender-se».). Cf. Plaute, Comédies, T. VI (Pseudolus, Rudens, Stichus), Paris, 1972, pp. 220-221. 
Nesta linha agiu Inácio de Loiola ao fundar, em Roma, a Casa de Santa Marta, que se destinava a acolher mulheres casadas ou que pensavam abraçar a vida matrimonial, libertando-as de uma vida de prostituição. Inspirando-se na Vida de S. Ignacio de Loyola do jesuíta espanhol Pedro Ribadeneira (1527-1611) ${ }^{(77)}$, o biógrafo francês Hercule Rasiel da Silva, autor em 1736 de uma História do admirável Dom Inigo de Guipuzcoa(78), evoca, deste modo, a experiência do fundador da Companhia:

"Foi ele o primeiro a contribuir para a construção dessa Casa. A exemplo dele, muitos senhores e damas da mais alta categoria forneceram grandes somas de modo que em pouco tempo se erigiu um grande edifício onde se instalou essa espécie de arrependidas... Ele próprio ia buscar as raparigas de vida fácil para as levar para lá e não corava por aparecer na cidade no meio de um grupo dessas criaturas. Diziam-lhe por vezes que perdia o seu tempo e que aquelas infelizes estavam demasiado endurecidas pelo pecado para o deixarem definitivamente. 'Mesmo que eu só as impeça de ofender a Deus por uma noite, dou o meu sacrifício por bem empregado: e não o lamentarei mesmo quando tiver a certeza de que elas regressam no dia seguinte ao seu comércio infame'.»(79)

A esta havia de juntar-se a Casa de Santa Catarina, destinada às filhas das prostitutas. O testemunho contemporâneo do português P. Bartolomeu Ferrão, exarado em carta de 12 de Abril de 1546, que dirigiu a Simão Rodrigues, dá conta do empenho do Geral da Companhia nesta obra:

«Nestas coisas que aqui muitas vezes acontecem leva não pequeno trabalho nosso Padre, tirando raparigas das suas casas, onde viviam com mulheres de má vida, de cujos exemplos o inimigo se podia servir, e colocando-as em lugares seguros, aprovados por Sua Santidade, de maneira que fiquem livres de perigo.» (80)

(77) Fontes Narrativi de S. Ignatio de Loyola et de Societatis Iesu initiis, ed. de Candidus de Dalmases, IV, Romae, 1965, p. 411.

(78) HERCUle RASIEl DA SILVA, Histoire de l'admirable Dom Inigo de Guipuscoa, La Haye, 1736.

(79) Citado por JeAn Lacouture, Os Jesuitas... cit., p. 132.

(80) Monumenta Ignatiana ex autographis vel ex antiquioribus exemplis collecta. Sancti Ignatii de Loyola Societatis Isesu fundatoris epistolae et instructiones, I, Madrid, 1903, p. 373; 
E se o espírito inaciano se revela, na praxis, tão contrário a tal espírito antifeminista, idêntica atitude nos transmitem as Sagradas Escrituras. Um dos testemunhos mais frequentemente invocados para desvalorizar a imagem da mulher é o capítulo terceiro do primeiro livro da Bíblia, o Génesis, versículos um a treze, passagem que tradicionalmente atribui à mulher a introdução do pecado no mundo. Acresce ainda que no capítulo anterior se narra a criação da mulher a partir da costela que Deus havia retirado ao homem (Gén. 2, 18-22), no contexto de um relato da criação, segundo a tradição Javista, em linguagem popular, à maneira de uma fábula: «uma narração mítica que interpreta a vida humana em determinado tempo histórico, apreendendo a realidade da vida de forma simbólica, porque uma narração artística resiste às vicissitudes do tempo e do espaço de modo mais consistente do que qualquer outra»(81).

A esta luz se compreende a reinterpretação do texto genesíaco 4b-3,24 por Armindo dos Santos Carvalho que, apoiada mormente no confronto com textos coevos do Médio Oriente, elimina do "mito adâmico» toda a sombra de pecado no sentido tradicional cristão ${ }^{(82)}$. Daqui resulta uma atitude de dignificação da mulher, como parece perscrutar-se nas palavras do sacerdote carmelita: «redescoberta na sua natureza literária de 'mito de origem', a narração deixa de ser instrumentalizada para inspirar ou legitimar teorias e práticas de poder, como lhe aconteceu em diversas interpretações pela cultura ocidental, e desprende de novo a sua força genuína e espiritualidade própria»(83).

CÂNDIDO De DALMaSES, S. J., Inácio de Loyola, fundador da Companhia de Jesus, Porto - São Paulo, 1984, p. 166. Neste contexto talvez ganhe importância recordar que Inácio de Loiola, na sua juventude, teve uma filha, Maria de Loiola, que havia de ocultar a sua paternidade sob o nome de Maria de Villareal. Cf. ROMEO DE MAIO, "Ignazio di Loyola e la donna", in: QUINTIN ALDEA (ed.), Ignacio de Loyola en la gran crisis del siglo XVI, Congreso Internacional de Historia (Madrid, 19-21 noviembre de 1991), Bilbao y Santander, 1993, p. 284

(81) JESÚs HERRERO, «O «Mito Adâmico» e a vida humana num livro de Armindo dos Santos Vaz - Um exercício da «razão vital e histórica» (II), Brotéria, 143 (1996) 588; AGOsTinHo DE Jesus Domingues, Os clássicos latinos nas antologias escolares dos jesuítas..., cit., pp. 408-409.

(82) Ibid., p. 599.

(83) ARMindo dos SANTOS VAZ, A visão das origens em Génesis 2, 4b-3,24, Lisboa, 1996, p. 461. 
Outros textos do Novo Testamento confirmam a dignificação da mulher. Na carta que São Paulo dirige aos cristãos de Colossos (Cl. 3,18-19), pode

ler-se: "Esposas, sede submissas aos maridos, como convém ao Senhor. Maridos, amai as vossas esposas e não vos exaspereis contra elas»(84). A afirmação da igualdade em Cristo já está inscrita num dos primeiros textos paulinos, a carta aos Gálatas (3.28): "Não há judeu nem grego; não há escravo nem livre; não há homem e mulher porque todos sois um só em Cristo Jesus» ${ }^{(85)}$.

(84) Bíblia Sagrada, para o terceiro milénio da encarnação, versão dos textos originais sob a direcção de Herculano Alves, Lisboa, Difusora Bíblica, 2003, p. 1935. Na Carta aos Efésios (Ef. 5, 24-25, 28 e 33), que hoje parece certo tratar-se de uma circular paulina enviada aos cristãos da Ásia Menor, também se encontram frases animadas pelo mesmo espírito: "Ora como a Igreja se submete a Cristo, assim as mulheres, aos maridos, em tudo. Maridos, amai as vossas mulheres, como Cristo amou a Igreja e se entregou por ela... Assim devem também os maridos amar as suas mulheres, como o seu próprio corpo. Quem ama a sua mulher, ama-se a si mesmo... cada um ame a sua mulher como a si mesmo; e a mulher respeite o seu marido". Ibid., pp. 1921-1922.

(85) Ibid., p. 1911. 
Margarida Miranda

Universidade de Coimbra

MIGUEL VENEGAS S.I. E O PRINCÍPIO

DE UM CICLO TRÁGICO NA EUROPA

\section{Introdução}

Com a renovação intelectual do Renascimento e do Humanismo e a revalorização do teatro antigo, passando desde a leitura até à tradução e representação dos dramaturgos greco-romanos, os humanistas chegaram à criação de uma dramaturgia própria.

A Castro de António Ferreira, obra prima do teatro clássico em Portugal, não foi um fruto isolado, mas antes o culminar de uma evolução literária que a crítica moderna não pode deixar de associar às tragédias de Buchanan e de Teive, bem como à fecunda actividade dramática do meio escolar de Coimbra, que a viu nascer. Sem o grupo de professores e de humanistas do Colégio das Artes de Coimbra, o teatro português não estaria certamente dotado das novas formas que o conduziram ao humanismo.

Ora, um dos momentos dessa evolução literária, anterior ao drama clássico nacional, foi sem dúvida a produção do teatro neolatino, ao qual devemos reconhecer um papel significativo na configuração do universo teatral moderno.

Será então a obra dramática de Miguel Venegas, de quem me vou ocupar, apenas um momento imperfeito da evolução para o verdadeiro teatro clássico, um rascunho grosseiro das obras-primas do moderno teatro ocidental? 
Penso que essa seria uma visão desfocada da realidade, se bem que durante muito tempo tenha sido essa a perspectiva dominante dos investigadores do teatro, em matéria de teatro jesuítico: a preparação, sempre imperfeita, do verdadeiro teatro moderno, um conjunto de exercícios escolares destituídos de originalidade e de mérito, a não ser o de terem dado um certo contributo para o desenvolvimento do teatro em vernáculo.

Miguel Venegas, um jesuíta da primeira geração, foi o herdeiro natural da melhor tradição dramática do Colégio das Artes de Coimbra, cujo ensino fora entregue à Companhia em 1555 - quatro anos antes, apenas, da estreia do dramaturgo em Coimbra. Depois das representações de Miguel Venegas em Coimbra (a Saul Gelboeus em 1559 e a Achabus em 1562), a obra de Miguel Venegas alcançou uma dimensão internacional incontestável. Se o poeta nunca chegou a imprimir os seus versos, a verdade é que, hoje, os seus manuscritos (alguns deles anónimos) encontram-se dispersos em bibliotecas de vários pontos do mundo, não só na Europa - em cidades como Coimbra, Évora, Lisboa, Roma, Perúsia, Messina, Bolonha, Chantilly, Colónia, Munique e Dillingen - como também em Nova Iorque e no Rio de Janeiro.

A Achabus, de 1562 tem a particularidade de ter sido a primeira tragédia representada em Roma, em 1565, logo seguida, aliás, da Saul em 1566. Ambas as representações foram realizadas no Colégio Germânico, uma instituição que, juntamente com o Colégio Romano, devia ser modelo universal da actividade escolar da Companhia em todo o mundo. Por outro lado, as obras dramáticas de Venegas encontram-se copiadas ao lado dos dramas de Stefano Tucci, Francesco Benci e Bernardino Stefonio, nos manuscritos que reúnem as mais antigas realizações dramáticas de Roma.

À representação de 1565, em Roma, seguiu-se ainda, em diversos pontos da Europa, uma longa série de representações dramático-musicais inspiradas nas mesmas fontes bíblicas, com os mesmos topoi dramáticos.

Assim, a partir de 1559, Coimbra e Roma assistiram ao nascimento de uma nova dramaturgia do sacro. Coimbra assistiu à produção e estreia de um 
arquétipo. Roma também quis ver, sancionou o género, e deu os primeiros passos para a codificação de uma actividade dramática regular, cujas formas vieram a ser reelaboradas por muitas gerações de jesuítas, em toda a Europa. A esse teatro que a Companhia não só acolheu mas promoveu em toda a Europa a partir de Roma, a historiografia jesuítica deu primeiro o nome de fabula erudita, drama sacrum et latinum e mais tarde tragoedia sacra.

Ao abordar o teatro de Miguel Venegas, devemos pois ter presente que não estamos perante uma prática escolar codificada, mas uma actividade literária e pedagógica ainda em definição, como demonstram alguns episódios da história do teatro nos colégios, que tenciono contar-vos.

Alguns desses episódios levam-me mesmo a pensar que as peças de Miguel Venegas e o êxito que acompanhou as respectivas representações nos maiores colégios da Europa estavam certamente na memória daquele grupo de jesuítas que, em 1586 e em 1599, integraram as várias comissões encarregadas da elaboração da Ratio Studiorum.

Contra o lugar comum veiculado pelos historiadores do teatro no séc. $\mathrm{XX}$, que não tiveram o privilégio de conhecer estes textos, o que no início era apenas exercício escolar, ou experiência de humanistas eruditos para uma elite de discípulos, tornou-se afinal um espectáculo público de grande dimensão social, capaz de responder aos gostos e às mais elevadas exigências estéticas da sua época. Não apenas um instrumento de catequese de intenção moralizante e vagamente retórica, mas uma expressão das grandes controvérsias do tempo (políticas, morais e religiosas), em linguagem de grande elaboração literária.

Afirmo portanto que os dramas de Miguel Venegas constituíram um verdadeiro repertório internacional e europeu, a que assistiam centenas e por vezes milhares de espectadores; os Coros do seu teatro - actualmente considerados os mais antigos exemplares musicais do género — ganharam autonomia artística, e foram interpretados fora das representações dramáticas; as suas tragédias e personagens deram origem a um ciclo trágico, de 
autores que reelaboraram as mesmas formas dramáticas e se inspiraram nas mesmas fontes bíblicas; a notoriedade de Miguel Venegas foi tão vasta que fez com que lhe fosse atribuída a autoria de peças bíblicas anónimas. (1)

Um teatro assim é, afinal, muito mais do que apenas um momento imperfeito de uma evolução literária. Com ele assistimos à fundação de uma poética dramática própria: uma dramaturgia essencialmente trágica, sacra, bíblica, retórica e musical.

Não vou deter-me a descrever as tragédias de Miguel Venegas, pois isso seria tema para outra comunicação, se bem que considere urgente e necessário disponibilizar este património em língua latina, não apenas aos historiadores da literatura e do espectáculo, mas também aos historiadores da cultura, das civilizações, das artes, da religião, da espiritualidade e das mentalidades.

Parece-me, porém, que a reconstrução deste fenómeno histórico desde as suas origens (isto é, a busca das raízes desta dramaturgia, de características profundamente trágicas, mas sacras e retóricas) não é menos importante do que a compreensão do objecto artístico propriamente dito, e das suas qualidades.

(1) Como a comédia Tobias e a tragédia Absalon. A Tragoedia cui nomen inditum Absalon encontra-se no Cód. 3092 da Biblioteca Nacional de Lisboa, fol. 90v-121, e a comédia Tobias nos fol. 121v-146v., embora existam outras cópias. Nigel Griffin já pode provar que o autor da Tobias não foi o nosso poeta mas sim Francisco Gomes, que em 1563 era professor de prima em Évora e ali fez representar a sua primeira peça.

Quanto à Absalon, embora sejam várias as cópias que chegaram aos nossos dias, todas elas se encontram anónimas. O autor do Catálogo de Reservados da Biblioteca Pública de Évora (vol. 3, p. 129) foi quem se inclinou pela primeira vez para atribuir a Absalon a Miguel Venegas, por ela se encontrar ao lado de outras obras do mesmo autor. Apresentou-a então da seguinte forma: Tragoedia Absalon (ab eodem?). Trata-se do Cód. CXIV / 1-40. Outros especialistas aceitaram esta atribuição. Na pormenorizada documentação jesuítica daqueles anos não encontrei, porém qualquer indício da sua composição por Miguel Venegas, nem sequer da sua representação no âmbito da actividade pedagógica daquele jesuíta. Entre 1559 e 1562 as cartas quadrimestrais não a referem e ela tão-pouco aparece nos códices que reúnem as obras especificamente escritas pelos padres do Colégio de Coimbra. 


\section{O drama bíblico de Miguel Venegas e o seu contexto dramático em Espanha}

Miguel Venegas não estudou com os jesuítas. Apenas ensinou como um deles. Formou-se e ensinou no Colégio Trilingue de Alcalá de Henares, uma instituição humanística votada essencialmente à filologia bíblica e à renovação da teologia. A sua formação académica, literária, bíblica, humanística e eclesiástica faz-nos pensar que, enquanto herdeiro do Humanismo bíblico de Alcalá de Henares, o teatro de Miguel Venegas só podia ser teatro bíblico. Por outro lado, enquanto formado no espírito da filologia moderna e na leitura dos autores pagãos, a sua obra nasceria necessariamente à imagem do género trágico, à imagem dos modelos de Séneca e dos autores clássicos. Em última análise, a crítica bíblica, que Venegas conheceu e que esteve no centro de toda a actividade humanística complutense, foi também a razão pela qual o autor soube descobrir, na exegese dos textos bíblicos, as matrizes do género trágico pagão.

Não podemos, porém, ignorar as diversas manifestações dramáticas que antecederam a obra de Miguel Venegas na Península Ibérica. Em Espanha, não podemos ignorar as representações dramáticas escolares nos mais antigos colégios da Companhia, nem o próprio teatro universitário e humanístico de Alcalá e de Salamanca, com o qual os dramas de Miguel Venegas mostram grandes afinidades.

\subsection{A dramaturgia de Miguel Venegas e o teatro jesuítico em Espanha}

Com efeito, embora a actividade teatral da Companhia seja tão antiga como o próprio ensino, a verdade é que a dramaturgia de Miguel Venegas parece não se enquadrar nos mesmos moldes do teatro que então já se vinha praticando nos colégios jesuíticos de Espanha: um teatro muito menos vinculado aos cânones clássicos, de temática religiosa inspirada nas Sagradas Escrituras, mas cujos valores éticos se sobrepunham largamente aos valores estéticos, com largas concessões à evolução dramática mais popular. 
De modo geral, no teatro jesuítico dos colégios de Espanha, escrito quer em latim quer em castelhano, podemos encontrar reminiscências do auto, da farsa, do drama alegórico, da comédia e da tragicomédia, isto é, formas dramáticas em que os géneros se cruzam, sem a preocupação de obedecer aos cânones de uma poética clássica. Podemos afirmar que, em Espanha, a produção dramática escolar não universitária (de autores como Pedro Pablo de Acevedo e Juan Bonifacio) tinha uma orientação clássica, mas prioritariamente religiosa e popular.

É muito significativo que num dos seus prólogos, Pedro Pablo de Acevedo peça ao público que não julgue a qualidade estética da sua obra mas sim a sua eficácia moral, razão pela qual Juan de Mal Lara e outros humanistas sevilhanos censuraram vivamente a obra de Acevedo. ${ }^{(2)}$

Ora, quando falamos de Pedro Pablo de Acevedo e de Juan Bonifacio, estamos a falar dos anos mais remotos do teatro escolar jesuítico, não apenas em Portugal e em Espanha mas em todo o mundo.(3) É nesta geração

(2) O autor alude a essas críticas em Philautus, vv. 105-112. Cf. V. PICÒN- GARCIA (ed) - Teatro Escolar Latino del siglo XVI: La obra de Pedro Pablo de Acevedo S.I., vol. I: V. PICÒN, A. CASCÓn, P. Flores, C. GAllardo, A. SiERra e E. TORRIEGO- Pedro Pablo de Acevedo S.I. Lucifer Furens, Occasio, Philautus, Charopus, Madrid, Ediciones Clásicas, 1997, p. 332 :

El grande obserbador de aquesta arte no me diga: "aqui faltó el decoro antiguo"; Mas túvose atención más al provecho, poniendo delante las cosas de los ojos que no servir el arte curiosamente.

A própria obra de Juan Bonifácio (professor nos colégios de Medina, Ávila e Valladolid), a qual se distingue da de Acevedo por propor temas e formas mais nobres, continua submissa à capacidade de compreensão de um público pouco culto. As personagens são tiradas da Sagrada Escritura ou da hagiografia, mas a sua caracterização é própria do tempo e do lugar histórico em que foram concebidas e representadas. Por outras palavras, a temática dramatizada é artificialmente inculturada na realidade de Castela do séc. XVI - o que dá àquele teatro um interessantíssimo valor documental, mas nem por isso o coloca entre os antecedentes literários que possam estar na origem do género trágico de Venegas, tal como este o concebeu.

(3) 1559 é a data a que se atribuem as mais antigas obra de Pablo de Acevedo, professor de Retórica no Colégio de Córdova e de Sevilha, e um dos primeiros nomes do teatro jesuítico em Espanha, cuja actividade de dramaturgo começou com a adaptação da comédia Acolastus de Gnapheus e Euripus de L. Brecht. Se 1559 é a data indicada pelos Ms da Egloga in honorem diuae Catharinae e da Comedia Metanea, no entanto, na introdução à edição mais recente do teatro de Pablo de Acevedo, Picón García duvida da autenticidade daquela data e prefere situar a primeira peça em 1559 e a segunda em 1561, baseando-se para isso nas cartas do 
que devemos situar Miguel Venegas, reconhecendo assim às suas tragédias coimbrãs de 1559 e 1562 um acréscimo de valor em antiguidade e originalidade.

\subsection{A dramaturgia de Miguel Venegas e o teatro humanístico universitário em Espanha}

Se, por outro lado, considerarmos a tradição do próprio teatro universitário e humanístico em Espanha, representado por autores como Fernán Pérez de Oliva (1494-1531), Juan de Mal Lara, considerado o criador de uma nova poética dramática que valorizou formalmente o género trágico e dotou o texto literário de um maior enriquecimento estético e artístico, e ainda por Juan Pérez de Toledo, que sucedeu ao nosso João Fernandes de Sevilha na cátedra complutense de Retórica (1537-1545), verificamos que, desde muito cedo, as Universidades de Salamanca e de Alcalá se mostraram favoráveis à produção do teatro humanístico, como exercício de aperfeiçoamento literário e de celebração académica.

As obras de Juan Pérez de Toledo (ou Petreius) são teatro erudito, exclusivamente em língua latina, e demonstram, mais do que quaisquer outras, a presença caracterizadora dos modelos de retórica, num drama entendido como meio de aperfeiçoamento literário. Além disso, a presença constante da música naquelas representações aponta também para o papel inovador que Venegas deu aos Coros musicais das suas tragédias em Coimbra.

\subsection{A dramaturgia de Miguel Venegas e as inovações dramáticas do teatro não escolar}

No entanto, por muito importante que tenha sido o teatro universitário na formação literária de Miguel Venegas, o humanista do Colégio Trilingue

próprio Acevedo e em outros testemunhos contemporâneos. Vd. V. PICÒN- GARCIA - Teatro escolar... p. 18 , n. 34 . 
de S. Jerónimo não podia ignorar a abundante tradição dramática que o precedia em Espanha, fora do âmbito universitário. Também ali se assistia a um movimento de reelaboração e dignificação das formas teatrais, de modo particular do teatro religioso, movimento esse causado em parte pelas correntes erasmistas, em parte pelo clima reformador vivido dentro da própria Igreja.

A obra dramática de Diogo Sánchez de Badajoz, por exemplo, mas principalmente a obra de Michael de Carvajal e de Vasco Díaz Tanco de Fregenal, embora nem sempre em língua latina, são composições dramáticas orientadas para a modernização do teatro religioso, e têm a particularidade de mostrar curiosas afinidades com o teatro de Miguel Venegas, que lhe é pouco posterior.

A Tragedia llamada Josefina, de Michael de Carvajal, a Tragédia de Absalon, muy sentida y dolorosa, a Tragédia de Amon, muy estraña e muy al natural e a Tragédia de Saúl y Jonatás en el monte Jelboé, de Vasco Díaz Tanco de Fregenal, sem esquecer a Tragédia Absalon composta pelo humanista Juan de Mal Lara, desenha o quadro dos que, antes de Miguel Venegas, em Espanha, já haviam criado formas, ainda que imprecisas, do novo género trágico, ao serviço da reforma espiritual do seu tempo: tragédias bíblicas, de ascendência menos popular, tendencialmente humanísticas, marcadas pela catequese e a reforma religiosa, e mais orientadas para os novos caminhos da tragédia senequiana.

Não deixamos contudo de observar que, durante muito tempo, a tendência em Espanha é para o predomínio das formas de comédia ou de tragicomédia, no que elas têm de imprecisão terminológica. Em função do novo ambiente religioso da Reforma católica, uma nova poética trágica (na linha de Vasco Díaz Tanco de Fregenal e de Michael de Carvajal), composta em latim e em vernáculo, já procurava enfim aliar os temas bíblicos aos cânones literários da Antiguidade. 


\section{O teatro de Miguel Venegas e o drama humanístico neolatino}

Se em Espanha é natural proceder à distinção entre teatro de colégio e teatro universitário, em Portugal, pelo contrário, essa distinção deixa de ser pertinente. O teatro jesuítico de Miguel Venegas é, sem dúvida, digno das mais típicas representações universitárias, onde Venegas começou e terminou o seu magistério depois de abandonar a Companhia. Tão digno que, quando mais tarde o jesuíta regressou a Espanha e se tornou professor na Universidade de Salamanca, acabaria por vir a derrotar o célebre Brocense numa espécie de concurso dramático, em 1570.(4)

$\mathrm{Na}$ verdade, as peças conhecidas de Miguel Venegas constituem uma criação dramática extremamente vinculada ao ensino da palavra e do virtuosismo verbal, ao mesmo tempo que procuram incutir nos seus actores determinados valores morais, ideológicos e catequéticos, sem nunca perder de vista a dimensão estética do texto literário - ao contrário do que acontecia no teatro jesuítico da Espanha.

Nada há nos textos de Venegas que denuncie a mistura de registos cómico e trágico, típica dos primeiros dramaturgos jesuítas espanhóis e dos próprios autores de teatro religioso não escolar. Os modelos de Venegas são os autores clássicos da Antiguidade, designadamente Séneca. Por isso o seu texto é exclusivamente em língua latina, de grande elaboração literária, modelado pelas exigências do ensino da Retórica; as suas personagens

(4) O episódio é narrado por GARCÍA SORIANO (El Teatro Universitario y Humanístico en España, Toledo, 1945, p. 225), quando ainda não era possível ao autor identificar este mestre Vanegas com o nosso Miguel Venegas, ex-jesuíta. Podemos porém confirmá-lo nos Libros de Claustros 1569-1570 do Archivo Universitario de Salamanca (AUSA 40), fol. 53v-54r; 103r, 135r-136r.

Em 1570 os estudantes representaram uma peça daquele célebre humanista conhecido como Brocense e outra de Venegas. Os respectivos autores solicitaram por isso ao Claustro a remuneração a que estavam habituados, pois para fazer representar tais peças haviam procurado vestes e outros adereços necessários. O pedido foi atendido no Claustro de 26 de Agosto de 1570, pois os deputados consideraram que a peça de Venegas fora superior. O vencedor recebeu a quantia de vinte e cinco ducados. 
bíblicas são concebidas à imagem das grandes figuras do imaginário clássico (Jezabel evoca Medeia, mas também Dido e Clitemnestra; o profeta Elias evoca a figura de Tirésias...) e as próprias figuras mitológicas pagãs coexistem tranquilamente com as verdades da fé cristã e com a mais profunda exegese bíblica de um humanista complutense.

Portanto, se a aliança entre os temas bíblicos e os modelos clássicos já conhecera os seus precedentes na história do teatro em Espanha, com Miguel Venegas parece ter-se dado um passo decisivo na criação do verdadeiro drama humanístico neolatino e cristão na península.

\subsection{A tradição do Colégio das Artes de Coimbra}

Este olhar retrospectivo ficaria porém incompleto se não lembrássemos os humanistas que precederam Miguel Venegas no Colégio das Artes em Coimbra. Os mestres chegados a Coimbra em 1547 eram os mesmos que em França já tinham elevado o teatro humanístico ao mais alto nível literário e pedagógico. Os estudos do Doutor Costa Ramalho e da Doutora Nair Castro Soares sobre o teatro humanístico em Portugal bem como os trabalhos deste Colóquio serviram para valorizar a obra de dramaturgos como Diogo de Teive e George Buchannan. Assim sendo, resta-me considerar que, quer o colégio de Guyenne, em Bordéus, quer o Colégio das Artes, em Coimbra, tiveram certamente uma função comum na caracterização do teatro escolar jesuítico.

Foi a humanistas como aqueles que Miguel Venegas veio suceder no ensino da Retórica e das Humanidades. Não admira por isso que, além da Castro de António Ferreira, também o teatro de Miguel Venegas seja visivelmente tributário da única tragédia conhecida de Diogo de Teive, a Ioannes Princeps. Esta peça constitui, na verdade, um dos intertextos mais próximos da Tragédia de Acab de Miguel Venegas. 


\section{O contributo de Venegas para a história do teatro e do espectáculo}

Abordemos agora o percurso do jesuíta em Coimbra. No colégio das Artes, como se sabe, a Companhia procurava reunir o escol dos seus mestres. Por essa razão Miguel Venegas pode cruzar-se com outros homens que efectivamente vieram a marcar de forma notável a Ratio Studiorum. Cipriano Soares, Pedro Perpinhão, Manuel Álvares e Pedro da Fonseca foram autores de obras eleitas como modelos e largamente difundidas na Europa, no campo da retórica, da gramática e da filosofia.

Se os nomes destes humanistas, companheiros em Coimbra, haviam de dar fama internacional a uma das mais antigas escolas de jesuítas em todo o mundo, a obra de Venegas também havia de dar celebridade ao Colégio Real de Coimbra em muitas partes da Europa, quando os seus dramas fossem representados nos colégios de Roma, Sicília, França, Áustria ou Alemanha. O teatro jesuítico ganhou assim uma dimensão europeia antes desconhecida, e esse impulso decisivo caracterizou por muitos anos aquela prática pedagógica.

Um dos contributos mais originais de Venegas para a história do teatro e do espectáculo foi sem dúvida o papel específico atribuído aos seus Coros trágicos, como já tive oportunidade de demonstrar em outras ocasiões. ${ }^{(5)}$ Eles inauguraram uma retórica musical harmónica mas estritamente homofónica, que se inscreve de pleno direito na tendência, que se havia de generalizar na Europa, para recuperar o velho ideal grego de união entre a poesia e a música. Acresce apenas que os Coros de Venegas, fruto da colaboração entre o humanista e o músico D. Francisco de Santa Maria, têm a particularidade de serem muito anteriores aos Coros musicais do teatro secular italiano, bem como às primeiras representações do dramma per musica da

(5) Cf. «Música para o teatro humanístico em Portugal: Dom Francisco de Santa Maria, Miguel Venegas S. I. e o Colégio das Artes de Coimbra (1559-1562)", Humanitas 55 (2003) 316-340; "Nas origens do melodrama: a Tragédia neolatina em Portugal» Península. Revista de Estudos Ibéricos 1 (2004) 251-262. 
Academia Florentina. Tinha pois razão o P. Luís da Cruz quando escrevia, anos mais tarde, no prefácio à sua obra, que havia Coros em todas as peças, pois sem música o teatro não deleitava; que o Coro cantava em cena, com vestes aparatosas; e que naquele género, os portugueses podiam orgulhar-se de ter feito algo notável.(6)

No limiar do séc. XVI, portanto, Luís da Cruz, antigo discípulo de Miguel Venegas em Coimbra, afirmava que fora precisamente em Portugal que nascera aquele género de peça coral dramática — integrada no drama, representada em cena e interpretada por alguém que também era personagem da peça.

Podemos portanto tirar duas conclusões: primeiro, que em Portugal, os jesuítas foram responsáveis pela criação de um género trágico novo, do qual a música é parte integrante e não intermezzo lúdico; segundo, que os Coros dramáticos do teatro neolatino português são certamente mais uma página a inscrever na chamada música humanística do Renascimento.

\section{As primeiras tragédias jesuíticas em Roma e a codificação gradual de um género dramático}

\subsection{A Achabus: 1565}

A peça que inaugura a era da tragédia sacra jesuítica em Roma é efectivamente uma Tragédia de Acab. O facto de o humanista Miguel Venegas, alguns anos depois, ter abandonado a Companhia, veio dificultar, como sempre, a identificação do autor. Os testemunhos da representação indicam apenas o título da peça e pouco mais. E na maioria dos Ms ela circula anónima.

O local da representação não foi o Colégio Romano, como se esperaria à luz da investigação do séc. XX, mas sim o Colégio Germânico. ${ }^{(7)}$ A primeira

(6) Luís da CRUZ S.I. - Tragicae, comicaeque actiones, a Regio Artium Collegio Societatis Iesu, datae Conimbricae in publicum theatrum, Lião, 1605.

(7) Nos primeiros anos do séc. XX, Gualtiero GNERGHI (Il teatro gesuitico ne' suoi primordi a Roma, Roma, 1907) afirmava o nascimento do teatro jesuítico em Itália, mas em 1994 Bruna 
representação não foi em 1566 mas em 1565, por ocasião do Carnaval. E o criador desta nova dramaturgia não foi Stefano Tucci, nem Bernardino Stefonio, mas Miguel Venegas, que fora enviado para Roma em 1562, mas deixara a cidade eterna rumo a Paris, alguns meses antes da representação.

A narrativa é-nos dada por uma carta do P. Polanco, dirigida a toda a Companhia, em 1565:

Innanzi quaresima, per allegrare il collegio, et diuertir molti di fuori da altri passatempi meno honorati, si rappresentarono nel collegio germanico due attioni fatte da persone della Compagnia. Una tragedia d'Acab, et una comedia d'Eustachio. Le quali, sì per esser in se molto buone et ben rappresentate, come per le uistosi intermedi, piacquero notabilmente a gli spettatori, fra i quali furono 7 , o uero 8 cardinali, e molto numero di prelati: et contentaronsi tanto, che fu bisogno ripetere le attioni più d'una volta, per questi et per quelli altri che ne faceuono instancia; e benchè sia grande il cortile del collegio doue si rappresentarono, nondimeno ci era che far assai in difendersi con le porte chiuse da quelli che uoleuono intrare, doppo di esser ogni cosa piena di gente di conto; et queste cose in tal tempo non solamente danno honesta et uirtuosa ricreatione in questa terra, ma ancora molta edificatione et credito in quel che tocca alle lettere e modo d'insegnarle. ${ }^{(8)}$

Embora este seja um terreno cheio de surpresas, não tenho conhecimento de nenhuma outra Tragédia de Acab, composta por um jesuíta antes de 1565 , a não ser aquela que M. Venegas fez representar aos seus alunos de Coimbra em 1562, no ano em que partiu para Roma juntamente com Pedro Perpinhão.

FILIPPI (La scène jésuite. Le théâtre scolaire au Collège Romain au XVII siècle, École des Hautes Études en Sciences Sociales, Paris, 1994, Tese de doutoramento policopiada) sustentava ainda a mesma ideia, atribuindo a criação da dramaturgia jesuítica a autores como Stefano Tucci, e Bernardino Stefonio.

(8) MONUMENTA HISTORICA SOCIETATIS IESU. Madrid-Roma, 1894-1996 (doravante MHSI) Polanci Complementa. Epistolae et Commentaria P. Ioannis Alphonsi de Polanco. 2 vols., Madrid, 1916-1917, Epistola 119, p. 571 
Ora, é precisamente a Achabus de Venegas que se encontra ao lado das obras de Stefano Tucci, Bernardino Stefonio e Francesco Benci, nos Ms que reúnem as mais antigas produções dramáticas de Roma. E mais significativo ainda é o facto de, num daqueles antigos Ms de Roma (Ges. 24 da Biblioteca Nazionale Centrale Vittorio Emanuele II, de Roma) a Achabus se encontrar ao lado de uma comédia Eustachio, anónima e sem data. Esta informação, entre outras, confirma a ideia de que a última grande realização dramática do mestre em Portugal foi afinal a primeira que os jesuítas em Roma levaram à cena, em 1565. Dela nasceu o arquétipo que inspirou as realizações dramáticas seguintes.

\subsection{A Saul Gelboeus: 1566}

O ano seguinte foi ocasião para novas representações, mas desta vez faltou a tranquilidade exigida pela demonstração pública de letras e de virtude, que era objectivo de todos os Actos públicos de Colégio. O episódio tem interesse, pois demonstra que nem sempre o teatro encontrava terreno favorável dentro do ambiente escolar da Companhia.

Contam-nos as crónicas do Colégio Germânico que o Carnaval em Roma trazia consigo uma onda de divertimentos que atraía também os alunos do Colégio Germânico, principalmente os italianos, e que, por essa razão, estes reclamavam aos superiores divertimentos e espectáculos também para si.(9) Os professores concordaram, uma vez que proporcionavam uma alternativa preferível às atracções do século, uma ocasião para saudável emulação entre actores, e exercício da nobre arte de discursar.

(9) Julio CORDARA, Collegii Germanici et Hungarici Historia libris VI compreensa, Romae, Typis Ioannis Generosi Salomoni, 1770, p. 37 ss.

Para o conhecimento dos vários espectáculos sacros e profanos que animavam a vida romana, nomeadamente as festas associadas ao Carnaval, existe um precioso instrumento de consulta documental: Fabrizio CRUCIANI - Teatro nel Rinascimento: Roma 1450-1550. Roma, Bulzoni Editore, 1983. 
A tragédia que correspondia às expectativas dos superiores foi mais uma vez uma peça de Miguel Venegas: a tragédia Saul Gelboeus, estreada em 1559 em Coimbra. Mas a comédia que, na mesma ocasião, representaram em vernáculo veio a provocar desagradáveis tumultos entre a multidão que invadira o colégio, como no ano anterior. Nobres e cardeais benfeitores sentiam-se gravemente ofendidos, pois na exiguidade do espaço, haviam sido grosseiramente empurrados, ou simplesmente excluídos do espectáculo, pela multidão desenfreada que invadira o recinto! Foram tais os desentendimentos que o Padre Geral, Francisco de Borja (recentemente eleito, em Julho de 1565) não hesitou em proibir os espectáculos, já que estes, além de causarem pesadas despesas, resultavam em protestos públicos e graves quebras da disciplina interna. E como se não bastasse, para garantir que o caso servia de emenda, o P. Geral viu-se ainda obrigado a tomar outra decisão importante para a vida do colégio: separar os alumni dos conuictores, ou seja, mudar os estudantes italianos para outro colégio, e sujeitá-los a uma disciplina própria, já que eram estes os principais responsáveis pelas desordens do Germânico. ${ }^{(10)}$

\subsection{Drama sacrum et latinum decretum est (1570)}

Durante três anos a proibição parece ter sido acatada, mas em 1570, o reitor do Colégio Germânico foi confrontado com novos protestos, e teve de chegar a um acordo, sancionado pelo próprio Geral: nada impedia os estudantes de representar teatro, desde que representassem algo erudito $e$ em lingua latina: modo fabulam luderent eruditam et, super haec, arcendae causa plebeculae, latino sermone concinnatam.

(10) O Colégio Germânico e Húngaro destinava-se a receber essencialmente os alumni vindos dos países germânicos, isto é, estudantes recebidos gratuitamente, ou a troco de serviços prestados no Colégio. Mas também recebia alguns conuictores italianos, ou seja, estudantes que pagavam o seu próprio sustento para viverem no Colégio. A medida disciplinar consistiu em enviar estes últimos para o Seminário Romano, fundado em 1564 por Pio IV, e desde logo confiado à Companhia de Jesus. 
Os estudantes não tiveram outro remédio senão aceitar as condições impostas. Doravante representar-se-iam tragédias sacras, em língua latina - como aquelas de Venegas, a que o Colégio havia assistido em 1565 e em 1566. E o cronista acrescenta: Borgia conniuente, drama sacrum et latinum decretum est.

Estamos diante do primeiro passo determinante para a codificação gradual do teatro que os jesuítas gostariam de ver praticar em todas as suas escolas: drama sacrum et latinum.

No entanto, o regresso do teatro ao Colégio Germânico não foi tão pacífico como se esperava. O que a seguir se passou é mais um episódio de repressão de uma manifestação dramática ao gosto popular e simultaneamente um passo em frente na confirmação da opção tomada.

No dia seguinte ao da primeira representação de 1570, o espectáculo ia dar-se de novo, a fim de receber a mais alta sociedade romana, quando os conflitos se repetiram, desta vez não já entre o público mas entre os próprios actores. Estava a récita para começar quando, de repente, os estudantes italianos do Colégio Romano invadiram o palco e anunciaram que tinham preparado uma comédia em vulgar, e que pretendiam representá-la ali mesmo!

Sem aguardarem resposta, começaram a improvisar o cenário, com a eventual cumplicidade de alguns companheiros do Germânico. Mas eis que, passada a primeira surpresa, os actores da tragédia se lançam aos gritos, com ameaças sobre os inoportunos concorrentes, diante do olhar atónito de nobres e de cardeais. Responderam os da comédia na mesma moeda, e de repente o palco converteu-se em campo de batalha. Embrulhados em grande algazarra, uns e outros distribuíam pontapés e bofetadas. Bancos e demais adereços teatrais serviam de arma de arremesso, e só ao fim de algum tempo os padres presentes conseguiram separar os adversários, que traziam a comédia proibida. O espectáculo foi suprimido e o desacato, ao que parece, serviu de emenda. 


\section{Uma poética da "tragédia sacra"}

Estou certa de que as primeiras representações das tragédias de Venegas no Colégio Germânico, bem como as circunstâncias que as rodearam, ou seja, a natural tendência dos jovens italianos para divertimentos mais mundanos aos olhos dos padres, é que determinaram, na verdade, a orientação da primeira legislação jesuítica sobre teatro.

Apesar das graves consequências daqueles episódios para a imagem de qualquer Colégio, o teatro não foi de modo algum banido do cânone de estudos jesuíticos, mas as prescrições da Ratio que o integram alguns anos depois, ecoam certamente acontecimentos como os que acabo de narrar. Doravante, a intenção dos superiores seria apresentar fabulas eruditas, sob a forma de drama sacrum et latinum. Por isso, a cópia romana da Achabus se intitula exactamente Tragoedia Sacra ex $3^{\circ} \mathrm{lb}$. Regum... E os termos da Ratio de 1599 , no que respeita ao teatro, não andam longe disso mesmo.

Tragoediarum et comoediarum, quas non nisi latinas ac rarissimas esse oportet, argumentum sacrum sit et pium; neque quicquam actibus interponatur, quod non latinum sit et decorum, nec persona ulla muliebris uel habitus introducatur. ${ }^{(11)}$

O argumento das tragédias e comédias - que deverão ser sempre raras e em língua latina - será sacro e piedoso. Não haverá interlúdios que não sejam em latim e decentes. Não haverá personagens nem vestes femininas.

Bem sabemos que, nesta matéria, a Ratio nem sempre era rigorosamente posta em prática. Em muitos colégios fora de Itália, a frequência das representações dramáticas ia muito além das prescrições canónicas, com quatro e cinco representações anuais. O género preferido era muitas vezes a comédia e a tragicomédia, com textos em latim mas também em verná-

(11) Ratio Studiorum 1599, MHSI, Monumenta Paedagogica Societatis Iesu 5, 1986, p. 371. 
culo. Em Espanha, por exemplo, os dramas de Pablo de Acevedo e de Juan Bonifacio, se bem que piedosos, não eram os mais exemplares em erudição nem em pureza linguística.

Pelo contrário, os dramas de Venegas e os que se lhes seguiram - de Simão Vieira e de Luís da Cruz, em Portugal, de Stefano Tucci, Francesco Benci e Horácio Torsellini, em Itália, eram efectivamente os que desde o início mais correspondiam à legislação superior. Não é por acaso que os copistas destas tragédias as intitulam nos seus Ms como Tragoediae sacrae. ${ }^{(12)}$ Se as Tragédias sacras de Miguel Venegas não eram uma obra-prima de técnica dramática, elas tinham já uma fisionomia própria muito singular, capaz de fixar o arquétipo de uma longa série de tragédias.

Ora, não esqueçamos que, quer as Constituições da Companhia, quer a Ratio Studiorum, atribuem aos colégios de Roma uma função exemplar no quadro escolar da Companhia. Por outro lado, Roma não era apenas a sede da Ordem; era também a capital do humanismo europeu. Por isso, tudo o que ali se fazia alcançava uma rápida difusão no universo dos jesuítas.

Assim, tendo em conta o natural valor normativo das práticas dos colégios romanos, o fenómeno a que assistimos a seguir é aquele a que poderíamos chamar a lenta elaboração de uma poética da tragédia sacra, que começa por ser, como vimos, uma poética de séria exegese bíblica, mas também estreitamente ligada aos modelos horacianos e senequianos de poesia, submissa à primazia do texto literário, ao serviço da Retórica e da parenética. Uma poética em que o dramaturgo procurava elevar o género aos cânones clássicos e entrelaçar a poética bíblica com os mais elevados modelos literários pagãos.

(12) Assim acontece não apenas com a Tragédia de Acab no Ms Ges. 142 da BNCVE (Tragoedia Sacra ex $3^{\circ}$ lb. Regum cap. 18-20-21) mas também com a Sedecias do P. Luís da Cruz, por exemplo. Com efeito, no mesmo Ms de Colónia que contém a Achabus, a Sedecias do P. Luís da Cruz aparece com o seguinte título; Tragoedia Sacra Hierosolyma Euersa per Nabuchodonosorem. Título semelhante recebe a Saul Gelboeus de Miguel Venegas num Ms de Perúsia: Historia Sacra V.T. et primi Libri Regum et in modum Tragoediae per doctiss. uirum S.I. traducta. (Biblioteca Comunale Augusta de Perúsia, Ms 666 (I.61), fol. 79-122. 
Para os superiores jesuítas, a nova designação (fosse ela drama sacrum, ou historia sacra, ou por fim tragoedia sacra) evocava certamente um certo grau de parentesco com as sacre rappresentazioni italianas, não só do ponto de vista temático, mas também do ponto de vista da extensão formal, da multiplicação de personagens, da pluralidade de lugares e da própria lentidão da acção dramática. Por outro lado, os termos não deixavam de salientar também um vínculo programático com os modelos clássicos da tragédia "regular», ou seja, tomava um caminho inteiramente diferente, ao submeter-se aos cânones estéticos da Antiguidade, incarnados pelos autores gregos e principalmente por Séneca. Retomava a inspiração religiosa originária, mas dava-lhe agora um carácter nobre e elevado. Superava a dimensão exterior da imitação realística da vida contemporânea, característica das sacre rappresentazioni, para se situar na intemporalidade mítica da Sagrada Escritura.

A Tragoedia sacra era assim concebida como a digna alternativa às tragédias profanas de tema histórico e mitológico, com que a cultura humanística já tinha consolidado a dramaturgia clássica em Itália. Umas e outras imitavam os autores antigos, ao gosto da cultura humanística, mas o novo género não perdia a inspiração religiosa. Antes procurava superar o carácter arcaico das antigas representações populares e recriar o tom clássico, grave e erudito que correspondia às exigências religiosas e morais da sociedade.

Efectivamente, anos mais tarde, os termos tragoedia sacra ganharam um significado eminentemente jesuítico, cunhado pelo P. Ortensio Scamacca (1562-1648), para designar a fabula erudita, composta em latim, sobre tema sacro (por oposição às tragédias profanas), e com objectivos claramente parenéticos. ${ }^{(13)}$

(13) Sobre a dramaturgia de Scamacca, vd. Salvatore BANCHERI, "La poetica della tragedia sacra nelle opere di Ortensio Scamacca", Italian Culture 6 (1985) 89-101. A vasta obra de Ortensio Scamacca compreende um amplo leque de argumentos trágicos, desde o drama sacro à tragédia de inspiração clássica. Esta última alterna temas míticos e históricos com temas religiosos. Formalmente a sua obra reflecte diversos momentos de evolução dramática, desde as sacre rappresentazioni de raiz medievalizante, até às tragédias mais "regulares", de inspiração clássica. 


\section{A europeização de um género, ou o princípio de um ciclo trágico}

Apesar de nunca terem sido impressas, as tragédias de Venegas a que Coimbra assistiu em 1559 e 1562, deixaram em breve as fronteiras nacionais e conheceram uma longa história de representações em toda a Europa. Como já outros reconheceram antes de mim, elas tornaram-se o arquétipo de um género artístico-dramático internacional, que se afirmou desde os primeiros anos da Companhia e que, como vimos, veio a ser designado por tragoedia sacra. (14)

Após as primeiras representações do Colégio Germânico e o manifesto interesse dos superiores da Companhia pela actividade teatral dos colégios, Mss da Saul Gelboeus e da Achabus circularam pelos colégios de toda a Europa durante mais de dois séculos. Prova disso mesmo são as numerosas cópias que ainda hoje se conservam em várias bibliotecas da Europa e da América. Se podemos pois falar em repertório europeu de teatro jesuítico, o teatro de Venegas pertence-lhe com toda a propriedade e ocupa nele um lugar primordial, ao lado do teatro de Luís da Cruz, Stefano Tucci, Francesco Benci e Bernardino Stefonio, por exemplo.

Deixo de lado a obra de Luís da Cruz para outros especialistas aqui presentes e recordarei brevemente nomes como Stefano Tucci e Francesco Benci, menos conhecidos entre nós.

O primeiro, cujas obras tiveram tão grande êxito que conheceram duas traduções ainda em vida do autor, começou por compor também vários dramas de tema veterotestamentário: Nabuchodonosor, Golias e Judith (entre 1562 e 1565), em que são visíveis os laços do drama com a parenética e com o ensino da Retórica.

Quanto a Francesco Benci, servir-me-ei apenas do testemunho de uma investigadora italiana, Daniela Quarta, que considera que a peça Saul (outrora

(14) Refiro-me aos comentários de Gualtiero Gnerghi, de Claude Henri Frèches, e de Daniela Quarta às duas tragédias de Venegas, mesmo quando abordadas como anónimas. 
tida em Itália como anónima, mas finalmente atribuída a Miguel Venegas) constituiu um modelo formal destinado a ser imitado no Colégio Romano, como demonstra claramente a peça Hiaeus do Padre Francesco Benci, provavelmente de 1590 - uma tragédia regular, dividida em cinco actos, que apresenta uma concepção dramática madura e consciente. (15) Parece-me porém que o modelo mais próximo será a Achabus e não a Saul.

Francesco Benci (1542-1594) foi autor de dois dramas inspirados no destino trágico da casa de Acab: um Hiaeus (Jeú era o nome do rei ungido por Elias para exterminar Jezabel e toda a descendência de Acab), que se encontra na BNCVE de Roma (Ges. 24 do Fondo Gesuitico), e ainda, segundo o Prof. Nigel Griffin, um Baal euersus, que foi representado cerca de 1590 em Ingolstadt, e de novo em 1599 em Dillingen. (16)

Já no séc. XVII, Ortensio Scamacca, professor no Colégio de Palermo, compôs também uma tragédia intitulada La Neomenia - sobre o episódio da vinha de Nabot, vítima da ambição de Acab e Jezabel.

Mas podíamos referir ainda outras peças anónimas, como uma Josafat (assim se chamava o rei de Judá que fez aliança com Acab), representada em Munique, em 1573, ou uma Jezabel, tragédia em cinco actos, representada em França, no Colégio de Rouen, em 1640, em que tomou parte Thomas Corneille, então com 15 anos de idade.(17)

(15) Daniela QUARTA - «Dramaturgia gesuita nel Collegio Romano: dalla tragedia di soggetto biblico al drama martirologico (1560-1644)», Atti del XVIII Convegno Internazionale, I Gesuiti e i primordi del teatro barocco in Europa, M. Chiabó; F. Doglio (ed.), Roma, 1994, p. 138 sqq.

Analisando algumas peças do mais antigo teatro jesuítico, Daniela Quarta atribui aos Ms de Venegas conservados anónimos em Messina e em Roma, um papel central na criação de uma dramaturgia do sacro e mesmo de topoi dramáticos muito concretos. A autora desenvolve aliás uma intuição já antecipada por Gualtiero GNERGHI (Il Teatro Gesuitico ne' suoi primordi a Roma, Roma, 1907). Naquele interessante estudo, a autora vai mesmo mais longe e afirma que a análise por si elaborada privilegia momentos fundadores de um estilo e de uma poética dramática que encontraremos depois no próprio drama martirológico, desenhando assim uma linha de continuidade na experimentação dramática do Colégio Romano.

(16) A notícia das duas últimas representações é dada em N. Griffin, Two Jesuit Abab dramas, University of Exeter, 1976, p. xiv e xv.

(17) L.V. GOFFLOT - Le Théâtre au Collège du Moyen Âge à nos Jours, N.Y. 1907, p. 169; Vd. também B. SOLDATI - Il Collegio Mamertino e le origini del teatro gesuitico, Torino, 1908, p. 83 . 
Estes são apenas alguns dos títulos que pude acrescentar à já longa lista de peças sobre Acab e Jezabel, publicada em 1976 pelo Prof. Nigel Griffin. Dela constavam, na verdade, cerca de 33 representações que iam desde 1562 até 1750, número agora ampliado com as últimas investigações, principalmente se tivermos em conta as numerosas oratórias musicais a que o mesmo tema deu origem. ${ }^{(18)}$

Se no séc. XVI temos notícia de que a Achabus de Venegas foi representada em Coimbra, Roma, Messina e Mainz, a abundância de Ms em toda a Europa é indício forte de outras representações, cujas notícias se perderam.

Por outro lado, muitas outras peças sobre o mesmo tema bíblico subiram ao palco em várias cidades da Itália, Polónia, França, Países Baixos, e principalmente nos países de língua germânica, onde a popularidade daquelas personagens deu também origem a uma série de dramas jesuíticos em vernáculo.

Até meados do séc. XVIII, portanto, o tema atraía o interesse dos Colégios da Companhia, principalmente em cidades que mais se debatiam com lutas religiosas, simbolizadas na idolatria de Baal (como Praga, Maastricht, Ingolstadt, Dillingen, Innsbruck, Ratisbona, Würzburg, Hildesheim, Rottenburg, Paderborn, Gorlitz, Munique, e outras).

Fora da Companhia, o mesmo material bíblico inspirava ainda a David Combattant, David Triomphant, e David Fugitif de Les Masures (1566), a Saul Furieux, de Jean de la Taille (1572) e a Athalie de Racine, para não falar das inúmeras oratórias e óperas que se lhes seguiram, sobre as figuras de Elias, Acab, Jezabel e todos os seus descendentes sobre quem recaía a punição de Acab. (19)

(18) Vd. Margarida MIRANDA - Miguel Venegas e o nascimento da tragédia jesuítica. A Tragoedia cui nomen inditum Achabus de Miguel Venegas (1562), Faculdade de Letras da Universidade de Coimbra, 2002, Tese de doutoramento policopiada. Na p. 218 e ss. foi possível reelaborar a já vasta lista de Griffin, alterando alguns dados e acrescentando outros.

(19) Athalia é o nome da filha de Acab e Jezabel que, tal como sua mãe, procurou impor o culto a Baal. 
O papel original de Miguel Venegas traduziu-se assim naquilo que poderíamos chamar a criação de uma espécie de "ciclo trágico» na Europa, à imagem dos ciclos trágicos que uniam a produção dramática antiga - como as peças do ciclo tebano, ou as peças do ciclo troiano. As mesmas situações trágicas e as mesmas personagens suscitaram, depois de Venegas, um vasto número de produções dramáticas, elaboradas por diversos autores em diversos pontos da Europa.

Podemos assim falar, com toda a propriedade, de um fenómeno de verdadeira europeização do teatro, uma vez que, enquanto neolatino, este teatro não conhecia barreiras linguísticas; enquanto jesuítico, não conhecia barreiras nacionais, pois à custa da rede escolar jesuítica na Europa, vivia-se então uma verdadeira União Pedagógica Europeia. 


\section{Série}

\section{Documentos}

Imprensa da Universidade de Coimbra

Coimbra University Press

2006

- $\mathrm{U}$

C • 